
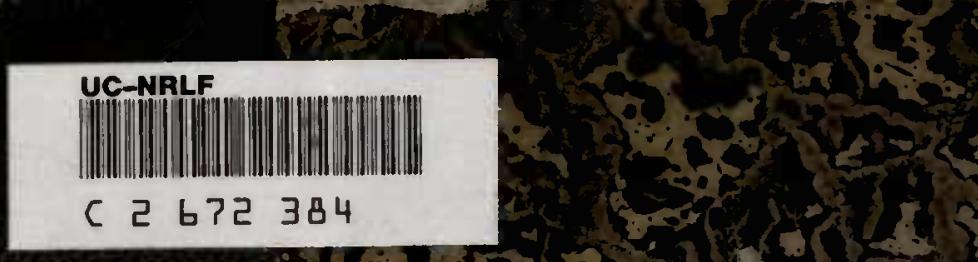

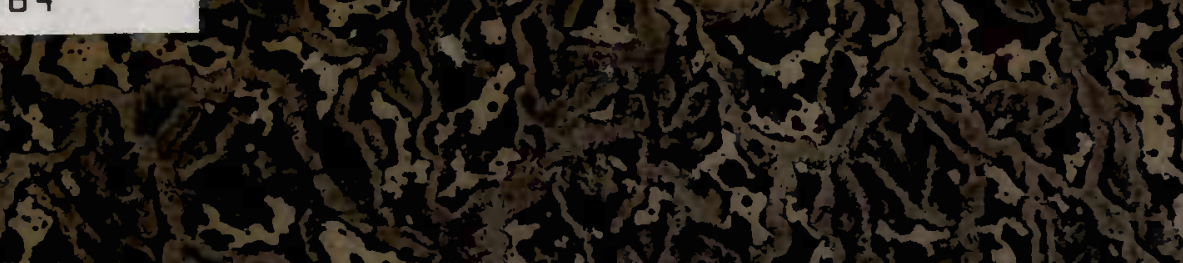
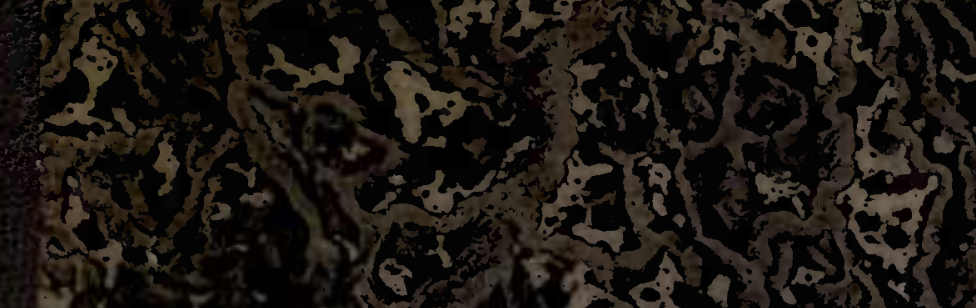

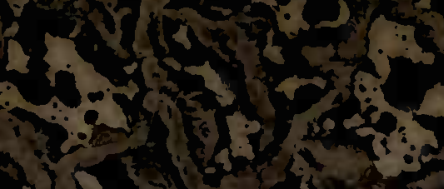

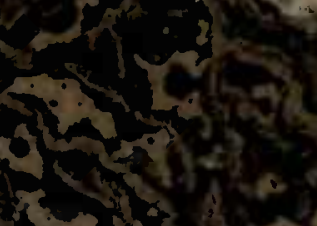

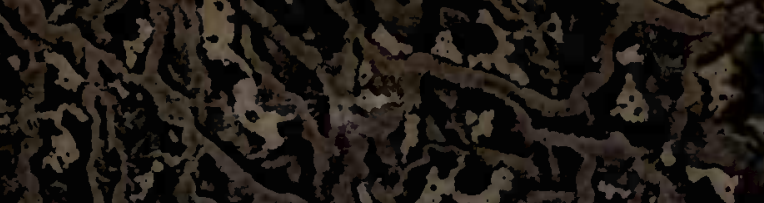

bar.t.

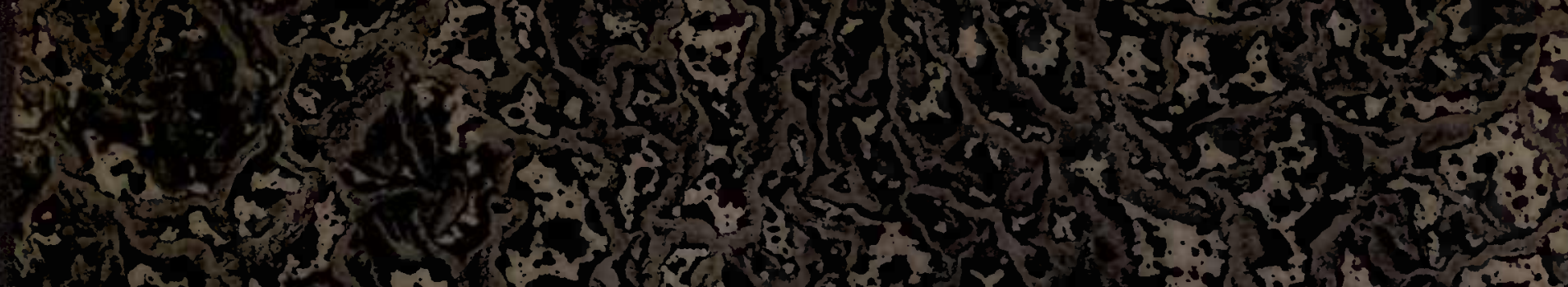

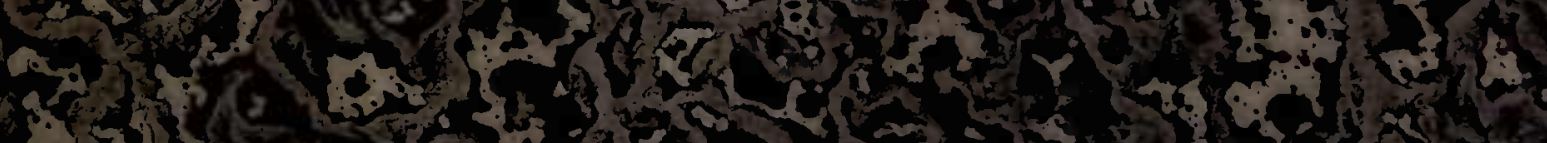

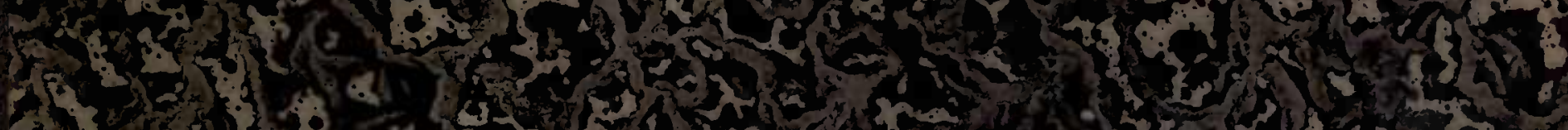

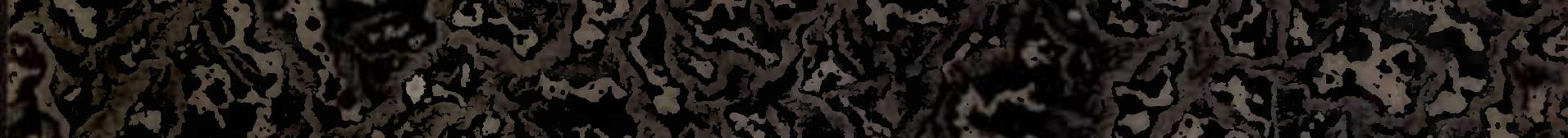



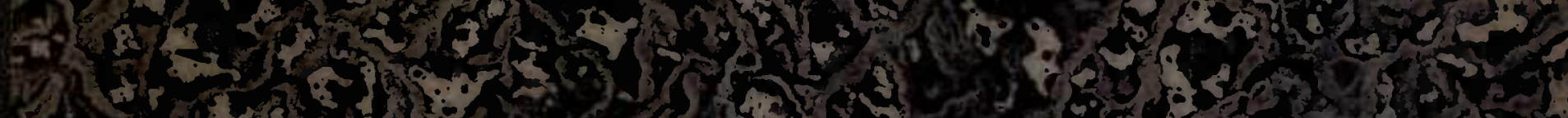

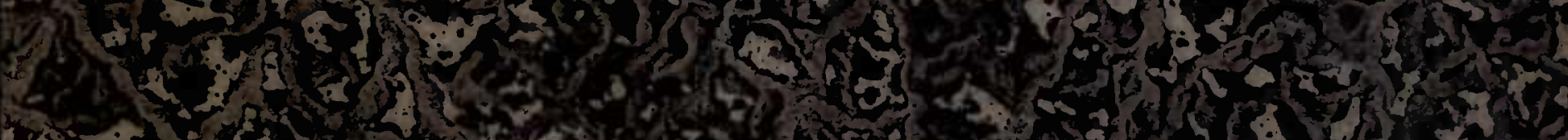

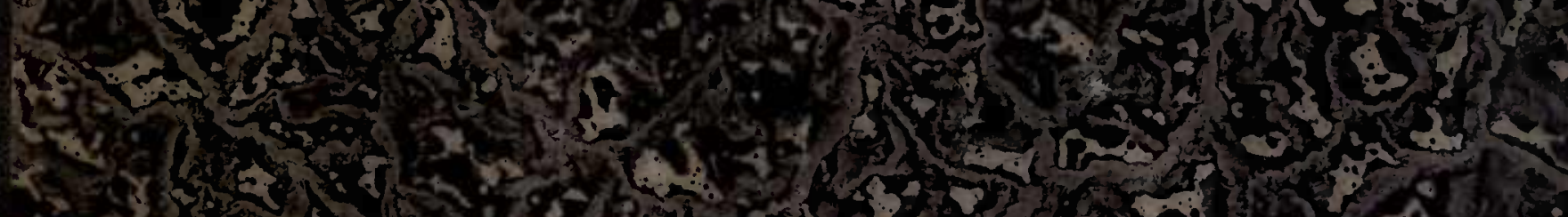

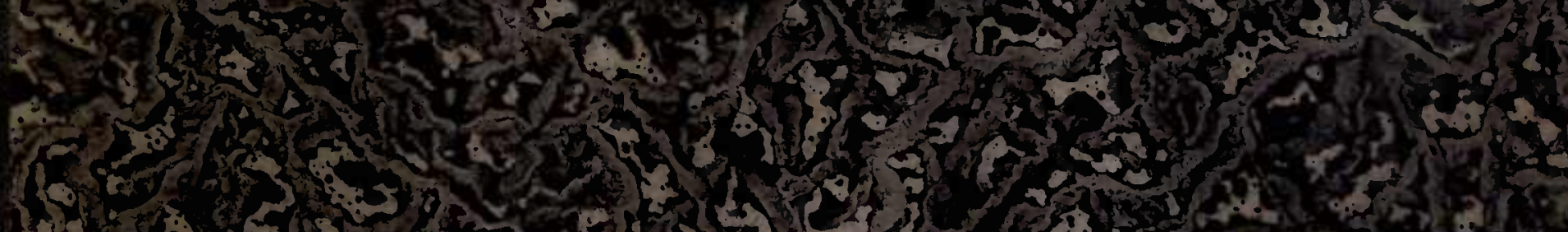

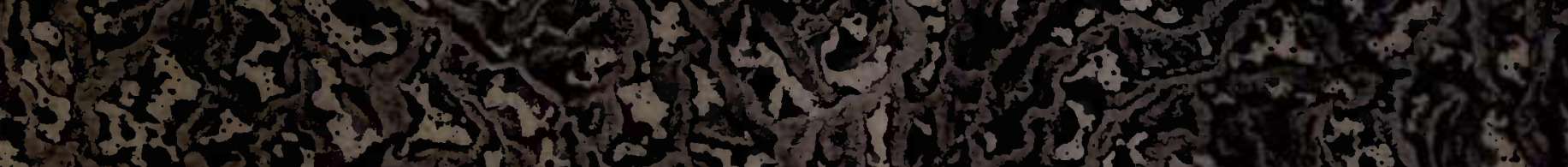

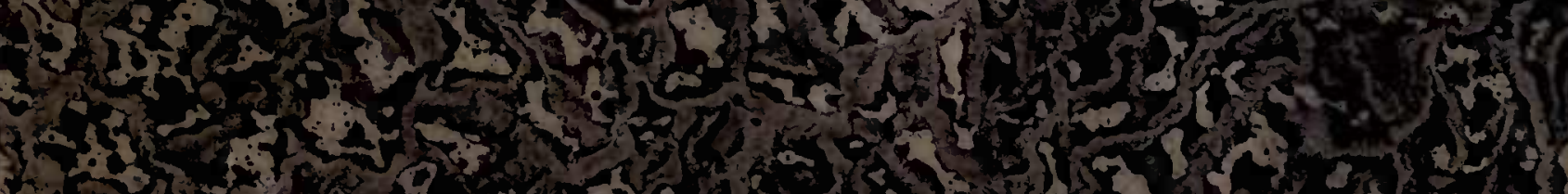

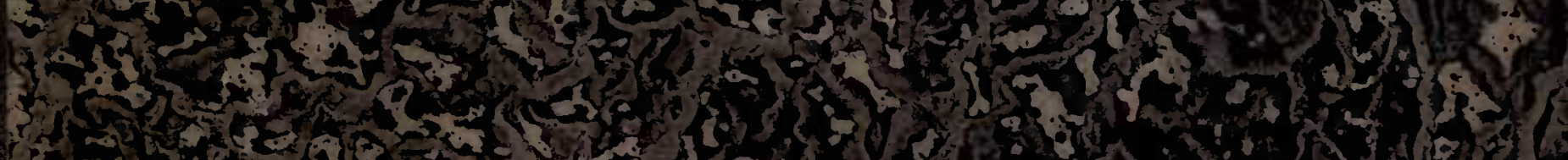

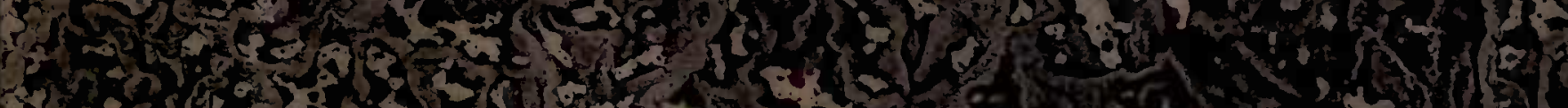

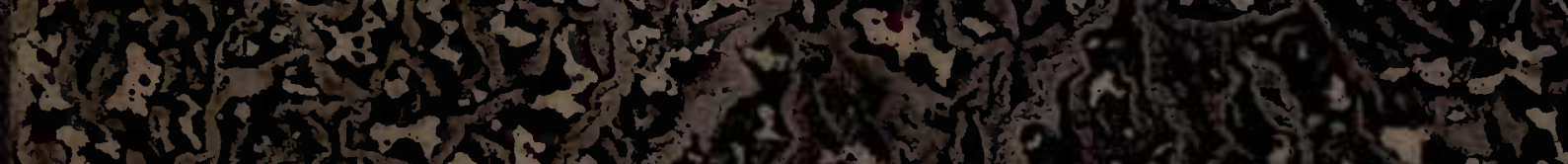

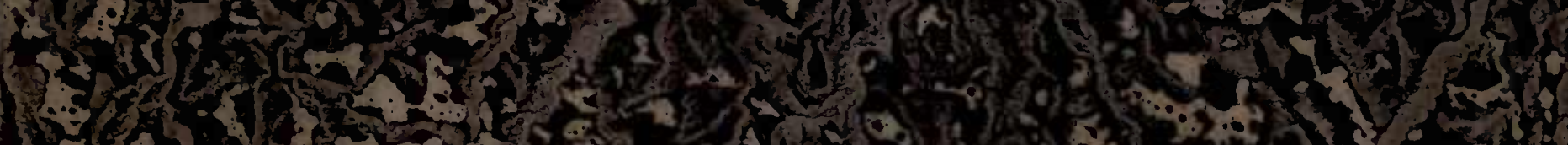

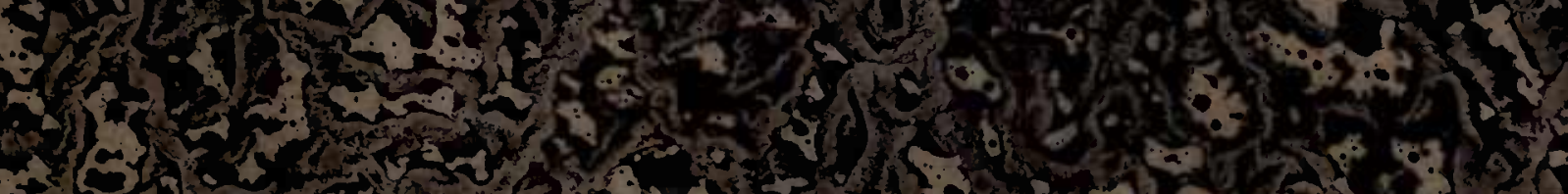

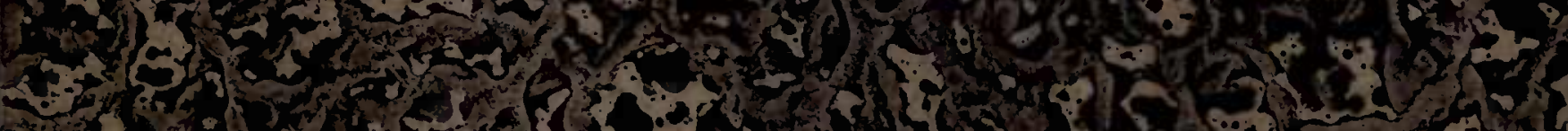

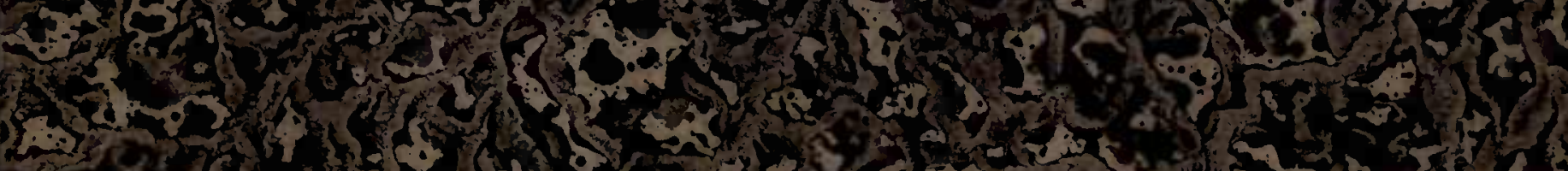

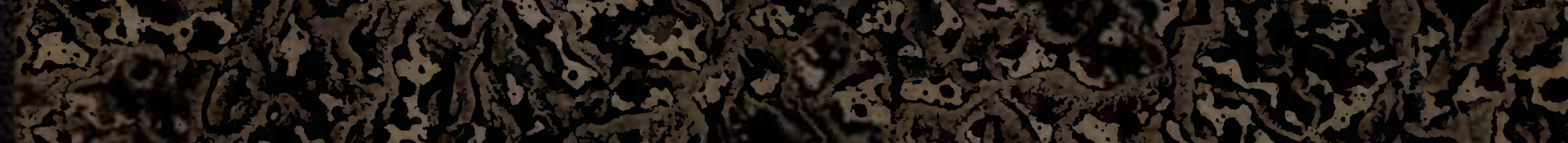

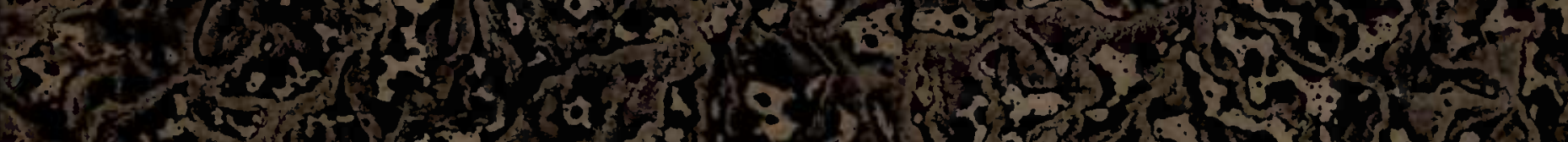

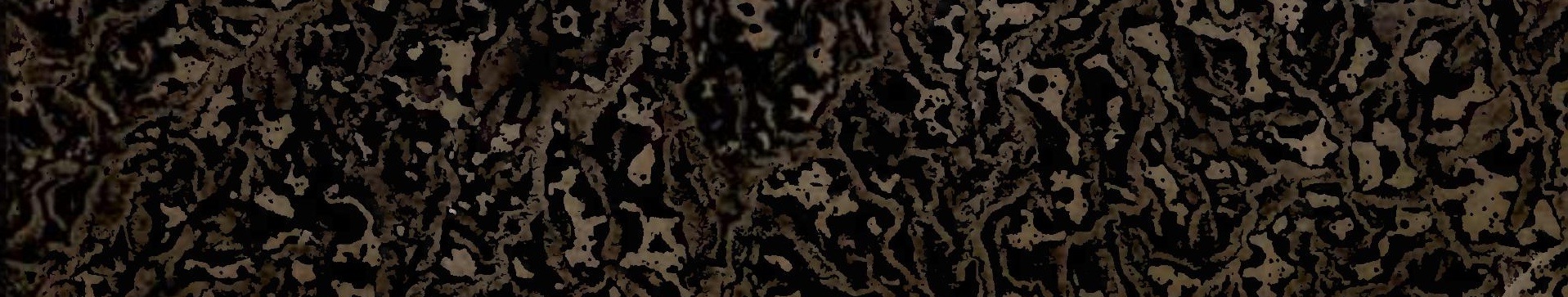

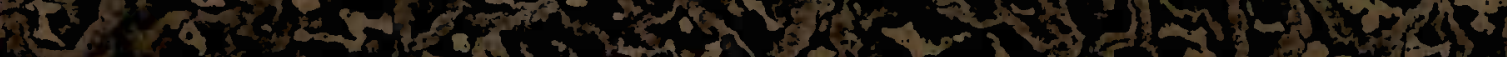




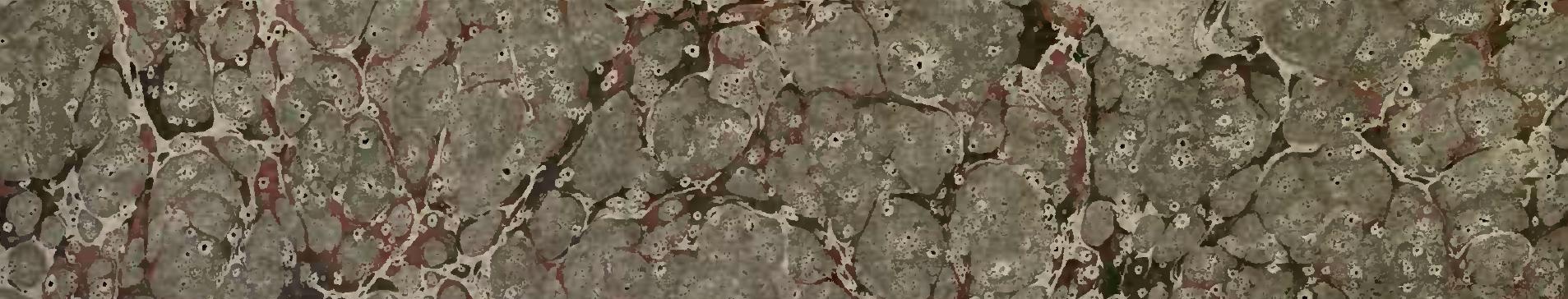

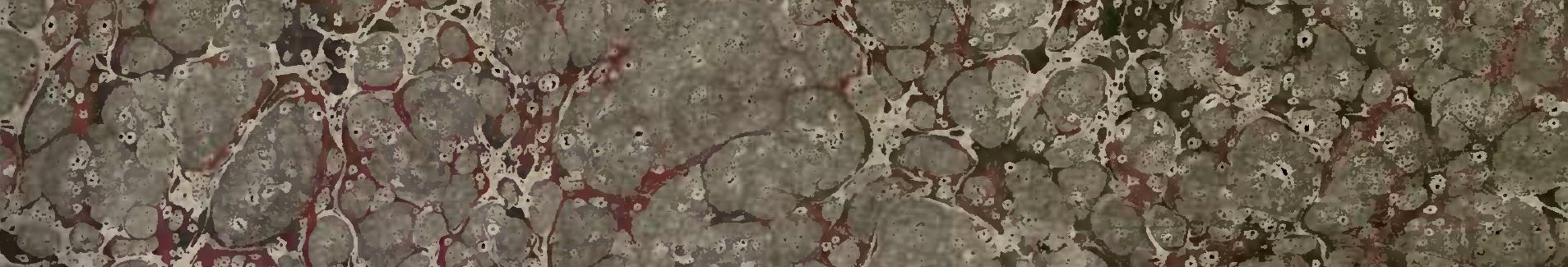
$106,2 x^{3}$ (ex)

(1)

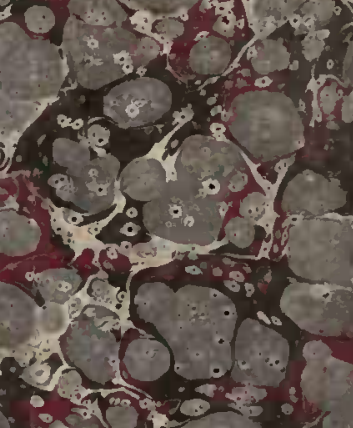

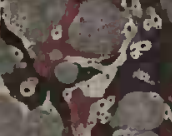

.10

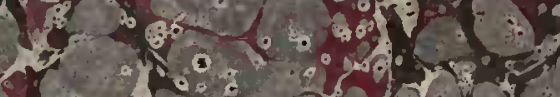

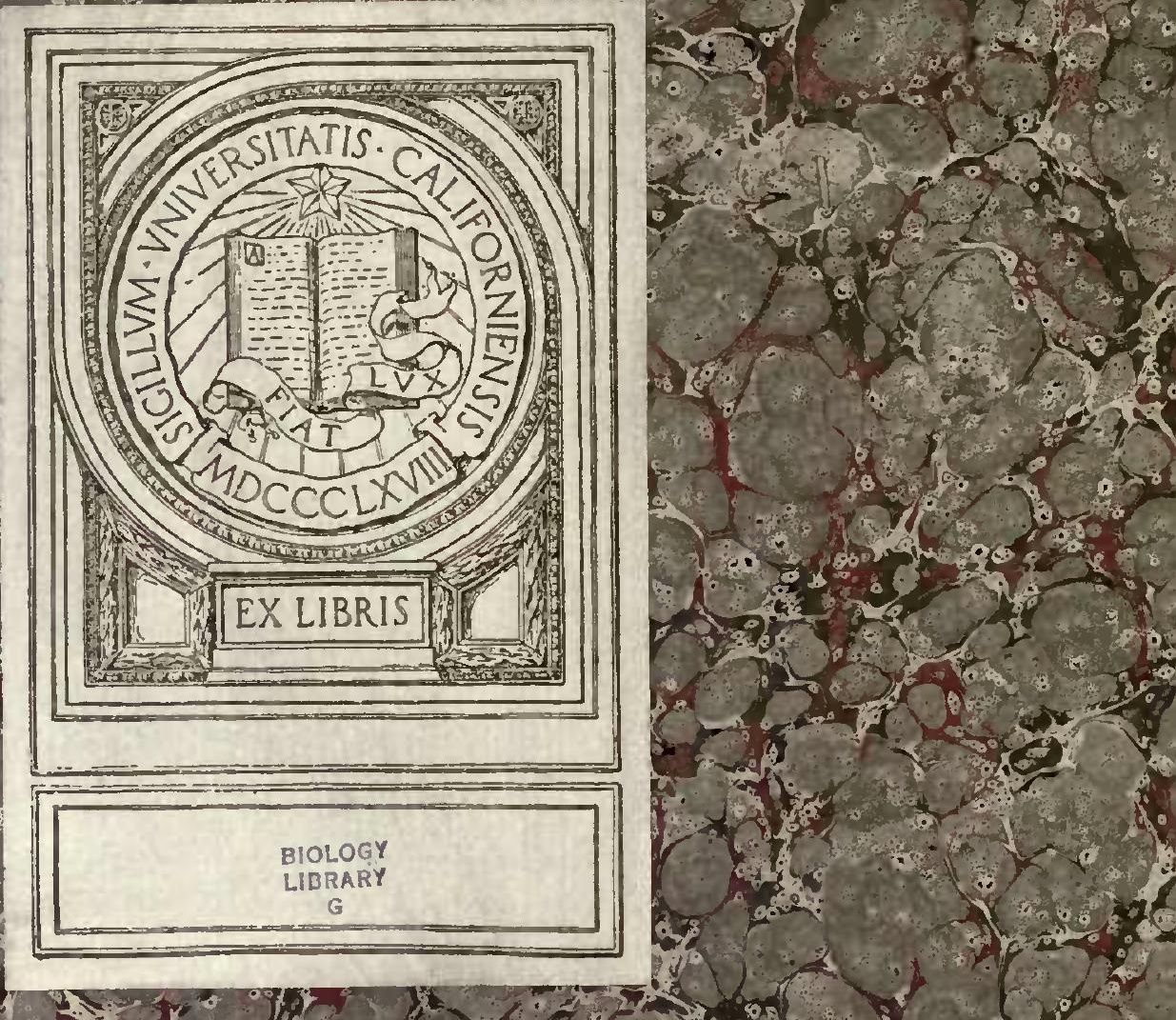

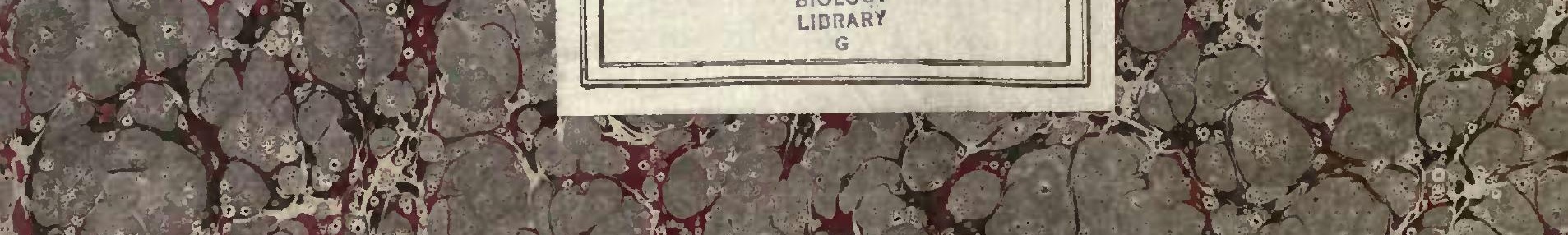
c. c 5 in a 2 s y cosent

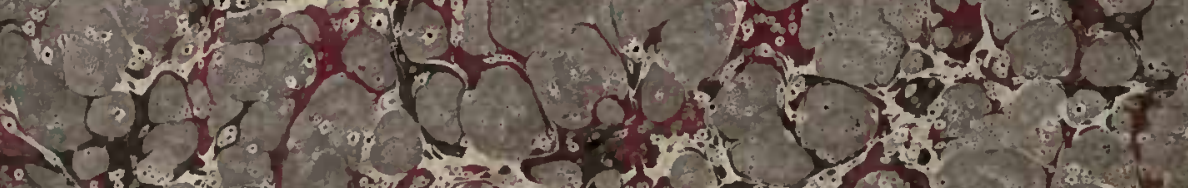
30 a

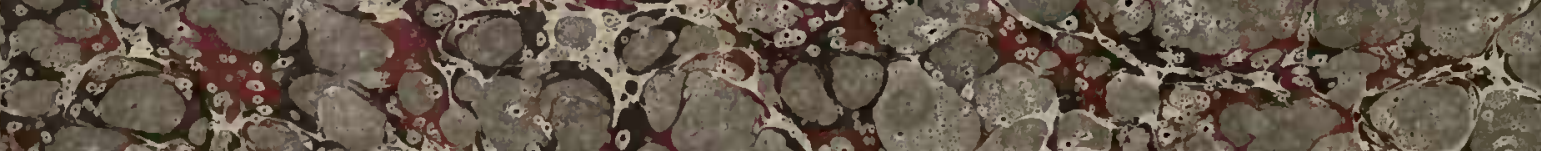
pring

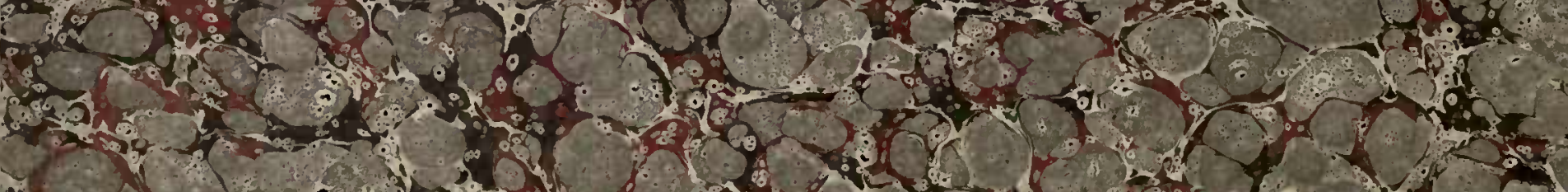




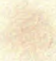

$\therefore \quad \therefore$ 


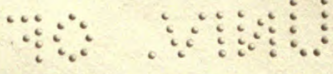

0
$\therefore$

$2+485$

N4
BIOLOGY
LIBRARI
G

5

tis. 
IX. On the Impregnation of the Ovum in the Amphibia. (First Series.)

By George Newport, F.R.S., F.L.S. \& c.

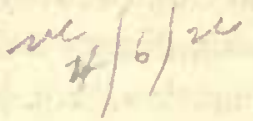

Received June 20,-Read June 20, 1850.

THE communication which I have now the honour to present to the Royal Society is a portion of a series of investigations on the Development of the Embryo on which I have becn for some years engaged, and which was conmenced in a paper on the Development of the Myriapoda, that was honoured with a place in the Philosophical Transactions for 1841. I now propose to give the results of my observations on the Amphibia, leserving to a future early occasion the continuation of those on the Invertebrata commenced in the paper alluded to.

The Amphibia, of all the vertebrated animals, afford to us the readiest means of investigating the difficult subject of Impregnation by actual experiment, and it is only, perhaps, by combining experiment with careful observations on the physical conditions that affect the development of the germ, and comparing these with the facts of the natural history and instincts of the species, that we may hope, ultiInately, to obtain some further insight into this one of Nature's most hidden secrets.

I shall endeavour, therefore, in this communication, to show the condition of the ovum in the Amphibia through its earliest changes, and also before and immediately after impregnation, and to detail experiments made with a view to learn by what means its fecundation is effected; - and in a future communication I propose to trace the development of the embryo from the time of fecundation to that of its liberation from the ovum, in the two chief divisions of the class, - the tailless and the tailed Amphibia. The subjects thus naturally form two series-Impregnation and Development.

\section{IMPREGNATION OF THE OVUM.}

The history of what we can now prove to be the agent of impregnation, the spermatozoon, deserves to be especially noticed. Although great attention has been paid by physiologists during the last thirty year's to almost every point of inquiry connected with the production and physical composition of the seminal fluid of animals, and its relation to the fecundation of the ovum, we have remained to the present time without any acknowledged proof either of the part which the different constituents of this fluid take in impregnation, or of the mode in which it effects impregnation. This perhaps is little to be wondered at when we remember how many years elapsed before the great discovery of HAM and LEEWENHOEK of the existence of moving bodies in the fluid, as part of its normal composition, was admitted. it is now one hundred and eighty-three years since LEEwENHOEK cominunicated the important discovery MDCCCLI. 
of these bodies to the Royal Society*, and regarded them as in some way essential to the fecundation of the ova; although his conjecture that they became the future embryos was erroneous. Eighty-five year's afterwards, Dr. Parsons, Foreign Secretary of the Royal Society, believed it to be "extreme nonsense to imagine that the insignificant animals called spermatic animals can contribute anything towards propagation," \&c.ף, and it was not until the publication of the obselvations of LEDERMÜLLER fluid, began to be admitted. Dr. HiLL, in the notes to his English translation of Swammerdam's Biblia Naturæ $\oint$, two years later, mentioned them as abundant in the Frog at the season of pairing, but that it was then the fashion to doubt even theil existence. Yet Nef Dham, ten years after this, while acknowledging that these bodies are found in the fluid of all animals, adopting the views of Buffon and Daubenton, stated that they do not exist until after the fluid is removed from the vessels, and decomposition has commenced $\|$. And later still, even in our own time, their existence has been denied in the most positive manner by Sir Everard Home $\%$. Spallanzani, however, was so well acquainted with them, as found in the Frog and Toad, that he has recorded his great surprise at not observing them in the latter on two occasions**. Bonnetwof and Greichen +w, also, well knew them to abound in the males of animals of distinct species at the season of impregnation, but discovered that they are usually absent in hybrids, a fact that has since been confirmed by Prevost and Dumas $\oint \oint$. 'These two observers, regarding the spermatic bodies, with LEEwENHовк, as essential elements of the semen, believed that they actually penetrate bodily into the ovum, and become by inetamorphosis part of the future embryo. Still more recently it has been stated byDr. BARRY \|\| to this Society that he has actually seen the spermatozoon within the ovum, a statement which my own observations do not enable me to confirm.

Before any satisfactory conclusion could be arrived at respecting the importance of the spermatic bodies in impregnation, it was necessary to ascertain their nature, to trace their mode of development and production, to establish the periods of their occurrence in different classes of animals, and to learn something of their chemical

* Philosophical Transactions, 1667, vol. xii. p. 1040.

+ Philosophical Observations on the Analogy between the Propagation of Animals and that of Vegetables. 8vo. 1752 (note), p. 44.

$\ddagger$ Pbysikalische Beobachtungen der Samenthierchen. Nuremb. 1756. And also, "Beyträge zu denen Beobachtungen deerer Saamenthiergen und Kleiste Aale gehörig. 12mo. Frankfurt und Leipzig, 1759."

$\$$ Book of Nature, folio, part 2 (note), p. 105, 1758.

\| Notes des Nouvelles Recherches sur les Découvertes Microscopiques de l'Abbé Spalluanzani par M. NeEDHAM. Lond. 1769, tom. i. p. 196.

If Lectures on Comparative Anatomy, 4to, vol. v. pp. 332 and 337. 1828.

** Dissertations relative to the Natural History of Animals and Vegetables. Lond. 1789, p. 151.

†† "Contemplations de la Nature ;" and "Evurres d'Histoire Naturelle," 4to, tom. iii. p. 454, \&c. 1779.

㕸 Abhandlung über der Samen- und Infusionsthierchen. Nuremb. 1788.

$\$ \$$ Anuales des Sciences Naturelles (Prem. Série), tom. i. p. 182, 1824.

III Proceedings of the Royal Society, vol. iv. p. 432. Phil. Trans. part 1, 1843, p. 33. 
composition, as well also as of the fluid portion of the semen in which they move. Most of these inquiries have been well followed out by Wagner, Siebold, Muluer, and more especially KöLLiker, and more recently by WAGNER and Leuckardt, froul whose labours we have now some positive information which enables us to deduce a fair conclusion respecting their function, although a direct proof of its correctness is still to be supplied. Most observers now believe witl KöLLIKer, that the spermatozoa (still so called) are not independent living organisms, but are inerely elementary constituent parts of the male body, an opinion in which my own investigations lead me fully to coincide. This opinion, indeed, is not entirely new, as a like view was held by some observer's at the beginning of the last century, when it was still questioned whether the spermatozoa are normal constituents of the semen. Dr. DrakE*, in his "New System of Anatomy," while acknowledging that he had seen the seminal animalcules, and combating on the one hand the theory of LeEwenHOEK respecting them, and on the other the view that had previously been held with regard to the ovum, doubted their separate organization, and suggested that they "may be nothing more than some large particles of mixed fluid, whose motions and different figure the microscope discovers to our eyes," \&c. G. Treviranusf more recently held a similar opinion, that they are not independent animals, but are analogous in their structure and properties to particles in the pollen of plants, and that their motion is of the kind discovered by RoBert Brown in vegetables. KöLLrKer *, however, first distinctly referred them to a class of known organic constituents of the living body, the vibratile cilia, a view which had previously been discussed and inclined to by MüLLER $\oint$.

But however much our knowledge has become settled in regard to the nature of the spermatic bodies themselves, and their mode of development, their relation to the fluid portion of the semen in which they are contained is still a matter of doubt. H. Goopsır || regards certain albuminous flakes in the fluid portions of the semen of Crustacea as the debris of dissolved cells, and as the source of nourishment and development of the spermatozoa; while a more recent observer, Dr. Kirkes \%, regards the spermatozoa as the elaborators of the fluid, and the conveyers of it to the ovum at the time of impregnation. 'This latter supposition was originally advocated by $W_{A G-}$ NER, VALentine and Bischoff. But two of these observers have recently changed their views**, and now regard the fluid portion as only of secondary importance in impregnation, and the spermatic bodies as of essential. This view, as Wagner statesfy, is founded chiefly on the fact that in some of the invertebrata the whole mass

* New System of Anatomy, by James Drake, M.D., F.R.S. vol. i. p. 352, 1707.

$\dagger$ Tiedemann, Zeitschrift, vol. v. part 2, 1835.

$\ddagger$ Beiträge zur Kenntniss der Geschlechtsverhältnisse und der Samen-flussigkeit wirbelloser Thiere. Berlin, 1841 .

\$ Elements of Physiology (Eng. ed.), part 6, 1841, p. 1478.

\| Anatomical and Pathological Researches, 1844, p. 40.

If Handbook of Physiology, 1848, p. 610.

** Bischoff in Mülter's Archiv, 1847. WAGNRR in Article "Semen," Cyclopædia of Anatomy and Physiology, part xxxvi. January 1849.

†† Loc. cit. p. 507. 
of the semen appears to be constituted almost or entirely of spermatozoa, while scarcely any liquor seminis can be detected; -and further, on the great improbability, perhaps impossibility, of the liquor seminis of those animals which expel their ova into water before impregnation being brought into contact with the ovum. But the same author justly remarks, that " even up to the present day this hypothesis of the influence of the liquor seminis has not met with any direct refutation." To this I may add, that however strong the presumption may be in favour of the ageney of the spermatozoa in those instances in which a liquor seminis has not been observed, it affords no sufficient reason for disbelieving that the spermatozoa are not resolved into fluid at the moment of fecundation; or that in those animals in which the liquor seminis occurs in abundance it is not that which impregnates the ovum.

The question then, so far as proof is concerned, both of the direct agency of the spermatozoa, and of the non-efficiency of the liquor seminis in impregnation, remains open, as well also as that which involves the knowledge as to how impregnation is effected.

It is to these questions that this communication which I have now the honour of laying before the Royal Society is chiefly directed. I propose first to show the time and mode of disappearance of the germinal vesicle, and the condition of the ovum in the Frog and Newt, immediately before and after impregnation, and to endearour to supply proof from actual experiments that the spermatozoa alone, in all cases of communion of the sexes, are the sole agents in inpregnating the ovum; and further, that inpregnation cannot be effected by the liquor seminis; and next to examine in what way the agency of the spermatozoa is influenced, impeded, or exerted.

\section{CHANGES IN THE OVUM WITHIN THE BODY.}

The ovum of the Amphibia has so frequently been the subject of examination by the best observer's that a further detailed account of its development may at first appear to be useless, after what we already know of its changes through the labours of Swammerdam, Leewenhoek, Roesel, Spallanzani, Prevost and Dumas, Rusconi, Baer, Reichert, Vogt, Bell and others. But apart from the fact already mentioned, that the ovum of the Amphibia affords us the best means of actual experiment on impregnation, there are questions which relate to its earlier conditions on which the observers named are not agreed, but which are of importance with regard to the physiology of reproduction in the whole of the vertebrata.

I shall state, therefore, what I have myself observed with regard to these questions from the time when the ovarian ovum is, approaching to maturity to that of its expulsion from the body, before entering on the subject of its impregnation.

As our means of comparing and testing the accuracy of all observations in natural history, and of experimental results in physiology, depend mainly on the correct identification of the objects examined, I may here state at once that the objects of the following details have been the Frog, Rana temporaria, and the Toad, Bufo vul- 
garis, among the Anoura; and the Triton palustris, Lissotriton punctatus and L. palmipes, among the Water Newts, the Urodela. Neither Spallanzani, Prevost and Dumas, nor Rusconi, to whose observations I shall have frequent occasion to refer, mention the species they have examined. Spaldanzani has given only the popular names of his animals, but Rusconi has given a figure of his, which appears to have been Rana esculenta, and as the description he has given of the ovun of this species agrees with the description given by Prevost and Dumas, it is probable that the species they employed was the same.

The Ovarium Ovum.-When the frog, Rana temporaria, is examined in the autumn, after it has ceased to feed, and is preparing to retire to its winter quarters, the ova within it have already attained to more than two-thirds of their ultimate dimensions before leaving the ovaries, and have begun to distend the abdomen. 'They remain in this state through the greater part of the winter, while the frog is hybernating, as Professor BenL remarks*, in the mud at the bottom of ponds and stagnant waters. But as the spring approaches, and the animal is aroused from its lethargy by increased temperature, the ova then rapidly acquire their full development. A fernale fiog, taken at the end of September, with her body enlarged with ova, was confined in water in a cold room, undisturbed through the winter, excepting only at intervals of examination. The weather being mild, and the temperature of the room during October and November being sometimes at ol but little below $50^{\circ} \mathrm{F}_{\mathrm{AHR}}$, the frog remained active, and came frequently to the surface to respire. In December the tempera-

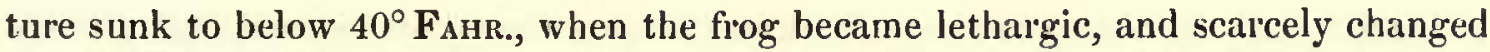
its place at the bottom of the water during nearly a fortnight, while the temperature was almost stationary, and ranged only from $35^{\circ} F_{A H R}$. to $37^{\circ} F_{A H R}$. On the 10 th of January, when it had again risen to $40^{\circ}$ FAHR., and that of the water to $37^{\circ} \cdot 5$ FAHR., the animal was still submerged and motionless; but on sudden exposure to the light of a candle it crept languidly, and almost imperceptibly, to a distance of about two inclses, and again became quiet. On the 26th of January the temperature of the room had risen gradually and continuously to $52^{\circ} \mathrm{FAHR}_{\mathrm{AH}}$, and that of the water to $48^{\circ}$ FAHR., but the frog remained submerged and perfectly quiet with its eyes partially closed. Althongh it was not cognizant of any object by sight, the irritability of its body was now much increased, as it moved instantly when tonched ever so lightly, but quickly relapsed into its previous state of rest. On the morning of the lst of February, the temperature being then $48^{\circ} \mathrm{F}_{\mathrm{AHR}}$, it was still submerged and motionless, but in the evening, when the warmth was increased to $52^{\circ} \mathrm{FAHR}_{\mathrm{AH}}$. I found it with its nostrils only above the surface of the water, and evidently beginning to respire freely, but its eyes were completely closed. When the light of a candle was suddenly cast upon it, the eyes were slowly opened, but its body remained immoveable. On the following day, February 2, it was evident that its hybernation bad been brought to a close, as it was then active, with its head out of the water, and its eyes widely open, 
and perfectly alive to external objects, as when the hand was slowly approached it withdrew beneath the water. The temperature at this time was $53^{\circ}$ FArr. During this period of hybernation the frog became slightly emaciated, and its abdomen, instead of being more enlarged, was somewhat diminished in bulk,-a good proof that during the inactivity of the respiratory and circulatory functions, the secretory also are lessened, and the development of the ova is arrested. But although no food was supplied to the frog at this time, and none probably is taken by the creature in its natural haunts, as at the time it conies forth but few of the objects on which it feeds are abroad, its body soon became enlarged, showing that the ova were then rapidly attaining their full development. Between the 2nd and 22nd of February the temperature of the room was occasionally as low as $42^{\circ} \mathrm{F}_{A H R}$, yet the creature remained active beneath the water, withont relapsing into its previous state of hybernation. It only continued longer beneath the surface without rising to respire. At this period, having found that some frogs in their natural liaunts had already come forth, I removed the subject of these observations also fiom the water to a damp loeality, and on the following day found it greatly changed in appearance. While confined in the water it was of a dull dirty brown colour, but some hours after its removal it cast its tegument, and changed to a bright yellow, with the usual brown markings, and had increased in size, both in its body and limbs.

The conclusion to which these circumstances seemed to lead was, that quickly after the frog leaves its hybernaculum, it casts its tegument as the insect escapes from its puparium, and acquires new vigour, while the ova are attaining their full growth. The Toad undergoes a similar change. About a fortnight later in the season than the Frog, I have seen many tonds in a shallow ditch of slow moving water in the act of casting their dark brown tegument, and acquiring one of a greenish yellow.

On examining several frogs taken from their natural haunts, I found them in, as nearly as posible, the same state of development with regard to the ova, jndging from external appearance, as the specimen I had wateled through the winter. A few had just paired, but the majority were still single. On opening the bodies of the latter, I found the ovaries greatly enlarged, and the ova apparently ripe, but still contained in the ovisacs.

It is at this period, therefore, immediately after hybernation, and before the ova have left the ovaifes, that the condition of the ovum is a matter of great interest with reference to the structure and contents of the germinal vesicle, the period at which the vesicle is changed or disappears, and the circumstances under which the ovum escapes from the ovary, and is received into the oviduct.

The Germinal Vesicle.-The fate of the germinal vesicle in the matured ovum is still a matter of doubt. Previous to the embryological researches of Dr. Martin

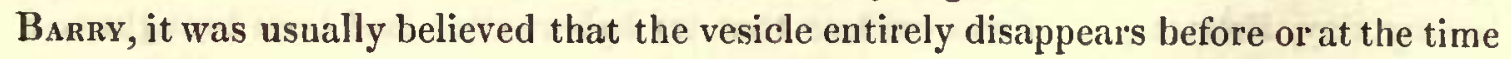
of fecundation of the ovum. But this view was combated by the author named, who, quoting the opinions of previous inquirers, contended that the germinal vesicle in 
Mammalia does not disappear, as believed by Purkinje*, in Birds and Amphibia, by bursting during the generative act, and pouring its contents into the germinal layer of the fecundated ovum. Neither, as supposed by BAER $\uparrow$, by being urged forwards and burst between the vitellus and its membrane before fecundation. Nor, as stated by RathкE*, with reference to the Crustacea, by disappearing while still within the ovary. Or', as supposed by Wharton Jones $\$$, in Birds and Ainphibia, by approaching the surface of the yelk, and by the giving way of the coats of the vesicle, and the effusion of its contents on the surrounding surface of the yelk. Or, further, as believed by Biscноғғ $\|$, by disappearing at the time of exit of the ovum from the ovary. On the contrary, Dr. BarRy has stated that the germinal vesicle returns to the centre of the ovum, and the germinal spot to the centre of the vesicle, before the ovum leaves the ovary, and that these do not become dissolved, but only are changed in character by a process of cell development within them, which ends in the production of two cells in the centre of the yelk, which are the foundation of the body of the future embryo.

Perhaps what I am about to mention may assist us to reconcile or correct the views of this embryologist, as well as those of the authorities he has quoted. It is well known that if the ovum of the Frog is examined before the yelk has attained to onehalf of its ultimate dimensions, the germinal vesicle is distinctly visible as a large circular body near the centre of the yelk, apparently granular in its interior, and more opake than the yelk itself. In the centre of the vesicle its nucleus, the germinal spot, is then equally distinct. If the ovum is examined when it has nearly acquired its full dimensions, the vesicle is still found to exist, but, as compared with the size of the entire ovum, is relatively smaller than at earlier periods, and is recognized with inore difficulty, owing chiefly to the yelk cells having both increased in number around it, and also acquired a darker colour. It is equally well known that all appearance of the vesicle is lost in the Amphibia, as in Birds, before the ovum is prepared for fecundation; but as to the way in which it disappears, observers are not agreed, or even as to the time.

Structure of the Germinal Vesicle.-Having collected a number of frogs that had recently left their hybernacula, and had not yet paired, I placed some in spirit for examination. On dissecting them afterwards, I found that in some the ova had nearly reached maturity, but liad not left the ovary (Plate XIV. fig. $2 p$ ). The yelks being rendered firm by the spirit, I was able, by gentle pressure, to break open some of these beneath the microscope, without diffluence of the contents. The aggregated yelk cells were then seen to consist of two kinds; the one dark-coloured, which form

\footnotetext{
* Symbolæ ad Ovi Avium Historiam ante Incubationem, 1825; and Article “Ei,” Encyclop. Wörterbuch, Band x. p. 112, 1834.

† "Lettre sur la Formation de l'CEuf," in Breschet. Repertorium, 1829.

†ntersuchungen ueber die Bildung und Entwickelung des Fluss Krebses, fol. Leipzig, 1829.

Philosophical Transactions, 1837, part 2.

\|| R. WAGNER's Lehrbuch, \&c., 1839.
} 
the upper portion of the yelk, and which diminish in intensity of colour from brown or black at the circumference to a leaden or grey in the centre; the other, which forms the inferior portion, consisting of cells that become lighter-coloured as they approach the surface. The whole form a mass of nucleated cells of nearly uniforn size, closely aggregated together. In the interior of the yelk, amidst the darkcoloured cells, and much more near the surface of the dark than that of the white portion of the ovum, I was surprised to find the germinal vesicle still entire (fig. 6), and of a somewhat oval, lenticular form, although irregularly compressed by the contraction of the whole egg in the spirit. It was of a dense white colour, and opake, from the action of the spirit, and was in striking contrast to the dark cells of the yelk, which adhered to its surface, and amidst which it lay imbedded like the kernel in a peach or apricot. On the surface of the black portion of the yelk was a minute orifice, already noticed by Prevost and Dumas*, the outlet of a canal that passes through this portion of the yelk to the germinal vesicle in its interior (fig. 6). This I believe to be the result of the yelk cells having only imperfectly closed around the germinal vesicle. It is however of some consequence in the futule development of the ovum, as it is in this canal that the cleavage of the yelk is commenced. The vitelline membrane was already formed, but I could not discover any orifice or perforation in it, either corresponding to the canal in the yelk, or to any other part of the surface. It is not possible to mistake the germinal vesicle for any portion of the lighter substance of the yelk, -first, from the fact that the vesicle at this period is of an intense, opake, white colour', very different from that of the yelk substance,next, from its being completely isolated from the lighter, and imbedded in the dark substance, - and lastly, from its being still invested with a distinct envelope. On removing the vesicle, and examining it separately, first, as taken from the yelk, without crushing it, and next by gentle compression, and with the highest powers of the microscope, the interior was seen to be filled with secondary cells. Each of these, formed by a distinct envelope, appeared to contain other, or tertiary cells, and strongly reminded me of the developmental cells of the spermatozoa in the male organs, since these again seemed to contain granules, or quaternary cells. In the midst of the secondary cells I was able to distinguish, in the centre of the germinal vesicle, in some specimens, one or two cells of larger size than the rest, and which I regarded as the remains of the germinal spot, or central nucleus. In those ova which, from their size and general appearance, seemed to be the most mature, the peripheral series of cells within the germinal vesicle were of smaller diameter than those nearer to the centre, as if the earlier developed secondary cells had disappeared and liberated their contents. The cells of the dark portion of the yelk that adhered to the germinal vesicle were also nucleated, but were of much smaller size than the peripheral cells of this body. I must remark, however, that saving the fact noticed, of having seen in some vesicles one or two cells near the centre of larger size than the rest, I bave not been 
able to distinguish any separate nucleus, or germinal spot, which seems, at this time, to have disappeared as a distinct body. The germinal vesicle thus near its maturity is a mother-cell that contains a multitude of danghter or secondary cells, each, apparently, including its own progeny.

It is thus certain that the germinal vesicle exists in the ovum of the Frog until after the period of hybernation. But in individuals that have been several days abroad, and in which the ova are so far matured as greatly to distend the body, and be nearly ready to leave the ovisacs, I have not always been able to detect the vesicle. The yelk has then a greater proportion of white substance in its interior, intermingled with the dark, and this, I suspect, is the result of the disappearance of the vesicle.

In the ovum of the Toad, when as nearly mature as that of the Frog before leaving the ovisacs, I have been unable to detect any trace of the germinal vesicle. The dark portion of the yelk is then quite distinct from the light, and forms a cortical stratum of intensely black pigment, scarcely more than one-sixth of the diameter of the yelk in thickness. The light portion is of a yellowish white, and from which the germinal vesicle, when present, is not readily distinguished. But at a little eartier period, although only a few days before the pairing of the Toad, I have found the vesicle fully as large and as distinct as before its disappearance in the egg of the Frog, but situated more distant from the centre, and nearer to the black, the future dorsal surface of the egg.

In the great Water Newt, Triton palustris, the yelk of the matured ovarian ovum is of a dull pea-green colour, which in spirit is changed to a greenish yellow. On breaking open the yelk of this species, after it has been hardened in spirit, I have always found the germinal vesicle of the same opake, intense white colour, of precisely the same structure, and situated in the same part of the yelk as in the Frog. It has also a canal passing from the middle of the surface of the darker-coloured portion of the yelk, through its substance to the vesicle, as in the Frog.

In the lesser Newts, Lissotriton punctatus and L.palmipes, the yelk is of a brown or liver colour on the future dorsal surface, with a white central spot, and of a white or pale straw colour on the ventral. In ripe ovarian ova of these species also I have found the germinal vesicle of the same white colour, and having the same structure as in the larger Triton and the Frog.

In each of these instances, not merely when the ovum is immature, but even when nearly ready to leave the ovisac, the germinal vesicle is situated in the interior of the yelk (fig. 6), and not immediately at the surface, and thus far the fact is in accordance with the observation of Dr. BARRY, that in the Mammalia the germinal vesicle is in the interior of the ovarian ovum, and does not disappear on the surface. But, nevertheless, it is not in the centre of the yelk, its place, as I have stated, is excentric.

Time of disappearance of the Vesicle.-It is well known that in frogs and toads the ovum is never impregnated until after it has left the body, and consequently not until long after it has left the ovary, and the germinal vesicle has entirely disappeared. 
This disappearance does not, I think, take place at the instant the ovum is about to leave the ovisac, but a short time before; as I have found the ova of the Frog in one instance more matured than in that already described, still contained in the ovisacs, and yet most of them without any remains of the vesicle which I could identify as such, and with the yelks containing a larger proportion of white substance, as in the Toad. In a very few, however, the vesicle was still present, and exhibited the structure I have described. Certainly, then, the vesicle is not burst at the moment the egg escapes from the ovisac. There seems to be a short period of time between the disappearance of the vesicle and the full maturity of the ovum, during which the yelk itself undergoes some further change, and acquires the appearance noticed in the matured eggs of the 'Toad, and in the most advanced of those of the Frog. No trace of the germinal vesicle can be detected in any ova that have left the ovary and are contained in the cavity of the abdomen, before entering the oviducts. I have examined many ova, both of the Frog and Newt, from the abdominal cavity, but in every instance the vesicle has entirely disappeared. In some specimens, which seemed to have been in the act of escaping from the ovary when the animal was killed by immersion in spirit, I have found in the place occupied by the vesicle an aggregation of white nucleated cells, which, examined by the microscope, exhibited a close resemblance to those seen in the interior of the vesicle. In the midst of these there has occasionally been one or two of larger size than the rest, and which I have imagined to be the remains of the germinal spot, and possibly the origin of the future embryo vesicle of the impregnated ovum, an opinion, however, which I have not had the means of verifying, and I must further state that $I$ have failed to recognize these larger cells in ova that were free in the cavity of the abdomen. Each of the three species of Newt, as well as the Frog, have presented similar appearances in the germinal vesicle and ovum under similar circuinstances.

Thus it is quite certain that the germinal vesicle disappear's in the Amphibia before the ovum enters the oviduct. I believe it does so in the interior of the yelk, not in the centre, but nearer to the dorsal than to the future ventral or white surface; and not, as has been supposed, on the dorsal or dark surface, between the vitellus and the vitelline membrane. 'This view is supported by the fact, that that portion of the yelk which incloses the vesicle in an advanced stage of the ovuu in the Frog is of a more or less intense black colour, while the vesicle is perfectly white; and that at a further advanced stage, after the vesicle has disappeared, and its place is occupied by a collection of white cells, the dark portion of the yelk still preserves its intense black colour, except at the point that corresponds to the central canal, which then has a learlen hue. Prevost and Dumas*, and also Rusconi $\uparrow$, have mentioned that there is a yellow spot at a corresponding part of the dark surface of the egg of the species they have exarnined after inpregnation, Rana esculenta?, but these appearances must

* Annales des Sciences Naturelles, tom. ii. p. 104.

† Développement de la Grenouilie Commune, 4to. Milan, 1826. p. 9. 
not be mistaken for the germinal vesicle arrived at the surface. There is a similar spot, and that too of an elevated form, on the egg of each of the Lissotritons. But independent of the fact that the germinal vesicle has entirely disappeared from the interior of the egg before it escapes from the ovary, this spot is shown not to be the vesicle, both in the fact that in the egg of Rana temporaria the dark portion of the yelk is unchanged, while in each case the spot is perforated, and leads into the canal that passed originally to the vesicle. I regard the spot as simply a protrusion outwards of the edges of the canal while closing, after the vesicle has disappeared. I slsall piesently show that a similar white spot is formed on the under surface of the egg of the Frog soon after deposition, and which might equally well be mistaken for the germinal vesicle.

Mode of disappearance of the Vesicle.-The mode in which the vesicle disappears may be inferred from the facts of its structure. Being filled with a progeny of cells which we may regard as of different periods of growth, and these again containing others, it is fair to conclude that this process of cell formation is that by which the parent vesicle is ultimately destroyed. At the time when the germinal vesicle has nearly attained its full size, the peripheral cells are smaller than those nearer to its centre, while the yelk cells that surround the vesicle are still smaller than either, and are of a dark colour. When, therefore, the vesicle has acquired its full size, by the simple vegetative endogenous growth of the contained cells, we may fairly presume that the death of the parent mother-cell, or germinal vesicle, takes place as the result of their enlargement, by the diffluence of its investing membrane; and the enclosed danghter cells, thus gradually set free in the midst of those of the yelk, as in the ideal (fig. 7), form one mass with the latter, and the moment of the actual disappearance of the vesicle thus escapes direct observation, its previous existence being indicated only by the unbroken ontline of the investing membrane.

These views lead me to agree with W and mode of growth of the germinal vesicle, but not as to that by which it disappears. Dr. BARRY indeed believes that the vesicle only becomes changed by its mode of developinent, and does not cease to exist. But most certainly it does disappear in the Amphibia, and, as I believe, through the growth of the young cells in its interior. I cannot therefore agree with Dr. BARRY that the changes in the vesicle end in the production of two cells in the centre of the yelk, that give immediate origin to the embryo; but rather believe that it is from one of the central cells of the germinal vesicle that the future embryo vesicle takes its origin, while the remainder of the liberated cells are distributed with this through the substance of the yelk, when the segmentation of this body takes place. 'This opinion is in accordance with that of VoGT*, who found that in the ova of Alytes obstetricans the germinal spots increase in number, and that a few hours after fecundation sull vesicles, similar to these spots, are scattered through the yelk. I have inyself found similar vesicles in the fecundated egg * Untersuchungen über die Entwicklungsgeschichte der Geburtshelfer-Kræte (Alytes obstetricans), 4to, 1842. 
of the Frog about three hours after impregnation (fig. $10 a$ ), but have not traced them to their origin. With regard to the disappearance of the spot in the germinal vesicle, the facts observed in the ova of the Frog agree with those noticed by KöLLIKER* in the ova of intestinal worms, that all appearance of the spot is lost before that of the vesicle. This circumstance, however, may be owing either to the spot having given origin to cells in the vesicle which quickly attain to similar dimensions, and from which it is not otherwise distinguished; or to its becoming entirely obscured by their multiplication. Although no observations have been made on the origin of the embryo vesicle that appears in the yelk after the disappearance of the germinal, I am still inclined to regard this as being in some way derived from the lost germinal spot, notwithstanding that KöLLIKER found a certain period of time elapse between the disappear"ance of the vesicle and that at which he was able to recognize this body.

Transit of the Ovum.- Thus, then, when the ovmin escapes from the ovisac and ovary into the cavity of the abdomen, the germinal vesicle and spot have entirely disappeared, and it consists only of the yelk enclosed in an exceedingly delicate, structureless, vitelline membrane. This is its condition in the Frog, Toad and Newts. It is then extremely delicate and easily lacerated. The mode in which the ovum passes into the oviduct has been the subject of much inquiry. I am quite certain, as SwamMERDAM long ago showed, that the ova, when mature, pass from the ovaries into the cavity of the abdomen, and from thence into the oviducts, in the Frogs, Toads and Newts, quite independent of any intercourse with the inale, as I have myself recently had an opportunity of proving. The frog I have already mentioned (p. 173.) as having watched through its season of hybernation, was kept apart from all others nntil the 2nd of April, at which time she had not deposited any ova. But from the altered form of her body it was evident that the ova had passed, or were at that time in the act of passing, into the oviducts. I then placed her in a vessel with others, some of which were males, but not one of these joined with her. Nevertheless, on the 6th of April she cast her ova, without having paired, and died on the following day. On examination after death, I found that the whole of the ova had left the ovaries, all of which, excepting only two still free in the cavity of the abdomen, had passed through the oviducts without any intercourse with the male. These ova of con'se were sterile, but it was worthy of note that their envelopes did not expand to so great an extent as those of the eggs of paired individuals.

Passage into the Oviduct.- In what way the ova pass from the cavity of the abdomen into the mouth of the duct has never been satisfactorily explained. Swammerdam examined the question with much care $\downarrow$, but was unable to form any decided opinion respecting it, as he correctly states that the mouths of the ducts are at a distance from the ovaries, and are not free to grasp the ova like the fimbriated extremities of the Fallopian tubes in Mammalia, but are confined in the peritonæun, which is continuous with that which passes over the pericardium and heart. Prevost and Dumas

* Müller's Archiv, 1843.

+ Book of Nature, part 2, pp. 108, 109. 
have since stated* that the ova after leaving the ovaries are seized by the tubes ("sont saisis par des trompes"), but they do not show in what way this seizure is effected. They have omitted to describe the structure of the parts concerned in the act, and have not mentioned the way in which the ova are conveyed to the tubes from the ovaries, or whether the mouths of the tubes approach the ovaries, as in Mammalia.

The entrance to the tubes in the Frog, as Swammerdam has correctly shown, is in the peritonæum (Pl. XIV. fig. $1 b$ ) at each side of the heart $(a)$, and $I$ have found it in nearly the same place in the Newts. The apex of the pericardium in the Frog is attached to the cartilage of the sternum by two layers of peritonæenm, which togetler form the mediastinum, and enclose between them the trunk of the median abdominal vein, a branch of the vena cava. Tracing one of these layers of peritonæum upwards and over the pericardium, we find in it an orifice (fig. 1. and $2 b$ ), at the part where it is reflected on itself to form the lateral portion of the suspensory ligament $(e)$ of the liver $(c)$. This orifice $(b)$ is elongated, oval and funnel-shaped, and, when dilated, forms a kind of pouch at the anterior boundary of the space or cavity between the liver $(c)$ and the heart (a), and laterally it is in free communication beneath the suspensory ligament with the common cavity of the abdomen. The oviduct $(\mathrm{g})$ conmences in this dilated orifice as a narrow tube with thick muscular parietes and with a thick mucous lining. It passes at first upwards and forwards, confined to the peritonæum, and then outwards above the base of the lung $(f)$, gradually increasing in its dimensions. Inmediately after it has passed the lung it becornes more enlarged, and as it passes backwards to the side of the spine forms many convolutions, which end in the dilated oviduct (fig. 1 . and $4 h$ ) or common receptacle for the eggs ready to be deposited.

'The commencement of the oviduct in the Newts is very similar to that of the Frog. In the Triton palustris it differs only in the entrance being larger, and situated more to the side of the body, and above the lung, to the base of which, as well as to the peritonæal investment of the heart, it is confined, as in the Frog; but it has a more free communication laterally with the common cavity of the abdomen than in that animal.

The ova escape from the ovaries into the cavity of the abdomen among the viscera both in the Frogs and Newts, and are carried forwards to the spaces between the liver and beart on each side to the dilated mouth of the oviduct. They certainly are not seized by the tubes as they escape from the ovaries, as they are constantly found free in the abdominal cavity, while the mouths of the tubes being confined in the peritowæum, and having no appendages, cannot be extended to reach them. Their transfer seems to be effected in the Frog in part by the action of the abdominal muscles forcing them onwards in the spaces between the viscera, aided perhaps by the peristaltic action of the stomach and intestines; and their entrance into the tubes, when arrived in the vicinity, seems to be induced by an ingurgitory or suction action at the mouth, occasioned by the alternating and pulsatory motion of the heart, with which the tube is 
connected by means of the peritonæum. The tube itself is formed of strong longitudinal and transverse fibres, which are continued into the peritonæum, and the former especially into the suspensory ligament, the free external margin of which bounds the outer side of the orifice. The transverse fibres are strongly marked at the commencement of the orifice, wluere there is a slight pouch ; so that when the eggs are entering, these fibres doubtless prevent their return and transfer them onwards. This, I believe, is the way in which the eggs enter the oviducts. It is quite certain from the anatomy of the parts that they cannot be grasped by the oviducts until they are conveyed to them. I have not actually witnessed the passing of the eggs from the abdomen into the ducts in the Frog, but $I$ have seen the eggs moved onwards in the smaller Newt, Lissotriton palmipes. Having deprived a female of this species of sensation and power of motion by division of the spinal cord through the medulla oblongata, I proceeded to open the abdomen to obtain ova from the oviducts for experiments on artificial impregnation. I then found that a number of ova were free in the abdominal eavity, and that some had very recently entered the ducts, while other's were in the immediate vicinity of the mouths. The heart was still pulsating vigorously and with great regularity, and I then saw that at each pulsatory action the ova passed slowly forward between the liver and lung, towards the mouth of the oviduct, which still contained two or three ova that appeared to have entered at the moment of the operation. I did not witness the actual entrance of an ovum, but saw that the action of the heart certainly had the effect of indncing the advance of it to the mouth of the tube, and quite sufficient to lead me to regard this as one of the chief means of its entrance into the duct.

It is not until the ovum has become clothed in the oviduct with its gelatinous envelope that it is susceptible of impregnation. This remark applies equally to the Frogs, Toads and Newts. The ova of the Frog and Newt at large in the abdominal cavity are always entirely without this envelope, and consist simply of the yelk mass enclosed in an extremely delicate vitelline membrane. They are so easily injured that it is only with great difficulty that they can be removed from the abdomen for examination unbroken. Those of the Newt, when taken up ever so carefully by means of a hair pencil, often burst the membrane simply by their own weight. But immediately after they have entered the oviduct and begin to acquire their envelopes, the yelk appears to undergo some change, as it becomes much firmer and is less easily injured. Shortly after the egg has entered the duct, it gains the first layer of an investment, which, from the great similarity it bears to the gelatinous layer gained by the ovum of the Rabbit in the Fallopian tube, and regarded by its discoverer in that animal, Mr. Wharton Jones*, as the origin of the chorion, I am disposed, with him, to look upon as the analogue of that layer. This covering adheres very closely to the vitelline membrane, and is scarcely to be distinguished from it, except at certain periods of change. It is acquired before the egg has arrived at the first convolutions of the ovi-

* Phil. Trans. part 2, 1837. 
duct. During the remainder of its passage the egg gains two other distinct layers of similar investuent, which, together, we afterwards recognize as the gelatinous envelope of the Frog and Toad, and the capsule of the Newts. These envelopes are not merely sinple means of protection to the egg during the production of the embryo, as has been supposed, but, as I shall presently show, are essential to it at the period of fecundation, and without which the egg is not susceptible of impregnation. The layer of envelope which I regard as the foundation of the chorion, is a dense, but very transparent thin covering, in immediate contact with the vitelline membrane, and is formed of cells so closely aggregated together as to have coalesced into a fibrous structure. The two layers external to this are also formed of cells, which, with their nuclei, are distinctly visible in the envelope of Triton palustris, in which they alternate in regular series. Although these layers, which constitute the jelly in the egg of the Frog, become detached in that of the Newts quickly after oviposition, and, expanding as in the Frog, they leave the egg at liberty in a chamber in their interior, they are nevertheless essential to the impregnation of the ovum, which takes place before or at the time of leaving the body, as in Frogs and Toads. Rusconi* removed the envelopes of the egg of frogs, and found that the embryo still became developed, and thence concluded that these coverings serve only mechanical purposes during the changes; but it will presently be seen that they have a more important function at a much earlier period. During the time they are in course of formation around the egg the yelk undergoes some further change. The light portion becomes of a whiter, and the dark portion of a deeper colour. Internally the cells vary more in size, the lighter-coloured being the largest. I have not succeeded in recognizing any embryo or central vesicle up to this period.

\section{CHANGES AFTER SPAWNING AND IMPREGNATION.}

First period of development.-It has been long known that a division or cleavage of the yells of the Frog's egg is one of the earliest and apparently invariable results of fecundation. The prinary division was first seen by Swammerdam, and was figured $\downarrow$ and inentioned, but was not understood by him. Spaldanzani long afterwards recognized it in the egg of the Toad (Alytes obstetricans $*$ ), which he says becomes about a day after fecundation marked "with two furrows which meet to form an angle,"that the furrows afterwards become deeper, and that "two small tumour's arise on each side of the furrows,"-changes which have since been more accurately and completely described by Vogt§. Spallanzani also says that the egg of the common Toad is " marked with four furrows which intersect each other at right angles nearly like the husk of a chestnut half-opened," but he seems to have thought this was the usual condition of the ovum. To Prevost and Dumas\|, however, we owe the important

* Développement de la Grenouille commune. Milan, 1826.

$\dagger$ Loc. cit. tab. xlviii. figs. 5,8 . $\ddagger$ Loc. cit. vol. ii. p. 159.

$\S$ Untersuchungen über die Entwicklungsgeschichte der Geburtshelfer-Kræte (Alytes obstetricans), 1842.

II Annales des Sc. Nat. tom. ii. p. 110, 1824. 
discovery of the cleavage of the yelk as a process of the fecundated egg; to RusCONI*, BAER $\downarrow$ and others, its full exemplification in the Amphibia; and to BARRY ${ }_{+}^{+}$and BischоғF its detection and elucidation in the Manmalia.

The agent immediately concerned in these changes is believed to be the embryo vesicle and its progeny, produced after the disappearance of the germinal vesicle. But it is yet uncertain what is the origin of the embryo vesicle, or whether it exists in the unfecundated ovum. As cleavage of the yelk certainly is not the result of the disappearance of the germinal vesicle, which disappears from all ova of the Amphibia, whether they are afterwards impregnated or not, I was desirous, at the commencement of my experiments on impregnation, to learn from direct observation whether the unfecundated ovum ever passes through any stage of cleavage; since the ascertainment of the fact in the negative would be an important test in the experiments I was about to make. For this purpose it was necessary to collect many pairs of frogs at the proper season, and when from symptoms which are soon recognized, it was found they were about to cast their ova, to wait patiently, perhaps for many hours, for the result, in order that the exact condition of the ovum, impregnated naturally, should be first ascertained. Swammerdam long ago remarked that the spawning of the frog takes place very rapidly "by a single effort|l." It is often completed, as I have found in the English species, in a few seconds, and usually in less than a minute, during which the male impregnates them, so that if the animals are not closely watched the opportunity of observing the earliest appearances of the ovum is lost. Having noted the condition of the impregnated ova of several pairs of frogs within the first few minutes after spawning, I found those of different individuals vary much with respect to the white or inferior surface, and exhibit appearances that may readily be mistaken for the breaking up of a vesicle on the surface. This appearance is due to a more or less complete state of maturity of the eggs of different broods, and according as their spawning has been retarded or hastened. The peculiarities are the most marked in the least matured, the white surface of the egg being the last completed part, and forming the base of the egg in the ovisac (fig. 5). Having noticed the appearances of the eggs when impregnated naturally, I was enabled to compare them with others impregnated artificially, and these with some of the same brood not impregnated.

Immediately after the frog has spawned the ova form a close rounded mass, which at first is scarcely so large as a walnut. They then seem to consist alnost entirely of dark-coloured yelks with thin gelatinous envelopes. The form of the egg is then somewhat oval, with the white portion a little more conical than the dark and differing slightly in different ova. In some there is a dark spot in the centre of the white, that looks like a depression or cavity, or perhaps a vesicle. I am not certain
* Loc. cit.
† Müller's Archiv, 1834.
$\ddagger$ Philosophical Transactions, 1839, 1840.
$\S$ Entwickelungsgeschichte des Kaninchen-eies, 1842.
11 Loc. cit. part 2. p 111 . 
that this appearance is in reality a vesicle, and thercfore am content to describe it as a spot, although it conveys the idlea of being a vesicle. In some ova there are two, four or six of these spots imbedded each in a small portion of white substance. When only a single spot exists, the white surface of the egg for some space around it is more defined than afterwards, and exhibits faint indications of a crucial division of the yelk on this surface immediately around the spot. This is the condition of a few ova immediately after spawning; but the majority have then advanced farther in their changes, and show four or six ronnded dark-coloured spots at a little distance in the place of the single central one. When four spots occur they are usually arranged in a quadrangle, and are less than their own diameter apart. They convey the idea of being derived from the central one; but $I$ bave never seen any division of this, and if such division takes place, I think it must occur before or at the very moment the ova are expelled. In a further advanced stage of the ovum the four dark spots have become larger, and are each imbedded in a distinct portion of the white surface.

One minute after deposition the spots are more widely separated, and are then each encircled by a separate patch of white substance. Two minutes after spawning six dark spots have made their appearance, one of whicb is situated nearly in the centre, and the remaining five are so arranged around this that the white patches in which they were inbedded seem to have coalesced. In three minutes the spots are further enlarged, and appear joined by a dark line of colour extending from each, so that the whole form, as it were, a knotted ring that includes a patch of the white surface of the yelk with one of the dark spots near the centre. In four minutes the ring around the included white substance is more distinct, and the white surface of the egg has increased in extent. In a further advanced stage at this period the white portion included in the ring exhibits the appearance of a white, very opake patch, the dark spot in the centre having disappeared. Around this opake white patch is the dark-coloured knotted ring, now become more uniform, and resembling a ragged chink or slight circular furrow or division in the white surface. The centre of this hemispbere of the egg thus comes to be occupied by a white patch instead of the dark spot. At five minutes this central white patch,-which, as before stated, and from what afterwards occurs, may readily be inistaken, on casual inspection, for the germinal vesicle, altered in its appearance and arrived at the surfuce,-were it not that we now know that this has long before entirely disappeared,--becomes more defined, and the dark circle around it is more uniform and distinct. At ten minutes the central patch is a little reduced in size, and the circle that incloses it begins to take the appearance of a diffused halo. At fifteen minutes the central white patch is more reduced, and the halo is spread wider, while the whole of this hernisphere of the egg has acquired a whiter appearance, and become more distinct from the dark colour of the sides and future dorsal hemisphere. At twenty minutes the central patch has become still smaller and rounder, and the dark balo much broader.

At this period an interesting circunstance occurs which may hereafter be found MDCCCLI. 
to have some reference to changes in the interior of the yelk, possibly to sonse rapid evolution of the so-called central or embryo vesicle in the locality originally oecupied by the germinal vesicle and spot, which, as we have seen, is nearest to the dark surface -it is the partial rotation of the entire yelk. $U_{p}$ to about this period the ova remain undisturbed in the water in a mass as they are expelled, and lie indiscriminately, some with the dark and some with the white portion of the yelk uppermost, or horizontal. But during the time that has passed since the ova have been in contact with water, the envelopes have imbibed fluid and expanded until these investments of the yelk have acquired a thickness equal to about two-thirds of the diameter of the yelk itself. The yelks that bave remained to this time with their white surface uppermost now change their position spontaneously by a partial rotation of the whole mass of each on its axis, within the vitelline membiane, until the dark surface of the whole is placed uppermost. Whether this change of position is merely the result of an expansion of the vitelline membrane at this period, when the ovum is rapidly ceasing to be susceptible of impregnation, as I shall presently show is the case after this lapse of time in the water, or whether it be also connected, as we may fairly believe, with changes going on in the interior of the yelk, I am not prepared to decide. It is inportant, however, to note that the ehange takes place at about the time at which I have found a great abundance of bright clear rounded vesicles distributed throughout the yelk, but chiefly in the place originally oceupied by the germinal vesicle. In some of these vesicles, which I regard as the progeny of the germinal vesicle, I luave seen irregular-shaped nuclei that appeared to be formed of a multitude of nucleoli. 'These vesicles eonvey to me the same idea as those seen by Bischorf in mamınaian ova, excepting only that in the egg of the Frog they contain compound nuelei.

At thirty minutes the central patch on the white surface of the egg has almost disappeared, and the halo around it is still more cliffused. At forty-five minutes it has entirely disappeared in most specimens, and its plaee is oceupied by a broad dark area which includes the boundary of the previous halo, and which appenrs to be occasioned by a slight depression in the centre of this surface of the yelk. One hour after spawning this depression is somewhat deeper. The white surface has become still more defined, and the dark has acquired a more intensely black colour. The egg remains in this state without further perceptible change during the sueceeding second and third hour, excepting only that the depression in the white surface becomies a little deeper, but it has almost disappeared at the end of the fourth hour, when segmentation or cleavage of the yelk is about to take place. But this is not invariably the ease. When it does remain it is always of an oval form, and the primary cleavage of the yelk, as it proceeds on either side from above downwards, meets in its centre and invariably passes through it transversely to its long diameter. These are the first perceptible changes in ova that are impregnated by the natural union of the sexes, and when spawning has not been retarded: But in some broods of eggs that bave been retained longer than usual in the oviduets, the whole of these changes have 
already taken place, in so far as regards those of the yelk, the white surface of which then exhibits an uniform appearance.

Changes immediately before segmentation or cleavage of the yelk.-Segmentation usually commences in from four to five hours. At about one hour and a half after spawning, the peripheral layer of cells on the middle of the dark or uppermost portion of the yelk of the impregnated ovum becomes separated from the inner surface of the vitelline membrane, and this separation goes on until a broad free space is left between this envelope and the superior layer of yelk-cells. This space, which we may designate the respiratory chamber, is at first but a small area above the middle of the dark surface of the yelk, and is commienced above the central canal. It seerns to be occasioned by a recedence towards the interior, or a shrinking, at this period, of the yelk-cells of the dark bemisphere of the egg, commencing in the centre of this palt and extending gradually, but in a less degree, to the circumference. This recedence goes on until the space left between the vitelline membrane and the yelk is equal to about one-sixth of the diameter of the whole mass, when the space appears to be occupied by a very transparent fluid, interposed between the now depressed surface of the yelk and the vitelline membrane. In the centre of the black surface is the minute orifice noticed by Prevost and Dumas*, and Bä̈rt, which leads into the central canal that communicated with the germinal vesicle in the ovarian ovum. It is in the margins of this canal that seginentation is commenced. While the space or chamber between the black portion of the yelk and the vitelline membrane is being formed, and from fifteen to thirty minutes before there is any sign of cleavage, the yelk becomes extended horizontally in a direction transverse to that in which the first cleft afterwards takes place, and assumes a transitory obtuse oval form, which it retains until the yelk begins to divide. The division, as correctly shown by $\mathrm{BA}_{\mathrm{A}} \mathrm{R}+$, commences in the extension in opposite directions of at first a faint indentation in the margin of the central canal, which quickly becomes deeper, and is carried across the surface of the yelk, and gradually more and more deepening and widening as it proceeds, is carried round the sides, and meeting in the middle of the depression on the under surface, or of the remains of the white patch when this has not already disappeared, is completed by passing through the middle of the yelk; which is thus divided into two portions. This first division occupies from twenty to thirty minutes before it is finished, and it is not until then that a second fissure is commenced. I have not had any opportunity of proving whether this division is the direct result of subdivision of the central vesicle, and the attraction of the yelk-cells in equal proportions around each division of that body, as believed by KöLLıкR $\oint$, and, as it seems fair to infer, is the case; but in addition to the ouservation by Prof. Sharpey $\|$, that the contraction of the entire yelk at the commencement of these changes, and the movements he has observed among its granules as they proceed, are in favour of this opinion-I may remark, that the extension of the yelk of the Frog's
* Loc. cit. tom. ii. p. 104, 1824.
† MürLen's Archiv, 1834.
$\ddagger$ Loc. cit.
\$ Mëllez's Archiv, 1843.
\| Quarn's Anat., Fifth Edition, 1848. 
egg in a direction transverse to the first cleavage, may also be advanced as conformable to the same view. It is further supported by the fact which $I$ have seen in the egg both of the Frog and Newts, that before the second or crucial cleavage is commenced the yelk becomes contracted, so that the first cleft for a time is almost impelceptible while it is extended in the transverse direction, or line of axis of the first division, after which the second or crucial cleft is commenced. To this I may add another fact which appears to be equally significant, and which occurs in the unimpregnated eggs both of the Frog and Newts, but more especially in the latter. Although no recedence of the yelk from the vitelline membrane takes place in the unimpregnated egg of the Frog, it becomes, nevertheless, slightly oval after the first few hours, but returns to its original shape some time afterwards. But the unimpregnated egg* of the Newts is not only separated from the vitelline membrane, but also is depressed, and has a distinct pit in the centre of its upper surface, and also assurnes an obtuse oval form, both which it retains, when the egg is preserved in water, until decomposition has commenced.

Changes in the impregnated and unimpregnated Ovum compared.-Having traced the egg impregnated by natural union of the sexes through its first period of development, I was able to compare the phases it exhibits with those of the artificially impregnated, and these with the appearances in unimpregnated eggs of the same brood, placed under precisely similar circumstances with reference to light, heat, air, water, and locality. The ova experimented on were all procured from the same female, and the seminal fluid from the male with which she was paired, and at the time the female was about to spawn.

Spallanzani obtained unimpregnated eggs of the Frog for his experiments by opening the body of the female and removing them from the distended oviducts. This mode is exposed to the objection, that in the removal of the ova they are liable to be brought into contact with the blood of the animal from the cut vessels, and that the ova thus obtained may not be the most mature, and fitted for experiment. It seemed desirable, therefore, to obtain them by another mode,-the total withdrawal of the influence of sensation, and power of tension in the muscles by division of the spinal cord through the medulla oblongata. 'The attempt was made with a female frog that had been paired for several days, and, from appearances, would have deposited her ova naturally in the course of a few hours. The spinal cord was divided as quickly as possible with a strong pair of scissors inmediately behind the brain, and this organ was also destroyed, so that all consciousness was annibilated. The attempt was successful. The muscles deprived of voluntary power instantly became relaxed and allowed of the ova being passed, by gentle compression of the body, through the natural passage without contact with the blood of the animal, in greater or smaller number at pleasure, and thus afforded easy means of experiment.

I may once for all state that it was in this way that the ova were always obtained in the following investigations.

* Or, possibly, partially impregnated. 
Recourse was had to a similar expedient to procure the seminal fluid from the male. Spallanzani had obtained the fluid, by vivisection, from the seminal vesicles themselves. But there seemed more objection to the adoption of this mode with the male than the female, the certainty of much of the fluid being lost, independent of the severity of the operation. Indeed Spallanzanr states, that he was never able to procure more than from two to three grains from a single individual. I therefore availed myself of a habit in the male frog, and which Spallanzani had previously noticed and taken similar advantage of in the Newt, to obtain the fluid in greater quantities than by the mode constantly adopted by that physiologist. When the male frog, like the Newt, is taken in the hand, or slightly compressed, at the season of pairing, a quantity of fluid is immediately passed. This consists chiefly of seminal fluid mixed with water expelled from the effect of the compression, or during the efforts to escape, as water is passed by other animals at the moment of capture. It abounds with spermatozoa in their most active state, and thus is fitted for experiment. It required therefore only to secure the limbs of the animal and compress it slightly, to obtain the fluid without severe injury. This ready mode was adopted on all occasions when the fluid was required, and the precaution taken always to examine a portion with the microscope, to be assured of its nature before employing it. Spermatozoa have never, during the season of pairing, been absent from it. At the end of the season they have been less abundant, and spermatozoal cells in greater proportion than at an earlier period. But in these cases I had reason to think that the chief part of the fluid consisted of water. It is probable that this was the case in the two instances of apparent absence of spermatozoa in the Toad, mentioned by Spallanzan ${ }^{*}$, and that the fluid did really contain spermatozoa, although few in number, and consequently easily overlooked, and that the ova were impregnated by these, and not by the fluid portion of the semen, as he appears to have supposed.

On comparing the white surface of the yelk of the unimpregnated with that of the impregnated egg, whether the egg had been fecundated naturally or artificially, I was not able to detect any difference during the first twelve minutes. The changes went on in both, and appeared to be almost identical in each. But after the time specified no further progress was perceptible in the unimpregnated ovum, which continued to exhibit the same appearance for several hours. But the white surface of the impregnated egg became more and more changed, up to the time of cleavage of the yelk, when it was almost an uniform surface.

These observations were afterwards repeated with similar results, and the conclusion to which they led was, that changes take place in the yelk from the period when the germinal vesicle disappears and the ovum leaves the ovary to the moment of its expulsion from the body, and which changes may proceed for some time afterwards quite independent of impregnation; and that these have some reference to the evolntion of the central or embryo vesicle: possibly also that they do not cease imme-

* Dissertations relative to the Natural History of Animals and Vegetables, 1789, vol. ii. p. 151. 
diately, but subside gradually when the stimulus imparted by impregnation is not supplied.

The experiments made to ascertain whether the unimpregnated ovum passes through any stage of cleavage, consisted of four sets, placed in four vessels of equal size, containing each about two ounces of water. Ova were passed from the same fernale as quickly as possible at the same time into each of these vessels. To one of these marked A, a considerable quantity of a mixture of seminal fluid, one part to three parts of water, was immediately added; to a second, B, only a single drop of this mixture; while the third and fourth, $C$ and $D$, contained only water with the unimpregnated ova, and the four vessels were then placed in every other respect under precisely similar conditions.

A few minutes after the impregnating fluid had been added to A, I examined some of the ova beneath the microscope, and found a vast abundance of spermatozoa adhering to every part of the surface of their gelatinous envelopes. On other ova firom the set $B$, there were also many spermatozoa attached, but in much smaller number than on the ova of set $A$.

In five hours and fifteen minutes, the temperature of the room during the interval having ranged only from $53^{\circ} \mathrm{F}_{A H R}$. to $54^{\circ} \mathrm{FAHR}$., segmentation had commenced vigorously, and was strongly marked in the whole of set A. But it had not commenced in set B. It did not occur in these until five hours and twenty-two minutes, when it began in these also. Thus there were seven minutes' difference in the commencement of the changes in these two sets of ova, a cireumstance which led to the belief that this difference might have some reference to the relative quantities of the impregnating fluid employed,-an opinion which I had long before been led to by observations on the impregnation of the common Earwig, Forficula, in which it had appeared to me that deficiency in the quantity of the impregnating fluid is unfavourable to fecundation.

No segmentation or cleavage of the yelk took place in the sets of ova marked C and $\mathrm{D}$, which, except in becoming a little oval, as already mentioned of unimpregnated eggs, remained, in so far as the appearance of the yelk surface was concerned, in the same state as at a few minutes after spawning, and they continued in exactly the same condition at the end of twenty-two hours. This I have since found constantly to be the case with unimpregnated ova, whether they happen to be exposed to a high or low temperature of the surrounding medium. The yelk of the impregnated egg gradually acquires a more intense black colour, which strikingly contrasts with the dull colour of the unimpregnated.

At the end of six days the majority of the ova in A and B were producing embryos, while those in $\mathbf{C}$ and $\mathbf{D}$ were fast decomposing.

These trials afforded the positive test I required from direct observation, as a fixed point in the experiments about to be commenced,-that segmentation certainly does not take place in the unimpregnated ovum. 


\section{SUSCEPTIBILITY OF THE OVUM.}

I was not aware, at the time of commencing my experiments in March 1849, nor indeed until very recently, of the extent to which the original investigations of SPaLlanzani, and of Prevost and Dumas had long ago been carried*, and it has only been since my experiments were completed, and during the preparation of this paper for presentation to the Royal Society, I have learned by careful reference to their first memoirs, that they have anticipated me in part of this inquiry-that of endeavouring to separate the spermatozoa by filtration from the more fluid portion of semen, and testing the effect of thęse two constituents in artificial impregnation. To them therefore be all honour for the result; although even they, as they honourably mention, had themselves been anticipated in this by Spallanzani, and that too with similar' success. 'The extraordinary results obtained by Spallanzanip in artificial impregnation, and the inperfect knowledge which we possess of the nature of the means by which it is effected, has induced me to endeavour to repeat and vary his experiment, and to conceive others, which, so far as I am aware, have not yet been attempted. I have been the more urged to this from the circumstance mentioned by Spallanzani, and already alluded to (p. 189), the occasional supposed absence of spermatozoa from fluid that is capable of fecundating; and also from a belief formed long ago with regard to the Articulata, that the spermatozoa, nevertheless, certainly are the efficient agents in impregnation, although full proof of the fact has been wanted. I have been desirous therefore of learning how far this belief can bear the test of direct experinent, or the fact be capable of demonstration by artificial means in the Amphibia. As, however, the experiments I have myself made vary from those of the authors mentioned,- have not been influenced by the result they had previously arrived at,- -have been somewhat more extended, and, as I believe, will now tend to place the fact of the direct agency of the spermatozoa in impregnating the ovum beyond doubt, -it has seemed desirable still to give them in detail, as assisting to establish an important point of knowledge by facilitating a comparison of the results of independent investigations.

Duration of susceptibility. - The length of time during which the ovum, after it bas been passed, remains susceptible of fecundation, is affected by several circumstances. I had reason to believe at the commencement of my experiment that this time is very short. Spallanzan found that when the egg of the Toad was expelled into water it was not susceptible of fecundation after a lapse of fifteen minutes*. This was at a raised temperature of the atmosphere, $81^{\circ} .5$ FArR. On the other hand, he also found that, at this temperature, ova retained fourtcen hours within the body of the female after death, and of course not in contact with air or water, might still be fecundated; and that when preserved in an ice-house fecundation might be effected at two days after the death of the parent $\$$. But Prevost and Dumas arrived at the conclusion\|

*-Annales des Sciences Naturelles, tom. i. et ii. 1824.

$\$$ Loc. cit. vol. ii. p. 178 . \$ Loc. cit. vol. ii. pp. 176 and 177.
+ Dissertations, \&c. vol. ii.

|I An. des Sc. Nat. vol. ii. p. 135. 
that the time is much more extended in the Frog; - that fecundation may take place when the temperature ranges from $53^{\circ} \mathrm{F}_{\mathrm{AHR}}$. to $59^{\circ} \mathrm{FAHR}$. at the expiration of one hour after immersion of the eggs; - that some eggs are fecundated at two, and a very few even at the end of three hours, after which no fecundation takes place. The results obtained by myself both on the Frog and Toad have been most in accordance with those by Spallanzani. This is the more worthy of notice from the circumstance that a slight difference between his and mine is readily accounted for by a corresponding slight difference of temperature, which Spallanzani, and Prevost and Dumas, have remarked, and since them also Mr. BeLL*, has great influence on the changes of the eggs and young. The temperature at which my test experiments were made, was a little lower even than that at which Prevost and Dumas made theirs; and yet I was not able to find any ova susceptible of fecundation after they had remained from thirty to forty minutes in water. On careful examination of Prevost and Dumas' experiments, I think the difference may perhaps be due to a circumstance which seems equally to affect some of Spalranzanis results, namely, the mode in which the impregnating fluid employed was obtained. These authors state that the fluid they einployed was expressed from the testicles of the frogs, so that from what we now know of the mode of origin of the spermatozoa, this fluid in all probability contained a large proportion of developmental cells that included spermatozoa not fully matured, but which might become liberated in the water at a longer or shorter period. Or, possibly, the fluid added to ova that liad been long in the water, had been very recently obtained; in which case the vigorous spermatozoa might effect the impregnation of ova that had become alınost insusceptible through the imbibition of water by their envelopes. I an led to this view by the fact that the jelly-like envelope of the Frog's egg begins to imbibe and expand the instant it is brought into contact with fluid; and from having ascertained that there is a close relation between the degree of expansion and imbibition of this envelope and the susceptibility of the ovum to become impregnated, and that these conditions are also greatly affected by temperature. The act of expansion of the envelope is an act of endosmose, and possibly this is one of the means by which the impregnating agent is made to exert its influence on the yelk. The yelk is not a passive recipient during the endosmic action of its coverings, but seems to participate in that action, as $I$ have seen portions of its surface heave and contract within the vitelline unembrane during the first hour the egg has remained in water. It may thence be inferred, that if the impregnating stimulus be not supplied quickly, the fitness of the ovum to become impregnated is diminished in proportion as its envelopes are expanded. If then it be proved that the spermatozoon is the agent in impregnation, but, so far as can be discovered, does not penetrate bodily into the ovum or its envelopes, and yet, as may be shown, must always come into contact with their surface, the more rapidly and to the grcater extent this expansion takes place, and removes the efficient body from that which it is in some way destined to affect, the 
less will be the chance of its impregnating the ovun, and the less will the ovum become susceptible of impregnation even by the most healthy and vibratile spermatozoa.

The extent and rate of expansion of the envelope of the Frog's egg, during the first half-hour it remains in water, very nearly coincide with the diminution of the fitness of the ovum to become fecundated. This is shown by observing the rate of expansion of the envelope during the first fifteen minutes of submersion, and then testing the fitness of the ovum, by experiment, during a similar period.

At the moment when the ovnm is expelled from the body, the envelope is merely a thin gelatinous layer, its entire diameter being equal only to about one-sixth of the diameter of the yelk. After it has been one minute in water, and begun to imbibe and expand, it is then equal to about one-fourth of the diameter of the yelk. At the end of two minutes it is enlarged to one-third, and in three minutes to one-half the diameter of this body. In four minutes it exceeds three-fifths, and in six minutes two-thirds, and it continues to imbibe fluid and expand at the same rate, until, at from ten to fifteen minutes, it very nearly equals in thickness the whole diameter of the yelk; and at half an hour (fig. 9) it is one-fourth greater than this. Prevost and Dumas* noticed the expansion of the envelope during the first six hours, but entirely overlooked the rate of expansion during the most important period, the first hour, and noticed only the general fact that the diameter of the envelope, at the end of the first hour and a half, was as 5 to 2.5 at the time of spawning, and that it had nearly acquired its full size at the end of three hours. My own observations agree with this latter statement. The expansion of the envelope is greatly retarded at the end of the third or fourth hour, until after cleavage of the yelk has taken place, when it again proceeds, but much more slowly than at first. If then we bear in mind the rate of expansion of the envelope during the first half-hour, the following experiments will give some idea of the degree of susceptibility of the ovum to become impregnated during that period.

Set E. April 6, 1850.-The temperature of the room, at the commencement of this set of experiments, being $60^{\circ} \mathrm{FAHR}_{\mathrm{A} \text {., }}$ ova were obtained from a female frog and seminal fluid from a male, by the mode already mentioned; the latter being mixed with an equal quantity of water.

I may here remark, that the ova in each of this set of experiments were placed in nearly sinilar quantities of water, and that as it had been shown in the experiments A, B, C and D (p. 190), that segmentation of the yelk proves the ovum to have been impregnated, although, as we shall hereafter find, not always sufficiently so as to produce the enbryo, I adopted this as a fair test of the susceptibility of the orum. I may here also mention, that although the date of inaking the several experiments detailed in this paper is recorded, it has been necessary, for reasons that will be obvious, to disregard the order of time at which the several sets were *. Loc. cit., vol. ii. p. 108.

MDCCCLI. 
made, and to detail them when considering the subject to which they more especially refer.

No. 1. P.M. $2^{\mathrm{h}} 52^{\mathrm{m}} \cdot-$ Eighty-three ova were passed into water, and the impregnating fluid added to them at the expiration of one minute. This was forty-three minutes after the fluid had been obtained and mixed with water; but on examination with the microscope at this period, the spermatozoa contained in it were still very active. This long period was determined on with a view to the more effectually testing the susceptibility of the ovum, as it will be shown that the spermatozoa are less and less efficient in proportion to the length of time they have been mixed with water. Segmentation commenced in a very large proportion of the ova at the end of three hours and fifty-five minutes. On the 14th of April, the eighth day, thirty-two embryos had been formed.

No. 2. P.M. $2^{\mathrm{h}} \cdot 5 \mathrm{I}^{\mathrm{m}}$. - Ninety-two ova were passed into water, and at the expiration of two minutes impregnating fluid was added to the same, forty-three minutes after it had been obtained. Segmentation commenced in these also at three hours and fifty-five minutes, and took place in almost every ovum. On the eighth day there were fortyfive embryos.

No. 3. P.м. $2^{\mathrm{h}} 24^{\mathrm{m}}$.-One hundred and twenty-seven ova were immersed in water for three minutes, and then exposed and bathed with impregnating fluid during twenty seconds, watcr being immediately afterwards added to them. No segmentation had taken place at the end of four hours and three minutes, but it took place in many of the ova at a later period, the exact time having escaped my notice. The fluid employed had been mixed with water only seventeen minutes. On the eighth day there were thirty-three embryos.

No. 4. P.M. $2^{\text {h }} 15^{\mathrm{m}}$. - Eighty-one ova were exposed to the air on a dry surface for three minutes without having been in contact with water, and were then bathed with impregnating fluid during five seconds and water inmediately afterwards added to them. The fluid in this experiment had been obtained only eight minutes. Segmentation commenced in several ova at four hours and five minutes, and on the eighth day there were fifty-three embryos.

No. 5. P.M. $2^{\mathrm{b}} 25^{\mathrm{m}}$. - One hundred and thirty-six ova were passed into water for five minutes, and were then exposed and bathed with impregnating fluid for several seconds, and water immediately afterwards added to them. The fluid had been obtained twenty minutes. Segmentation occurred in one ovum at four hours and eight minutes, and in others quickly after. On the eighth day only ten embryos had been formed.

No. 6. P.м. $2^{\mathrm{h}} 17^{\mathrm{m}}$.- One hundred and thirty-nine ova were exposed to the air, on a dry surface, for five minutes, and were then touched freely with fluid during five seconds, applied with a hair-pencil, and water was then quickly added to them. 'The fluid employed had been obtained twelve minutes. Segmentation took place in four hours and eleven minutes. On the eighth day there were thirty-seven embryos.

No. 7. P.M. $2^{\mathrm{h}} 21^{\mathrm{m}}$. - T Two hundred and five ova were retained in water for fifteen 
minutes, were then exposed, well-bathed with impregnating fluid, and water immediately added to them. The fluid employed had been obtained twenty-six minutes. Segmentation commenced in four hours and fourteen minutes, but was more general in four hours and seventeen minutes. On the eighth day there were forty-five embryos.

No. 8. P.M. $2^{\mathrm{h}} 24^{\mathrm{m}}$.-About one hundred ova were submerged for half an hour, and impregnating fluid obtained forty-four minutes before was then supplied to them, but not more than six or eight ova became segmented, and only two embryos were formed.

The following summary will more immediately indicate the results:-

Table I. - Set E.

\begin{tabular}{|c|c|c|c|c|c|c|c|}
\hline Experiment. & Ova. & Time. & Medium. & Fluid obtained. & Segmentation. & Embryos. & Per-centage. \\
\hline No. 1 ...... & 83 & j" & Water. & 43 & 35 & 32 & .38 \\
\hline No. 2 ...... & 92 & 2 & Water. & 43 & 355 & 45 & .49 \\
\hline No. 3 ...... & 127 & 3 & Water. & 17 & 43 & 33 & .26 \\
\hline No. 4 ...... & 81 & 3 & Air. & 8 & 45 & 53 & $\cdot 65 \cdot 5$ \\
\hline No. 5 ...... & 136 & 5 & Water. & 20 & 48 & 10 & .07 \\
\hline No. 6 ...... & 139 & 5 & Air. & 12 & 411 & 37 & .26 \\
\hline No. $7 \ldots . .$. & 205 & 15 & Water. & 26 & 414 & 45 & .22 \\
\hline No. 8 ...... & 100 & 30 & Water. & 44 & $\ldots \ldots$ & $\mathscr{Z}$ & .02 \\
\hline
\end{tabular}

Thus then at a temperature of $60^{\circ} \mathrm{F}_{\Lambda \mathrm{HR}}$. the susceptibility of the ovum to become impregnated is greatest at the time it is passed into water, and for two or three minutes afterwards, and segmentation then takes place more quickly, even when the seminal fluid has been for nearly three quarters of an lour mixed with water, than after longer immersion. The fitness of the ovum to become impregnated is gradually diminished, and segmentation takes place more tardily, according to the length of time which the ovum has remained in water, as is seen by comparing the results of Nos. 1 and 2 with 7 and 8 . On the other hand, while the desiccating effect of exposure to air more arrests the fecundation of the ovum and the occurrence of segmentation of the yelk than a continuance for a corresponding length of time in water, it seems to be less prejudicial to the fecundity of the ovum than immersion in that fluid, as appears to be shown by comparison of Nos. 4 and 6 with 3 and 5, the difference in the number of ova produced being too great to lead us to attribute this to difference in the length of time the impregnating fluid had been obtained.

In the foregoing set of experiments, the quantity of impregnating fluid supplied to the ova was but little attended to, it being added very freely in each case. In the following set I was desirons of knowing what difference would result from the fluid being applied more sparingly, or but for a very short space of time. Spallanzani had made experiments with a similar view, but his appeared to be open to sorne objections, as he had not noted some important circumstances which greatly affect the result, as the temperature of the medium, the length of time the fluid employed had been obtained, \&c. In the experiments now made, these circumstances were 
attended to, and I noticed a curious fact which I first remarked in experiments in 1849. It is what I may designate partial impregnation, and is indicated by a portion only of the yelk becoming segmented. This frequently happens with ova that have been brought into contact with only very sinall quantities of seminal fluid, and but for short spaces of time, as in some of the following experiments. These ova, so far as I have observed, never produce embryos. Segmentation is arrested in some at the very commencement (Plate XIV. fig. 11), in others it goes on to the second or crucial fissure, and in a very few cases may proceed somewhat further (fig. 12), but is never completed to granulation of the yelk. This, I think, is a fact which deserves some consideration with reference to the formation of the embryo.

Set F. March 22, 1850.-Temperature of the room at the time of the experiment was $48^{\circ} .5 \mathrm{~F}_{\mathrm{AHR}}$., and that of the water employed $46^{\circ} .5$ FAHr. As the proof of impregnation is the segmentation of the yelk, and as my object now was to observe the effect of small quantities of impregnating fluid applied only for very short periods of time at a low temperature of the surrounding medium, it is not of consequence that this set was not watched to the full development of the embryo. 'To show the degree of susceptibility of the ovum under the combined influence of these circumstances, it was sufficient to attempt the impregnation at a low temperature, and after the lapse of an interval to remove the ova to a room of the same, or nearly the same temperature as in the set E. This was done at the end of one hour and a half.

No. 1. A.M. $12^{\mathrm{h}} 12^{\mathrm{m}}$.-Fifty-one ova, passed on a dry surface, were each touched lightly and quickly, once only, with a stnall hair-pencil dipped in impregnating fluid mixed with water, at eleven minutes after it was obtained, and water was then added to them. At the expiration of one hour and a half they were removed to a room of the temperature of $59^{\circ}$ FAHR. Segmentation did not occur until the expiration of six hours and $a$ half, and at the end of eight days only four embryos had appeared.

No. 2. A.м. $12^{\mathrm{h}} 20^{\mathrm{m}}$. - Forty-two ova were immersed in water for five minutes, and then exposed, and touched for an instant only as above, and again placed in water. The inpregnating fluid had now been obtained nineteen minutes. Segmentation commenced in some of these at six hours and three quarters, but nearly all of them were only partially impregnated, and not a single specimen produced an embryo.

No. 3. A.m. $12^{\mathrm{h}} 19^{\mathrm{m}}$.-Fifty-eight ova inmersed in water for five ininutes, wcre exposed, touched for an instant as above, and again inmersed for one minute, aftel which, they were well rubbed in the water with a clean pencil, and fresh water then supplied to them. The fluid employed bad been obtained twenty-three minutes.

Not a single egg gave any signs of having been imprcgnated, either perfectly or partially, nor did a single ovum produce an embryo.

No. 4. A.M. $12^{\mathrm{h}} 23^{\mathrm{m}}$.- Forty-two ova were passed into a solution of carmine (the pigment employed by water-colour painters) for five minutes, and were then washed with water, touched for an instant, as above, with impregnating fluid at twenty-seven minutes after it was obtained, and water then supplied to them. Not a single egg 
'became fully impregnated or afterwards produced an embryo. In two or three ova there were slight indications of partial impregnation.

No. 5. P.м. $12^{\mathrm{h}} 37^{\mathrm{m}}$.- Sixty-five ova having remained fifteen minutes in water, were exposed, and thoroughly bathed with impregnating fluid applied with a hair-pencil, fifty-one minutes after it had been obtained, and water was then added to them. Segmentation did not take place in these ova.

No. 6. P.м. $12^{\mathrm{h}} 38^{\mathrm{m}}$.- Seventy-seven ova, passed into a solution of carmine for fifteen minutes, were exposed, and thoroughly bathed with impregnating fluid as in No. 5 , and water was then added; but not a single egg gave any sign of impregnation.

Influence of Temperature.-From these experiments, it seemed evident that thic susceptibility of the ovum to become impregnated is diminished in proportion to the degree of expansion of its envelope and its imbibition of fluid, conditions which are greatly affected by the temperature of the medium in which the ovnm is placed during the first hour; and there secms reason to suppose that this diminution may be clue to the extent to which the envelope becomes influenced by temperature, rather than to any insusceptibility at that time in the yelk itself. The following experiments, made a few hours after the above, tend to support this view.

Set G. March 22, 1850. Atmosphere $48^{\circ}$ FAнr. Water $47^{\circ}$.

No. 1. P.M. $4^{\mathrm{b}} 30^{\mathrm{m}}$ :-Fifty-eight ova were passed from the female from which the ova used in the preceding experiments were obtained, four hours and a half after division of the spinal cord; and seminal fluid mixed with water, and obtained fifteen minutes before, was immediately added to the water in which they were immersed. The ova were removed at the end of twenty-five minutes to a room in which the temperature was then $62^{\circ} \mathrm{F}_{\text {AHR. Se }}$ Segmentation took place in almost every ovum a few minutes within the sixth hour, at which time the temperature of the air was $64^{\circ}$ $F_{A H R}$, and that of the water $62^{\circ}$. At the eighth day, fifty-three out of fifty-eight ova had produced einbryos.

No. 2. P.M. $5^{\text {h. }}$-Sixty-three ova from the same female were well bathed with inpregnating fluid, and water was then added to them. The fluid in this case had been obtained three quarters of an hour. Segmentation took place in the majority of these at the end of five hours and a half.

No. 3. March 23. P.M. $12^{\mathrm{h}} 45^{\mathrm{m}}$.- One hundred and twenty-four ova from the same female, twenty-four hours after section of the spinal cord, were passed into water, and impregnating fluid soon after it was obtained supplied to them. The ova were placed in a temperature of about $60^{\circ}$, and nearly the whole produced embryos.

These facts proved that the ova employed were still fitted to become impregnated when the fluid was supplied to them in sufficient abundance, and for a sufficient length of time, and within the period during which the envelope continues to expand and imbibe most rapidly. This condition is always promoted by an early removal from a low to a comparatively high temperature during the period of expansion, as in Set G, in which segmentation took place in flom five hours and a half to six hours, and when 
the removal from low to high temperature was within the first balf hour; while it did not occur, in the only experiment in which it happened in Set F, No. 1, until the end of six hours and a-half, when the removal from a similar low to a like high temperature was not made until one hour and a half after impregnation.

The influence of temperature is thus as marked in its effects on the impregnation of the ovim as it can be proved to be on the future development of the embryo. Impregnation is accelerated, and also is more certain in its occurrence in a high than in a low temperature. In the latter it becomes retarded and is less determined. This applies equally to the susceptibility of the ovum, and to the fitness of the impregnating fluid to effect impregnation. But in proportion as this fitness is exalted by increase of temperature, so is the duration of the capability to receive in the one, and the efficiency to communicate in the other diminished. Spallanzani found that the ova of toads placed in an ice-house could be impregnated at the end of forty-one hours*. Prevost and Dumas ff also mention that they were successful, and that too to a great extent, with ova that had been twenty-four hours in water, the temperature during the period ranging from $18^{\circ} \mathrm{Cent}$, $\left(64^{\circ} \cdot 4\right.$ FAHr. $)$ to $22^{\circ}$ Cent. $\left(71^{\circ} \cdot 6\right.$ FAHr. $)$, and with some eggs that had not been immersed even at thirty. six hours ${ }_{*}^{*}$, the temperature being then from $12^{\circ}$ Cent. to $15^{\circ}$ Cent. $\left(53^{\circ} 6\right.$ to $59^{\circ} F_{A H R}$.). The results obtained by myself have been inuch less successful. Out of one hundred and forty ova obtained from a female frog, killed twenty-four hours before and preserved at or below the temperature of $55^{\circ} \cdot 5 \mathrm{~F}_{\mathrm{AHR}}$, at which the experiment was made, only a very few became partially segmented, but not one produced an embryo ; although an abundance of impregnating fluid, abounding with spermatozoa, and obtained only a few minutes before it was employed, had been supplied to them. It is evident therefore that this failure was due chiefly to the ova, and not to inefficiency of the impregnating fluid. On the other hand, I have been equally unsuccessful with ova from a frog that had been killed only two hours and a half when the impregnating fluid employed had been more than four hour's and a half mixed with water. In this case the failure appeared to bave been due chiefly to the spermatozoa, nearly the whole of which, on inspection by the microscope, were found to be motionless and appeared to have lost their vitality. At the same time it must be mentioned that the female from which the ova employed in No. 3 of the last set of experiments were obtained still existed, in so far as the vitality of the muscular system was concerned, and therefore can hardly be inentioned in comparison with MM. Prevost and Dumas' observation. But while the numerical results obtained by myself have been less favourable than those of $\mathbf{S P}_{A \mathrm{~A}}$ LANZAN or the physiologists now mentioned, the general facts, so far as they are open to comparison, are in full accordance with them. The difference in the details of our respective observations appears to have been due in chief part to the influence of temperature at the time of the impregnation of the ova, or within the first two or three hours after the impregnating fiuid has been supplied. Thus, if the temperature

* Dissertations, \&c., vol, ii. p. 177.

+ Loc. cit., vol. ii. p. 140.

$\ddagger I d, \mathrm{p} .134$. 
has been gradually rising at the time of impregnation, the fecundation of the ovum, as I have stated, has more certainly taken place than when the temperature was subsiding, the condition of the ova and of the impregnating fluid employed being equally fit in each case. Spaldanzani has shown that in his experiments ova did not become impregnated after they had remained fifteen minutes in water. In the experiments by myself I conld rarely obtain fecundation after thirty minutes' im inersion. 'The difference of time between these results may fairly be attributed to difference in the temperature at which the experiments were made, and in great measure to the in fluence of this on the endosmosis and expansion of the envelopes. But it was possible that some other agent might be concerned in these results, and that light, as' well as heat and immersion in water, might greatly inflnence them. 'To put this to the test, and to learn whether the difference depends entirely or chiefly on the amount of temperaturc, I have made two sets of experiments at precisely the same time, performed in the same way, with ova from the same female and impregnating fluid from the same inale, the only difference being that within a very few minutes after the impregnating fluid. was supplied, one set was removed to a higher and slightly rising temperature, from which all light was excluded; while the other was allowed to remain freely exposed to light, but in a room of ten or twelve degrees lower temperature, and which was becoming still further reduced.

The influence of light and heat on the development of the embryo has alrealy been referred to by Spalcanzani, Prevost and Dumas, Rusconi, Dr. W. Edwards, and Mr. BeLL. Rusconi expressly states that light has no influence on the development of the germ*, but his observations, as well as those before inade by Spalcanzani, show that heat has a very marked inflnence, and this has been fully confirmed by Dr. W. Enwaros, and Professor Beck. Very recently also the subject has been referred to by $\mathrm{Mr}$. Higannotron $\uparrow$, and I have great pleasure in stating that my own observations on the influence of heat, and the little effect of light on the development of the tadpole, are in accordance with the observations made by him. But: the object I have had most in view has been, as above stated, to mark the effect of heat, withont light, on the changes of the ovum, more especially during the period of fecundation, the first three or fonr hours after the egg is laid; and onwards to the termination of what I shall hereafter propose to consider, when describing the development of the embryo,- as the end of the third period - the closure of the laminces dorsales and the establishment of ciliary aëration on the surface of the body.

Set H, March 20, 1850. Atmosphere $59^{\circ}$ Fahr. Water $57^{\circ}$ Fahr.

No. 1. P.M. $1^{\mathrm{h}} 14^{\mathrm{m}}$ - Eighteen ova, as they passed from the body of a frog, were touched lightly once with a hair-pencil that had been dipped in impregnating fluid olstained two minutes before, and mixed with about three parts of water. After these ova had remained ten minutes in water, this was removed and fresh supplied.

These ova assumed the ovoid form at the expiration of three hours and thirty-six

* Loc. cit., p. 20. + Proceedings of the Royal Society, May 16, 1850; and Phil. Trans. Part II., 1850. 
minutes, and segmentation commenced at three hours and ffty-six minutes, and was general in two minutes longer, at which time the temperature of the dark cupboard in which the ova of this set of experiments were placed had been raised to $64^{\circ} \mathrm{F}_{\mathrm{AHR}}$., and that of the water they were contained in to $60^{\circ} \mathrm{FAHR}$.

In four days and a half, thirteen of these ova had produced embryos that were then at the end of the third period of development, and on the eighth day the whole of them had advanced to the period when they leave the ovum and attach themselves to the exterior of the envelopes, - the end of the fourth period of development. The inean temperature of the locality in which these ova and the embryos produced from them were placed, was about $60^{\circ} \mathrm{F}_{\mathrm{AHR}}$. for the entire period of eight days.

No. 2. P.M. $1^{\mathrm{h}} 55^{\mathrm{m}}$.-Forty-eight ova were touched once, as they passed from the body of the frog, with a hair-pencil that had been dipped in a small quantity of residual fluid retained with spermatozoa on a filter, in separating these from the fluid portion of frog's semen, obtained and mixed with water forty minutes previous.

The temperature of the cupboard having been raised as in No. 1, segmentation commenced in three hours and ffty-five minutes, but was more general in four hours. Many of these ova were only partially impregnated, and of consequence did not produce embryos. Otber's passed through their changes, as in No. 1, and in nearly similar periods of time. On the eighth day ten embryos had been produced.

No. 3. P.м. $2^{\text {h }} 3^{\mathrm{m}}$. - Fifty-seven ova were well bathed as they passed from the frog with the fluid portion of semen that had passed through two filter papers and been separated from most of the spermatozoa, and which when examined with the microscope was found to contain only a very few of these bodies.

No segmentation had taken place in any of these ova at the end of four hours and five mimutes, but several had become ovoid. At four-hours and thirty-seven minutes segmentation bad taken place in one ovum, and this alone produced an embryo.

Set I, March 20, 1850. Atmosphere $48^{\circ} \mathrm{F}_{\mathrm{AHR}}$. Water $47^{\circ} \mathrm{F}_{\mathrm{AHR}}$. -This set was the counterpart of the preceding, Set $\mathbf{H}$.

No. 1. P.M. $1^{\text {h }} 15^{\mathrm{m}}$. - Nineteen ova were treated in exactly the same way as in No. $1 \mathrm{H}$, and at the expiration of ten minutes were removed to fresb water, and placed where they were most exposed to light.

No segmentation occurred in any of these ova until the expiration of seven hours und forty-five minutes. The temperature of the room had then sunk to $47^{\circ} \mathrm{F}_{A H R}$., and that of the water with the ova to $46^{\circ}$ FAHr. All the changes in these ova were so exceedingly slow, that at the end of the eighteenth hour, the temperaturc during the interval becorning slightly further reduced, the segmentation of the yelk had not advanced further than to the formation of the first equatorial and secondary median furrows. On the fifth day the development of the germ had not proceeded further than to the commencement of the formation of the area germinativa, the end of the second period, the mean temperature during the interval having been $45^{\circ} .49 \mathrm{~F}_{\mathrm{AHR}}$.; while the ova in No. $1 \mathrm{H}$ had reached the end of the third period, the mean tem- 
perature in which they had been retained being $59^{\circ} 5$ FAHr. On the eighth day, when, as already shown, the thirteen embryos of No. $1 \mathrm{H}$ had left the egg, only three had been developed in this set of observations, No. 1 I, and these had reached only to the commencement of the formation of the laminæ dorsales, the mean temperature of the room during the entire period being then advanced to $45^{\circ}{ }^{\circ}{ }_{2} \mathrm{~F}_{\mathrm{AHR}}$; and the completion of their third phase of development did not take place until the tenth or eleventh day.

Thus while three embryos only were produced in this experiment, No. 1 I, during exposure to light and at a mean temperature now raised to $47^{\circ} \cdot 38 \mathrm{~F}_{\text {AHR., }}$ thirteen in No. $1 \mathrm{H}$ were developed in about one-half the space of time from a similar number of eggs removed from the light, and at a mean temperature of $59^{\circ} .5 \mathrm{~F}_{\mathrm{AHR}}$; ; so that we seem here to have good reason to believe that a low temperature of the medium not only retards the development of the embryo, even when exposed to light, but injuriously affects the fecundation of the ovum.

The result of the next experiment coincides with the above.

No. 2. P.м. $\mathrm{I}^{\mathrm{h}} 56^{\mathrm{m}}$.-Fifty-one ova were touched in the same way with spermatozoa from the filter paper, as in No. $2 \mathrm{H}$, and were retained in the sane temperature as the preceding.

A few of the yelks became ovoid in about six hours, but seginentation did not commence until seven hours and two minutes, and then only in a very few. "Two embryos only were produced from this set.

No. 3. P.м. $2^{\text {h }} 5^{\mathrm{m}}$.-Fifty-five ova were bathed with filtered fluid in exactly the same way as in No. $3 \mathrm{H}$; but not a single ovum became segmented. Not one produced an embryo.

Thus while segmentation took place in No. $1 \mathrm{H}$, in three hour's and fifty-six minutes, when the temperature was rising from $59^{\circ} \mathrm{F}_{\mathrm{AHR}}$. to $64^{\circ} \mathrm{F}_{\mathrm{AHR}}$, it did not occur in No. 1 I, until seven hours and forty-five minutes, when the temperature during the interval was sinking from $48^{\circ} \mathrm{F}_{A H R}$. to $47^{\circ} \mathrm{F}_{A H R}$. This sufficiently marks the great influence of temperature during the earliest periods of change in the ovum; and this injurious effect of reduction of temperature at that period is further shown in the relative number of embryos in these comparative experiments. That the injurious effect of reduced temperature at the time of impregnation is mainly the cause of this result, and not the diminution of temperature after the period of impregnation, seems to be shown in the circumstance, that while at the end of the eighteenth hour the ova in the set $\mathrm{H}$ had already passed through all the stages of segmentation, and the surface of the yelk had become granulated, and the blastoderma had begun to be formed even although the temperature in that case subsided a little after segmentation had cominenced,--from $59^{\circ}$ to $57^{\circ}$, - the corresponding set of ova, No. 1 I, had advanced only to the octuple division of the yelk. A similar difference in the rate of development we have seen takes place in the growth of the embryo. At the end of three days the embryos of set $\mathrm{H}$ were advanced to the stage at which the laminæe MDCCCL. 
dorsales are proceeding rapidly to meet, and form the median dorsal sulcus of the growing body. But the corresponding ova in set I had not been carried further than to the earliest perceptible indications of the area germinativa.

These facts sufficiently prove the great influence of temperature on the development of the embryo in its earliest stages, as the comparative numerical results do also its effects on the impregnation of the ovum. Out of eighteen ova placed in the higher and increasing temperature, thirteen produced embryos at nearly similar stages of growth ; while of nineteen ova maintained in a low and diminishing temperature only eight became segmented, and but three of them arrived at the tadpole state.

A somewhat similar but more marked result took place with the ova of No. 2 in the two sets of experiments. The impregnating means employed in these trials had already been forty minutes mixed with water on the filter. Out of forty-eight ova employed in set $\mathrm{H}$, twenty-five became segmented, and ten of these produced young. But in set I fifty-one ova gave birth to only two embryos.

In the third experiment of each set the difference is as strongly marked. As the filtered fluid employed in both was the same, and the very few spermatozoa contained in it were by the same means brought into contact with the ova in each, it might have been expected that each would have produced embryos. But while the production of a single tadpole in the one case, at a high temperature, may be looked upon as leading to the inference that these bodies are the efficient agents in impregnation, the entire absence of all appearance of impregnation in the ova of the other set, to which the same fluid had been equally applied, seems to point to the cause of failure in this case as depending on the prejudicial effect of a low temperature of the surrounding medium on their agency.

The temperature of the surrounding medium ought, therefore, always to be borne in mind when we are attempting to deduce conclusions from experiment on impregnation and development. The presence of light appears to be only of secondary consideration as compared with heat; since in set $\mathrm{H}$, from which light was carefully excluded, not only did impregnation take place more certainly and rapidly than in set $I$ which were exposed to light, but the embryos also were produced in greater number, and acquired maturity in less than one-half the space of time than in the latter; the only difference of circumstance between the two sets being degree of temperature.

Influence of Aëration.-Next in importance to heat is a free aëration of the ovum. This is of less consequence with reference to impregnation than to the subsequent production of the embryo. In every set of experiments there are always sorne ova more advanced than others. These are ova which have been nearest to the surface of the water, and which, consequently, have been more completely aërated as well as exposed to a slightly higher temperature than other's at a greater depth. It is from this cause chiefly that the results of experiments on artificial impregnation, and even of observations on naturally impregnated ova, are always less complete and 
successful than what takes place with regard to the ova in the natural haunts of the species. The ova in a state of nature are usually deposited in well-aërated places, clear, slow-moving water, or shallow and but slightly turbid water. It is almost impossible to afford to ova that are the subjects of experiment, either in broad flat dishes, or in glass vessels in one's study, the amount of aëration required to ensure complete success. By too frequently changing the water in the vessels the embryos often become injured; while if the water be not changed, development is arrested, and decomposition commences, and the experiment entirely fails. Even when these difficulties are obviated by a gentle withdrawal of the water, and a renewal of it with equal care, the perfect stillness of the fluid in the interval of our observations does not allow of that extent of aëration to the embryo which it gains in a perfectly natural state, either in slow-moving waters, where I have usually found the eggs deposited, or in pools of still water, the surface of which is agitated by currents of air, and affected by diurnal changes of temperature.

Thus then we may conclude that the procreative force of the germ, and of the impregnating fluid, is augmented by increase of heat, but the duration of the force is lessened. It becomes less and less energetic in proportion as the temperature is diminished, but the period during which it is capable of being exerted is extended. In each of these conditions aëration is of essential consequence, and becomes more and more necessary in proportion to the increase of heat.

\section{THE AGENCY OF THE SPERMATOZOA IN IMPREGNATION.}

It is evident from the last-inentioned experiments, that however great may be the influence of temperature in accelerating or retarding impregnation and development, and however much the operation of this influence may be interfered with by want of proper aëration of the ovum, the impregnating force does not equally pertain to all parts of the seminal fluid, but is to be found in some only of its constituents. Experiments made before those now detailed,-and to which $I$ had been led by a conviction that the opinion formerly entertained, that impregnation is effected through means of the fluid portion only of the semen, was not in accordance with facts $I$ had very long been acquainted with in the Articulata,-convinced me that the spermatozoa themselves, and not the other constituents of the semen, are the efficient agents of impregnation. LeEwenhoek, and, as I have since found, Prevost and Dumas, not only believed this to be the fact, but also held the opinion that the spermatozoa penetrate bodily into the ovum; and this view has been more recently

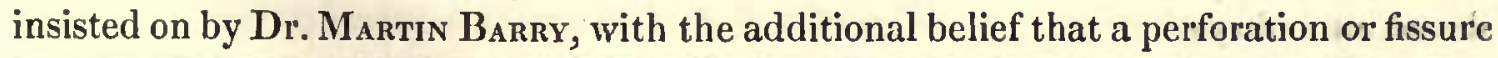
exists in the envelopes of the ovum, through which the spermatozoon enters. On carcful examination of the envelopes of the ovum of the Frog, I have not been able to detect any fissure or orifice. The question of the agency of the spermatozoa, nevertheless, appears to be capable of solution, however difficult it may be to ascertain the mode and particular nature of such agency. The separation, as far as possible, of 
the spermatozoa, by filtration from the fluid in which they move, and testing the ova with these and the fluid separately, afford good proof of the agency of these bodies; while immersion of the ova in coloured fluids, at the moment of their passage from the body of the frog, seems equally fitted to ascertain the believed existence of a fissure or perforation through the envelopes during their expansion. The experiment of filtration was originally performed by Prevost and Dumas with well-marked results, and it has since been repeated by the first of these observers * by a different mode, -endosmose through the operation of galvanic currents. The mode pursued by myself was that originally adopted by these observers :-careful inechanical filtration, by simply passing the fluid portion of diluted semen through folds of filtering-paper. The paper I have employed, and which alone was fitted for the purpose, was the best Swedish filtering-paper employed by chemists in their most delicate analyses. A large proportion of the spermatozon were always retained, even on a single filter, although a few usually passed through; but this, as the results show, was not in reality a disadvantage, when a few only were present in the filtered portion. When three or four folds of filtering-paper were employed, the whole of the spermatozoa were removed.

Filtration of Seminal Fluid. - Fluid obtained from a male frog, immediately after removal from the female, was mixed with about twice its quantity of water and placed on the filter. Portions of this fluid as they passed through were repeatedly examined with the microscope. Some of these filtered specimens contained a very few spermatozoa, usually not more than three or four in the drop examined, but sufficient occasionally, as the results proved, to effect impregnation.

Filtration Experiments.-Set K. March 14, 1849. Atmosphere 55 ${ }^{\circ} 5$ Fahr. Water $55^{\circ} \mathrm{FAHR}$.

No. 1. A single drop of the filtered fluid was added to one ounce of water, in which forty-six ova were immersed. Not a single egg became segmented or produced an embryo.

No. 2. A single drop of the diluted fluid, not filtered, but two hours after it had been obtained, was added to one ounce of water with ninety ova. Not a single egg was segmented or produced an embryo.

No. 3. Two drops of filtered fluid were added to one ounce of water with sixty ova, but not one egg became impregnated.

No. 4. Three drops of filtered fluid were added to one ounce of water with one hundred and five ova. Two of these were partially impregnated, as shown by their becoming imperfectly segmented (Plate XIV. fig. 11 and 12), but neither of them produced an embryo.

No. 5. Three drops of diluted fluid, not filtered, but two hours after being mixed with water, were added to one ounce of water with seventy-six ova. Several of these becarne segmented, but more tardily than in the following experinent, No.7. At the end of seventeen days fifteen embryos had been produced from these ova. 
No. 6. Thirty drops of filtered fluid were added to one ounce of water with two hundred and ten ova. At the expiration of five hours two ova had become segmented, and two embryos were afterwards produced.

No. 7. Thirty drops of diluted fluid, not filtered, were added to water with two hundred and fifty ova. At four hours and forty-two minutes segmentation had commenced in two or three of these, and in five hours had occurred in almost every ovum. Nearly the whole of these produced embryos.

No. 8. About thirty drops of the same diluted fluid, not filtered, were added to water that contained about two hundred ova, passed from the body of a frog killed twenty hours before. A few of these ova became imperfectly segmented, but not one produced an embryo.

From these first experiments with filtered fluid, it seemed that the portion of semen which passes through the filter has not the power of impregnating, unless there are spermatozoa present in it; while similar quantities of diluted semen that has not been filtered, are efficient and impregnate, as in Nos. 4, 5, 6 and 7. Further, it is shown, from No. 8 , if we may judge from one experiment, that ova which have remained in the body of a frog twenty hours after actual death and cessation of the organic functions, and in a temperature of $55^{\circ} \mathrm{F}_{\mathrm{AHR}}$., may be affected by the stimulus of the impregnating fluid, but not sufficiently so perhaps as to result in fruitful impregnation.

During the time these ova were under observation, in March 1849, an opportunity occurred of observing the effect of reduced temperature on the rate of developinent of the embryo when its formation has been somewhat advanced. On the seventh, eighth and ninth days after impregnation of the ovum, and when the temperature luad already been considerably reduced, the season became severe, and in order to test the effects of cold, the eggs were removed to the open air and exposed to a keen wind. The temperature of the atmosphere was then $38^{\circ} F_{A H R}$. During the night of the tenth day, the water in which the ova were contained was frozen to a mass of ice. Yet many of these ova, as above shown, produced embryos. Spaldanzani had already remalked, that the eggs of the Frog may be inclosed in ice, and yet afterwards produce embryos, if the envelope does not become frozen*.

The experiments made to ascertain whether cleavage of the yelk may be taken as a test of impregnation ( $\mathrm{p} .190$ ), seemed also to show that, within certain limits, a large or small quantity of seminal fluid has some influence on the more or less early occurrence of this phenomenon. It occurred to me, therefore, that in making the experiments now given, two questions might be examined: one, as to whether the extremely minute quantities of seminal fluid disseminated in water, as mentioned by Spallanzani, are as efficient to produce the embryo at the low temperature of the season at which the Frog spawns in this country, as in the warmer region of Italy; and the other, whether the presumed efficiency of such minute quantities depencled on the presence of the spermatozoa; and it seemed possible to put these 
questions to the test in one set of experiments. But, in attempting to do so, it was a matter of importance, first, to obtain some approximative knowledge of the actual quantity of spermatic fluid employed by SpaLLANZANI, in his more remarkable experiments, to enable nue to compare the results of my observations with those of his. Spallanzani states, that by his mode of obtaining the seminal fluid, by vivisection, he could only procure from "two to three grains*" from each individual. Three grains weight of fluid are equal, by measure, to nearly three minims of our medicinal standard. But it may be presumed that in so delicate an operation as that of removing the fluid from the vesiculæ seminales, from which Spallanzanr states he usually obtained it, he could rarely be very precise in his determination of the quantity. I assume, therefore, for the sake of comparison, that the quantity he speaks of as "a grain" was about equal to a minim of our medicinal measure. Three grains of fluid (? minims), be says, were mixed with a pint and $a$ half of water, and one drop of this mixture (the seminal fluid in which was equal to $\frac{1}{3840}$ th part of the whole at $16 \mathrm{oz}$. per pint) applied directly to an ovum on the point of a needle, was "frequently" sufficient to render it fruitful $\uparrow$. The drop spoken of in this experiment was a much less quantity than the grain or minim; indeed, Spallanzani states that it did not exceed the "fiftieth of a line" (? fifth) in diameter. The quantity of fluid obtained by myself from a frog was usually about six minims, and this I mixed with twice its quantity of water, thus making eighteen minims. One drop of this mixed fluid measured, as I found, one-third of a minim, and consequently contained one-third part of seminal fluid, or one-ninth of a minim of the seminal fluid. Yet the result of the employment of one drop of this mixed fluid added to one ounce of water, in which the proportion of seminal fluid was then made to be $\frac{1}{4320}$ th part of the whole, did not lead to the same result as the experiment by Spallanzanr. The difference arose, perhaps, firom the operation of two or more causes:-first, the much lower temperature of the atmosphere at the time of making my experiment, than at that of Spallanzani's; next, the diminished efficiency of the seminal fluid, owing to the length of time (two hours) it had been removed fiom the body. Both these circumstances, but especially the first, as already shown, operate unfavourably in experiments on impregnation, more eggs being fertilized at a high temperature, when the changes go on rapidly, and especially when the seminal fluid has been most recently obtained, than under the opposite conditions. The general results of my experiments, however, may be regarded as quite confirmatory of Spallanzani's more remarkable one, as they prove, like that, that only an exceedingly small proportion of seminal fluid is necessary to fertilize the ovum.

* Loc. cit., vol. ii.p. 189.

† Loc. cit., vol. ii. p. 192. There is some confusion of statement in the translation of Spatianzani's work, now referred to, respecting the quantities mentioned by the author, as "pint" is the word used in some passages and "pound" in others (p. 191), apparently synonymously, while the latter is further spoken of as "twelve ounces."-G. N. 
But however satisfactory these experiments were with regard to that fact, they still left the question of the immediate agency of the spermatozoa in impregnation in doubt. I therefore repeated them with greater precision, and with that object only in view, and took especial care to obtain as perfect a filtration and separation of the spermatozoa from the fluid as possible. The results were far more interesting and instructive than I had anticipated, as I found by repeated examination by the microscope that the filtered fluid was almost completely deprived of spermatozoa, one or two only being occasionally detected in it, with a very few nuclei and spermatozoal cells. One circumstance that tended to increase the value of this set of experiments, and to prove the influence of the spermatozoa, was, that the ova employed were not fully matured, and hence I had less expectation of a favourable result. The quantity of seminal fluid obtained was larger than usual, and this was mixed with twice its quantity of water. This mixed fluid was divided, as before, into two portions, one of which was filtered, and the other not. The experiments were commenced in the early part of the day, and the temperature of the atmosphere of the room, and that of the water employed, was nearly the same, $51^{\circ}$ FAHr., and the whole of the experiments were placed as nearly as possible under similar circumstances.

Set L. March 18, 1849. Atmosphere $51^{\circ} \mathrm{F}_{\mathrm{AHR}}$. Water $51^{\circ} \mathrm{F}_{\mathrm{AHR}}$.

No. 1. Ten minims of the mixed fluid were added to two ounces of water, into which one hundred and fifty ova were immediately passed. One hour afterwards I found a great abundance of spermatozoa adhering to the surface of the envelopes. Segmentation of the yelk commenced in five hours and forty minutes in a few ova; and took place in others at a later period. A few only of these ova produced embryos.

No. 2. Ten minims of the filtered portion of the mixed fluid were added to two ounces of water, and about one hundred and fifty ova were passed into it. When these ova were examined at the expiration of an hour, not a single spermatozoon was detected on any of them; and when repeatedly examined at the end of five and six hours, not one showed any signs of cleavage. This change did not take place in any of them even at a later period, and not one produced an embryo.

As the ova in these two experiments were the first that passed from the body of the Frog, it was fair to regard them as being the most matured; segmentation ought, therefore, if it occurred at all, to have taken place at an earlier period in these than in others afterwards obtained from the same female.

No. 3. The filter paper employed in separating the fluid used in the last experiment, No. 2, and which retained the separated spermatozoa in a minute quantity of fluid that had not passed through, was placed in two ounces of water, and one hundred and thirty ova from the same female were shed upon it. When some of these ova were examined at the end of an hour and a half, spermatozoa in vast abundance were found adhering to every part of their surface, but the whole were then motionless, and apparently dead and partially coiled on themselves (Plate XIV. fig. $8 \mathrm{c}$ ). In 
some of these the body appeared to be slightly enlarged. Segmentation commenced in very many of these ova in five hours and ten minutes, and was almost universal in thein a few minutes later. Nearly the whole of these ova produced embryos, there being only nine ont of the one bundred and thirty that were abortive. I have sometimes found a much larger proportional number of unproductive ova in some broods in the natural haunts of the Frog.

There was one exceedingly interesting fact in this experiment,-it was that the smaller and apparently less matured ova were as fully impregnated as the larger and Inore perfect. The whole set of observations was the more interesting from this circumstance. These ova were smaller than usual and had not the white surface so complete, but were very like the ova in which $I$ have described the changes in the lightcoloured surface (p. 185). When first placed in water with the filter paper and spermatozoa, the surface of the yelks became more contracted and irregular, within the vitelline membrane, than in other ova I have employed. Hence I had much doubt, at first, whether any satisfactory evidence would be obtained from this set. But the contrary has been the case, as it is evident that some ova may be impregnated at a little earlier period than usual ; and that when a great abundance of spermatozoa is supplied, ova less matured than other's may be equally well impregnated. 'The greater efficiency of a larger as compared with a smaller number of spermatozoa, with reference to the earlier or later segmentation of the yelk, has already been shown; and the difference is very marked in the first and third of this set of experiments, both with reference to the occurrence of segmentation and to the relative fecundity of the ova. On the other hand, the experiment No. 2 proved that the liquor seminis is not the fecundating portion of the seminal fluid:

Circumstances having prevented me from making known the result of these experiments at the time they were obtained, I determined, during the past spring, to repeat and vary them, to obtain, if possible, still more conclusive proofs that the spermatozoa alone effect impregnation. Accordingly, in March and April of the present year (1850) I repeated them, with the following precautions :- first, that the frogs in each case had been some days paired, and at the time of the experiment were nearly ready to spawn; next, that the seminal fluid used was obtained fiom the male paired with the fernale from which the eggs were taken; further, that the condition of the specimen of fluid used was correctly ascertained; and lastly, that the ova were placed in flat dishes, under precisely similar circumstances, with similar quantities of water, repeatedly changed. Two sets of experiments were made at the same time.

Set M. April 4, 1850. Atmosphere $60^{\circ}$ FAHR.

'The seminal huid employed, mixed with an equal quantity of water, was placed on a single, and caught on a double filter paper, and the clear fluid that passed was then examined with the microscope. The fluid that bad traversed the three filters was almost completely deprived of spermatozoa; as, after many very careful examinations, both 
of drops as they passed the last filter, and of portions from the capsule it was caught in, there was only one instance of the presence of spermatozoa. In this I saw two, but perfectly motionless. The fluid that passed through the first or top filter, I had reason to suspect was contaminated by a small quantity having travelled over the sides of the filter. I knew also, that a few spermatozoa always penetrate through a single filter, or rather perhaps are carried through by the fluid. Accordingly, I detected several spermatozoa in this portion. The fluid that remained in the interior of this filter abounded with very active ones. It was not employed until fifty-three minutes after it had been procured from the Frog.

No. 1. Seventy ova were passed on a dry surface, and a portion of the fluid which had traversed three filters was poured carefully over them, and water was then added.

In four hours and twenty-five minutes I found one ovum partially impregnated, and the yelks of others were somewhat shrunk, and a little irregular, an appearance frequently seen in ova that have not been impregnated. Not a single ovum, however, was fruitful.

No. 2. One hundred and twenty-seven ova were shed into water on the second of the three filters, which still retained a portion of the fluid from the first, and in which I had found a few spermatozoa. At four hours and fifty minutes several of the ova had begun to be divided, and out of this set of eggs sixteen embryos were produced.

No. 3. One hundred and sixty-three ova were passed into water on the topmost of the three filters, and four hours and fifty minutes afterwards a very large proportion of them had become segmented, as was expected, although from the circumstance of the seminal fluid having been more than one hour mixed with water before it was employed, the number was not so great as usual. But it was not entirely due to this cause. Many of the ova had been injured before impregnation, and these became irregular and pear-shaped. At the end of twelve days forty-nine well-developed embryos had been formed.

Set N. April 4, 1850.

Four filters were now used instead of three, the seminal fluid being obtained and mixed as before. The fluid which had passed through the whole of these filters, contained not a trace of spermatozoa or of the nuclei of cells. That which had passed through two only still gave an occasional perfectly motionless spermatozoon, but not a single one in motion; the flinid from the uppermost or first filter, as in Set M, still swarmed with myriads of active spermatozoa. It was thus proved that the filtration was complete.

No. 1. One hundred and thirty-one ova were passed on a dry surface, and a portion of the fluid which had traversed the four filters was poured over them, and water was then added. But not a single ovum gave any sign of having been impregnated, not one becaine segrnented, nor was a single embryo produced. The ova became slightly irregular, shrunken, and depressed at parts of the yelk, a condition which, as I had 
noticed this in other ova, I was inclined to attribute to some normal change in the yelk itself, perhaps of an imbibing or endosmic character.

No. 2. One hundred and ninety-seven ova were shed into water mixed with the remaining portion of fluid which had passed through the four filters, but not a single egg gave even a trace of seginentation. Many of the yelks had the same peculiarly irregular ontline as in No. 1. These two experiments I regarded as a satisfactory proof that it is not the fluid portion of the semen which impregnates.

No. 3. Two hundred and four ova were passed into water upon the third filter, already immersed in it, and the fluid on which showed an occasional spermatozoun. I was unable to detect any impregnated ova in this experiment, but, as the result showed, a few had been affected, as four embryos were produced.

No. 4. Three hundred and seventy-one ova were passed into water upon the first or topmost of the four filters, and which had already been placed in the water. At four hours and thirty minutes, almost every yelk had become segmented. The change had occurred some length of time before this, as the second or erucial segmentation was commenced. This experiment seemed to be a. most direct and conclusive proof of the ageney of the spermatozoa. At the end of four days almost the whole of the eggs were producing embryos, many of which were advanced to the fourth period of development. One hundred and twenty-scven became fully formed and vigorous, besides nearly as many nore which did not complete their changes, from an accidental cause.

Before these concluding experiments were made, I had already, in March last, repeated the preceding; but, as the filtration was less perfect, have thought it unnecessary to give them in detail; they agreed however in the results. 'The whole have confirmed in the fullest manner the experiments first made, and have proved, as I trust, satisfactorily that the spermatozon alone are those parts of the semen which effect the impregnation of the ovum. Having repented the filtration in five separate sets of experinents, on different occasions, and with exactly the same general results, I can no longer entertain any doubt of the direct agency of the spermatozoa. The conclusion, I think, is rendered certain by facts now shown, which escaped the notice of Spallanzanr, and of Prevost and Dumas. Segnientation of the yelk takes place earlier when impregnation is effected by a large, than when oceasioned by a very small number of spermatozoa, the temperature of the surrounding medium, and all other circumstances, being alike in the two cases, as in the experiments $S e t$, A as compared with Set B (p. 190). 'This fact is supported by another, equally significant. When only a very small number of spermatozoa exist in the fluid, then the rernarkable result of partial impregnation often takes place, and the ova are unproductive. On the other hand, when spermatozoa are supplied in full abundance to the ova, not only does segmentation of the yelks take place more rapidly, but also more extensively, and almost every ovum produces an embryo.

With regard to the liquor seminis, it seems equally decisive that this portion of 
the seminal fluid does not effect impregnation. WaGNer and LeuckardT* lave justly remarked, that it is aluost impossible that the liquor seminis can have any action on ova which are expelled into water before the semen is ejected by the male, as in the case of frogs and fishes; and it is wortby of note, that in the experiments now detailed not a single ovum was either completely or partially impregnated when immersed in water mixed only with the liquor seminis, obtained through filtration; nor even when the ova were carefully bathed, as they passed from the body of the Frog, and before they had been brought into contact with water, with the filtered fluid from which the spermatozoa had been completely separated, as in Set N, No. 1, or even when the finid still contained a very few dead and perfectly motionless spermatozoa. Yet this fluid can hardly be regarded as entirely without use, although it now appear's to be of very secondary consequence. When the ova were placed in water with which only the liquor seminis had been mixed, the yelks becane contracted exactly as is often the case in the unimpregnated ovuin. Whatever may be the nature of this fluid, it does not appear to be essential to the conveyance of the structural peculiarities of the male parent to the offspring. These appear to be communicated by the spermatozoa alone, as not only did the ova that were impregnated by spermatozoa from the filter paper, as in Set N, No. 4, becoine segmented quickly, but the embryos produced from them came forth with all the usual characters of tadpoles, and have passed, or are now passing (June 20) through their stages of growth as perfectly and as quickly as other's which have been produced in the natural haunts of the speeies through the mutual concurrence of both sexes. 'Thus the liquor seminis does not even hasten the course of development of the young. Neithel does it accelerate that of fecundation, either through direct imbibition or from becoming a solvent to the bodies of the sperinatozoa; as we have seen that segmentation of the yelk takes place most quickly in proportion to the number of spermatozoa, within certain limits, in contact with the ovum. And such also is the case in a state of nature.

These facts appear to give tlat direct negative and refutation to the hypothesis of the immediate agency of the liquor seminis in impreguation which WAGNER and LEUCKARDT + remark it has not hitherto met with; and they lead to the supposition that one of the chief uses of the fluid is merely that of a vehicle through which the spermatozoa are more readily brought into contact with the ova. Possibly it may bear that relation to the spermatozoa in the viviparous vertebrata, in which it chiefly occurs, which the fluid medium into which the ova of Amphibia and Fishes are expelled, bears to the spermatozoa in those classes. This view may derive sone support from the fact that the liquor seminis has recently been shown by chemical analysis to consist chiefly of a thin solution of mucus, with small quantities of chloride of sodium and phosphates and sulphates of the alkalies*.

* Cyclopædia of Anatomy and Physiology, vol. iv. "Semen," part xxxiv. January 1849, p. 507.

† Loc. cit., p. 507.

$\ddagger I d$. 


\section{NATURE OF THE AGENCY OF THE SPERMATOZOA.}

Having obtained full evidence by direct experiment that impregnation is effected through means of the spermatozoa, we have now to inquire as to the manner in which it is induced by them, and as to the nature of the agency they exert. Spermatozoa have been found adhering to the surface of the impregnated ovum by BARRY, Bischoff, Pouchet and others, in the Mammalia; as they were long ago seen by Prevost and Dumas on the ovum of the Amphibia ; and since by Siebold, Kölliker, myself and others in the Invertebrata. They have been constantly present in those experiments on artificial impregnation which I have now detailed, in which the yelks became segmented after the egg had been in contact with seminal fluid, or with the filter paper used to remove them from the liquor sanguinis; but they have not been detected on ova which did not undergo the cleavage of the yelk, or which liad been immersed only in fluid separated during filtration. Whenever present in fluid in which ova have become impregnated, the spermatozoa have always been found in motion, until after they have become attached to the surface of the ovurn, when their motion has soon ceased. In the Lissotritons, in the few experiments I have made on this division of the Amphibia, I have seen the motion continue for a long time after they have been in contact with ova. This leads to the supposition that a vibratile condition or power of motion is in some way essential to their porrer to effect impreguation; notwithstanding that, as WAGNER and LeUCKARDT have remarked*, no movenents have as yet been perceived in the spermatozoa of the Isopoda and Amphipoda. If this vibratile condition be essential to their function, then the length of time which it is continued may be of importance.

Duration of Motive Power in Spermatozoa.-Spallanzani found that water mixed with but a small quantity of seminal fluid of the Frog retained the property of impregnating ova longer than pure semen $\gamma$. When inclosed in a glass tube, the semen of the Toad was not impaired at the end of six hours, but was useless at the end of nine*; while a small quantity from the Frog, mixed with water and preserved at a temperature of about $40^{\circ}$ FAHr. $\S$, was still efficient at the end of thirty-five hours. Results obtained by myself have fallen short of this extended period, even when the influence of temperature has been attended to. The difference of result may to some extent be accounted for in the condition of the fluid, and in the way in which it has been obtained. Spallanzani says he obtained it both from the vesiculæ seminales and the testes after opening the body. It is probable therefore that a large part of what he procured had not arrived at maturity, and instead of consisting almost entirely of active spermatozoa, as when it is obtained by compression of the body, the

* Loc. cit., p. 503.

† Dissertations, vol, ii. p. 193.

$\ddagger I d . \mathrm{p} .168$.

$\$$ It may be well here to mention, that for the purpose of more easily comparing the observations recorded by Spaldanzant, and Prevost and Dumas, with the results obtained by myself, I have, throughout this paper, reduced the data given by them to the scale of FAHRENHEIT, employed by myself; the scale used by SPALLANzani being that of Reaumur, and by Prevost and Domas the Centigrade. 
mode adopted in my experiments, it included a large proportion of developmental cells from which the spermatozoa escaped at longer or shorter periods after the fluid had been mixed with water, or had been retained for some time out of the body. I have very rarely found the seminal fluid of Rana temporaria obtained in the way stated, and at a temperature of about $50^{\circ} \mathrm{F}_{\mathrm{AHR}}$., retain any impregnating influence for more than four or five hours. Thus, after mixing it with an equal proportion of water, very many of the spermatozoa have soon become motionless, and in less than two hours a moderate proportion only have continued active. At three bours there have been still fewer moving; while at four hours the great inajority of them have exhibited most unequivocal signs of lost vitality, being either extended at length or coiled on themselves (Plate XIV. fig. $8 \mathrm{c}$ ), as they usually appear when motionless, and adherent to the surface of ova. If any, at this length of time, have been still moving in the fluid, they have been few in number, and their motions exceedingly feeble. Occasionally I have detected others, at this lapse of time, in the act of escaping from the cells (fig. $8 a$ and $b$ ), and these have always been the most energetic in their movements immediately after their liberation. Further, I bave noticed that in those specimens of fluid which have contained most developmental cells, the spermatozoa have been longest in a state of activity.

The following have been the results of observations on spermatozoa attached to the surface of ova, or contained in the water in which ova were immersed. At three-quarters of an hour after mixing recently obtained seminal fluid with the water and ova, vibratile spermatozoa have continued to be exceedingly abundant and in a state of great activity. At one hour and a quarter there were still an abundance in motion, but many were now perfectly motionless, and apparently dead. At one hour and " half I was not able to detect any movement in even a single spermatozoon out of a vast abundance which adhered to the surface of the gelatinous coverings of the ova, although I sought for this very carefully. Neither could I detect even the slightest indication of the spermatozoa having penetrated into these coverings, either near the surface or in the vicinity of the thicker envelope, which I regard as the chorion, and which immediately covers the vitelline membrane. After a lapse of some time all the appearance of spermatozoa on the exterior of the envelopes ceased. The longest period, after contact with spermatic fluid in water, at which $I$ have hitherto been able to recognize these bodies on the surface of the frog's egg has been six hours and one or two minutes, and about half an hour after segmentation of the yelk had commenced. This was on ova impregnated artificially, on the 14th of March, at a temperature of the atmosphere of the room of $54^{\circ} .5 \mathrm{FAHR}$. and $53^{\circ} .5$ of the water employed. A few motionless spermatozoa were then still found on the surface, but most of them appeared to be becoming disintegrated. The surface of the egg-envelope was then covered at.places with numerous small granules, possibly the remains of spermatozoa which had disappeared.

A somewhat similar result has ensued when spermatozoa have been two hours mixed 
with water before ova were passed into it. At five minutes after immersion of these ova, I have found large quantities of spermatozoa already adhering to the surface of their then expanding envelopes. But many of them have already been coiled on theinselves, and were perfectly motionless. The water still contained very many disseminated through every part of it, but most of them, with few exceptions, have appeared to be rigid, and to have become enlarged in diameter, but not increased in length. 'This change has appeared to be due to the hygroscopic nature of these bodies, as formerly pointed out by Sicbold*. Possibly this nature may have some reference to impregnation. Repeated observations lead ine to believe that, in whatever way the spermatozoa are concerned in impregnation, they do not penetrate bodily into the ovum, but merely adhere to the surface.

Prevost and Dumas concluded $\downarrow$ from their investigations, that the spermatozon of the Triton and Frog do penetrate into the envelope of the egg; and they state that they had fecundated ova taken from the ducts of the Triton, and after the lapse of three hours, having first carefully washed them to remove all that were merely adbering to the surface, have made sections of the envelopes of the egg, and, with the aid of the microscope, have found living spermatozoa still struggling within. Their words are-“ Une grande quantite d'animalcules encore mouvans, et qui semblaient se débattre dans cette espèce de gelée où ils se trouvaient emprisonnés. On en voyait partout même au contact des membranes de l'œuf." Further, that they had repeated this experiment on the ova of the Frog, and found the envelope penetrated in like manner with spermatozoa, still moving, but not changing place. I regret much that my investigations do not enable me to confirm these observations, which seem to me to be due to the circumstance of these physiologists having regarded the objects on the surface as being in the interior. 1 have many times sought for spermatozoa within the substance of the egg-envelope of the Frog, at different periods between that of first contact with impregnating fluid and the time when cleavage of the yelk has conmenced, and have constantly found them on the surface, but have never, even in a single instance, observed any appearance of thein in the substance of the envelope, nor anything which induced me to suspect that they penetrate bodily into it. They have been present on the surface, and adherent to it, even from within a few seconds after contact, to so late as the sixth hour, but have usually been motionless; and most of them have had the caudal portion folded back on the body. I was led to make these observations on the egg of the Frog,-before I was aware of MM. Prevost and Dumas' views, - from the circumstance of $\mathrm{Dr}$. Martin Barry having mentioned ${ }_{\uparrow}^{+}$that an orifice or fissure exists in the thick investing membrane of the ovum of the Rabbit, through which, at the time of impregnation, he believed the spermatozoon to enter. All the observations I have been able to make on the ovum of the Frog, both microscopically and experimentally, are opposed to the belief in the existence of any perfo-

* Mülleg's Archiv, 1836.

† Loc. cit., vol. ii. p. 133.

$\ddagger$ Philosophical Transactions, 1840, p. 535 . 
ration either before or at the time of impregnation. With regard to the ovum of the Tritons, I have recently made the following observations, since becoming acquainted with the views of the authors named.

A female Lissotriton punctatus, obtained on the 17th of May, produced several ova on the morning of the 19th. Cleavage of the yelk (which, I may remark, was entirely overlooked by Rusconi* in his account of the Newts) commeneed in two of these ova at the expiration of eight hours, the temperature during the period having ranged from

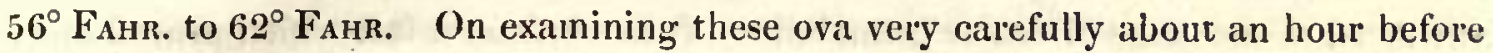
the eleavage commeneed, there were what I regarded as portions of the bodies of spermatozoa on the surface, but certainly no traces of any in the interior. While engaged in this examination the same female produced another egg, which she inelosed as usual in a folded leaf. On this specimen, examined at the end of balf an hour, I could not detect any spernatozoa on the surface, which led me to inagine that it had not been impregnated, a supposition which ultimately proved to be correct, as no segmentation of the yelk took place in it. Some time after this, the temperature of the atmosphere being $62^{\circ} \mathrm{F}_{\mathrm{AHR}}$., I saw the same newt enclosing another egg in a leaf. This I immediately removed for examnination, and thinking that this, like the previously deposited egg, had not been impregnated, no traces of spermatozoa being found on its surface, I placed it for about a minute in a sinall capsule filled with water, into which a quantity of fluid had just been expressed from a male that had been liept separate from the female. The fluid on examination was found to be composed almost entirely of very active spermatozoa. The egg was examined three minutes after immersion, and seareely five minutes after it had been laid, and multitudes of spermatozoa were then seen adhering to its surface. Most of them were still vibrating rapidly, while others were motionless. But although I was able to distinguish every part of these bodies, I could not detect any in the act of penetrating, or which had already penetrated into the substance of the envelope, and most certainly not one was imbedded in the interior. Neither were there any in contact with the yelk-membrane, or in the yelk-chamber of the envelope.

The egg of the Newt is peculiarly fitted for an examination of this kind, from the fact of the existence of this yelk-chamber, or space in the interior of the envelope. This is formed by the gelatinous covering which the egg gains in the oviduct imbibing fluid by endosmose and becoming expanded immediately it comes into contact with water, when the inner layer separates from the vitellary membrane, with which it has been in contact within the duct; and as the outer layers more and more expand, the yelk, covered only by the vitellary membrane, is left free in a large cavity in the interior, surrounded by a thin fluid. The spermatozoa of the Newts, as is well known, are of large size, and are easily recognized; so that in the event of their having penetrated the egg-covering before it leaves the duct, or at the moment of its expansion, or after the chamber has been formed in it, they can hardly escape observation.

* Amours des Salamandres Aquatiques, 4to. Milan, 1821. 
I preserved this egg confined to one spot in a minute glass capsule, and in exactly the same position beneath the microscope, for forty-eight hours. During the first three quarters of an hour many of the spermatozoa on its surface exhibited as vivid motions as at first, but still adhered to the same parts, and had not, so far as I could perceive, changed their posture or their place in the least, or had penetrated in the slightest degree into the envelope. At the end of twelve hours I found that the yelk had undergone the usual process of cleavage, which, at that time, had already been advanced to the stage of coarse granulation of the surface, a fact which proved most distinctly that this egg had been impregnated. Spermatozoa were still distinctly recognized over the whole surface of the envelope, but their motions had now ceased. On the following morning, May $20 \mathrm{tl}$, the changes were found to have proceeded uninterruptedly, as the yelk was then finely granulated over its whole surface. At a little later period, the end of twenty-four hours, a few spermatozoa were still adhering to the surface of the envelope, but the whole were perfectly motionless, and many had evidently disappeared. Still, not one conld be detected in the substance or in the chamber of the envelope. At twenty-eight hours the granulation of the yelk was nearly completed, and its surface was becoming smooth, and there were still a very few motionless spermatozoa on the exterior of the envelope. At the end of forty-eight hours, May 21st, I was still able to recognize the bodies of several spermatozoa which had not yet disappeared, but which had become very indistinct, as if in a state of diffluence. At the end of sixty hours I could no longer detect any trace of them. The egg that was the subject of these observations proceeded regularly in its changes, and ultimately produced the embryo; all the stages of which I have traced and delineated for future communication to the Royal Society.

Subsequently to these observations I saw ova passed by another female, Lissotriton palmipes, and on submitting these to the same close examination as the above, within five minutes after their production, I again found what I regarded as the remains of spermatozoa on the surface of the egg-covering, but not a trace of any in the interior or in the vicinity of the yelk.

Endosmosis of the envelopes during impregnation.-But although the facts now Inentioned are so opposed to the view that the spermatozoa penetrate bodily in to the ovum, it is due to the distinguished observers to whom I have referred to enter somewhat more fully into the questions which their observations involve; and while I am free to admit the possibility of mistake or oversight on my part, to mention the details of some experiments made expressly with the view to ascertain whether the envelopes of the ovum of the Frog are permeable in any part to solid particles of inatter; or whether there exists any orifice in them by which such particles can enter. It is well known that during the transit of the ovum through the oviduct the vitellary membrane becones invested with a thick gelatinous covering, the first thick layer of which may be regarded as the rudimentary chorion, and perhaps may be analogous in its function, in some respects, as it seems to be in its place and mode of origin, to 
the albuminous investment of the ovum of the Rabbit. I cannot, with Rusconi*, regard this envelope of the Frog's egg as being merely a meclianical protection during the process of development. It is formed of cells with distinct nuclei, and from what I shall presently mention, seems to be essential to the ovum at the commencement of the changes, and to be intimately connected with the act of impregnation. Rusconi deprived the ova of the green aquatic frog, ? Rana esculenta, of their gelatinous envelopes at a period subsequent to impregnation, and found that they passed through their changes as well as when covered by them; and he thence conchuded that the envelope is of no use further than to protect the egg from the injury it might receive through inechanical disturbance, "des petits chocs qui pourroient nuire à son developpement $\downarrow$." Certainly it affords this protection to the germ, but to conclude that this is its sole office appears to be somewhat premature. I have found that it is almost impossible to remove this envelope from the Frog's egg at the woment of deposition, or even during the first few minutes after submersion, and before it has become expanded by imbibition of fluid; although it may be removed without inuch difficulty from the egg of the Newt, the yelk of which, in the vitelline membrane, lies free and unattached in its interior. But some time after the expansiun has taken place I have myself founi that the frog's egg may be deprived of a large partion of this covering, and yet produce an embryo equally well as if it had remained protected. On the other hand, one most important function of this investment seems to be indicated in the following facts. Spallanzani found that ova of the Frog deprived of their envelopes before contact with the male influence, were not impregnated; and further, that ova taken directly from the ovaria, are not susceptible of impregnation $*$.

A remarkable fact which I noticed, at a time when I was not fully aware of its interest and importance, enables me to confirm this observation. I captured a pair of frogs, the female of which, a short time after they were in iny possession, laad a large hernia formed by a protrusion of part of the great oviduct through an accidental wound in the posterior part of the rigint side of the body, and in consequence of which she was unable to deposit her ova. This wound had been received before the union of the sexes, but the hernia was formed afterwards, during the passing of the ova from the ovaria. The result of this was, that when some of the ova had passed into that part of the duct which protruded through the wound, the sac formed by it was constricted, and became so enlarged by the expansion of the egg-envelopes, that the remainder of the ova were prevented from entering it. On opening the abdomen of the frog after death, I found that a very large proportion of the ova which had left the ovarium on that side of the body, were lying in the cavity of the peritonæum, among the viscera, being entirely prevented from entering the duct, which was filled throughout its whole extent, to its very orifice, with eggs which had already entered, and were prevented from passing on. On the left side of the body the ova had

* Loc. cit., p. 8.

MDCCCLI.
† Loc. cit., p. 9.

$2 \mathrm{~F}$
‡ Dissertations, \&c., ii. 152, 3. 
also quitted the ovarium, but the whole on that side had passed into the oviduct in the usual way. The eggs found in the cavity of the body consisted only of yelk-masses in their vitelline membranes. I immediately placed some of these eggs in water, with seminal fiuid obtained from the male with which this female had been paired; but not a single egg became impregnated, or gave afterwards any sign of formation of the embryo. I had some hesitation in regarding this experiment as quite conclusive,that impregnation cannot take place before the egg has gained its gelatinous envelope, and consequently while it is still within, or has but just escaped from the ovary,from the possibility that these eggs might have been for some time in the cavity of the body, and that some change might have been induced in them through long detention. In so far, however, as that this was in accordance with Spallanzani's experiment, it seemed to point to the nature and importance of the covering which the egg gains in the oviduct.

Since my attention has been more particularly directed to this point of investigation, I have repeated the experiment on the ova of the Newt, Lissotriton palmipes, with precisely similar results. I opened the body of a female with great care (after dividing the spinal cord through the medulla oblongata), for the purpose of obtaining ova from the oviducts, for artificial impregnation, and immediately saw that a number of ova were free in the cavity of the abdomen, and were in the course of being transferred to the entrance of the tubes, as stated in the first part of this paper. These ova, like those which had recently escaped from the ovarium in the Frog, were without any other covering than their vitelline membranes; most certainly $I$ was unable to detect any other, and they were so delicate that it was with difficulty they were removed into water to which fluid from the inale had been added. But although uninjured in the removal, and in every way carefully treated, not one gave any sign of cleavage of the yelk, which, as I have before stated, I have constantly found take place in the impregnated ova of newts as well as of frogs, although the fact of its occurrence was overlooked by RUsconI ; not one egg afterwards produced the embryo. Thus then it seems fair to conclude that the egg in the Amphibia is not fitted for impregnation until after it has entered the oviduct and acquired its gelatinous covering.

I have already shown that there is a remarkable coincidence between the rate of expansion of the gelatinous covering, immediately after the egg is placed in water, and the susceptibility of the egg to become impregnated; and that in proportion as the covering becomes enlarged and distended by imbibition of water, the susceptibility of the egg becomes diminished; until at the end of about half an hour it is almost completely lost, at which time the rate of expansion of the envelope is also greatly lessened, and the envelope itself has attained to more than two-thirds its future diameter. Now Spallanzani found that the susceptibility of the ovum, when immersed in water, had ceased at the end of fifteen minutes, at which time the envelope is considerably enlarged. Prevost and Dumas also observed that the expansion of 
the envelope is greatest during the first three hours, and rightly regarded the occurrence as connected with impregnation, and with this opinion made experiments to test their views. They placed ova taken from the oviducts in ink, and found the envelopes blackened with the imbibed fluid*; but they remark- "bientôt cette imbibition s'est arrêtée à cause de la reaction chimique de l'encre qui coagulait la matière muqueuse." Afterwards they employed the blood of the Frog mixed with water, and found the envelope deeply reddened when immersed in it; and thence concluded that the envelope in its normal condition admits of the entrance into it of solid particles of matter held in suspension in the fluid. But each of these experiments appears to be open to a different explanation. It is probable that the chemical action of the ink, by altering the condition of the envelope, allowed of the admission into it of solid particles only in proportion to the change in the tissue; and that the colour given to the envelope by frog's blood was due to particles of colouring matter which adhered to the surface, rather than to the admission of these into the substance of the tissue. This conclusion is founded on the following trials.

The imbibition of water by the covering of the egg being so distinctly marked, I had intended, like the authors mentioned, to endeavour to ascertain whether coloured water could be as readily absorbed as pure water. Through accident, however, I omitted to put this question to the test until late in the season of last year, and after the whole of my frogs had spawned. But having placed several ova in rectified spirit for future examination, at the moment of passing them from the body of a frog, I determined to test the result of the immersion of these in coloured fluid, although well aware of the correct objection that would be made, that the experiment must of necessity be inconclusive. I put some of these into a solution of carmine in water, and watched the result. The envelope, which, while the egg was in spirit, was white, opaque, and adhered closely around the yelk membrane, began to imbibe and expand the instant it was placed in the solution; and at the expiration of an hour there seemed reason to believe that the trial had succeeded. The envelope was much enlarged, and the fluid had penetrated into it, carrying with it some colouring matter; as on carefully washing the surface repeatedly in clean water, to remove the deposit on the exterior, the substance of the interior was seen to be coloured, and it was evident that the colouring matter had penetrated as far as the deepest or thick layer of the envelope. This result appeared to favour the view that the spermatozoon enters the ovum. When the ova were again examined at the end of the third day's immersion, they were of a deep red; the deepest stratum of colour being then between the vitelline membrane and the thick or innermost layer of the envelope. The entire egg presented the appearance of a globule or bead of red glass, with a dark red centre, surrounded by a lighter-coloured halo. The eggs were then thoroughly washed and placed in clean water. At the end of six loours part of the colouring matter had again been removed from the interior, and the eggs were of a less deep hue, and the

$$
\text { * Loc. cit, ii. p. } 132 .
$$


water they had been immersed in was coloured. I then again removed them to clear water. At the end of sixteen hours they had parted with more colour, but were still red, more especially between the inner portion of the envelope and the vitelline membrane, and the water had again acquired a red hue, thus showing that both endosmose and exosmose must have taken place.

As it might fairly be objected that these ova, changed by immersion in spirit, were unfitted for experiment, I made trial with others which had not been impregnated, and being infertile, had remained in water many days withont giving sigus of decay. When these were placed in the carmine solution, their envelopes became as deeply and thoroughly imbued with colouring matter throughout their whole substance as in the former; and when placed in clear water they parted as readily with a portion of it, so that it was evident that whenever the density of the fluid in which these dead and infertile ova were immersed, was altered, a change by endosmose or exosmose inmediately took place in the fluid retained mecbanically in their tissues. To this cause, perhaps, may be ascribed the colouring of the ova in Prevost and Dumas's first experiment with ink, while other experiments, which I shall mention, made on living and impregnated ova, lead me to regard the colour in the experiment with frog's blood as merely the result of adhesion of colouring matter to the surface.

The immediate objects I had now in view were, to learn whether impregnation is effected by any direct and palpable infiltration of seminal matter throngh the envelopes of the ovum; - whether the admixture of other inatters with the seminal fluich will prevent or arrest impregnation; - and whether the spermatozoa collected on a filter paper, and then placed with this in a fluid of great density, are as efficient as in clear water.

With these views, I prepared a very dense solution of carmine pigment in water, and added parts of this to suall quantities of water with ova, either before the seminal fluid was mixed with the water, or immediately afterwards, and I expected the results to show whether any solid particles, held in suspension in the fluid, passed through the envelopes. The previous trials had shown that solid particles do pass through the dead tissue, but it was doubtful whether the like result would occur in the living.

Carmine Experiments.-Set O.. March 13, 1850. Atmosphere $53^{\circ}$ F $_{\Lambda \mathrm{HR}}$

No. 1. Eleven unimpregnuted ova were passed into water mixed with carmine.

The envelopes became as fully expanded, and imbibed fluid as freely as in the impregnated ova, and acquired a red tint ; but much of the colour was due to the deposition of granules of matter on the surface, while I was unable to detect any similar granules within their texture. On the contrary, on removing part of the surface of the envelopes, the interior, although slightly reddened, exhibited an uniform appearance.

No. 2. Thirty ova were passed into water that had been mixed with seminal fluid, and immediately afterwards a solution of carmine was also added. 
Twenty-six of these ova became impregnated and produced embryos; thus showing that impregnation takes place very quickly, and is not prevented by the addition of a dense colouring fluid, added after contact with the impregnating fluid.

No. 3. Forty-one ova were passed into a solution of carmine in water which had been mixed with seminal fluid immediately before the passing of the ova.

Thirty-three of these ova also produced embryos. It was evident, therefore, that when seminal fluid is freely mixed with a dense inedium that holds solicl particles of matter in suspension, the spermatozoa are not necessarily prevented from effecting impregnation of the ova. Thus the ova of the Frog, although usually deposited in slow-running or clear still water, nay be deposited even in slightly turbid water without impediment to the natural process of impregnation, as the water and spermatozoa may be brought into contact with the ova at the same instant.

No. 4. Thirty ova were passed into water mixed with fluid that had been almost completely deprived of spermatozoa by filtration.

Only one ovum exhibited any signs of impregnation, but not a single embryo was produced.

No. 5. About two hundred and twelve ova were passed into a dense solution of carmine and water in which the filter paper with spermatozoa, separated from the fluid employed in No. 4, had already been placed, and the water and ova were then freely agitated together.

The result of this experiment was very marked. Only a few of these ova becane segmented, and the change proceeded much slower in them than in the ova of experiments Nos. 2 and 3. At the end of twelve days only five embryos hat been produced. Thus a dense solution of carınine, applied to the spermatozoa before they are brought into contact with ova, may have the effect of preventing impregnation, apparently by operating as a mechanical impediment. These ova, excepting only a few removed for the following experiment, No. 6, which were taken from the mass as stated, were allowed to remain in the carmine for twenty-four hours before they were placed in clear water.

No. 6. Forty ova taken from the last experiment were removed to cleal water at the end of one houl and a quarter, having first been thoroughly washed. The result was as decided as in No. 5. Only two embryos were formed; so that there was further reason to believe that impregnation takes place very quickly, and that the result in No. 5 was not entirely due to long continuance in the solution, but to some impediment at the time of contact.

No. 7. A thick solution of carmine was mixed with seminal fluid and water, and three minutes afterwards a mass of ova were passed into it.

This experiment was similar to No. 3, excepting only that the solution of carmine was much more dense, and the ova were not passed nntil three minutes after the fluids had been mixed. There was a nuarked difference in the result. Only a few of these eggs became segmented, and only eight out of a large mass produced embryos. 
But there were several eggs that appeared to have been partially impregnated, the whole of which were abortive. Partial impregnation, as before stated, is shown in a very imperfect cleavage of the yelk, sometimes on one surface only, and sometimes complete as regards one half of the yelk, but imperfect or irregular in the other.

No. 8. Forty-two ova from the last experiment, No. 7, were removed from the carmine at the end of thirty seconds, and were immediately well washed to get rid of the adhering spermatozoa and granules of colouring matter. Not one of these ova produced an embryo, but several had become partially impregnated.

These experiments were made in the middle of March, when the season was unusually cold, and the mean lowest temperature of the room during twelve days was only $43^{\circ} \mathrm{F}_{A H R}$, and the mean highest $47^{\circ} \mathrm{F}_{\mathrm{AHR}}$; at a higher temperature the results, I have little doubt, would have been more favourable. The eggs had been impregnated lowever when the temperature, during the first twelve hours, was $55^{\circ}$ FAHR., so that the question respecting the infiltration of solid matter with the water absorbed by the envelopes of the eggs was not affected.

About four hundred and twenty eggs were employed in this set of experiments ; yet I could not detect any granules of the colouring matter of carmine beld in suspension, and of dimensions equal to those of the spermatozoa, which had passed into the tissue of the envelopes of the eggs, although they had become tinged by the colouring matter in combination with the water. Abundance of granules of colouring matter of most minute size, and not more than one-third the diameter of the spermatozoa of the Frog seen beside them, adhered to the surface of the envelopes, and it was to these chiefly that the red colour of the whole was due. Every part of the envelope exhibited the same uniform appearance, the granules being pretty equally distributed over the surface, and the suffusion of colour was uniform in the interior. These facts appeared to be conclusive with reference to the question of the presumed existence of a fissure or perforation through the coverings of the egg of the Frog before, or at the moment of fecundation, as is supposed to exist in the ovum of the Rabbit. I have not been able to detect any appearance of orifice or fissure in the egg of the Frogenvelopes, and the course of which, if such really exists, would no doubt be indicated by some deposition of the colouring matter of the carmine, to a greater or less extent, in its tract. 'The result of these experiments was thus most unfavourable to the belief that the spermatozoa penetrate bodily through the membranes of the ovum; and to that of the supposed existence of a special opening in these membranes for their admission.

I ought now, however, to mention one experiment that seemed to favour the opinion that the spermatozoon enters the ovum. I had taken several ova, together with the oviducts into which they had passed, from the body of a Lissotriton palmipes, and others from that of Triton palustris, for the purpose of artificial impregnation. Some of these I pressed from the oviducts into a very clear solution of carmine, taken from a solution which had remained undisturbed for nearly a fortnight, so that the granules 
in suspension had subsided, and only the colouring matter actually combined with the water gave it its red hue. At the end of half an hour I removed the ova from the solution to clear water for examination, and then found that the interior of the envelope was coloured by the water which had entered, but that the greater portion of the colouring matter had been arrested and separated at its entrance and adhered to the surface. One ovum of Lissotriton palmipes, however, to my great surprise, had a little dense mass of colour deposited at one point only of the dark surface of the ovum, not merely within the envelope or its chamber, but actually beneath the vitelline membrane, between it and the yelk, as was distinctly proved by turning the egg on one side and viewing it in profile. Not one of the other eggs, placed in the solution, either of the Triton or Lissotriton, showed any appearance like this; so that while I am debarred from expressing a decided opinion that the spermatozoon does not enter the ovum, I can only regard the appearance mentioned as entirely accidental, and not as a normal occurrence; but as resulting, perhaps, from some minute puncture or other accident during the removal of the eggs from the body or the oviduct.

But in order, if possible, to remove another source of doubt, it seemed necessary to make some trial with the colouring material employed by Prevost and Dumas in their experiments ; and some further examination of that used in my own ; and to ascertain whether any solid particles or granules of matter, held in suspension in ink or in carmine, and equal in size to the spermatozoa of the Frog or the Newt, can be passed through the filter, or can be separated from the fluid portion by filtration, like the spermatozoa, when precisely the same mode is followed, and the same means and same description and number of filter-papers are employed, as in the filtration of the seminal fluid. The solution of these questions it was evident must tend to confirm or to unsettle the previous conclusions. I first tried ink, and used a part of the identical filtering-paper employed to separate the spermatozoa. The ink passed quickly and freely through three filters without losing any of its intense black colour, and carried with it only a very few extremely minute granules, much sinaller in size than the spermatozoa of the Frog; so that it seemed fair to conclude that the colour imbibed by the ova from ink, in -MM. Prevost and Dumas' experiment, was dne to the admission of the chemically combined colours of the fluid, and not to an admission into the texture of the egg-envelopes of solid particles held merely in suspension in the fluid. Consequently this experiment seemed to negative the supposition that, from the fact of the interior of the egg-covering becoming blackened, solid particles of inatter, equal in size to the spermatozoa, must have penetrated into the envelope during its expansion; and there seemed less reason to believe that the spermatozoa,bodies very much larger tlian the ink-granules,-could enter it. Carmine was then tried. A solution of this colour could scarcely be made to pass through even a single filter. 'This seemed to be due chiefly to the fact that the greater proportion of the colouring matter of the carmine used (the water colour pigment of artists) was combined with gum and an eartly base, and consequently most of the colour was in 
suspension rather than in chemical combination. When placed on a single filter, the solution passed through with extreme difficulty and slowness. When a nicroscopic drop of the fluid so passed was examined with a power of three bundred diameters, it was found to contain a large quantity of granules suspended in clear fluid. When made to pass, but with still greater difficulty, through a second filter, it still contained a quantity of minute grinules, but each less than one-half the diameter of the spermatozoon. It is possible, therefore, that some extremely minute granules may penetrate into the texture of the envelope, formed as it is of aggregations of cells; but it seems to be very improbable that any of the larger-sized objects, such as the spermatozoa, can enter: and it is even much more improbable, that if the chief colour of the ova in my experiments was due, as I believe, to granules of carmine on the surface, and not in the interior of the ova, that in MM. Prevost and Dumas' experiments with frog's blood, the ova should bave become reddened by the admission of particles of this into their interior, since it need scarcely be mentioned that the colour of the blood is due only to the particles suspended in it; and MM. Prevost and Dumas remark, that they were not able to detect any blood-globules on the surface. To what else, then, than to these, or to their broken-down particles, could the reddened colour of the ova in their experiments be due ?

The conclusion, then, to which I an led by these experiments is, that although the envelopes of the egg imbibe coloured fluid, they do so less easily than when the fluid is not coloured, unless it is in chemical combination; and although atoms of solid matter, very much smaller than the spermatozoa, may possibly be carried by infiltration into the texture of the egg-envelope by the act of endosmose during its expansion, it appears to be extremely unlikely that the large bodies of the spermatozoa are so carried in ; an improbability which is raised almost to a certainty by the fact that the spermatozoa are not seen attached to the egg with a centripetal direction of the axis of their bodies, but are constantly applied laterally to, or are entangled amongst the loose tissue of the surface, extended at length or partially folded on themselves.

\section{AGENCY OF SPERMATOZOA AS AFFEC'TED BY CHEMICAL MEDIA.}

The experiments with carmine having led to an unexpected result in the impediment which this medium offers to the impregnation of the ovum when immersed in it before contact with the spermatozoa, I was desirous of ascertaining what effect would be produced on the ovum by the destruction of the spermatozoa by chemical means, immediately after they had been applied to it. Mr. Guluiver* long ago showed that the spermatozoa of different animals are variously affected by different chemical tests; and Dr. Frerichs $\downarrow$, more recently, has found that a solution of caustic potass has the property of entirely dissolving and destroying them. This material, therefore, seemed to be peculiarly fitted for the object in view. But before any experiment, in

* Proceedings of the Zoological Society, part 10. p. 101. July 26, 1842.

† In Cyclopædia of Anatomy and Physiology, Article "Semen," p. 506, January 1849. 
which this was employed, could be relied on, it was necessary to confirm the facts ascertained by chemical investigation, by observing the mode of action of solutions of caustic potass, and other chemical agents on the spermatozoa, by means of the microscope. As my observations on the effect of chemical agents on the spermatozoa have been confined for the present to those of the Frog, I shall state the results of these observations with the microscope before mentioning the experiments.

All the observations were made immediately after the spermatozoa employed had been obtained, by the course already mentioned, and not by vivisection from the vesiculæ seminales or the testes, sources which are objectionable from the facts shown in Dr. Frerichs' analyses, that a large quantity of albumen is always found in the inmature cells in the testes, with which the spermatozoa, obtained from that source, are constantly mixed, while there is no trace of albumen in the mature spermatozoa.

1. Solution of Caustic Potass.-The solution employed was in the proportion of twenty grains of caustic potass (Potassa fusa) to one ounce of water. This was the solution employed on most occasions in the following experiments, and which quickly and entirely dissolves the spermatozoa. When a drop of semen, in which the spermatozoa are active and abundant, covered by a pellicle of talc on a plate of glass, is attentively examined, while a very small quantity of the potass solution is applied to the edge of the talc, the act of clissolution is easily witnessed. As the solution spreads beneath the talc the spermatozoa first brought into contact with it are instantly destroyed, while the motions of those at a distance become slower and slower, until, when the fluid has nearly approached, they entirely cease. The instant the fluid comes into contact with the spermatozoa, they roll up on a sudden into a spiral form, the change commencing at the apex of the caudal extremity, and each becomes a rounded mass, which quickly dissolves and disappear's in the homogeneous fluid. The action of the potass in this destruction of the spermatozoa, as seen by the microscope, is very similar to, in appearance, and strongly reminds one of the action of fire on the barbs of a feather, which become frizzled in an instant, leaving only a scoria that soon disappears.

2. Nitrate of Potass.-This, as in the preceding case, was in solution in the proportion of twenty grains to an ounce of water. It destroys the spermatozoa much less quickly than the caustic potass. When applied, as above, to the edge of the talc, the spermatozoa first become on a sudden motionless, and are in general elongated, and afterwards are very slowly dissolved.

3. Diluted Acetic Acid.-When this is applied to the spermatozoa in the same way as the solution of potass, it quickly destroys all signs of vitality. The movements immediately become slower and very soon entirely cease, and the spermatozoa are extended at full length, and are but rarely folded on themselves, as they usually are in natural death. I could not satisfy myself that the acid has any other effect on them chemically than that of contracting and rendering them smaller. It did not appear to dissolve them. Mr. Guldive R* has mentioned that the spermatozoa of the 
snake (Natrix torquata) are not affected by acetic acid, but he makes no reference to its action on those of the Frog.

4. Gum-Arabic.-A thick solution of gum appears to act on the spermatozoa mechanically only, and almost immediately deprives them of motion by the obstruction it opposes to them. When a minute drop of spermatic fluid is placed in the midst of one of gum solution, and covered with talc, those sperinatozoa which have become mixed with the gum cease to move instantly, and remain with the tail and body coiled in various directions; while others at the edges and in the midst of the fluid, where they are less mixed with gum, still move feebly for a few seconds, but become motionless as the gum collects around them.

These circumstances will better enable us to understand the following experiments, the object of which was to endeavour to learn how far the influence of the spermatozoa, and the act of impregnation of the ovum partake of a chemical or of a mechanical nature; and also will help to determine the length of period of contact requisite for impregnation.

The following experiments bear on these inquiries :-

Potass experiments. - Set P. March 25, 1850. Atmosphere $48^{\circ} \mathrm{F}_{\mathrm{AHR}}$. Water $46^{\circ} \mathrm{F}_{\mathrm{AHR}}$. No. 1. P.M. $1^{\mathrm{h}} 40^{\mathrm{m}}$.-Fifty-four ova were passed from the Frog on a dry surface, and were instantly bathed with recently-obtained impregnating fluid mixed with water; and at the lapse of fifteen seconds were washed by means of a hair-pencil loaded with the solution of caustic potass before mentioned; after which the eggs were again washed freely with water.

No. 2. P.M. $1^{\mathrm{h}} 45^{\mathrm{m}}$.-Thirty-nine ova were treated in precisely the same way, except that the interval between the application of impregnating fluid and the solution of potass was only five seconds.

The ova were removed, after the first day, to a room in which the average temperature was about $60^{\circ} \mathrm{F}_{\mathrm{AHR}}$, and at the end of the eighth day twenty-one embryos, advanced to near the end of the fourth period of development, had been produced in No.1, and two embryos, at a similar stage, in No.2. This, at first thought, appeared to be an extraordinary fact, seeing that the solution of potass so quickly decomposes the spermatozoa, and even renders the ovum sterile, as was afterwards found ; but, on examination of the details, the experiments admit of explanation :- first, the seminal fluid was employed immediately it was obtained, and before the application of the potass, which was not used, in the first case, until after a lapse of fifteen seconds, and in the second case, of five seconds; next, that in both instances the solution of potass was, as quickly as possible after its application, diluted and removed by repeated washing of the ova with water. Nevertheless, these experiments prove that the ovum becomes impregnated very quickly after the application of spermatozoa, and, in these cases, even within the short interval of fifteen seconds in the one, and five seconds in the other, the difference in the number of embryos produced in the two apparently indicating the extent in each of the deleterious effect of the solution. 
No. 3. P.M. $1^{\text {h }} 50^{\text {m}}$.-Forty-seven ova were passed on a diry surface, and spermatic fluid was instantly applied to them, and within ten seconds afterwards the ova were washed with the solution of potass, which was allowed to remain, and water was then added. At the end of the eighth day not a single embryo had been produced. The difference between this experiment and the above was the non-removal of the potass, and the more free bathing of the ova.

No. 4. P.м. $1^{\mathrm{h}} 53^{\mathrm{m}}$.-Forty-five ova were passed on a dry surface, and were first bathed with solution of potass, and then with seminal fluid in water, and afterwards they were removed with No. 1 and 2, to higher temperature.

At the expiration of the eighth day three embryos had been formed. This result at first appeared to be niore difficult of explanation than the former. But, when the circumstances are considered, it seems to admit of quite as easy an interpretation. The bathing of the ova freely with seminal fluid mixed witl water, five seconds after the application of the solution of potass, diluted this solution too much to allow of its effect on the whole of the spermatozoa applied to the ova, while this very dilution enabled the impregnating influence of these bodies to take effect in some of the ova. The fact, bowever, leads to an inference of some importance with reference to the action of the potass on the envelopes of the ovum, and seems to show that this action is less immediate on the envelopes than on the spermatozoa.

No. 5. Fifty-nine ova were bathed with seminal fluid and water, and five seconds afterwards with a solution of nitrate of potass (in the proportion of twenty grains of the salt to one ounce of water), and water was then added to them.

No. 6. Seventy-two ova were treated in precisely the same way.

Not one embryo was produced in either of these experiments.

No. 7. Forty-four ova were washed with diluted acetic acid immediately after they had been shed from the female, and five seconds afterwards, seminal fluid with water was added to them.

No. 8. Seventy-six ova were washed with diluted acid, and treated in every way as in No. 7.

Not a single embryo was produced in either of these trials.

The action of acetic acid is almost instantaneous on the envelope of the ovum, which it quickly contracts, and renders slightly opaque.

Besides those media which act chemically on the spermatozoa and the ova, I unade trial, in this and the two following sets of experiments, with a solution of gumarabic, the effect of which appears to be entirely mechanical; and as the results are curious and seemingly important with reference to the nature of the agency of the spermatozoa in impregnation, I defer the mentioning of them until I have to show the effect of media which operate mechanically on the ovum or the spermatozoon in impregnation.

The result of the preceding experiments was so remarkable, that it seemed necessary that they should be repeated with greater precision, with reference to exact periods 
of time, than can always be done when alone and unassisted. It was evident that a proper understanding of the nature of the act of impregnation, if ever this becomes known, will be led to chiefly by attention to the periods of time in which it is effected. I obtained therefore the assistance of a friend, to note the spaces of time which elapsed in each stage of the following experiments, so that these might be performed with the quickest dispatch, and the attention of the experimenter be not withdrawn from each until it was completed.

Set $\mathrm{Q}$. March 30, 1850 . Atmosphere $49^{\circ}$ FaHr.

The seminal fluid employed in this set of experiments was not obtained from the usual source. From some cause or other it could not be so procured. I therefore killed a male frog, by dividing the spinal cord in the medulla oblongata, and pressed out the fluid from the testes, which were gorged with spermatozoa, as found by examination with the microscope. From the presence of a great number of spermatozoal cells, and from the water with which I mixed the fluid becoming slightly turbid and albuminous, it was seen that it was not fully matured, a circumstance to be borne in mind with reference to the experiments, which were commenced some minutes after the fluid had been thus obtained. It was doubtful also whether the eggs were quite mature.

It is necessary further to mention, that in these experiments two solutions of potass, with different proportions of the salt, were employed; one having twenty grains in one ounce of water, and which, to avoid repetitions, I shall designate "strong solution;" and the other having only eight grains of the salt in one ounce of the fluid, and which I shall refer to as the "weak solution."

No. 1. P.M. $4^{\mathrm{h}} 45^{\mathrm{m}}$. - Forty-five ova, passed on a dry surface, were bathed with seminal fluid and water, and five seconds afterwards with the weal solution of potass, and were then washed, and placed in clean water. The whole time occupied in the experiment did not exceed thirty-five seconds.

On the following morning, segmentation was found to have taken place in twelve ova. This as well as the following sets of ova were then removed to a higher temperature, in which they were allowed to remain; but no embryos were produced.

No. 2. P.M. $4^{\mathrm{b}} 58^{\mathrm{m}}$. - Fifty-three ova were treated in exactly the same way, but with the strong solution of potass; the interval between the application of the impregnating fluid and the solution being ouly two seconds, and the whole time occupied forty-five seconds.

Segmentation took place in three or four ova, but not completely. Several ova also were altered in form; but not a single embryo was produced.

No. 3. P.м. $4^{\mathrm{h}} 52^{\mathrm{m}}$.- One 'hundred and twenty-two ova, passed on a dry surface, were immediately well bathed with seminal fluid and water, and two seconds afterwards with weak solution of potass, which was allowed to remain with the ova, and water was then added. The whole time occupied was forty-five seconds.

Segmentation took place in a great number of these ova, certainly from fifty to 
sixty, and there were nine also which became shrivelled and decayed. Notwithstanding the great proportion of ova segmented, not one produced an embryo.

No. 4. P.M. $5^{\text {h }}$.-Sixty-six ova, passed on a dry surface, were bathed as in No. 2, with impregnating fluid, and one second afterwards were washed quickly with strong solution of potass, and water was then added; the period occupied being sixty-two seconds.

Only two ova became segmented, while, excepting only eight or nine ova, the whole of the remainder were shrivelled, irregular, or compressed in form, and distinctly spoiled, apparently by the action of the potass, thus showing that endosmose and exosmose through the envelopes had taken place.

No. 5. P.M. $4^{\mathrm{h}} 55^{\mathrm{m}}$.-Fifty-four ova were passed, and washed with the weak solution of potass, and afterwards, at an interval of two seconds, with impregnating fluid and water, and water was then added and allowed to remain. The whole time occupied was fifty seconds.

One ovum only became seginented; but several others bad slightly altered their form to the obtuse oval, as if about to beeone divided: no embryo was produced.

No. 6. Р.м. $5^{\text {l }} 2^{\mathrm{m}}$.-Seventy-nine ova were washed with strong solution of potass, and one second afterwards with inpregnating fluid, and water was then added.

Not one ovum became segmented, nor did even one yelk retain its proper shape. The whole were irregular and spoiled. Five ova had the envelope clouded and opaque, and the surface of uthers was translucent with refracted light, like crystallized carbonate of lime. In one egg only had there been any attempt at segmentation. This experiment, like No. 4, seemed to show that the act of expansion of the chorion is an act of endosinose.

No. 7. P.м. $5^{\mathrm{h}} 15^{\mathrm{m}}$.- Nitrate of Potass. Seventy-seven ova were passed on a dry surface, and were well bathed with impregnating fluid in water, and one second afterwards with a weak solution of nitrate of potass, and water was then added to them; the whole time occupied being thirty seconds.

Segmentation took place in forty-three of these ova, and the whole retained their uatural form and size. The effect of the nitrate of potass, as compared with the caustic solution, was thus very marked, as showing that the momentary application of the nitrate does not prevent or arrest impregnation in weak solution (eight grains to one ounee of water), even when applied after the impregnating influence. The experiment was also interesting in another respect. It proved that the ova were susceptible of being impregnated, and that the fluid from the testes was efficient to induce the first evidences of impregnation. But none of these ova, or of the ova in the preceding experiments of this set, produced embryos. Subsequent observations will show that this failure was not due to the nitrate of potass, but perhaps was attributable to the conjoint causes of low temperature at the time of impregnation, and of some imperfection both in the seminal fluid and the ova.

No. 8. P.M. $5^{\mathrm{b}} 9^{\mathrm{m}}$.-Seventy-six ova were washed with diluted acetic acid as in Set $\mathbf{P}$, 
No. 7 , and one second afterwards with impregnating fluid, and water was then added to them. The time occupied was forty-five seconds.

The result was more decided than in the experiment referred to. The envelopes of the ova immediately became clouded, and no segmentation took place in any of the yelks, some of which became shrivelled and changed in form.

The result of the preceding experiments being doubtful as to the cause of the nonproduction of embryos, especially with reference to the first three, and the seventh experiments, in which many ova became segmented, I obtained some additional pairs of frogs from their native haunts, and within twenty-four hours afterwards, before they had in any way become debilitated by confinement, repeated the experiments at a higher temperature.

Set R. April 3, 1850. Atmosphere $60^{\circ} \mathrm{FAHR}$.

No. 1. P.M. $3^{\mathrm{h}} 5^{\mathrm{m}}$. - Eighty-two ova, passed on a dry surface, were touched for an instant only with a pencil dipped in impregnating fluid and water, and one second afterwards were washed with strong solution of potass, and then with water, and water was then added. The whole time occupied was only fifteen seconds.

No. 2. Twenty-five ova were treated in precisely the same way with the same solution (which also was employed in the following experiments); the interval being two seconds, and the whole time twenty seconds.

Segmentation took place, but only very partially, in about twelve ova of the first, but completely in one only of the second experiment. The whole of the remaining ova were shrivelled and decayed; their envelopes exhibiting the same clouded and refractive property noticed in the last set. At the end of five days two embryos had been produced in the first experiment, and one in the second. It was thus far confirmatory of the experiments with potass in Set P, that if this salt be applied to the envelope several seconds after the application of the impregnating fluid, and be again quickly removed or diluted with water, impregnation may already have taken place, and the action of the caustic will not in that case affect the production of the embryo; especially if the experiment be made when the temperature of the surrounding medium is becoming increased. But if the solution be applied before the application of the seminal fluid, then the spermatozoa will in most cases be decomposed, and no impregnation follow. In either case, however, the undiluted solution acts also on the ovum itself within a very short period, and destroys or renders it sterile. This was further proved in the succeeding experiments.

No. 3. P.M. $3^{\mathrm{h}} 10^{\mathrm{m}}$.-Fifty-eight ova were passed on a moistened surface, and were immediately afterwards washed with the solution, and at the expiration of one second were bathed with seminal fluid and water; the time occupied being only fifteen seconds, as in No. 1.

No. 4. Sixty-nine ova were treated in exactly the same way, the interval being one second; and the whole time occupied only twelve.

Partial segmentation had taken place in one ovum of No. 3 ; but the whole of the 
remaining ova, both in No. 3 and 4, were destroyed. Many of the yelks had begun to change form within the first hour, and the envelopes exhibited the same refractive appearance as in the previous experiments.

Anticipating from the former experiments what probably might be the ultimate result in these, I now determined to put beyond the possibility of doubt, both the fitness of the seminal fluid employed to effect impregnation and the healthiness of the ova, and their susceptibility to become impregnated; and to show from these facts that a non-production of the embryo in this set of experiments inust be due to the action of the potass solution, and not to any unfitness in the spermatozoa or the ova. Accordingly,-

No. 5. P.M. $3^{\text {h }} 17^{\mathrm{m}}$. - Sixty-two ova, from the same female employed in the preceding experiments, were bathed with a portion of the seminal fluid and water which had been employed in No. 1 and 2, and were then placed side by side with these, in a separate dish.

At the expiration of four hours and thirteen minutes, the temperature being $60^{\circ}$ FAHr., from thirty to forty of these ova had become segmented. Some of the ova had been injured mechanically, but nearly the whole that had not been injured were impregnated. On the seventh day there were twenty-three embryos, thirteen of which had already left the egg-envelopes; others were somewhat less advanced, thus proving the fitness of the seminal fluid to impregnate, and the ova to produce. The number of embryos too was fully as great as could have been expected, seeing that many of the ova had been slightly injured, and that the seminal fluid had already been one hour and twenty-six minutes mixed with water.

The result of this experiment was borne out by the following.

No. 6. P.м. $3^{\mathrm{h}} 31^{\mathrm{m}}$.-Nitrate of Potass. Seventy-four ova were well bathed witl impregnating fluid and water on a previously dry surface, and one second afterwards with a strong solution of nitrate of potass (twenty grains to one ounce of water), and water was then added to them; the whole time of the experiment being twenty seconds.

No. 7. Fifty-nine ova were treated in exactly the same way, save that the interval between the application of the impregnating fluid and the solution of potass was three seconds, and the whole period twenty-five seconds.

Segmentation commenced in each of these sets in four hours and fourteen minutes, when from twelve to fifteen ova were undergoing this change in No. 6, and thirteen in No. 7. At a later houl there were many more in each experiment only very partially segmented, and which proved to be unproductive. At the end of the seventh day there were twelve embryos in No. 6 advanced to the same stage as in the simply artificial impregnation No. 5, and ten embryos in No. 7 , but at a little less early stage of growth, a circumstance which $I$ attributed at the time to imperfect aëration.

No. 8. P.м. $3^{\mathrm{h}} 37^{\mathrm{m}}$. -Seventy-nine ova were bathed with the same solution of nitrate of potass as above, and three seconds afterwards with impregnating fluid in water; the whole tine occupied being twenty seconds. 
Segmentation took place at a little later period in this than in the preceding experiments. It commenced at four hours and twenty minutes, when twenty-five ova were undergoing the change. This was a full proportion of impregnation as compared with No. 5, seeing that the impregnating fluid had already been mixed with water one hour and forty-six minutes. Twenty-five embryos were the result of this experiment.

The results thus support the explanation already given, with reference to the effect produced on the envelopes of the ovum being less iminediate than on the spermatozoa; since, in this case, twice as many ova became segmented, and ultimately produced embryos, as in those experiments in which the solution was applied after the seminal fluid, and while endosmosis of the egg was inost rapid, and when the solution remained undiluted.

The general results of this set of experiments, compared with those of the last Set, $Q$, appear also to show that the non-production of embryos in the whole of that set,after segmentation had taken place in several of the experiments, as in Nos. 1, 2, and especially No. 3, with solutions of the caustic potass; - and still further, No. 7 with the nitrate,-may fairly be attributed to some defect in the seminal fluid or in the ova; since, if such were not the cause, and the failure had been due either to the chemical effect of the media on the ova, or to the moderate temperature of the atmosphere $\left(49^{\circ}\right.$ FAHr. $\left._{\text {A }}\right)$ at the time of experiment, - segmentation of the yelk would hardly have taken place. This supposition appears to be the more likely, when we recollect that in the Set $\mathbf{Q}$, and in that set only, the impregnating fluid was obtained from the testes, compressed and broken down in water,-that the eggs were of doubtful maturity,and that this was the only set of experiments in which no embryos were ultimately produced; although, I may now mention, that greater care was taken to ensure a favourable result than in most of these investigations, - the ova being removed at the end of twenty hours to an average temperature of $60^{\circ} \mathrm{FAHR}_{\mathrm{A} .,}$ - were retained in flat shallow dishes,- and had the water changed daily. Both sets, however, $\mathbf{Q}$ and $\mathbf{R}$, seem to prove that the act of impregnation, as evidenced in the fact of the yelk becoming segmented, must take place, or be commenced very rapidly ; and, apparently, almost at the instant of contact of the spermatozoon with the coverings of the ovum; as seems to be shown in the fact, that segmentation took place in many of the ova when the space of time between the application of the spermatozoon, and that of the solution,- -which previous observation (p. 225) showed was sufficient to decompose it inmediately, - was scarcely more than one or two seconds. Thus in Q 4, and R 1, it must have commenced in the interval of one second, even when the strong solution was used; and in $\mathbf{Q} 2$ and. $\mathbf{R} 2$ with the same solution in two seconds. When the weaker solution was used, a greater number of ova became affected in similar spaces of time, as in Q 2 and 3. These experiments seem to show that the act of impregnation had already been commenced before the application of the solution; as, in the experiments which are the converse of those now mentioned, in regard to the time when the spermatozoa and the solution were applied, a different result ensued. Thus when the solution was applied to the ovum first as in Q 6 and R 3 and 4, and one 
second afterwards the impregnating fluid with spermatozoa, no impregnation, or but a very partial one, was effected. The ova in these three experiments amounted to two hundred and six, and yet only one ovum became very partially affected. A like result ensued even when the weaker solution was employed at an interval of two seconds, as in Q 5, when out of fifty-four ova segmentation occurred but in one.

When the interval between the application of the impregnating fluid, in the first instance, and that of the solution subsequently, was extended to five seconds, then a greater proportion of ova becaine segmented, as in Q 1 , with the weak solution, when out of forty-five ova twelve became changed.

These were the results when the experiments were made at different temperatures, as at $49^{\circ}$ FAHr. with the $\operatorname{Set} \mathrm{Q}$, and $60^{\circ} \mathrm{F}_{\mathrm{AHR}}$. with the Set $\mathrm{R}$. They cannot, therefore, be attributable to inertness of the fecundating agent, or of the object to be fecundated, occasioned by an unfavourable temperature of the surrounding medium. The fact of the occurrence of segmentation in some ova, but not in the majority of the ova of different experiments, as in $Q 1,2,3$ and 4, seems further to show that the influence of the momentary application of the potash solution was produced chiefly, and in the first instance, on the spermatozoa, or impregnating bodies, and not so immediately on the ova; since if the ova had been first, or most affected, none of them, probably, would have become impregnated.

Further, I may perhaps be allowed to remark, that the arrest of impregnation was due mainly to the nature of the chemical agent employed; and the extent of interference with the fecundatory process was in proportion to the more or less immediate action of this agent on the spermatozoon. Thus we have seen that but few ova were impregnated when the solutions of caustic potass were employed; but when the nitrate of potass was used as in $\mathbf{Q} 7$, forty-three out of seventy-seven ova were segmented; while in R 6,7 and 8, in which the total number of ova was two hundred and twelve, there were fifty-three segmented, and these produced forty-seven embryos.

The object of these sets of experiments, therefore,- - that of endeavouring to ascertain within what period of time after the contact of the spermatozoon with the ovum its fecundatory function is exerted,--appears to have been somewhat fulfilled;-in so far as that in these experiments on the Amplibia the commencement of the act of impregnation appears to have been almost instantaneous. Yet there seems reason to believe that momentary contact of the impregnating body, even in the ovum of these animals, is not in itself sufficient to complete the fecundation, although it may tend to induce that condition of the yelk, segmentation, which we now are assured is always indicatory of its having been influenced by the fecundatory agent. If momentary contact were sufficient for the completion of the function, then partial impregnation, which so frequently takes place when spermatozoa are few in number, or in contact only for very brief periods, could hardly happen; while every ovum in which the process of cleavage is begun ought to pass through all its changes to the production of the embryo, circumstances being favourable to its development. But this we have

MDCCCLI. 
seen in the foregoing experiments is not the case. On the contrary, duration of at least some seconds of contact, varying no doubt in different tribes of animals, and, apparently also, quantity of spermatozoa, seem to be essential to fruitful and healthy impregnation, as appear's to be shown in the filtration experiments, Set L 3, as coulpared with L 1 (p. 207). Possibly momentary contact inay suffice to occasion segmentation, but certainly with duration of contact the ovum is fecundated.

This leads us further to inquire whether any endosmosis of the material substance of the spermatozoon is imbibed by the ovum during any period of impregnation, before or during segmentation of the yelk ?-and whether those media which do not act chemically on the spermatozoon or the ovum can arrest the agency of the former? BischоғF has already shown that sperinatozoa are in contact with the ovum in some Mammalia, the Rabbit* and Dog $\gamma$, from quickly after the entrance of the ovum into the Fallopian tube until segmentation is nearly completed, and the yelk has acquired a tnberculated or mulberry-like surface. In the ovum of the Frog I bave shown that the spermatozoa are in like manner seen on the envelopes from immediately after immersion in impregnating fluid until segmentation has commenced. In the Newt we have seen that when impregnation is effected artificially, they may be recognized on the surface for a much longer period,--from the time of contact with fluid, until the surface of the yelk has reacquired its original smoothness, a period, in my observations, of from thirty-six to forty-eight hours. The persistence of these bodies to a period after the first evident changes in the yelk have commenced, seems to favour a supposition that their function is not completed in momentary contact. Although we are at present unable to trace their influence beyond what is now stated, I think it can be shown that their function can be arrested by media which affect them mechanically, when submitted to such media at the moment of contact with the ovum.

\section{AGENCY OF THE SPERMATOZOA AS AFFECTED BY MECHANICAL MEDIA.}

The object of the next experiments was to learn whether the interposition of a dense fluid medium, which does not act chemically on the spermatozoa, would be as effectual in preventing the influence of these bodies on the ovum as in the carmine experiments, the effect of which seemed to be mechanical.

As the experiments were made at different periods, it will be seen, that although on two of these occasions the temperature of the atmosphere differed, the general results were similar.

Gum and Starch Experiments.-Set S. March 25, 1850. Atmosphere $48^{\circ}$.

(a.) Gum. No. 1. P.м. $2^{\mathrm{h}} 22^{\mathrm{m}}$.- Seventy-six ova were passed on a dry surface and were inmediately bathed with a thick solution of gum-arabic, and fifteen seconds afterwards with seminal fluid and water, and fresh water was then added to them. 'The whole time of the experiment was sixty seconds.

* Entwickelungsgeschichte des Kaninchen-eies. 4to. 1842, tab. 2, 2 and 4, fig. 17 to 28.

$\uparrow$ Entwickelungsgeschichte des Hunde-eies. 4to. 1845, tab. 1 and 2, figs. 10 to 16 . 
No. 2. Fifty-eight ova were treated in exactly the same way, the interval being about fifteen seconds, and the whole time sixty.

The seminal fuid employed was obtained from two males, the fluid used to No. 2 being from a male which had paired four days before. Out of the whole number of eggs in the two sets, amounting to one hundred and thirty-four, not one produced an embryo.

No. 3. March 30,1850 . P.M. $5^{\text {h }} 5^{\mathrm{m}}$ : Atmosphere $49^{\circ}$ FAHR. $_{\text {A }}$

One hundred and eight ova were passed on a moist surface, and were immediately bathed with a thick solution of gum as above, and one second afterwards with seminal fluid in water; the whole time occupied being sixty seconds.

Segmentation took place in two, or at most only three of these ova, and even in thein very inperfectly, and much slower than in the corresponding ova of the set to which they belonged, Set Q (p. 228-9), in which the fluid employed was obtained from the testes of the Frog, and regarded as immature.

No. 4. P.M. $5^{\mathrm{h}} 18^{\mathrm{m}}$. - Fifty-eight ova passed on a moistened surface were immediately bathed with solution of gum, and one second afterwards with seminal fluid from the sume male as No. 3. The whole time occupied was forty-five seconds.

'The result of these two experiments, as compared with others of the set to which they belonged, Set $Q$, was exceedingly curious. In the experiments with the nitrate of potass as in Q 7, segmentation was carried to some extent, and the divisions of the yelk were multiplied; while only four ova out of the fifty-eight, in this with gum, gave any evidence of segmentation, and the process was not advanced further, either in this or in the preceding experinent, No. 3, than to the completion of the primary division of the yelk into two hemispheres. Thus not only was the process entirely prevented in the great majority of the ova, but it was also very inuch retarded in those in which it did take place, and this simply, as it appeared, by the mechanical hindrance of the gum. Could it be that the effect was produced on the endosmic action of the yelk? These trials certainly appeared to show that the obstruction was a mechanical one. I need scarcely remark, that no embryo was produced in either of these experiments.

No. 5. April 3, 1850. P.M. $3^{\mathrm{b}} 25^{\mathrm{m}}$. Atmosphere $60^{\circ} \mathrm{F}_{\mathrm{AHR}}$.

Sixty-one ova were passed on a moistened surface and were inmediately bathed with impregnating fluid, and two seconds afterwards with a thick solution of gum-arabic, and water was then added; the whole time occupied being only twenty seconds.

This experiment, when compared either with the four preceding ones, made at a temperature of the atmosphere eleven degrees lower, or with that which follows, No. 6, seems to point to the exact nature of the operation of the gum. At four hours and five minutes from fifteen to twenty ova had become segmented, and others were in the act of becoming so. At seven hours and a half more than one-half of the whole number had changed, and werc perfectly healthy. Thus, in this case, in which the gum was applied after the seminal fluid, impregnation occurred earlier than in corresponding experiments of the same set, $\mathbb{R} 6,7$ and 8 , witl mitrate of potass, when it happened in from four hours, and fourteen to twenty minutes. It was even as. 
rapid as in the artificial impregnation, $\mathbf{R} 5$ (p. 231), in which it took place in four hours and thirteen minutes. On the eighth day twelve embryos had been produced.

These facts seemed to show, precisely as in experiments with solutions of potass, that impregnation is commenced very quickly; and further, that it was not arrested by the gum when applied only two seconds after the spermatozoa, but that the change proceeds almost as uninterruptedly as in a perfectly natural impregnation, since the number of embryos was almost as great as in No. $5 \mathrm{R}$, seeing that the fluid employed had heen obtained and mixed with water one hour and thirty-four minutes.

No. 6. P.M. $3^{\mathrm{h}} 22^{\mathrm{m}}$. - Seventy ova, passed on a moistened surface, were bathed with a thick solution of gum, and two seconds afterwards with some of the impregnating fluid employed in the last experiment, and water was then added; the whole time occupied, as above, being only twenty seconds.

This experiment was the converse of the preceding. At four hours and twenty-eight minutes only one egg out of the whole had become segmented; but others gave signs of being about to change, and some bours later a few had done so, but there were not at most more than ten. At the end of the seventh day two embryos had been produced.

Thus while a comparison of these two experiments seems to show that the gum acts simply as a mechanical obstruction to the process of fecundation, this experiment, No.6, when compared with Nos. I to 4, made at eleven degrees lower temperature, shows also the influence of a higher degree of temperature in accelerating fecundation.

The two following experiments were made with a view to test the efficiency of the fluid and ova employed, now at one hour and fifty minutes after the fluid had been obtained: when examined at this time with the microscope, there were still an abundance of active spermatozoa.

No. 7. P.M. $3^{\mathrm{b}} 4 \mathrm{l}^{\mathrm{m}}$.-Eighty-five ova were accordingly placed in water with some of the impregnating fluid and allowed to rensain to test its efficacy.

At four hours and twenty-four minutes nearly the whole of the ova bad become segmented, and on the seventh day forty-two embryos had been produced.

No. 8. P.M. $5^{\mathrm{h}} 50^{\mathrm{m}}$.- One hundred and thirty-two ova were now passed into the remainder of the impregnating fluid, which had at this time been four hours mixed with water.

When examined at the end of five hours and ten minutes, not a single specimen had become impregnated. This was proved by the result, that at the end of seven days not a single embryo had been formed. The fluid had thus lost its fecundating property at the end of four hours in a temperature of $60^{\circ} \mathrm{F}_{\text {AHR. }}$.

No. 9. April 6, 1850. Atmosphere $60^{\circ}$ Fahr.

P.M. $1^{\mathrm{h}} 50^{\mathrm{m}}$.- One more experiment was now made with the gum solution, for the purpose of comparing it with the following experiments with starch.

One hundred and twenty-two ova were passed on a diy surface and covered with a thick solution of gum, and three seconds afterwards with impregnating fluid that had been mixed with water only thirty minutes. The time occupied was not noted, but fresh water was added to the ova at the end of fourteen minutes. 
Segmentation took place only, in two or three ova, at four hours and twenty-four minutes, and at the end of ten days only three embryos had been produced.

(b.) Starch. No. 10. P.м. $1^{\mathrm{h}} 40^{\mathrm{m}}$.- - One hundred and fifty-eight ova were passed into a solution of starch in water, and at the end of ten seconds one-half of the whole quantity of seninal fluid, obtained from a single frog, and previously mixed with water, was added to them.

After the ova bad remained in the solution and been gently agitated during twenty minutes, they were carefully washed and removed to clear water.

At four hours and twenty-six minutes only a very few of these ova, not more than eight or teu, bad beeome segmented, notwithstanding the large quantity of recent impregnating fluid that had been added to them. At the end of ten days only five embryos had been produced.

It was remarkable that very few of the ova in this experiment cohered together, as the frog's ova almost invariably do when placed in fluid. On the contrary, most of them remained separate and isolated, although their envelopes had imbibed water and expanded to their usual extent in a similar space of time.

No. 11. P.M. $1^{\mathrm{h}} 47^{\mathrm{m}}$.- Seventy-one ova were passed on a perfectly dry surface, and immediately afterwards were covered, by means of a hair-pencil, with a thick solution of stareh, and at the expiration of ten seconds with impregnating fluid, and water was quickly added.

The water was changed at the end of fifteen minutes. At four hours and twentyfive minutes, only two or three ova had become segmented. At the end of ten days three embryos had been produced.

The concluding experiment with starch was the counterpart of No. 5, with gim.

No. 12. P.M. $1^{\mathrm{h}} 44^{\mathrm{m}}$.-One hundred and nineteen ova were passed into water, with which one-eighth part only of the seminal fluid, obtained from the Frog, had already been nixed. Two seconds afterwards a solution of starch was added to these ova, and at the end of sixteen minutes they were removed to clear water.

In four hours and twenty-six minutes segmentation had commenced in many of these ova. The exact number I omitted to ascertain. But the change had taken place in a much shorter space of time, and was more general, although scarcely one-fourth part of the quantity of seminal fluid that had been employed in No. 10 was used in this case. Nevertheless, in ten days twelve embryos had been formed.

This experiment, therefore, was quite confirmatory of the conclusions drawn from its counterpart, No. 5, with gum, and Nos. 10 and 11 as fully bore out those deduced from Nos. 1 to 5, with the same; while the entire set seem to be in full accordance with the already arrived at conclusion, that fecundation is commenced almost immediately the fecundating body is in contact with the ovum. Thus, then, with regard to the nature of impregnation, we seem to have obtained sufficient proof that the act is effected through the agency of the spermatozoon, and not through that of the liquor seminis, as was formerly supposed. 
TABLE II.-Experiments with Media that act chemically or me-

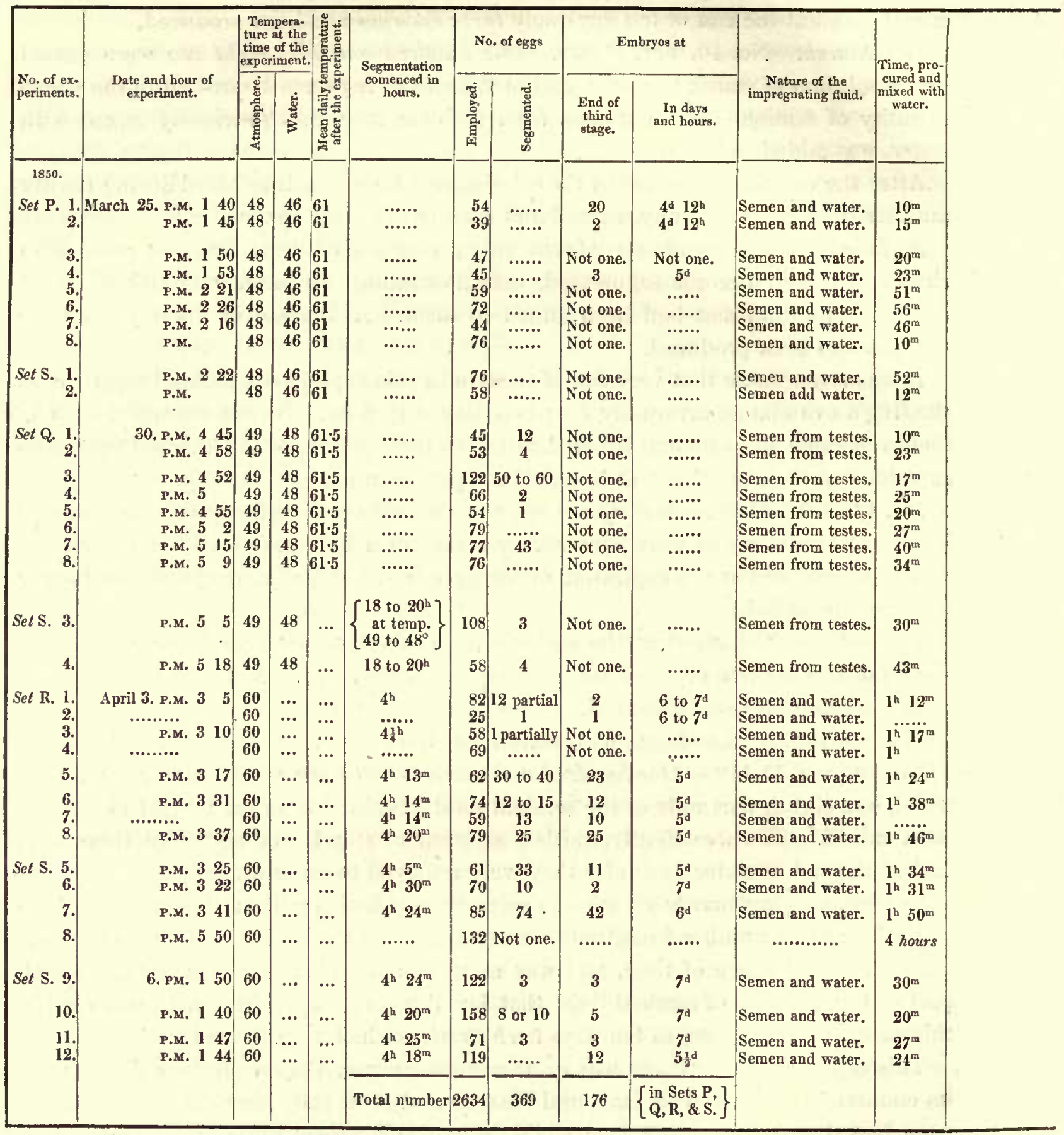

\section{RECAPITULATION AND CONCLUSIONS.}

It may now be well to recapitulate briefly some of the facts and views derived from the foregoing observations and experiments. First, then, the germinal vesicle disappears in the Amphibia before impregnation; and before, or at the time of the bursting of the ovisac, and extrusion of the egg from the ovary into the cavity of the 
chamically on the Spermatozoon or the Ovum in Impregnation.

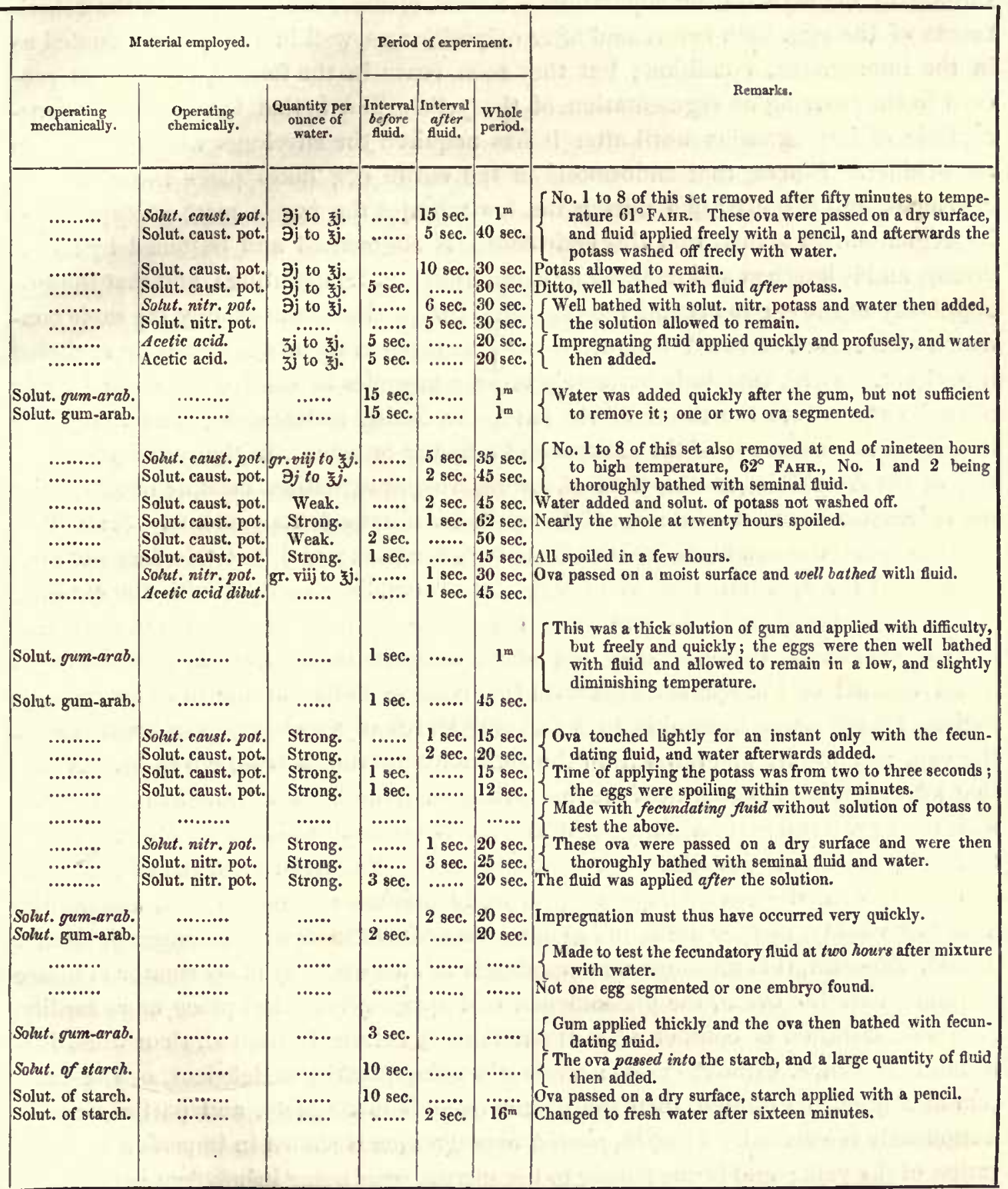

abdomen. It does not return to the centre of the yelk, nor escape to the surface, but is lost much nearer to the lattel than to the former position; and its disappearance is the result of the endogenons development of cells in its interior. The egg is cast loase into the abdomen, and then consists only of the yelk mass in its vitelline membrane, and it is transferred to the mouth of the oviduct by the joint action of 
the abdominal muscles and the motions of the viscera, and not necessarily through the aid of the male during copulation. Second, changes are going on in the constituents of the egg, both before and after oviposition as well in the unimpregnated as in the impregnated condition; but they soon cease in the former, and do not proceed to the cleaving or segmentation of the yelk. Third, that the egg is not susceptible of impregnation until after it has acquired the envelopes which it gains in the oviduct. Fourth, that endosmosis of the entire egg takes place through these envelopes, and is most rapid during the few minutes the egg is most susceptible of impregnation. Further, that this endosmosis is augniented and hastened by an increase, and is lessened and retarded by a diminution of temperature; and that the susceptibility of the egg to become impregnated, and produce, is in exactly the same condition with regard to heat; whether the egg be exposed to, or whether it be excluded from light. Fifth, that only extremely minute granules of solid matter can by any possibility pass into the tissue of the envelopes during endosmosis; and that there is no evidence whatever of the existence of a fissure or orifice, in the envelopes of the egg of the Amphibia, at the time of, or before impregnation, capable of admitting the spermatozoon to the interior of the yelk-membrane or its contents. Sixth, that it is the spermatozoon alone which effects impregnation; and that this does not take place until the spermatozoon is brought into immediate contact with the external envelopes of the ovum. Seventh, that the liquor seminis, when entirely separated from spermatozoa, certainly does not effect impregnation. Eighth, that although direct contact of the spermatozoa with the ovum is indispensable to effect impregnation, I have never been able to detect any traces of these bodies in contact with the yelk-membrane, or even within the substance of the external envelope. Ninth, that impregnation is commenced the instant the spermatozoa are brought into contact with the egg, but a certain duration of contact is essential to its completion. Tenth, that impregnation is not effected when the whole or the majority of the spermatozoa in contact with the envelopes have previously become motionless and, apparently, have lost vitality, as they are found to have done after the lapse of a longer or shorter period. Eleventh, that although an exceedingly minute quantity of spermatozoa suffice to impregnate the ovum, the phenomenon of impregnation takes place more tardily, even with duration of contact when the number is extremely limited, than when it is in full abundance, without excess; while when the quantity is deficient, or the duration of contact too limited, then the phenomenon is incomplete, and partial impregnation only is effected. Twelfth, partial impregnation is shown in imperfect segmentation of the yelk; and is due chiefly to the spermatozoa being insufficient in quantity, or in duration of contact, or inefficient through diminished vitality; and it may also result from diminished susceptibility in the ovum. Thirteenth, partial impregnation of the ovum is of frequent occurrence, as I found in my first experiments with fluid that had passed through filtering-paper, but which still contained a very few spermatozoa, either motionless or exceedingly feeble; and further, partial impregnation is of 
much the most frequent occurrence when the ova are placed in dense fluid before contact with the spermatozoa, as in the experiments with carmine. Lastly, when the ova are only partially impregnated they are usually, and perhaps always unproductive.

These facts lead us to inquire, whether impregnation takes place through any catilytic influence of the spermatozoa as suggested by BischofF, while in a state of activity, and at the instant they are brought into contact with the ovum, or whether impregnation results from a diffluence of the spermatozoa thus brought into contact with the surface, the substance into which they may be dissolved being carried by endosmosis with the water imbibed through the tissues; or whether it is the result of the conjoint influence of both these conditions; - the first action induced being instantaneous and catalytic, and possibly dependent on the persistence of organic vitality in the spermatozoa, while the completion of the impregnation may depend on the inbibition of some material influence or substance derived from the impregnating body ; - a view which the gradual disappearance, of the bodies of the spermatozoa from the surface of the ovum, both in the Frog and Newt, seems to favour; as we have already seen that endosmosis is an active and important function of the envelopes of the ovum at the very period when impregnation is effected.

All the experiments now detailed seem to show that in those vertebrata which expel their ova into water before impregnation, as in the tail-less Amphibia, and in which-from the nature of the medium into which the ova are passed-we may infer that the function takes place most quickly, impregnation is cornmenced at the very instant of contact of the spermatozoon with the ovum, and even may be completed within very short spaces of time-but duration of at least some seconds of actual contact,- -even in these animals' ova, is essential to the perfection of the function;-but this period, we may fairly conclude, may differ in different classes of animals, and possibly may have some relation to the greater or less facility with which the spermatozoa are brought into contact with the ova.

When the experiments last detailed are compared,-the effects produced by the application of media which influence the spermatozoon and the ovum chemically, -with those of which the effect is merely mechanical, we seem to bave made some advance towards a future knowledge of the nature of the impregnating power. Although we are as yet entirely without proof that any material influence or substance is actually transmitted from the spermatozoon on the surface of the ovum to the yelk in the interior, we have evidence that fluids are imbibed by the ovum by endosmosis through its tissues; and although not a trace of the spermatozoon is detected in the interior of the ovum, we have seen that it remains for a long time on the surface, and gradually disappears, apparently by diffuence; so that it may be fair to conclude, that the agency of this body is material in its operation. On the other land, the effect which we find is produced on the yelk by the direct and even momentary contact of the * Müller's Archives, 1847.

MDCCCLI. 
spermatozoon with the envelopes of the ovum, seems closely to resemble that of the socalled catalytic power of certain known bodies, in so far as that contact, during only very short spaces of time, with the surface of the ovum, appears to be sufficient to induce certain changes in the interior. These changes, too, as known of catalysis, are carried only to a certain extent when the exciting agents,-in this instance the spermatozoa,- - are feeble in action or but very few in number; and then, as we have seen, the yelk may become only more or less partially segmented; or the changes in it, having proceeded to a certain extent, may then become arrested, apparently from deficiency of the originally exciting cause. Then, again, we find that although segmentation of the yelk may take place, embryos are not produced unless there has been some continuance or duration of contact of the impregnating with the impregnated body; and that the number produced seems to have reference to the duration and to the full sufficiency of the exciting cause. But neither what we at present know of the so-called catalytic power or of endosmosis, appears alone to be sufficient to account for the whole of the phenomena of impregnation. Simple contact of the sperinatozoon does not appear to be sufficient to determine the transmission of more or less of the material structural characters of the male parent to the offspring; while diffluence and endosmosis of the substance of the spermatozoon can hardly be imagined to occur in a brief second or two of time sufficiently to effect the full impregnation of the yelk, and induce its invariable consequence, segmentation. Possibly, we may hereafter find that the first changes induced by contact of the impregnating body are completed by its diffluence, and by the material constituents into which it is dissolved, being transferred to the yelk by endosmosis.

\section{Description of the Plate.}

\section{PLATE XIV.}

Fig. 1. The female Frog, Rana temporaria, dissected to show the situation of the entrance to the oviducts $(a)$ at each side of the heart $(b)$. The liver $(c)$ is drawn back and removed a little from its natural position to show the spaces $(d)$ along which the ova pass from the cavity of the abdomen to the mouths of the oviducts $(g)$, to be received into the dilated or uterine portion of the ducts $(h)$. (i.) The stomach. ( $\left(k_{\text {. }}\right)$ Intestine. $\left(l_{.}\right)$Colon and rectum. $(m$.$) The bladder.$

Fig. 2. A portion of the commencement of the oviduct magnified, partially concealed by the root of the lung.

$a$. The entrance to the duct between the heart and liver. (e.) The suspensory ligament of the liver. $(f$.) The base of the lung around which the oviduct $(g)$ passes.

Fig. 3. The female Frog, exhibiting the viscera in situ before the ova have left the ovaries $(p)$ and with the oviducts $(g)$ enlarged with secretion, for the for- 
mation of the envelopes of the ova as they pass through to the uterine or dilated portions of the ducts $(h)$.

Fig. 4. The female Frog after oviposition, with the organs of digestion and the liver removed to show the condition of the ovaries $(p)$ with their fatty appendages $(q)$, the hyoid and thyroid muscles $(n)(o)(p)$, the lungs $(f)$ and the contracted state of the oviducts $(g)$, and their uterine enlargement $(h)$ with the rectum $(l)$, and the bladder $(m)$ then beginning again to be enlarged.

Fig. 5. Structure of the ovarian ovum.

$a$. The ovum while still attached to the inner surface of the ovary and projecting into the cavity, exhibiting the dark surface within the ovisac, which is traversed by minute vessels $(b)$.

Fig. 6. Vertical section of the ovum, showing the situation of the germinal vesicle and the canal in the yelk, which corresponds to the centre of the dark surface of the yelk.

Fig. 7. The presumed mode of disappearance of the vesicle.

Fig. 8. Spermatozoa of the Frog. $a$ and $b$ escaping from the vesicle of development, $c$, as seen on the egg after contact.

Fig. 9. An ovurn with spermatozoa half an hour after impregnation.

Fig. 10. A small portion of surface of the yelk at the commencement of segmentation, highly magnified. (a.) Yelk-cells at the same period. (b.) The smallel' cells of the last, more highly magnified.

Figs. 11 and 12. Examples of partial impregnation at twenty-eight hours after contact with the spermatozoa. 


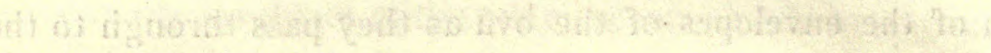

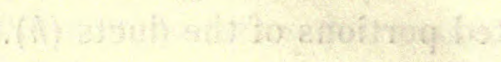

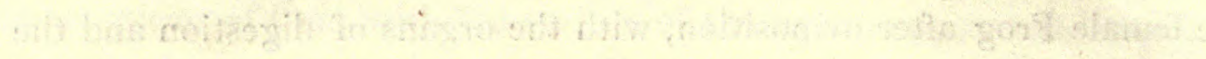

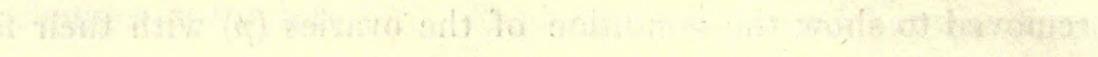



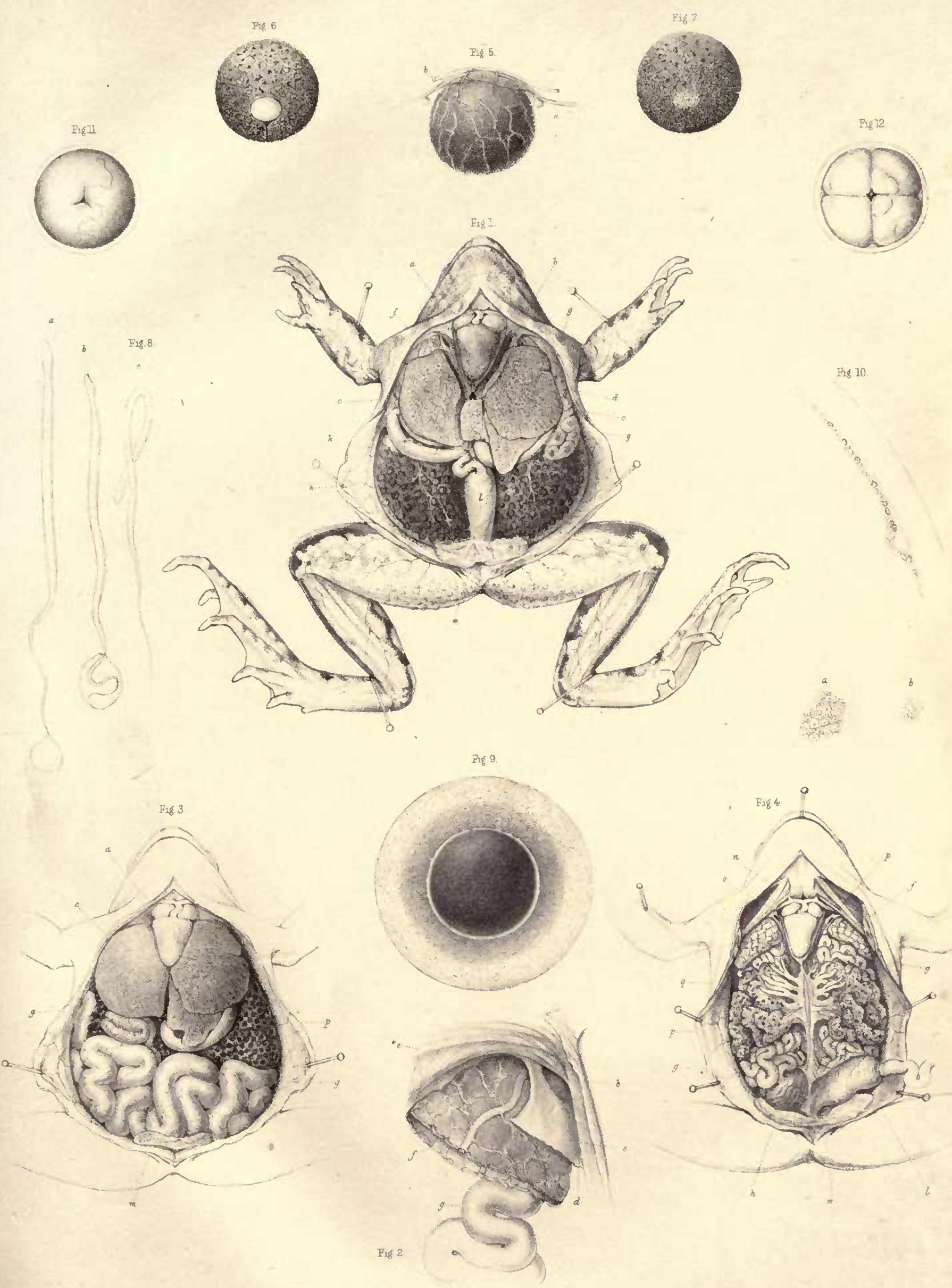

X. On the Intpregnation of the Ovum in the Amphibia. (Second Series, Revised.) And on the Direct Agency of the Spermatozoon. By George Newport, F.R.S., F.L.S. \& c.

Received May 10,-Read June 17, 1852.

HAVING shown in a former series of investigations, which has been honoured by a place in the Philosophical Transactions for 1851, that the sole agent of impregnation of the ovum, in all cases of communion of the sexes, is the spermatozoon,and having then supplied both direct and negative evidence that impregnation is not effected by the liquor seminis, - I endeavoured, in a subsequent communication to the Royal Society, in June 1851*, to arrive at some .knowledge of the manner in which impregnation is effected, and of the nature of the impregnating influence.

Up to that period, and indeed, until very recently, I had never been able to detect any evidence of the existence of spermatozoa within the envelopes of the fecundated egg, but had constantly found them in great abundance; and easily recognized, in contact with the exterior surface. Experiment also, made by immersion of the egg in coloured fluids, showed that the substance of the envelopes, although permeable by fluids, is uniform in its structure; but no evidence was afforded by it of any natural canal, fissure, or perforation through the envelopes of the egg of the Frog, capable of admitting the spermatozoon to the interior, as has been supposed to exist in the egg of the Mammalia $\uparrow$.

Hence the conclusion which seemed to be fairly led to, was, that some influence was transmitted from the spermatozoon on the surface of the envelopes, through their substance, to the yelk which they inclose,--as the commencement of impregnation. But it was especially pointed out in my First Series the spermatozoon does not appear to be sufficient to determine the transmission of more or less of the material structural characters of the male parent to the offspring ;" and that, "possibly, we may hereafter find that the first changes induced by contact of the impregnating body are completed by its diffluence, and by the material constituents into which it is dissolved, being transferred to the yelk by endosmosis ;" Further, in my second communication, I remarked,- " I am not yet prepared to assent to the view, that simple contact alone, even of the spermatozoon, is sufficient to complete the changes which result in the formation of the embryoß." Again, in

* Proceedings of Royal Society, vol. vi. p. 82.

+ Philosophical Transactions, 1840, p. 533, Plate XXII. figs. 165, 167.

$\ddagger$ Philosophical Transactions, 1851,1 . 242 .

$\$$ See "Impregnation of the Ovum (Second Series)," June 19th, 1851, MS. No. 762, p. 49, in the Archives of the Royal Society. 
a subsequent part of the same communication, these considerations are further referred to, as being those alone on which the transinission of structural peculiarities seemed likely to be explained*.

Recent observation has now supplied to me a fact which renders these considerations, which heretofore were regarded as hypothetical, much more probable; but, at the same time, it necessitates a revision of the view that an impregnating influence is transmitted from the surface to the interior of the egg; and also some correction of the deductions from experiment by which this view seemed to be supported.

The fact referred to, is, that the spermatozoon of the Frog penetrates bodily into the substance of the thick envelopes of the egg, and comes into direct communication with, at least, the membrane which incloses the yelk in the interior.

It is my duty, therefore, to Science, and to the Royal Society, knowing this to be the case, to revise and to extend my views, and to submit them again to the Society in their amended form; making, in self-correction, the certainty of fact now take the place of negative observation.

In doing this, I shall endeavour to show, that, although still regarding the spermatozoon, for reasons to be adduced, as the organ of a special condition of force, or vitality in the male body,-its influence on the egg in fecundation is direct and immediate, and not operative, as heretofore supposed, merely through the envelopes; but, nevertheless, as I have before shown, that it is exerted only so long as the spermatozoon continues to give evidence of its vitality or force in its power of motion.

Before proceeding to show that the spermatozoon penetrates into the envelopes of the egg it is necessary that I should point out some of the conditions which affect the fulfilment of its fecundatory function, both in regard to the spermatozoon itself and to the ovum. These are, on the one hand, the persistence of vital power in the spermatozoon as influenced by the temperature of the surrounding medium; and on the other, the endosmic property of the gelatinous coverings of the egg, and the susceptibility of the yelk which they inclose, to become impregnated.

\section{THE VITALITY OF THE SPERMATOZOON AND OVUM COMPARED.}

1. Of the Spermatozoon.-It has been elsewhere shown $\uparrow$ that when the mature spermatic fluid of the Frog los been more than four hours removed from the living body, and mixed with water, at a temperature of $50^{\circ}$ FAHr. or but a few degrees higher, it usually has already ceased to have any power to fecundate the egg; and its efficiency has been found to have been diminished in proportion to the length of time it has been obtained and so mixed. Nearly the whole of the observations I have since made have coincided with these results. Yet there have been two marked instances in which fecundation was effected by fluid, which had been obtained, and

* Loc. cit. p. 56 .

+ Philosophical Transactions, 1851, p. 213. 
mixed with a small quantity of water, twenty four hours before it was employed. In the first case, the fluid was obtained when the temperature of the atmosphere was $51^{\circ}$ FAHr., and afterwards sunk to $49^{\circ} \mathrm{F}_{\mathrm{AHR}}$., but had again risen to $51^{\circ} \mathrm{F}_{\mathrm{AH}}$. at the time of the experiment. When examined with the microscope, immediately before it was used, the fluid still contained a quantity of very active vibratile spermatozoa, and also an abundance of spermatozoal cells, still in course of development. This fact seemed to afford an explanation of the cause of the efficiency of the fluid for so great a length of time, spermatozoa being liberated from the cells during the whole period. Thus the fact of the prolonged fecundity of this fluid seems to confirm, instead of oppose the conclusion arrived at,-that, the inore mature the fluid is before its removal from the body, the more efficacious it is, but only for a given extent of time, since it is then composed almost entirely of very active spermatozoa, with but very few cells of development. Spallanzani, as formerly mentioned*, found that the fluid of the fotid terrestrial Toad (Bufo calamita?) at a high temperature of the season, $70^{\circ} \mathrm{F}_{\mathrm{AHR}}$. to $73^{\circ} \mathrm{FAHR}$, at which this species spawns in Italy, had lost its fecundatory influence at the end of six hours $\gamma$; but that in the temperature of an ice-house, $40^{\circ}$ FAHR. it retained its efficacy for twenty-five hours*. Further, that when the fluid was preserved in the testes of the dead animal, at the temperature of the season mentioned, it became effete in nine or ten hours; but that it continued to be efficacious, when retained in those organs in the temperature of an ice-house for thirtyfour hours. Again, he found that the fluid of the green aquatic Frog (Rana esculenta), when mixed with a large quantity of water, and placed in an ice-house, the temperature of which he gives at $3 \frac{1}{2}$ REAUM. $\left(39 \cdot 87^{\circ}\right.$ FAHR.) retained its fecundatory property for thirty-five hours $\S$. But it must be borne in mind, with regard to these observations, that the species of Toad (Bufo), pair later in the season, and at a higher temperature than those of the Frog; and also that the fluid employed by Spallanzani in all his experiments, was obtained by vivisection, either from the testes or the vesicles; and no doubt contained, as in my experiment just mentioned, many undeveloped cells; and, consequently, not being fully matured, retained its influence longer than it would have done, under the same circumstances, in its perfect condition.

But Prevost and Dumas\|, in some experiments made to ascertain the length of time during which the fluid of the species they experimented on,-the Rana esculenta, -retains its fecundatory property, observed that it was efficient at twenty-four hours, although removed from the body and preserved during that time, in a temperature that varied from 18 to 22 cents., or from $64^{\prime}$ to $71^{\circ}$ FAHr. 9 This result, differing so much, in regard to temperature, from the results formerly arrived at by SpalLanzani, in regard to the Frog, and from the majority of those since obtained by myself, rray, I think, in great part be accounted for in the fact that, like the Toads, the Rana

* Loc. cit. p. $212 . \quad+$ Dissertations, \&c., vol. ii. p. 169.

It Annales des Sc. Naturelles, tom. ii. 1824.

MDCCCLIII. $\ddagger$ Loc. cit. p. 169.

I Loc. cit. p. 140.
\$ Loc. cit.p. 194. 
esculenta spawns at a higher temperature, and later in the season than the R. temporaria, the subject of my observations, and that the fluid employed by Prevost and Dumas, was always obtainèd, as they state, by vivisection, and was expressed from the testes, and necessarily must have been in great part immature, and contained many spermatozoal cells, from which the fecundatory agents were liberated at different periods during the observations, and thus appeared to show that the fluid continues to be efficacious, at a high temperature of the atmosphere, for a much longer period than is really the case. In my own experiments the fluid employed being obtained, without vivisection, by simple compression of the body fron the seminal ducts and vesicles, has usually contained only perfectly mature and very active spermatozoa, with but few cells of development. In this condition, as I have stated, it has retained its fecundatory property only during the first three or four hours. Yet, in the exception above mentioned, and also in the second one alluded to, which occurred more recently, the fluid was efficacious at the end of twenty-four hours in the first, and twenty-six hours in the second instance, the temperature being similar on the two occasions. In both instances the fluid contained a very large quantity of developmental cells, and had been procured from individuals which were not fully prepared for the exercise of their fecundatory function. Further, I may add, that in each of these instances, after the fluid had been supplied to some eggs to test its effect, I found many undeveloped spermatozoal cells adhering to the surface of the eggs, and detected soine spermatic bodies in the act of being liberated from them. 'These facts, then, are confirmatory of the suggestion respecting the results obtained by Prevost and Dumas.

The presence of undeveloped cells in the fluid obtained from the living Frog is explicable in two or three ways: first, in that of the animal having but recently been taken from its natural haunts, either early in the season, or at a later period, after a continuance of unusually cold weather and easterly wind, or after the sexes have but recently united; in either of which cases, as also in certain others, in which the individual itself has been late in the development of its reproductive organism, developmental cells are thrown off from the testes together with already liberated spermatozoa, and are usually abundant in the efferential ducts and vesicles. It may thus be seen that in judging of the length of time during which the fluid preserves its fecundatory influence, and consequently, the spermatozoon its vitality, after removal from the body, it is necessary to take into consideration, not only the temperature of the surrounding medium, but,also the precise condition of the fluid itself. In perfectly natural impregnation by the Frog there is reason to believe that the fluid contains but very few undeveloped cells, and that it is not employed until it has acquired its full maturity, and that,- as the time of its actual employment is exceedingly brief,-the oviposition of Rana temporaria occupying scarcely a single minute, the retention of the impregnating influence and vital force of the spermatozoon may be even for a much shorter space of time than I have mentioned-from three to four 
hours. But this time may differ in different species of the Anoura, and of the higher vertebrata, and may have some relation to the particular economy of each animal.

The general conclusion which seems to be deducible from a comparison of the observations of Spaldanzanl and of Prevost and Dusias, with those by myself, in regard to the tail-less Amphibia, is, that-making allowance for the difference of species and habit of the animals experimented on, and for the degree of maturity of the fluid, which there seems reason to think does not attain its perfect condition until it has passed into the efferential ducts and vesicles-the vitality of the spermatozoon, and the duration of its fecundatory power, are in a ratio inverse to that of an increase of temperature in the surrounding medium.

\section{EVOLUTION OF VITALITY IN THE SPERMATOZOON AND OVUM.}

Wagner and LeUCKardT have already pointed out* that the power of motion possessed by the spermatozoon is closely connected with the completion of its structure and composition, and is gradually evolved as the development of this body proceeds. This power of motion I shall presently endeavour to show I regard as the visible exponent of its fecundatory force, or form of vitality, and that a similar power is cvolved concurrently with this in the spermatozoon in the contents of the egg, the evolution in both being more or less influenced by temperature, according to the species. These facts are well shown both in the Frog and Toad.

Several pairs of Frogs were collected on the 2nd of March, when the temperature of the season was low, and strong easterly winds prevailed, during which Frogs seldom spawn, except in very sheltered places. As one female had passed some eggs, and believing that the others were equally advanced, I selected a pair, which appeared to be the most mature, for experiment. The fluid from the male was obtained with the greatest ease, in full quantity of a white and somewhat opake. colour. When examined with the microscope it was found to consist in chief part of developmental cells, containing each its motionlèss inmature sperınatozoon. Besides these cells it also included many others less far advanced, and in which I was unable to distinguish this body. In addition to these there were some also from which the spermatozoa were in the act of being liberated, besides many very active spermatozoa already set free. These constituted nearly one third of the whole mass. It was evident from these circumstances that the fluid was immature, and not fitted for experiment. Five days afterwards, March $9 \mathrm{th}$, I again exaınined fluid from this male, which had been kept since the previous examination, in a separate vessel, so that there was no mistake in its identity. The mean temperature of the room during the interval was $42^{\circ}{ }^{\circ} \mathrm{F}_{\mathrm{AHR}}$, and the water in which the Frogs were preserved

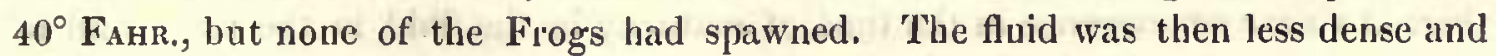
of a less white colour, and was composed almost entirely of very active and fully developed spermatozoa, with but very few cells from which these bodies had not

* Article "Semen" in Cyclopædia of Anatomy and Physiology, part xxxvi. (January, 1849) vol. iv. p. 504. 
been liberated. There were, however, some of which the contents appeared to be perfectly granular, and these I regarded as sper'matozoal cells in the earlier stage of development.

The female with which this inale had been paired was killed on the 4 th, at the time the experiments were to have been commenced. It was then found that the eggs, like the fluid from the male, were immature. The whole of the eggs had escaped from the ovaries into the cavity of the peritoneum among the viscera, and were crowded together in a mass on each side, at the anterior part of the abdomen, and were without any gelatinous covering. A few only had begun to enter the oviduct on the right side of the body, and acquire their envelopes. In most of these eggs the ges'minal vesicle had already disappeared.

The fluid and eggs of the common Toad (Bufo vulgaris) are developed in precisely the same way as in the Frog. On the 30th of March 1851, I examined the bodies of a male and female Toad for the purpose of experiment. The great efferential ducts and vesicles in the male were then entirely empty, no fluid having yet descended into them. But the testes contained a vast quantity of spermatozoal cells, some of which were distended by the spermatozoon, as if in the act of being liberated. But not a single spermatozoon was free, or showed any sign of motion. The whole were still immature, the caudal portion being as yet short and imperfect.

In the female the ovaries were distended with eggs and occupied the wlıole of the visceral cavity between the intestines. The eggs were of a sooty black colour, with but a slight trace of the grey surface, and appeared to be nearly mature, but had not yet left the ovary. The germinal vesicle of a large size, circular in its outline, and somewhat flattened, still existed in nearly the whole of them.

It is thus evident that the pairing of the sexes, both of Frogs and Toads, takes place before the semen is fully inatured, or the eggs have descended into the oviducts, and that there is a near concurrence in the time of maturity in both.

These facts seem to lead to the conclusion, that when, as in some of the fore-mentioned experiments, the male fluid contains a very large proportion of developmental cells, which occasion its white appearance, it is not fully matured for its function; that the first portions of fluid which descend into the efferential vessels are usually immature ; and that it is not absolutely necessary that the spermatozoa should be fully formed before the cells escape from the testes. It seems fair then to infer from these facts that the completion of the development of the spermatozoal bodies takes place in the deferential vessels, or in the vesicles, perhaps in both: further, that the quantity of fluid produced, when too great to be contained in the ducts, may become accumulated in the vesicles, to be furnished at the instant it is required; and that there is a near concurrence in the time of maturity in the fluid in the male, and of the eggs in the female, the former being only slightly in advance, in regard to time, of the latter, at the natural period of their encounter; a condition which perhaps may be necessary to the full and healthy fecundation of the whole brood. 


\section{OF THE OVUM.}

The vitality of the eggs of the Frog appears to be of longer duration than that of the fertilizing agent, the spermatozoon. The egg, as formerly shown*, leaves the ovary quickly after, or at the time when its germinal vesicle disappears; but, as experiment has proved, it is not then entirely fitted for its function. It has yet to be enveloped in a thick covering, which it gains in its transit through the oviduct, before it is susceptible of impregnation. Its condition when escaping from the ovary to the oviduct seems to be analogous to that of the spermatozoon when it leaves the testis to enter the efferential duct. Neither the one nor the other has yet attained its full maturity. When the eggs are collected in the dilated or uterine portions of the oviducts they seem to be in a condition parallel to that of the spermatozoa in the lower portion of the efferential ducts and vesicles. When nearly the whole of the eggs are collected in the uterine cavities their maturity is then almost completed; but a period of retention, even in these structures, seems to be necessary to ensure the fertilization of the whole, as some of them, - as I have found by the persistence of the germinal vesicle for a short time, even after the egg has escaped from the ovary into the cavity of the abdomen, as the undeveloped spermatozoal cell passes from the testis into the efferential duct,-are later in their development than others. Further, it may be remembered $\downarrow$, that so far from the contents of the yelk being in a dormant condition at the time of oviposition, as some inquirers have supposed + , there are changes still going on within it, and which are perceptible to the eye, in the condition of the white surface, for ten or twelve minutes after oviposition; after which they become less and less narked, and soon entirely cease if the egg be not fecundated.

Thus then from a comparison of the state of the fecundatory agent with the body to be fecundated, we might have expected to have found some close coincidence in the retention of their vitality, and this indeed, in a state of nature, seems to be the fact. Spawning seldom or never takes place by the act of the species until each sex has attained its full inaturity of function. The eggs are sometimes voluntarily retained by the female Frog, for several hours or days within the uteri, although arrived at maturity, if the proper evolution of spermatozoa in the male be not completed. I have had evidence of this in the fact, that when the union of the sexes has been of long continuance, the female has sometimes passed a very few ova, and then has continued without further oviposition for many hours, sometimes for a day or two, before the mass was expelled, and the function of the sexes consunmated. These first extruded eggs have almost always been found to be unimpregnated.

When the eggs have been deposited, the circumstances which affect their fecundation are precisely similar to those which affect the spermatozoa,-the temperature of the surrounding medium, and the length of time during which they remain im-

\footnotetext{
* Philosophical Transactions, 1851, p. 180. † Loc. cit. p. 185. ¥ Wagner and Leuckardt, loc. cit.
} 
mersed in water after expulsion from the body. The length of time during which they are susceptible of impregnation has relation to each of these conditions; and these have now acquired additional interest in the establishment of the fact that the spermatozoon penetrates into the envelopes of the eggs, and that, consequently, the rate of expansion of the envelopes has a further direct relation to its function.

The following experiments will illustrate the foregoing observations:-

It may here be remarked, that although, as in my former paper, the date of the experiment is recorded, it is so only for the convenience of reference, and not with any regard to priority of period at which the experiments were made; the details being given only in illustration of the general statements enunciated.

April 2, 1852. Atmosphere $55^{\circ} \mathrm{F}_{\mathrm{AHR}}$. The first three of the following experiments were made with the eggs and fluid from a pair of Frogs which had been obtained from their natural haunts only three bours before the female was killed, by dirision of the spinal cord, for the purpose of the experiments.

No. 1. Eighty-six eggs passed from the Frog at one hour and a half after death, were supplied with fluid from the male with which this female had been paired,-the fluid having been obtained and mixed with water one hour and a half before it was employed.

On the seventh day fifty-two embryos had been produced from these eggs, and some of them were then escaping from their envelopes.

No. 2. Thirty-seven eggs, obtained from the same female, were supplied with a portion of the same fluid as the above, after it had been mixed with water about two hours and three-quarters.

Twenty-eight embryos were produced from these eggs at the same time as the above.

No. 3. Sixty-eight eggs from the same Frog at six hours and three-quarters after death were inmersed in the same portion of mixed fluid and water in which the eggs of No. 2 had been fecundated. In this experiment the fluid had been six hours and three-quarters mixed with water.

At the end of three days the eggs still had a healthy appearance, but on the seventh day not one had given any evidence of having been impregnated, nor was any embryo ultimately produced. Thus the fluid had lost its fecundatory property, at a temperature of $55^{\circ}$ FAHR. between the end of the third and of the seventh hours.

As it was possible that the failure in this experiment was due as much to the eggs as to the fluid employed, it having already been shown that impregnation is sometimes effected with fluid which has been twenty-four hours removed from the body,the following experiments were then made :-

No. 4. Sixty-nine eggs obtained from the same female at one hour and twenty minutes after death were bathed with fluid procured from another male, and which had been mixed with water thirty hours previous. These eggs preserved their regularity of outline for nearly six hours, at the end of which time one egg showed traces of 
partial impregnation, while the yelks of the others were changing form and becoming irregular. But not a single embryo was produced.

No. 5. Eighty-one eggs were obtained from another Frog, a few minutes after it had been killed by division of the spinal cord, and a portion of fluid which had been mixed with water twenty-four hours and a half, and kept in a temperature which had sunk from $54^{\circ} \mathrm{F}_{A H R}$. to $51^{\circ} \mathrm{F}_{\mathrm{AHR}}$, , but at the time the fluid was employed had again risen to $55^{\circ} \mathrm{F}_{A H R}$. - was supplied to them.

This fluid on examination by the microscope was found to contain an abundance of spermatozoa, the whole of which were perfectly motionless, so that I was not able to detect even one which gave any sign of vitality. Yet the eggs in this experiment retained their natural healthy appearance for several hours; but not one was impregnated, nor was even a single embryo produced. On the contrary, after thirteen hours, the yelks of some of them assumed a pyriform shape, while those of others became shrivelled and withered.

No. 6. Thirty-six eggs were passed from a Frog, which had been killed about three-quarters of an hour, and some fluid which had been obtained and mixed with water forty-four hours before was shed over them, and pure water was then added.

The envelopes of these eggs became expanded as under perfectly healthy and favourable conditions; but within two hours of the contact of the eggs with the fluid the yelks of the whole became very irregular, shrivelled, and contracted, and assumed an appearance very similar to that which first results from the application of a strong solution of potass. Not one egg retained its spherical shape, but the whole entirely perished; and it may be needless to add, not an embryo was produced.

'These facts then support the statement alceady made, that only while the spermatozoon continues to give evidence of vitality in its power of motion does it exert any fecundatory influence on the egg. 'They seem, too, to show that the period during which this vital force is retained by the mature spermatozoon after it is passed from the body of the Frog is perhaps shorter even than what I have stated, and that the limit, in regard to time, depends much on physical influences. In addition to this, they seem to show that after all ocular evidence of power in the spermatozoon is lost, this body is inert, until decomposition has commenced, when its material constituents become injurious and destructive.

The following experiments have more direct reference to the vitality of the egg, and appear to indicate that this is much longer retained than that of the spermatozoon, and is less quickly affected by external causes.

April 2, 1851. Atmosphere 55 .

No. 1. Thirty-eight eggs were passed from a Frog killed twenty-four hours and " half before, and some fluid which had been obtained and mixed with water about one hour and a quarter was then added to them,

Segmentation commenced in some of these eggs in about four hours and a half; and on the seventh day eight embryos had been produced. 
No. 2. Seventy-three eggs were taken from a Frog which had been killed about thirty hours, and were bathed with fluid which had been one hour and twenty minutes mixed with water.

At the end of six hours several of these eggs lad become irregular, but one had certainly been fecundated, as one embryo afterwards came to maturity.

No. 3. One hundred and sixty eggs from the Frog which supplied those employed in the experiment No. 2, were bathed with fluid from another male, immediately after it had been obtained, but not a single egg was inpregnated.

No. 4. Thirty-seven eggs were passed from a Flog which had been killed forty-four hours before, the temperature of the atmosphere during this period having risen fron $50^{\circ} \mathrm{FAHr}$, to $55^{\circ} \mathrm{FAHr}$. These eggs were bathed with fluid which had been obtained about three quarters of an hour. At the end of six hours I found, to my surprise, that one egg had become segmented, but that the yelks of the others were flattened, shrivelled, and irregular, as if they had been affected by the solution of potass, or by decomposing seminal fluid. On the seventh day the egg which had been segmented had produced an embryo.

From these results, then, it appears that while the spermatozoon at a mean temperature of the atmospbere of $55^{\circ}$. FAHr. usually loses its vitality, and is inert in less than four hours, and but rarely is efficient at a longer period after inmersion in water, the egg retains its reproductive property for a very much longer time, especially if not removed from the body of the dead animal, only losing it at twenty-four hours after the death of the parent, and occasionally retaining it for forty hours.

'The experiment No. 4, in which the latter fact is shown, is interesting, from the circunstance that the same results are produced by the living vibratile spermatozoon on the yelks of the dead eggs, as the majority of these were, as that which is occasioned by the application of dead and decomposing spermatozoa to the envelopes of the living one, as shown in No. 6 of the preceding set; and further, that these results so closely resemble in appearance the first effects produced on the yelks of living eggs by the application of strong solution of potass; thereby showing not only that powerful endosinic action takes place rapidly through the coverings of the egg, but also that the influence of the spermatozoon on the yelk, whatever may be its precise nature, is direct and immediate.

\section{ENDOSMOSIS OF THE EGG IN RELATION TO ITS VITALITY.}

It has before been shown that the endosmic action of the envelopes of the egg, on immersion in water, is closely connected with the act of fecundation; and we have now further proof of this in the fact that the vitality of the egg inay be preserved for many hours if the envelopes be not brought into contact with water ; so that the insusceptibility of the egg to become impregnated, after a lengthened period of imnersion, is due to a diminution of the expansive property of the tissue of the 
envelopes, and the distension of the tissue with fluid, rather than to the loss of vitality in the contents of the yelk.

This view has led me to endeavour to ascertain more precisely than heretofore,first, at what length of time, after immersion in water, the egg usually becomes insusceptible of impregnation; and next, to what extent the act of fecundation is accelerated by a given increase of temperature, when the experiments are made with portions of fuid from the same male, and with eggs from the same female, at, as nearly as possible, the same time, all the conditions being similar except in regard to the temperature of the surrounding medinm.

With this object, I have recently made two sets of observations consisting each of nine experiments. One set was conducted in a room, the temperature of which was

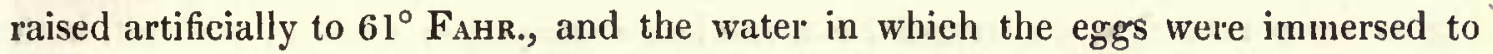
$60^{\circ}$ FAHR.; while the other was carried on in an adjoining room where the temperature was only $55^{\circ} \mathrm{F}_{\mathrm{AHR}}$., and the water einployed $53^{\circ} \mathrm{F}_{\mathrm{AHR}}$. In order to place the whole of the experiments under as similar conditions as possible, it was necessary that the corresponding experiments in each set should not only be made at about the same time, but should also be supplied with fluid in exactly the same state, and the eggs be immersed in like quantities of water, for the time specified in each experiment, before the addition of the fluid. When the time of immersion had elapsed the water was quickly withdrawn, and the fluid poured over the eggs, and fresh water was immediately supplied to them. As much time was unavoidably occupied in passing the eggs into their respective vessels, and noting the period of immersion, it became necessary to commence the experiments with those which had been longest in water, in order that the fluid supplied to the whole should be as nearly as possible in the same condition, in each experiment, at the moment of its application, and be furnished to the eggs in similar quantities. To ensure this, the fluid was mixed, as soon as it was obtained, with fifteen times its quantity of water, and was employed at about thirty-five minutes afterwards. The quantity of this mixed fluid poured over the eggs of each experiment was ten minims by measure, excepting only to the first and second experiments of each set, to which twenty minims were added; but even with this advantage, as was seen, with no more favourable change in the result. After the end of the first hour, the eggs which had remained in the lower temperature were removed to the higher, and the two sets of experiments were then placed side by side to wateh the time of commencement of segmentation, as indicatory of the more or less accelerated impregnation. The number of embryos subsequently produced showed the ratio in which the eggs had been fecundated after different periods of immersion*. Each set consisted of nine separate experiments, the time of immersion of the eggs being forty-five, thirty-five, twenty-five, fifteen, ten, seven, five, three, and one or two minntes in each.

At the highest temperature, $61^{\circ} \mathrm{FAHR}_{\mathrm{AH}}$ atmosphere, and $60^{\circ} \mathrm{FAHR}$. water, a tem* For the details of the experiments, see MS. paper in the Archives of the Society. 
perature which is always most favourable to fecundation, there were no signs that any change had even been commenced in those eggs which had been immersed for a longer period than thirty-five minutes. But it must be borne in mind that the fluid employed had been thirty-five minutes mixed with water, and consequently had begun to lose some of its efficacy. The results of the corresponding experiments at the lower temperature-Atmosphere $55^{\circ}$, Water $53^{\circ}$-were similar, but less marked.

On comparing the two sets of investigations, it was found that no evidence of fecundation occurred in either of them, when the eggs had been immersed during forty-five minutes before the impregnating fluid was supplied to them; and that only the very earliest symptoms of any influence having been communicated to the eggrs, after thirty-five minutes' immersion, occurred in those which were submitted to the higher temperature, in the irregular contraction of the yelks; while in each set, both in the higher and lower temperature, some of the eggs, after twenty-five minutes' immersion, showed unequivocal signs of partial fecundation in the formation of the respiratory chamber, the result of the contraction and depression of the upper portion of the yelk previous to segmentation. But in both sets there were some eggs which, after fifteen minutes' immersion, had become fecundated, and produced embryos. The relative number of embryos produced after iminersion for this and shorter spaces of time was certainly greatest in the higher temperature; since, when the total number of eggs employed in the last six experiments in each of the two sets, in which only any embryos were produced, were compared with the number of embryos, it was found that in the higher teuperature there were seventy-eight embryos from five bundred and thirty-six eggs; while in the lower temperature, from six hundred and two eggs, there were only seventy-six embryos.

The period at which segmentation occurred in the fecundated eggs of the two sets corresponded also with the above results. In most of the eggs fecundated in the higher temperature segmentation commenced about ten minutes earlier than in those which had been fecundated, and remained during the first hour in the lower temperature.

These results seem to show, that while the eggs are more rapidly affected, they are also more certainly impregnated, and the embryos produced in greater numbers at a higher than at a lower temperature. But it must be borne in mind that the number of eggs fecundated in these experiments can only be regarded as comparative, and as mere approximations to what takes place in a state of nature, the experiments having been made with fluid which had been removed from the body, and considerably diluted with water, more than half an hour before it was employed, and consequently when its efficacy had been considerably diminished.

These facts, then, go to confirm the previous conclusions, that the organic force or vitality of the spermatozoon is of shorter duration than that of the egg; since, if the results of these experiments be compared with those obtained from former ones, it will be seen that the insusceptibility of the egg depends very much more on the endosmic action of its envelopes after immersion in water, than on any loss of vitality : 
further, that the non-fecundation of the egg may depend much more on diminished vitality and inefficiency of the spermatozoon, than on the insusceptibility of the egg itself.

\section{QUANTITY OF SPERMATOZOA ESSENTIAL TO FECUNDATION.}

On a former occasion* I endeavoured to arrive at some conclusion as to the minimum quantity of spernatozoa necessary to effect impregnation, and to draw some comparison between the results obtained by nnself and certain of the more remarkable ones by Spallanzani $\uparrow$. It then seemed to me, that although the general results obtained were in accordance with Spallanzani's, yet that a larger proportion of fluid, and consequently a greater quantity of spermatozoa, was required than was supposed by him. I have, therefore, made further investigation on this subject, and have sought to obtain some knowledge of the quantity really necessary to fecundate the egg. Prevost and Dumas formerly made a similar ittempt*, and M. Quatrefages has recently done the same $\$$. The results of the observations by Prevost and Dumas, QUATREFaGes, and myself, although differing greatly in detail, coincide with the general results obtained by SPALLANZANI, - that only an exceedingly small quantity of seminal influence, and consequently only a very limited number of vibratile spermatozoa is necessary to effect impregnation. They agree, too, in the fact that the number of eggs impregnated is always inuch fewer than that of the spermatozoa supplied to them; and, consequently, that there is reason to think that fecundation is not the result of a single, isolated spermatozoon, although it has not been ascertained what is the number actually required. The course $I$ have pursued in putting this curious question to the test, has been different from that of either of the distinguished naturalists mentioned. It has not been that of diluting the impregnating fluid in a very large quantity of water, and then applying a minute drop of the water to the Frog's egg, as done by Spallanzani ; - nor has it been that of reckoning the number of spermatozoa on a given surface of a micrometer plate, and then immersing the plate in water with a quantity of eggs, and afterwards observing how many of them became fecundated,- - the course followed by Prevost and Dumas; - nor has it been by estimating the number of spermatozoa in a given bulk of fluid, and then ascertaining the number of eggs fecundated by them, as done by Quatrefages with those of the Hermella and Teredo; but it has been by direct application of the spermatozoa on the point of a pin to the surface of a single egg in a glass cell; and then observing beneath the microscope the number of spermatozoa deposited from the point of the pin, applied in a similar way as to the egg, on a plate of glass. Yet only approximative results can be arrived at by this, or by the other modes of proceeding, although it is satisfactory to find that the general results obtained in this way are in agreement with those obtained by the observers mentioned; and further, that the mode adopted has led to some additional results, which seem to be of value.

- Philosophical Transactions, 185I, p. 206.

‡ Annales des Sc. Naturelles, tom. ii. 1824.
† Dissertations, \&c., vol. ii. p. 189.

$\$$ Annales des Sc. Nat. $3^{\text {me }}$ série, tom. xiii. p. 129.

2 к 2 


\section{TESTS OF FECUNDATION.}

I have given some account in my former paper* of a space, or chamber, which is developed between the vitellary envelope of the egg and the upper surface of the yelk, within the first hour and a half, subsequent to the encounter of the spermatozoon with the egg; and I have referred to it in the details of these experiments, as occurring in sorne of the eggs which had been immersed during twenty-five minutes before the fecundatory agent was supplied to them, and as marking their having been affected by its influence. The formation of this chamber is one of the earliest and nost certain indications that the egg has been more or less impregnated. The earliest symptom of impregnation occurs somewhat sooner than the formation of the chamber, or within the first half-hour, and consists in a marked increase in the degree of undulatory heaving and sinking of portions of the surface of the yelk, motions which take place slightly in the unimpregnated egg, but are increased in the impregnated; although, even in that, they are not sufficiently permanent to be easily recognized as proofs of fecundation. The irregular contraction and shrivelled appearance of the yelks, noticed in the preceding observations, may, perbaps, be due in part to this cause. The formation of the chamber is the result of the contraction and depression of the upper surface of the yelk, occasioned, as there is reason to think, by changes which are going on within the substance of the upper hemisphere of the yelk, around the embryo vesicle, or its progeny, and which changes appear to be due to the operation of the speruatozoon; as $I$ have never observed the chamber in any egg which has not been inore or less fecundated. 'The fact of the existence of a chamber, therefore, Iray always be regarded as a proof of fecundation. It is commenced sooner or later according to the temperature of the surrounding medium, and to the more or less complete fecundation of the egg. It is usually perceptible in about one hour, or one hour and a quarter after the impregnating fluid has been supplied to the egg, and is distinctly marked in less than one hour and a half, when the eggs are preserved in a temperature of from $50^{\circ}$ to $55^{\circ} \mathrm{F}_{\mathrm{AHR}}$, and its size is increased during the first three hours. It is commenced in a slight depression in the centre of the upper surface of the yelk, at a point which corresponds to the entrance to the central canal, and it takes place much sooner in eggs which have been completely fecundated, even at moderate temperatures, than in others which have been more sparingly affected. I have seen it begun in a fully impregnated egg, in a temperature of $52^{\circ} \mathrm{F}_{\mathrm{AHR}}$, at fiftythree minutes after encounter with very mature spermatozoa. When it has attained its greatest superficial extent it appears like a clear watch-glass cavity, filled with a perfectly transparent, limpid fluid above the dark upper surface of the egg. After the third hour it becomes slightly further enlarged in its axis from above downwards by the formation of a shallow, funnel-shaped depression on the surface of the yelk, the centre of which is the minute orifice seen by Prevost and Dumas, and Baer, and this is continuous with the canal above alluded to. I have never found this chamber

\footnotetext{
* Philosophical Transactions, 1851, p. 187.
} 
absent from any egg which has produced an embryo. Its formation is preliminary to the subsequent cleavage of the yelk. It thus affords, within a very.short space of time, a certain test of fecundation, and as such is exceedingly valuable in all experiments by artificial impregnation.

\section{PARTIAL, OR INCOMPLETE FECUNDATION.}

But although the formation of the chamber gives certain proof that the egg has been influenced by the spermatozoon, it is only the actual seginentation of the yelk, carried through the first four stages, which shows that its fecundation has been completed; since the egg may be only partially influenced, and consequently may not produce an embryo, although the respiratory chamber may be formed, and the early stages of segmentation of the yelk be commenced. When this is the case the change seldom proceeds beyond the second or third stage of cleavage, and even then there is usually some irregularity in its occurrence. Sometimes only the chamber itself is developed, and the process then stops; at other times the chamber is completed and a little white spherical body makes its appearance, and is but just perceptible within the entrance to the central canal; but more frequently a white spherical body, not more than one-fourth the size of the original germinal vesicle, appears on the surface of the yelk within the chamber; at other times there are two of these white bodies, each of which is scarcely more than one-half the size of the single one, and sometimes the bodies are of a dark or grey colour. In other cases the yelk begins to be divided in the margins of the canal, but does not proceed with its change; or it may go on, as just stated, to the several stages. In other cases the yelk divides very unequally. These instances of partial impregnation or fecundation may occasionally be produced by application of exceedingly minute quantities of seminal influence, as some of the following experiments will show.

\section{DEFICIENCY OF FECUNDATORY INFLUENCE.}

(a.) Pin-point application of the fluid.-These experiments were commenced in the season of last year (1851), but have been repeated at different periods during the season of the present year.

March 30, 1851. Atmosphere $56^{\circ}$ FAHR. -A single egg was passed into each of four glass cells, with a small quantity of water, sufficient only to preserve the eggs moist and promote the expansion of their envelopes. Within two minutes afterwards two of the eggs were each touched once with the point of a common-sized pin, which had been so lightly dipped, into a mixture of one part of fecundatory fluid, obtained about one hour and five minutes before, and four parts of water,-as to cover a portion of its surface equal to about one thirtieth of an inch in extent. The two remaining eggs were touched, the first once only, and the second twice, with the point of a pin slightly curved, and which thus was made to retain a much greater number of spermatozoa in the fluid which adbered to it than the pin with the straight point. 


\section{MR. NEWPORT ON THE IMPREGNATION OF THE OVUM IN THE AMPHIBIA}

Each cell was then filled with water, so that the egg which it contained was completely immersed. Within the second minute after the eggs had been touched with the loaded pin, there arose from each, at the point of contact, a microscopic bubble of air, the egg which had been twice touched having two bubbles. These were found by subsequent observations to be due to the circumstance of the eggs having been exposed to the air, for a short time before they were touched, and their surface become slightly dried, so that when the fluid was applied to it a small bubble of air became involved and imprisoned in it, before the eggs were immersed in water. This circumstance and its explanation are mentioned simply to show that the occurrence had no relation to the act of fecundation, as at first I had supposed was probable.

I endeavoured to obtain some idea of the number of spermatozoa deposited from the pin point, during its momentary contact with the egg, in these experiments. But the result seemed to give but little hope that either of the experiments would be successful, or that any fecundation could be effected by the application of so minute a quantity of influence, as it was found that the number of spermatozoa deposited on a plate of glass, beneath the microscope, when the pin point was applied to the glass in the same way as to the egg, did not exceed from six to ten or twelve of these bodies. Yet the results of the experiments were watched. Within the first half-hour the eggs were removed from the temperature of $56^{\circ} \mathrm{F}_{\mathrm{AHR}}$. to one of $65^{\circ} \mathrm{F}_{\mathrm{AHR}}$. But at the end of ten hours it was found that only in one instance had any fecundation been effected. The grey central spot on the dark surface of the yelk was still present in three of the eggs, and no respiratory chamber had been formed in either of them. But partial fecundation had been effected in the fourth egg, which had been twice touched with the loaded pin point. In this instance the dark surface of the yelk was depressed, and the respiratory chamber had been formed between it and the envelope, and two spherical opake white bodies appeared within it, lying side by side on the middle of the surface of the yelk; but no segmentation of this had taken place, or even had been commenced.

One cause of failure, in these first experiments, appears to have been the diminished efficacy of the fluid, which had been obtained and mixed more than one hour before; as it will presently be seen that even a less proportion of the fluid sometimes is effectual when employed inmediately it is procured.

As it was late in the season of last year when these experiments with minimum quantities were commenced, the spawning of the frogs being then nearly at an end, I was fortunate in procuring, on the second of April, a single unspawned pair of frogs from their natural haunts, and thus was enabled to repeat the experiments with the fewest disadvantages. This was done within four hours after the frogs were captured. The fluid in this instance was very mature, was obtained in good abundance, and was mixed with an equal quantity of water, and employed in the experiments a few minutes afterwards. 
April 2, 1851. Atmosphere 55 ${ }^{\circ}$.-Ten eggs were passed into a large glass cell, and each egg was touched once only witl the pin point dipped lightly into the fluid for each egg. This experiment was perfectly successful, as the chamber was formed above the yelk in four or five of these eggs, and at the end of five days three of them had produced embryos. In these instances the pin had been allowed to remain in contact with the egg, and the fluid to drain off it for one or two seconds.

Six eggs were also placed in another cell and each was touched with the loaded pin point when the fluid employed had been obtained about a quarter of an hour. Two of these eggs became partially fecundated, as shown in the formation of the respiratory chamber. In each of these the yelk became slightly elongated, a symptom which always precedes the first cleavage; yet they did not undergo further alteration, but with the remaining four were abortive.

Twenty-three eggs were included in a large cell as a further experiment, and each egg was touched once with the pin-point loaded each tiıne, when the fluid employed had been one hour and three quarters mixed with water. Four of these also had the chamber formed, and segmentation commenced in them, at the end of four hours and a half; but the majority were only partially fecundated, as only one of the twenty-three eggs produced an embryo. The fact of this production, however, shows, that an exceedingly small amount of influence, even at a long period after the fecundatory fluid has been removed from the body in which it is generated, is sometimes sufficient to occasion the development of an animated being; and that although a plurality of spermatozoa, supplied to the egg, appears always to be necessary to ensure fecundation, yet that the resnlt seems to depend less upon the abolute given number, or numerical relation of these bodies, to the egg, than on the measure of vitality possessed by those which are brought into actual encounter with it, as a very small number appears to be more efficient when employed immediately after their removal from the body, than a much larger number after a prolonged interval.

(b.) Pin-head application of fluid.-'The preceding experiments having been made with the smallest quantity of fluid, and consequently with the fewest spermatozoa that could be applied directly to the egg, it was desirable to increase the number of these bodies without applying them in excess, and for this purpose the head of a very small pin, the smallest size used by insect-collectors, was employed, instead of the point of a larger sized pin. An endeavour was also made, as in the previous trials, to ascertain the number of spermatozoa which the head of this sized pin, dipped lightly into fluid, was likely to be the means of conveying to the egg. It was then found that the loaded pin-head deposited on a plate of glass, in the minute quantity of fluid which adhered to it, from at least fifty to one bundred and fifty spermatozoa; a number which was not only fully sufficient to fecundate each egg to which the pinhead was applied, but also other eggs which might happen to come into contact with these in the same cell and water in which the experiment was made.

Six eggs, placed in a single cell, were each touched once only with the pin-head, 
which had been dipped into fluid only once for the whole, the time occupied in touching them being about five seconds. Each of these eggs became fertilized, and segmentation commenced in two of them in exactly five hours, and in the remaining four in from three to foul minutes later. The period at which segnientation commenced having been very carefully watched, and the whole of the eggs having been submitted, during the interval, to the same physical conditions of heat, light, quantity of water and degree of aëration, the result, in regard to the difference of time at which they began to change, seemed to be accounted for only on the assumption that it was due to a greater quantity of influence applied to the first two than to the others; and this opinion has since been more fully borne out by other experiments. The fluid at the time it was employed had been thirty-five minutes mixed with water. On the fifth day each of these eggs was producing an embryo.

Three eggs were placed in separate cells, and each egg was touched once with the pin-head loaded only once for the three, the fluid employed having been twenty-three minutes mixed with water. After four hours and forty minutes two of these eggs were undergoing segmentation, and on the fifth day both were producing embryos. The third egg was not impregnated.

Twenty-two eggs, in a large cell, were each touched once with the pin-head loaded for each egg when the fluid had been one hour and forty-seven minutes mixed with water. Some of the eggs in this experiment were touched on the white surface, others on the dark, and others at the side, or about midway between the white and dark surfaces.

In the same cell with these eggs, but at a little distance from them, were placed eighteen other eggs, which were not touched with the pin-head, but were simply allowed to remain in the same cells with the twenty-two eggs experimented on, and the cell was then filled with pure water. At the end of four hours and fifty minutes the chamber had been formed, and segmentation had commenced in each of the twenty-two eggs experimented on. But in addition to these there were also two of the eighteen $g$ which had not been experimented on undergoing seginentation. These, during the expansion of their envelopes, had come into contact with some of the fecundated eggs, and had also become fecundated by some of the spermatozoa which had been supplied to them. Five days afterwards the whole of these twentyfour eggs were producing embryos! so that not only had the quantity of spermatozoi employed been fully sufficient to fecundate the eggs actually touched, but also others present iu the same water with them.

In another experinent, inade before the preceding, but with some of the same brood of eggs and same sample of fluid, I placed five eggs in a cell, and touched each once, very lightly, with the pin's head loaded once only for the whole. This was when the fluid had been only eighteen minutes mixed with water. The object of this experiment was to learn whether there is any difference in the result when the eggs are touched at different parts of their surface. Accordingly the trial was made by touch- 
ing some eggs on the dark surface, others on the under or white surface, and others at the sides between the two. At the end of five hours and seven minutes the chamber had been formed and segmentation was taking place in each egg, and on the fifth day each had produced an embryo, thus appearing to show that it is of little consequence, with reference to fecundation, as to which part of the egg the fecundatory agent is applied to. But this conclusion is subject to certain conditions, as I shall proceed to explain.

\section{PORTION OF THE YELK MOST SUSCEPTIBLE OF FECUNDATION.}

On attentively examining the preceding experiments, it seemed difficult to understand how it happened that when similar quantities of the same fluid were applied by the pin-bead to different eggs of the same brood, at the same time, and the whole of them placed in exactly similar conditions in regard to heat, light and aëration, that some should become fecundated and others not, if, what appeared to be shown in the last detailed experiment, - that the egg can be fecundated equally well by the application of the fecundatory agent to any part of its surface, be strictly correct. There at first seemed to be no other way of accounting for the differences in the results, except on the hypothesis, either that it was due to some insusceptibility in the entire egg itself,-which thus presupposed great imperfection in each brood of eggs, a conclusion at variance with observation,- or that it resulted from the mode in which fecundation was attempted.

During the past season (1852) I have put the question, thus raised to a more rigid test, in order to learn whether the egg really is as susceptible of fecundation in one part of its structure as in another.

In ordel to obtain solne decisive results I repeated my experiments on three separate occasions, with eggs and fluid from three pairs of frogs, at nearly similar temperatures of the atmosphere. On the first occasion, April 5th, the temperature was $54^{\circ} \mathrm{F}_{\mathrm{AHR}}$., on the second, the following day, it was $55^{\circ} \mathrm{F}_{\mathrm{AHR}}$, and on the last occasion, April 9th, it was $53^{\circ} \mathrm{FAHR}_{\text {AH. }}$

In all the preceding experiments the eggs had been allowed to remain in exactly the same position, at the time of applying the fluid, as that in which they had passed from the body of the frog; so that sometimes the dark, and sometimes the white surface was uppermost, and at other times inclined more or less to either side, and occasionally the two were perfectly horizontal. When the fluid was applied by means of the pin's-head to the part desired, some portion of it necessarily flowed over other parts, if the surface which received it happened to be inclined to one side or the other.

But in my more recent investigations care was taken to place every egg in a perfectly vertical position, before attempting to fecundate it, so that in one set of eggs the central part of the dark surface of the yelks was uppermost, and in another the centre of the white surface. These precautions led to very definite results. In the 
first experiment, made on the 5th of April, with fluid which had been mixed with water about one hour and fifty minutes before, twelve eggs contained in a single cell were each twice or thrice freely touched with the loaded pin's-head over the centre of the white surface. Three of these eggs became partially impregnated, as shown in the formation of the chamber in each, and segmentation comnenced in one of them, but no embryo was produced from either. Fourteen eggs in another cell were touched at the same time, and in the same way as the preceding, with the loaded pin's-bead, over the centre of the black surface of the yelk. The whole of these eggs produced healthy and well-formed embryos.

These experiments were repeated on the following day on the eggs of another frog, with fluid which had been obtained only about twenty minutes before it was einployed. Fourteen eggs were each touched once only on the centre of the white surface, the pin-head being loaded for each egg. But not one of these eggs became fecundated, nor was even one of them partially impregnated. In another cell, at the same time with these, thirteen eggs were touched on the centre of the dark surface, and four of them became partially fecundated, but only two embryos were produced. The failure in this experiment certainly appeared to be due to the eggs, rather than to the mode of attempting their fecundation.

At the tine of making this experiment I placed two eggs, each in a separate cell, with their white surface uppermost, and then filled the cells, the one with nearly pure fluid, and the other with equal parts of fluid and water. Each of these eggs became fecundated, and underwent segmentation, although more slowly than usual, but the development of their embryos was not completed, as it became arrested at a particular period, a circumstance which is presently to be explained. Yet these experiments showed that when the egg is completely imnersed in fluid its position at the moment has but little reference to the act of fecundation, provided the fecundatory agents are present in good abundance. A further trial was made on the 9th of April, when six eggs, placed in one cell, were each twice touched on their whitc surface, the pin's-bead being loaded each time it was employed. But neither of these eggs produced an embryo. Six eggs, placed in another cell, were also twice tonchcd, like the preceding, on their dark surface. The whole of these eggs became fecundated, but only five embryos were sufficiently matured as to leave their envelopes. The fluid employed in these two experiments had been mixed with water about fifty-five minutes before it was applied to the eggs, and consequently was becoming slightly deteriorated.

The conclusion which seems to be deducible from a comparison of these experiments is, - that when the egg of the frog is completely immersed in water charged with the fecundatory agents, or to which these are supplied quickly after the immersion of the egg, as in the natural fecundation of the species, the actual position of the egg at the moment of its encounter with the spermatozoon, has but little reference to the act of fecundation, every part of its surfuce having then an equal chance of 
becoming affected. In like manner when the fluid is applied directly to any given part of the surface artificially, when the egg is exposed in an empty cell, and the fluid is allowed to gravitate, before the egg is immersed in water, it is of little consequence what part is first touched with it, since it may spread over the surface to the most susceptible portion; there being in reality one part of the egg which is more susceptible than another. The extremes of susceptibility and insusceptibility appear to be, on the one hand the centre of the dark, or future upper surface of the yelk, and on the other that of the white or under surface*.

That these conclusions, deduced from experiment, are correct, seems to be shown in the fact, formerly pointed out $\uparrow$, that the gerninal vesicle originally, and its progeny subsequently, at the time of fecundation, occupies the centre, not of the entire egg itself, but of the upper or dark hemisphere of the yelk; and this possibly may be the structure to be fecundated.

These facts deserve consideration in connexion with that of the first changes in the yelk taking place in this hemisphere; first, in the shrinking of the yelk at this part; the formation of the chamber above it, subsequent to fecundation; the existence of a canal in its centre, in the margin of which the cleavage of the yelk commences; and, lastly, in this being the portion of the yelk in which the first lineaments of the embryo become apparent.

In connexion with these remarks, it is but just to mention that a former observer, Dr. Martin BarRY, has distinctly referred to the changed germinal vesicle as being the structure in which the future embryo, in the Mammalia, originates + .

\section{EXCESS OF FECUNDATORY INFLUENCE.}

At the time of commencing the foregoing experiments with small quantities of fluid, I made others of a directly opposite character with an excess of the same. Four eggs were placed each in a separate cell, and within one minute afterwards the cells were filled with a mixture composed of equal parts of seminal fluid and water. This was half an hour after the fluid had been obtained. I had expected, from the vast quantity of spermatozoa present in the fluid, that segmentation of the yelk in these eggs would have taken place very quickly; but to my great surprise, although the eggs were preserved in a temperature of $60^{\circ} \mathrm{F}_{\mathrm{AHR}}$. no segmentation whatever had commenced in them at the expiration of twelve hours! at which time an abundance of spermatozon adhered to every part of the surface of their envelopes. But no chamber was formed in either of these eggs, as neither of them had been fecundated.

* During the present year I have most fully confirmed these views by numerous experiments, and have proved to my full satisfaction that the white surface of the egg is least, and perhaps not at all, susceptible; while of the dark surface, that the centre, which is occupied by the canal, and its contents, is the fertilizable part.-G. N., April 18, 1853.

+ Philosophical Transactions, 1851, p. 176.

$\ddagger$ Ibid. 1840. 
This result appeared to be far more inexplicable than any I had previously noticed. A somewhat similar one had occurred once before, but I had attributed that to some imperfection in the eggs employed, an explanation which did not apply in this case, as eggs from the same female had all been fecundated in other experiments.

Four eggs were then passed from another frog, immediately after death, each into a separate cell, which was filled with a mixture of two parts of water and one of seminal fluid, obtained only a few minutes before it was employed. Two of the eggs were allowed to remain in this mixture in their cells, but the others, after a few minutes' immersion, were well-washed, and supplied with pure water, and the whole were then placed in a temperature of $60^{\circ} \mathrm{FAHR}_{\text {AH. At }}$. At the end of four hours I found the surface of the first two eggs covered with an abundance of spermatozoa; and a chamber had been commenced, and the upper surface of the yelk was depressed, in each, thus showing that some degree of fecundation had been effected, but no segınentation had taken place in either of these eggs at the end of five hours and a half, although the temperature of the room had been raised during the interval from $60^{\circ}$ FAHr. to $67^{\circ} \mathrm{FAHr}$. The sixth hour was almost completed before either of these yelks gave any indication of the probability of this change. Segmentation then commenced, but in a very irregular manner. In one egg the division was not in the centre, but at the side of the yelk, and proceeded no further than to about one-half the extent across the surface. In the other the surface of the yelk within the chamber merely became sulcated twice in the same direction. Neither of these eggs proceeded further with their changes, and of course no embryos were produced. The two remaining eggs did not undergo any change whatever, and consequently had not been impregnated.

Although these failures were still attributed to some immaturity of the eggs, I began to suspect that they might be occasioned by the immersion, or smothering of the eggs in fluid of too great a density; yet this suspicion appeared to be so hypothetical as scarcely to merit consideration, when it was remembered that on a forner occasion when I had covered eggs with a solution of gum* and afterwards applied the impregnating fluid to them, some of them became fecundated. I was well aware that Spaldanzani had found in his experiments that the greatest number of frogs' eggs became fecundated when the fluid employed was very much diluted with water f ; but I did not then know that M. Quatrefages bad made an observation ${ }_{\uparrow}$ which completely coincided with the result obtained by myself. This acute naturalist found that when he employed the pure semen of the sea-worns, the Hermella and the Teredo, not a single egg was fecundated, and that when he mixed it with only a small quantity of water, so as to obtain "un liquide très opalin," that then only a very sinall number of eggs showed any traces of fecuudation. He ascribed these results simply

* Philosophical Transactions, 1851, p. 236.

+ Dissertations, vol. ii. p. 190.

* Annales des Sc. Naturelles, $3^{\text {me }}$ Série, tom. xuii. p. 129. 
to the circumstance of the fluid being too thick; but as we shall presently find, this; perhaps, may admit of a different interpretation.

My first object having been to learn how small a number of spermatozoa is sufficient to fecundate an egg, it may well be supposed that the facts just mentioned were exceedingly puzzling, and they were rendered still more so by the circumstance that a different result occurred with three other eggs from the same frog, employed at the same time as those in the preceding experiments. Two of these eggs, placed like the others, each in a separate cell, in a mixture of one part of seminal fluid to six parts of water, two hours and twenty minutes after the fluid had been obtained, became fecundated. In each of these the chamber was formed above the yelk, seginentation took place, and proceeded regularly, and each egg subsequently produced an embryo. In the third egg the chamber was formed, but the yelk became irregular in outline, and did not undergo segmentation. It had merely three parallel depressions on its upper surface, after which it became strangely altered in form, and was abortive. The cause of this failure seemed to be the same as in the preceding experiments,- -an excess of spermatozoa in encounter with the egg, as subsequent experiments tended to show.

Seven eggs were passed into one large cell, and one egg into each of two separate cells, and the cells were then filled with a mixture of fluid and water, which was so dense as to appear turbid and opaline. This appearance was in part due to the fluid containing a large proportion of devclopmental cells. The result in each instance was very marked. The fluid at the time it was employed had been mixed with water about one hour and five minutes, and the temperature at the time the experiment was made was $56^{\circ} \mathrm{F}_{\mathrm{AHR}}$., but the eggs were soon afterwards removed to a temperature of $62^{\circ}$ FAHr. At the end of five hours the yelks of two of the eggs had become partially segmented, but the changes were continued onty in one. The remaining eggs had been more injurionsly affected. Their yelks had become shrivelled and contracted, and resembled withered apples. In this experiment it was evident that the effect had been occasioned by an excess of inpregnating influence, but in what way it was not then easy to understand. The yelks of these eggs looked very like those of eggs which had been in contact with solution of potass, or of those to which stale and decomposing fluid had been supplied.

But it was possible that this change of form might be due to some injury sustained by the eggs in their removal from the body of the frog, or to some accidental canse in their removal to the cells, before fecundation. In order, therefore, to remove all doubt in this respect, another trial was made with two other eggs, which were so carefully passed into cells as to avoid all suspicion of injury to them, and the cells were then filled with mixed fluid like the preceding. The yelks of each of these eggs also changed their form, and one of them became irregularly contracted and pearshaped. Of the whole of the eggs employed in these experiments only one underwent seginentation, and producerl an embryo. The others were not fecundated. It was 
thus evident that an excess of fecundatory fluid is as unfavourable to the production of the embryo as a defieiency.

\section{DEFICIENCY AND EXCESS OF FECUNDATORY INFLUENCE COMPARED.}

The results of these experiments with the fecundatory agent in excess require to be further explained, and also to be compared with those obtained with deficieney of the agent, in order that the nature of both may be properly understood. If this be done it will be seen that fecundation of the frog's egg depends very much on the physical influence of temperature; and that this has a close relation with the intensity of the force, or the degree of vitality evolved in the spermatozoon, at the time of its application to the egg; and probably also witl the influence which the spermatozoon supplies through a greater or less amount of material substance to the body to be fecundated, at the time of its encomnter, as in the following experiments niade in March 1852.

The experiments by pin-point application of fluid show that only a very small amount of influence is actually required to set up. those changes in the yelk which result in the formation of the embryo; and other observations have convinced me that the result is the more certain at a slight increase than at ever so slight a diminution of temperature. The effect of the application of minimu certain when the influence bas only very recently been obtained, and consequently while still endowed with its greatest degree of vitality. But even at that time a given amount is required, and if such be not supplied the result is incomplete, and partial fecundation only is effected. First then in regard to minimum quantities.

Six eggs were placed each in a separate cell, and three of these were touched once only with the pin-head loaded with fluid obtained about twenty-five minutes before, while the other three were each touched once with the fine pin-point loaded in like mannel. Yet although there was only an interval of one minute between the application of fluid to the two sets of eggs, two of the former by pin-head application had the chamber developed, and segmentation commenced at the end of three hours and forty minutes; while one egg only of the three supplied by pin-point application began to be segmented in three hours and forty-eight minutes, although the whole were placed under precisely similar conditions in regard to light, heat, quantity of water and degree of aëration. The third egg of the first set was not impregnated, neither were the two remaining ones of the second set. Thus there was a difference between the two sets of eggs, not only in the extent to which they were fecundated, but also in the rate of the accomplishment of fecundation to the extent of eight minutes, in about three hours and three-quarters. There was also a perceptible difference of time in the formation of the respilutory chamber of the two, after the first hour, as was remarked by a distinguished physiologist who was present with me when these comparative trials were made. The two eggs of the first set, and the single egg of the second, which underwent seginentation, afterwards produced embryos; the remaining eggs were abortive. 
A second comparative trial was made on the 15th of March. Three eggs in separate cells were each touched once with the fine pin-point loaded with fluid which had been obtained only twenty minutes before. The temperature at the time of the experiment was $56^{\circ} \mathbf{F}_{\text {AHr., }}$, but the eggs were removed within a few minutes afterwards to a higher temperature, which was gradually increased to $64^{\circ} 5$ FAHr. Segmentation took place in one of these eggs in three hours and thirty-nine minutes, and this egg afterwards produced an embryo. But the remaining 'two were not impregnated. Three other eggs in separate cells, were, at the same time as the preceding, each once touched with the loaded pin-head, and two out of the three underwent segmentation at the end of three hours and thirty-three minutes. In a further experiment, made at the same time, sixteen eggs included in one cell were touched with the loaded pin's-head when the fluid had been obtained about half an houl before. Four of these eggs underwent seginentation in three hours and fifty-three minutes, and afterwards produced embryos, the remaining eggs being unproductive. Another experiment was made with nineteen eggs in a single cell, by pin-head application of the fluid, and eleven of these were fecundlated and began to be segmented in three hours and forty-two minutes, and ultimately produced embryos, the remaining eight being sterile. Some of these failures were probably due to the circumstance that the fecundatory fluid was not applied to the most susceptible part of the egg, yet the general results sufficiently show not only that fecundation is more surely and quickly effected at a moderately high than at a low temperature, but also that it is so, more or less certainly and quickly, in proportion to the amount of influence supplied.

These facts lead us to some further consideration of the results of the application of definite quantities of the fecundatory agent to the egg, as affecting the development of the embryo, and possibly also as influencing both the evolution of its physical structure and psychical condition. I have little hesitation in believing that whatever be the precise nature of the influence communicated by the fecundatory agent to the egg, that it is only after full and complete impregnation that perfectly normal and healthy embryos are formed, and ultimately attain to the maturity of the species. And yet we have already seen that when there is great excess of the agent, either that no embryo is produced, or that its development is not completed.

A few days after making the last-mentioned experiments I repeated them with another object in view, and then obtained a result which had occurred on previous occasions, but being less distinctly marked had been almost overlooked.

About twenty eggs bad been placed in separate cells, and fecundation attempted by pin-head application of fluid which had been obtained from a partially exhausted and debilitated male, at the end of the season, and which had been employed from want of a more bealthy individual. The fluid, when examined by the microscope, was found to contain very many perfectly motionless spermatozoa, besides a large quantity of cells. The inefficiency of this male was inferred from the circumstance that the 
female was prepared to spawn, as was proved by her having passed a few eggs; but these remained unimpregnated, and she still retained the remainder within her for nearly a day, at which time the male was removed for the experiment. The employment of this male was thus accidental, it being the only one $I$ then possessed.

'The fluid was applied to the eggs within a quarter of an hour of its being obtained, and the eggs were at once placed in a temperature of $61^{\circ}$ FAHr. I remarked that development appeared to go on more slowly than usual, althongh most of the eggs underwent seginentation, and fifteen of them produced embryos, which were placed together in one vessel. A few days afterwards I was surprised to find that two of these embryos were greatly malformed. One had a short falcated tail narrowed at its base, where it was not broader than at its extremity, and the tail of the other was scarcely more than a short narrow stump, so that the embryo had nuch difficulty of locomotion. A few days later three other of the embryos became distorted, and one of them died much altered in form at the period of absorption of the external branchix.

'These circumstances are l'ecorded merely as simple occurrences which point to the necessity for further experiment on this curious and important subject, and not as results from which any very positive conclusions can be dednced. Nevertheless, I nay add, that I think I have before observed that embryos which have been the result of fecundation with very small quantities of fluid, are usually smaller than others which are produced from full and natural impregnation.

The effect produced by immersion of the egg in pure fluid is as curions as the l'esults above mentioned obtained from minimum quantities, and at first it is less easily to be understood. I can find no more expressive term by which to indicate it than that of smothering, and this, perhaps, may be found to be a more literally correct ex . pression of the fact than at first is apparent. It has already been shown that free aëration is nost essential to the development of the embryo, and I believe it is equally so, in a minor degree, to fecundation. 'Thus while the egg may be fecundated in a dense fluid, composed of equal parts of seminal fluid and water, its changes usually take place much more slowly than when the proportion of water is considerably increased; while if it be immersed in pure fluid, and be allowed to remain in that for some hours, it may still be fecundated, and its changes be cominenced, but these will not proceed to the full development of the embryo. If the egg when immersed in pure fluid be retained in a moderately low temperature, then the development of tae embryo may go on slowly for a time, but with less rapidity than when the egg is freely aërated in pure water. But if, on the other hand, it be retained in seminal fluid, at a high temperature, then it usually happens that although the respiratory chamber be formed, as the result of fecundation, segmentation will proceed slowly, or jrregularly, and the embryo, which is begun to be formed, perish. That want of proper aëration is in part the cause of this infertility seems to be shown in the following experiments. 
April 5, 1852. Atmosphere 54 ${ }^{\circ}$ - - Two eggs were placed in separate eells, which were immediately filled with nearly pure fluid. In about one hour afterwards the respiratory chamber was beginning to be formed in both these eggs, but its progress was slow. One egg was then washed as completely as possible with a powerful jet of water, thrown upon it by a syringe, and the eell was then filled with pure water, while the eell with the other egg was replenished with more of the fecundatory nixture. After the addition of fresh water to the first egg its envelopes began to expand, and it was then seen that the substanee of these coverings was flled with spermatozoa, lying in every direction and so crowded around the envelope which immediately invests the yelk, as to render the whole semi-opake. The envelopes of the second egg were much more opake than those of the first. Yet the respiratory chamber was developed, after a lengthened interval, in both, but earlier in the egg which had been washed and placed in water than in that which remained in the fluid. At the expiration of twelve hours the second egg was washed and placed in pure water like the first. Both eggs were preserved, from within an hour or two after their first encounter with seminal fluid, for four days in a temperature which ranged from $59^{\circ} \mathrm{FAHr}$. to $64^{\circ} \mathrm{F}_{\text {AHr. }}$. At the end of three days and a quarter, or about seventyeight hours, in this temperature the development of the embryo had advaneed so far in the first as to the union of the laminæ dorsales, and the narrowing and elongation of the body, a stage of development at which the function of aëration is becoming more energetic in the evolution of ciliary action. At this stage of formation the development of the embryo became arrested, although the egg was properly supplied with water, and from this period it decayed. The second egg, which had remained twelve hours in the inixed fluid before it was supplied with fresh water, perished inuch earlier, and before there were any distinet evidences of the formation of an embryo.

On other oceasions $I$ have found that the egg does not become fertilized at all, but the yelk contracts irregularly, and resembles the yelk of eggs affected by solution of potass.

These are the usual results of immersion in undiluted fluid, which, contrary to what oceurs with minimum quantities, appears to be most prejudieial to the egg, in its pure state, when the temperature of the surrounding medium is much increased; so that the cause of failure in these cases of excess may reasonably be attributed, in great part, to a smothering of the egg, through impeded aëration; aceelerated, perhaps, by sonie ehemical ehange, through increased temperature, in the remains of the spermatozoa, with which the envelopes of the egg are crowded in their interior.

\section{THE MOTION OF THE SPERMATOZOON IN RELATION TO ITS FUNCTION.}

The possibility of the fecundatory function being in some way connected with the motion exhibited by the contents of the pollen in plants, and with that of the spermatozoa in animals, has not eseaped the consideration of the best observers. Mr. Brown, the most distinguished of botanists, many years ago, made this the 
subject of his particular investigation*; and M. BrongNiart $\gamma$, SchleIden + , NÄGELi $\oint$, Griffith \|, and more recently Suminsin $\Phi$ and Henfrex*** have done the same. But although neither of these able inquirers succeeded by direct experiment in proving that the motion of the particles of plants is essential to the act of inpregnation, M. Hofmeister w p , and very recently also Mr. Henfrey ${ }_{\text {tr }}^{\text {th }}$, have noticed facts in regard to that of the spermatozoid filaments discovered by NägeLr and SumiNSKI, in the Cryptogamia, which seem to show that, in plants, it is of great importance to the function of these bodies. The motion of the spermatozoon in animals has cqually attracted the attention of zoologists. Prevost and Dumas\$\$, as already stated, Siebold, Müller, Wagner, Köluiker, Bischoff, Quatrefages, and especially WAGNer and LeUcKard, have studied it attentively; but so intricate is the inquiry concerning its nature and import, that the last two anthors dismiss the consideration of the question without arriving at any conclusion, and state that they do not venture to decide \|\|. . Heretofore I regarded impregnation as being commenced by transmission from the spermatozoon on the surface of the egg, to the contents in the interior, of some influence characterized by motion. But I have regarded this motion as being only the visible indication of a peculiar force, or form of vitality, in the impregnating agent, the spermatozoon, by which it is destined to arrive at, and is to expend on the object to be fecundated, and the effect of which is to strengthen, to augment, and possibly also to modify the nature of the formative changes, which are going on in the yet unimpregnated egg, per se; but which will subside, and soon entirely cease, if not reinforced through the agency of the spermatozoon. Nevertheless, I have not been prepared to assent to the view that simple contact of the spermatozoon, even with the vitelline membrane, is sufficient to complete the changes which result in the formation of the embryo (see p. 233). The powerful endosmic action of the envelopes of the ovum, at the time of oviposition, is opposed to this conclusion; since, if simple contact

* A brief account of microscopical observations, made in the months of June, July and August, 1827, on the particles contained in the pollen of plants, and on the general existence of active molecules in organic and inorganic bodies, by Rовевт Brown, F.R.S., etc., 8vo. July, 1828 ; also additional remarks on active molecules. (Id.) July, 1829.

$\uparrow$ Recherches sur la génération et le développement de l'embryon dans les Végétaux Phanérogames (Notes). Annales des Sciences Nat. tom. ix. 1828.

$\ddagger$ Grundzüge der wissenschaftliche Botanik.

\$ Schlemen und NäGel1's Zeitschr. für Wiss.-Botanik; Heft i. 168; Zurich, 1844.

\| Transactions of the Linnean Society of Londun, vol. xx.

If Zur Entwickelungsgeschichte der Farrnkrïuter, 4to. Berlin, 1848.

** On the development of the ovule in Orchis morio, Transactions of the Linnean Society of London, vol. xxi., and Proceedings, vol. ii. p. 27, April 8, 1849.

†† Untersuchung des Vorganges bei der Befruchtung der CEnothereen, Botanische Zeitung, v. 785, 1847.

++ Annals and Magazine of Natural History, vol. ix. June, 1852; Transactions of Linnean Society, vol. xxi.

Part II.; also Proceedings, June 17, 1852, vol. ii.

$\$ \$$ Annales des Sciences Naturelles, tom. ii. 1824.

III Article "Semen," Cyclopædia of Anatomy and Physiology, vol, iv. par. xxxiv. p. 508. 
or encounter of the spermatozoon with the ovum were sufficient, it might be expected, as has been well remarked*, that the influence of the spermatozoon of any animal of the same class would be competent to effect the impregnation of any species.

Yet all the phenomena connected with the origin and death of the spermatozoon seem to be in accordance with the view, that its motion is essential to its function. Whatever be the relation of this motion to its peculiar faculty, it is evident that motion is intimately associated with, and dependent on, its material composition, and structural development. In the Frog, the spermatozoa are usually completed very early in the season, when the animals begin to emerge from their hybernacula, in the beginning or middle of February; but, as we have seen, they only begin to pass into the efferential ducts from the testicle, at the time when the pairing of the sexes is commenced; from which time, to that of spawning, a period of from ten days to a fortnight or three weeks, according to the temperature of the season; they are more fully matured, and acquire greater vibratory power, and are collected in the vesiculæ seminales for expulsion at the instant after oviposition. In the Toad the spermatozoa are developed at a later period of the season, but at a relatively corresponding period in the life of the animal. The male Toad, like that of the Frog, usually emerges from its hiding-place a few days, or a week or two earlier than the female. I have taken the males in the middle and at the end of March, at which time I have not been able to detect any seminal fluid in their vesiculæ seminales; yet they are then exceedingly salacious and disposed to pair, and I have sometimes found the contents of the reproductive organs in a similar state, even after the sexes lave been for two or three days in union. The testicles, nevertheless, are then filled with an abundance of spermatozoal cells in the course of development, and also with a great quantity of spermatozoa, each still included in its vesicle of development; but as yet immature, motionless, and with only a very short caudal extension from its thick cylindrical body. Besides these there are usually a few spermatozoa, more matured than the rest, which exhibit movements while still retained within their cells, which are enlarged, and from which they are soon to be liberated.

Thus motive power in the spermatozoon is coincident with the completion of its structure and composition, and as such, may fairly be regarded as essential to its function. In the Frog the motion of the spermatozoon is most intense and persistent at the full period of connubiality. On the other hand, I have constantly noticed in all my experiments on artificial inpregnation, that where impregnation has not been effected, all the conditions being favourable to it, or when I bave found by trial that the male fluid has ceased to be efficient, that then nearly the whole, or perhaps all of the spermatozoa, have been perfectly motionless, and apparently dead. This is also the condition in which I have usually found the few spermatozoa which are retained in the reproductive organs a week or two after pairing, when the male Frog and Toad may be regarded as in the state of aged individuals, the season of reproduction * WaGNEE and LeucraRdT, loc. cit. p. 508. 
having passed, and the function being fulfilled. Thus too, I have noticed that, when from accident, but more especially when from reduction of the temperature in the surrounding medium, the season of spawning has been greatly retarded, the impregnating power of the male is much diminished, and perhaps is almost exlausted, through constant shedding of the spermatic fluid, which, I have found, often takes place when the oviposition of the female is delayed, and the individuals are disturbed or interfered with. The female is then forsaken by her partner, and when this occurs it rarely happens that the connubial intercourse of these two individuals is reconmenced. When this separation has taken place, there is usually but a small quantity of fluid remaining in the male organs, and even in that, the number of spermatozoa is considerably diminished, and their power of motion is exceedingly feeble; while the quantity of molecules and cells is increased. When several days, or a week or two have elapsed, there are not only fewer spermatozoa, but those which remain are much more feeble in action. This is exactly what occurs also in the Toad. On the sixth of June I found that the testes and efferential ducts in a male Toad, which had been kept from pairing during the whole season, were still filled with spermatozoa, together with a very small quantity of liquor seminis with active molecules moving in it; but that, though the spermatozoa were in full abundance, nearly the whole of them were entirely motionless, while the motions of the few which still gave evidences of vitality, were exceedingly feeble, whether the spermatozoa were exanined simply in the fluid portion of the semen, or whether they were mixed with water, in which, as is well known, the motions are always at first greatly increased.

A similar reduction in the number of the spermatozoa and diminution of their motive power, appears to exist in animals which have become exhausted through long confinement ol want of food; at least, if we may so judge, from a few observations on the Tritons. A Triton palustris, which had been captured on the seventh of May, and accidentally confined without food till the sixth of June, was examined inmediately after death. The efferential ducts were well-filled with spermatozoa contained in a distinctly perceptible quantity of liquor seminis. When the spermatozoa were exanined, without the addition of water, their motions were regular, but apparently very much slower than usual, being uniform and undulating, without that peculiar rapid ciliary action of the spirally twisted tail, which is so constantly referred to as characteristic of the spermatozoa of the Tritons and of some other Amphibia. When water was added, the motions were immediately accelerated, and the tail, which before was merely flexed, and almost longitudinally extended from the body, became folded and entwined around it, and its rapid ciliary movernents were commenced. But these gradually subsided within a very few minutes. In another specimen, which had been captured at the same time as the preceding, and confined under similar circumstances, but which, at the time of exanination, had been already dead for more than twenty-four hours, scarcely any spermatozoa remained in the testes, or in the efferential ducts. There was a great quantity of cells, with granular nuclei, in 
the body of each testis, but scarcely a single spermatozoon. 'The few spermatozoa which remained were most of them dead, and decomposition appeared to have commenced in them, and there was a large proportion of active molecules. Amongst these were one or two spermatozoa still in action, and the molecules were accumulated around them by the attraction of the current in the fluid, induced by the ciliary action of the tail, and were propelled onwards, frequently in a spiral direction, from the base of the tail to the anterior extremity of the body; thus showing that the motions around the spermatozoon are due to the action of the filamentous tail, flexed upon, and twisted spirally round the body; in accordance with the observation of WAGNEn and LeuckardT.

But it has been remarked, in opposition to the view, that power of motion in the spermatozoon is essential to its function, that motion is not detected, or but very faintly, in many instances in which the spermatozoa are united into simple and uniform cords, as they often are in the deferential vessels of insects; and that then only a slight waving, or trembling of the mass, the consequence of hygroscopic conditions induced by the fluid around, is, under such circumstances, observed. An aggregation of the spermatozoa into cords takes place in the Tritons as well as in insects. When the semen is expelled by the Triton at the time of conjugation, it is composed almost entirely of white cord-like, flocculent masses of spermatozoa, which, at that moment, exhibit only the faint undulatory motion noticed in them while still within the deferential vessels. Yet, immediately after these masses are ejected from the vessels, and are in contact with water, at the moment of being received into the cloaca of the female, as I shall hereafter have occasion to show, - the motions of the spermatozoa are not only greatly increased, but that peculiar vibratory ciliary action of the tail, which, while the spermatozoa are still within the seminal ducts is very indistinct, and perbaps can scarcely be said to occur-is immediately set up, and the motion of the body of the spermatozoon is changed from the undulatory action before obselved, to the jerking or watch-spring movement pointed out by observers, and thought to be the motion peculiar to the sperınatozoon of this class of animals.

Thus then, the fact of only a slight wavy motion of the spermatozoon being perceived in some cases, ceases to be of importance, as an argument against the view that motion is closely connected with the function, since it is evident that the true spermatic force is not set up until the spermatozoa have become more or less separated from each other, through their residence in some fluid vehicle. The movements of the spermatozoon in insects are very similar to those of the spermatozoon of the Triton, and the circumstances which affect both are in full accordance with the fact of the existence of, and the necessity for, a distinct liquor seminis, as part of the normal composition of the seminal fluid, in the Mammalia; while this portion of the fluid is not needed, and consequently is almost entirely absent in the Amphibia, Fishes and most Invertebrata. A comparison of the facts in the two divisions of animals seems to point to the true nature and use of the liquor seminis, as being that 
of a mere vehicle for the ready transmission of the spermatozoon to the ova, and as allowing greater freedom of motion to these bodies.

It is true, as WAGNER and LeUcKardT have stated, that but little motion can be observed in the spermatozoa of Insects when they are united into cords; yet this seems to be due rather to their union into these masses, and to have reference to their mode of ejection from the body of the male, as in the Triton, and is known to take place during their collection in the deferential vessels, than to any real absence of a power of motion in them. This is not their condition when brought into contact with the egg at the time of impregnation. When the fluid of the male insect, during pairing, is passed into the spermatheca of the female, where it may be destined to remain for an indefinite time, the spermatozoa compose the chief portion of it, as in the Tritons; but, during their residence in the spermatheca, the spermatozoa are Inixed with a fluid, which is supplied by a gland attached to that organ, and which becomes to them a vehicle like the liquor seminis, and allows of their separation and independent motion, and thus appears to answer the purpose of the true liquor seminis in the Mammalia. At the period when the ova are descending from the ovaries, the movements of the spermatozoa become more distinet; and when these bodies are brought into contact with the egg, as it passes the outlet of the spermatheca, they become inore isolated, and their movements more intense, as I have seen in the case of the Orthoptera. From these circumstances I am led to believe that some degree of motion will ultimately be observed to mark the perfect condition of the impregnating agent in all animals. The facts already mentioned coincide with this view, and point to the probability that the degree of impregnating force in each individual may perhaps be indicated relatively by the degree or intensity of motion in the spermatozoon, and the duration of this force by the length of time which the spermatozoon continues in motion.

The established fact, that a difference in the structural conformation of a body is the invariable result of a difference in the relations, proportions, and composition of its material constituents, has always afforded reason for presuming that some material influence may be transferred from the substance of the spermatozoon to the contents of the ovum, at the time of impregnation. The function of impregnation appears to be one of definite relations and proportions. Thus we have seen, when only a few spermatozoa were applied to the ovum on the point of a pin, that full impregnation was but rarely effected. In most instances of such limited application, the yelk underwent only partial segmentation, and its changes were then gradually arrested, and no embryo was produced. If, however, the pin point which had been charged with spermatozoa, instead of being applied to the ovum for an instant only, was allowed to remain in contact with the egg for a second or two, and thus by capillary attraction became drained of the spermatozoa which adhered to it, and, as a consequence, thus made to deposit a greater number of these bodies, which were not afterwards attempted to be removed or destroyed, then impregnation was sometimes 
completed, and an embryo became developed. But if, instead of the spermatozoa being thus supplied in a minimum quantity from the point of a pin, they were supplied in greater quantity from the head, then impregnation was almost always effected; and this result was rendered the more certain by allowing the head to be drained of the adbering bodies for a moment or two, as from the point, by which a much larger quantity of the impregnating agents was deposited. In these instances it was rare that impregnation was not effected. These results appear to show, that, whatever may be the precise quantity necessary to effect healthful impregnation, it has some definite relation to the effect to be produced in the contents of the ovum-that a definite quantity of spermatozoa, or spermatic influence is required to fecundate, and that the perfection of fecundation has relation to the degree of impregnating influence. They seem to show, also, that fecundation is not the simple result of the penetration into the egg of a single isolated spermatozoon, but probably of some definite nuinber of these bodies, or of a definite amount of influence supplied through their encounter. We are thus led to perceive that the same law of relation between cause and effect,- - between a definite amount of inflnence expended, and definite results, - which has long constituted the basis of our knowledge respecting chemical affinities, and which is now being demonstrated, as that also of the other forces of inorganic nature, may equally pervade and control these material combinations among the organic affinities. Further, the observations, now mentioned, seem to put to rest the last remaining question respecting the independent animality of the spermatic bodies, and to show that these, like the cilia, are mere elementary parts of the adult male organization,- -as many physiologists believe*,-as the contents of the ova are of that of the female.

All my experiments on the egg of the Amphibia serve to show, that even with a definite quantity or number of spermatozoa, no impregnation is effected, if, before the spermatozoa are brought into contact with the egg, they have all ceased to exhibit that motion which constitutes their marked characteristic. Thus then, it seems that, independent of the important question as to whether these bodies yield any material substance for combination with the constituents of the egg, through the usual chemical affinities of matter,-the quantity of influence to be supplied to produce the healthful result is definite, and that, whatever be its nature or essence, it is always characterized by a definite degree of motion in the spermatozoon. Further, all the observations I have made on the spermatozoa tend to show that their motion is rendered more vivid and intense by an increase of heat, but that, in proportion to such increase, it is so much the sooner exhausted; as, on the other hand, it bas long been known that it is diminished by reduction of temperature, but increased in duration. 'Many of the observations lead to the view, that the power, in a given quantity or number of the spermatozoa, to effect impregnation, is inore in proportion to the amount, quantity, or intensity of the motion exhibited by these bodies than to their actual

\footnotetext{
* Kölliker, Siebold, Müller, Wagner, \&c.
} 
numbers. Thus the spermatozoa, like the ova, are more efficient at a given temperature, within the first two or three minutes after they are passed from the body, than at a later period. At that time there is not only a greater number of spermatozoa in a given quantity of fluid in a state of activity; but the whole of them exhibit a greater intensity of motion than after they have been for some time mixed with water. In the Toad, which, in this country, as already stated, pairs at a few weeks later in the season than the Frog, and which seems not only to require a higher temperature of the surrounding medium, but also a relatively higher temperature for the development of the ova, the spermatozoa are most active, and most fitted to impregnate at the instant of expulsion; as is shown in the mode of interconrse of the sexes in that animal, and in the fact that, if the fecundatory fluid be not immediately applied to the strings of ova as these are passed, the unsprinkled ova are infertile. The oviposition of the Toad is an exceedingly slow process, and usually lasts, as Spallanzani observed, from ten to fifteen hours: in one instance $I$ found it continued during seventeen hours, but it was completed in others in eight or ten. The act of impregnation, therefore, is necessarily also prolonged. But the length of time during which the spermatozoa continue efficient to impregnate after removal from the body, is shorter than in the Frog. Spallanzani found that, at a temperature of $81^{\circ} \mathrm{F}_{\mathrm{AHR}}$, it does not exceed fifteen ininutes. I also have noticed that the inotions of the spermatozoa cease much earlier than in the spermatozoa of the Frog.

Thus the conclusions to be drawn from the facts of natural impregnation in the Toad, fully agree with those deduced from artificial impregnation in the Frog, and seem to establish the view, that while an increase of temperature is required for the fulfilment of the reproductive function in that animal, and to maintain the efficiency of the spermatozoa, the fecundatory force of the agent is of shorter duration, and corresponds to its more early cessation of motion.

\section{PENETRATION BY THE SPERMATOZOON IN EFFECTING FECUNDATION.}

'The penetration of the spermatozoon into the substance of the egg, or even into its envelopes, has been so much disputed, and so repeatedly denied, that it is only on what may perhaps be regarded as indisputable evidence, that any one ought to reassert it. Up to a very recent period I could not, myself, admit it as probable; because, throughout my investigations, I had not been able to detect any appearance in the fecundated egg or its envelopes, either of the Frog or Newt, which rendered it likely that the spermatozoon penetrates into or through them. Yet the fact of penetration was stated by the older naturalists, not so much, perhaps, from any decided proof of its occurrence, as from a confidence that it was only in this way that the function of the spermatozoon could then be understood. LEEuwenhozk, and those of his day, not only believed that the spermatozoon penetrates bodily into the suhstance of the egg, but also that it becomes the futule embryo. In later times, M. Prevost having, with M. Dumas, seen the spermatozoon within the gelatinous envelope of the 
egg of the Frog, as they show, conceived that this body becomes,--not the embryo itself, but the foundation of the nervous system of the embryo. Since then, Dr. MarTin BARRY announced to the Royal Society that he had seen spermatozoa within the substance of the egg of the Rabbit ; through the envelopes of which, he has stated, that there is a natural perforation or cleft at the time of fecundation*; a view.which has met with inuch opposition, as no physiologist has hitherto (1852) verified his observation with regard to the existence of a perforation or cleft in the egg-envelopes; or has announced that he has seen the spermatozoon within the ovum of that animal. Indeed so general has been the opinion that there is no penetration by the spermatozoon, even into the envelopes of the egg, notwithstanding WAGNER's 1 announcement that he had seen spermatozoa within the envelopes in the eggs of Fishes, that one of the most recent inrestigators, M. Quatrefages, in alluding to MM. Prevost and Dumas' views, observes, that "it is useless to allude to the question of penetration by the spermatozoon, as he believes that the only living author of the theory has himself renounced it + ." But very recently it has been announced, in a paper on the Ascaris Mystax, by Dr. Nelson, communieated to the Royal Society $\S$, that the spermatozoon in that animal does penetrate into the substance of the yelk; and a somewhat similar account of that of the Earth-worm was formerly given by Dr. Arthur FarRe \|. Yet, witl all due respect for the observations of these able investigators, I must still have hesitated to admit the fact of any penetration, even into the envelopes of the egg, had I not more recently been convinced of this fact by direct observation, in correction of my former opinions, in so far as relates to the penetration of the spermatozoon into the envelopes of the eggs of the Frog, and its arrival at the vitelline membrane. To them, then, be all honour on this subject, while I subjoin my testimony to a fact which I had heretofore failed to observe.

It was during the month of March last (1852), while making experiments on the Frog's egg by artificial impregnation, before some scientific friends, that certain appearances were noticed beneath the microscope within the expanded jelly of the egg, which led to a suspicion of the probability of penetration by the spermatozoon. Heretofore I had employed, in my observations, either a deep glass cell, in which the egg was completely immersed in water, or the common object-glass of the microscope. In the experiments now referred to, a sluallow glass cell was employed, which was capable of containing only a single egg. This, while it admitted light freely around the egg, was too shallow for its complete immersion, and the egg was therefore covered by a drop of water, into which the object-glass of the microscope was passed,

* Philosophical Transactions, Part II. 1840, p. 533, Plate XXII. figs. 164, 165 and 167. Ibid. Part I. 1843 , p. 33.

† Elements of Physiology (English Edit. by Dr. Wrimis), note, p. 74, 1841.

$\ddagger$ Annales des Sciences Nat. $3^{\text {me }}$ Série, tom. xiii. 1850.

§ Proceedings, June 19, 1851, vol. vi. p. 86. Philosophical Transactions, 1852.

|| See Dr. CArpenter's Principles of Human Physiology, 1st edit. 1842, p. 617.

MDCCCLIII.

$2 \mathrm{~N}$ 


\section{MR. NEWPORT ON THE IMPREGNATION OF THE OVUM IN THE AMPHIBIA}

while viewing the egg, instead of the observation being made through the double medium of air and water. This was the method of examination in all the subsequent experiments.

The appearance which first led me to suspect that spermatozoa do penetrate into the envelope, was produced by an acicular body, which seemed to have its narrowed extremity in near proximity to the vitelline membrane. The direction of the longitudinal axis of this body was in a line with the centre of the yelk. But what appeared to be its larger end was farthest removed from the yelk; and this circumstance seemed to show that the appearance could hardly be due to the presence of a spermatozoon, which, if the observation were correct, must bave penetrated in a direction the reverse of that of its usual motion.

It was necessary, therefore, that the suspicion raised by this observation should be settled. I had again and again found, as before shown, that the egg of the frog may be impregnated, under certain conditions, by the direct application of spermatozoa to almost any part of its surface, and this enabled me to put the question of penetration to the test. In the first trial, an egg was placed in a single cell, and immersed in water for one minute-the water was then removed, and the egg touched on one point only of its surface with the head of a pin, loaded with the fecundating fluid, which had been obtained and mixed with water about two hours before. I had expected that on watching the egg beneath the microscope, from the instant of contact with the pin's-head and the re-filling of the cell with water, to have been able to detect the spermatozoon during its passage through the envelope. But this I failed to do, in the present instance,--no spermatozoa were detected in the interior of the envelope, although many were easily observed on the surface at the point to which they had been applied by the pin. Yet, this egg, placed in a temperature of $66^{\circ} \mathrm{F}_{A H R}$., underwent segmentation in three hours and thirty-two minutes, and ultimately produced an embryo. A similar trial was made, at the same time, with an isolated egg after immersion for two minutes in water, which was then withdrawn, and the fecundating fluid applied as before. In this instance, several spermatozoa had penetrated for a short distance into the envelope, but had not reached the covering which immediately invests the yelk. No respiratory chamber was formed above the yelk in this egg, nor was any embryo afterwards produced. In a third instance, with an egg, which had been immersed for five minutes, the experiment was equally unsuccessful. On the 24th of March a further trial was made with an isolated egg, after one minute's inmersion. The fecundating fluid employed had been obtained only sixteen minutes before it was used, and was applied by the head of a pin, once only, to one point of the egg. In this case, at the expiration of half an hour, I distinctly saw a single spernatozoon sticking by its larger extremity into the vitelline membrane, and a few minutes later there was evidence of the respiratory chamber being about to be formed. This egg underwent segmentation, and afterwards produced a good embryo. In a second egg immersed for three minutes, and in a third for five minutes, there were no appear- 
ances of spermatozoa in the interior of the jelly, although they were in abundance at the point on the surface, to which they had been applied by the pin. Neither of these eggs underwent any change. But in a fourth trial, with an egg immersed for ten minutes, and to which the spermatozoa were applied in the same way as in the preceding, I saw, at the expiration of fifty minutes, four spermatozoa sticking in the vitellary membrane; soon after which the chamber was commenced, and at a later period segmentation of the yelk took place, and an embryo was produced. This was with fluid which had been obtained nearly an hour before it was employed. In a further trial, with an isolated egg, to which a full quantity of fluid was added, by three or four applications of the loaded pin's-head, after the egg had been one minute in the water, I detected several spermatozoa, within half an hour afterwards, sticking like the preeeding into the vitelline membrane, and this egg also produced a good embryo.

It was thus evident, that in some cases, spermatozoa certainly penetrated through the envelope; but as there was also one instance, in which the egg had become fecundated, and afterwards produced an embryo, in which $\mathbf{I}$ had not seen spermatozoa within the envelopes, it was necessary to pursue the investigation further, to be quite assured of the fact of penetration as connected with the act of fecundation.

On the following day an opportunity occurred to me of examining the egg after impregnation by the natural union of the sexes. I had several pairs of frogs in a basin of water covered by a glass bell jar, when, having my attention directed for a few minutes to some other object, one pair of frogs spawned suddenly, as I knew by the sound of a plunge or splash in the water, which always occurs after the act, at the moment of separation of the sexes. Nearly the whole of the eggs were deposited in a mass, but there were a few which were detached from the rest, and were lying at the bottom of the water. This seemed a good opportunity to examine these eggs, which had been expelled naturally, singly, in search of the spermatozoa within the envelopes. Fifteen of these detached eggs were placed, each in separate cells, and carefully examined, during the first hour and a half after their expulsion. In the first eight or nine of these eggs, I was not able to detect even a single spermatozoon within their substance, and I began to look upon the previous observations, made by artificial impregnation, rather as the result of accident. In the tenth egg, however, I most distinctly saw spermatozoa in contact with the vitellary membrane, but in one or two eggs examined after this no spermatozoa were to be seen. Out of the fifteen eggs examined, there were only two in which I could detect spermatozoa. As each egg had been carefully marked, and a note made, as to whether or not any spermatic bodies had been detected within it; and as previous investigation had shown, that when any fecundation has been effected the yelk of the fecundated egg becomes depressed, and a chamber begins to be formed, in about one hour, or little more, after the spermatozoon is supplied to the egg, between its upper surface and the investing membrane,-there were ready means of learning, within a short tine, 
whether any, and which of these eggs had been fecundated. At the expiration of one hour and twenty minutes, the temperature being $54^{\circ} F_{A H R}$, the chamber was beginning to be formed in the two eggs in which I had seen spermatozoa sticking in the vitellary membrane, and these bodies were still readily detected in them, and continued to be so for two or three hours afterwards. These two eggs ultimately produced embryos. But no change took place in any of the thirteen eggs, in which I could not detect spermatozoa,-no respiratory chamber was formed within, nor was any embryo produced. It was evident, therefore, that these had not been fecundated, and it is probable that the whole of the detached eggs were those which lad last been ejected from the oviducts, possibly after the act of fecundation by the male had been completed. Having found spermatozoa in two only of these detached eggs, I then examined several of those from the mass. In each of them I found numerous spermatozoa sticking around the yelk membrane, and very many, in the clear space between the membrane and the granular middle portion of the envelope, which had not arrived at the membrane, and in every instance the eggs had been fecundated, as the chanber was being formed at the time of examination, about an hour and a quarter after the eggs lad been deposited, so that the act of penetration by the spermatozoon through the envelopes as far as the vitellary membrane, seemed thus to be clearly established as connected with the act of fecundation. This was the case with all the eggs taken from the upper and iniddle portion of the mass. But in a very few eggs taken from the sides of the mass, I was not able to detect any spermatozoa, within the envelopes, or found only solitary instances of them. In these cases it was remarkable that no chamber had yet been formed above the yelk, although in some, in which spermatozoa were detected, it commenced at a later period, so that these appeared to confirm the deduction from experiment with reference to quantity of influence, or number of spermatozoa required to effect fecundation; while the penetration of the spermatozoa, as far as the vitellary membrane, and the subsequent development of the chamber above the yelk, appeared in the relation of cause and consequence, direct or indirect. I could not then observe, in the eggs thus examined, any penetration by the spermatozoa completely through the vitellary membrane into the substance of the yelk; although numerous spermatozoa were attached, by their larger ends, to every portion of the membrane, sticking out from it at right angles, with what, at first, appeared to be a knob or knot at the distal end, or rather as if that part of the spermatozoon had been shrivelled up or scorched. This appearance, as I subsequently found, was due to a loop, or distortion of the tail of the spermatozoon, consequent, apparently, on the death of this body. It was this looping of the tail which gave the appearance of a thick end to this part of the spermatic body first detected within the envelopes in a previous observation. All the spermatozoa seen in connexion with the vitellary membrane were perfectly motionless; so that when the looping of the tail has taken place the fecundatory influence of these bodies may be held to have been already exercised and exhausted. 
At the expiration of three hour's fiom the commencement of these observations, although the number of spermatozoa which had first been noticed within the coverings of the eggs submitted to examination appeared to have been dininished, there was still an abundance attached to the vitellary membrane. These appeared to afford a good opportunity for endeavouring to ascertain whether any part of the body of the spermatozoon is passed through the membrane into the cavity of the yelk. With this object in view, I placed a glass cell, which contained an egg, on one side, and waited for the rotation, or rather the gravitation, of the yelk within its envelopes. By this change of position of the yelk within its coverings-and which always takes place, if fecundation, or any change in the position of the entire egg, has been effected, - the flattened surface of the yelk, and the chamber above it, were brought beneath that part of the vitellary membrane into which spermatozoa appeared to have sunk deepest,- - so that if any of these bodies had passed, or were in the act of passing, or had been partially protruded through the membrane into its cavity, which contained the yelk, it was fair to expect that they might thus have been detected. But not the slightest trace of penetration, even by a single spermatozoon, could then be observed*.

I may here remark, in anticipation of a future communication, that, previous to segmentation, the mass of the yelk does not appear to be invested by any distinct envelope within its so-called vitellary membrane, but the whole seems to be kept together by the natural coherence of the granules or cells of which it is composed; so that when the position of the egg is changed the yelk mass rotates within the vitellary envelope as a consequence of this change, owing probably to the excentric position, within its substance, of the progeny of the germinal vesicle $\downarrow$, contained in the

* Since this paper was communicated to the Society, I have succeeded, through the adoption of a different mode of examination, in detecting spermatozoa within the vitelline cavity in direct communication with, and penetrating into the yelk. They were first seen by myself, in company with a friend, on the 25th of March of the prescnt year (1853) within the clear chamber abore the yelk, at about forty minutes after fecundation, when the chamber begins to be formed. I have since repeatedly observed them within the chamber, and in some instances still in mution, in which state I have had opportunities of showing them to my friend Professor ELLIS of University College, and to two other medical friends, so that the presence of active spermatozoa within the vitelline cavity in the fecundated egg of the Frog may now be regarded as indisputable. The details of my investigation I reserve for a future communication, and will merely now add, that the spermatozoa do not reach the yelk of the Frog's egg by any special orifice or canal in the envelopes, but actually pierce the substance of the envelopes at any part with which they may happen to come into contact; as I have constantly observed while watching their entrance: sometime after they have entered the yelk chamber they become disintegrated, and are resolved into elementary granules. The importance of this fact of actual penetration by the spermatozoon into the yelk is indicated by W following remark:- "The truth is, the 'how' of the fecundation is as far from our knowledge to-day as it was thousands of years ago; this process is still enveloped in what we feel inclined to consider 'its sacred mystery.' It would be different if we could prove that the spermatozoa really yielded the material foundation for the body of the embryo; that they penetrated into the ovum, and were developed into the animal (which was the assumption of Letuwnem, Andry, Guatier), or else, that they became metamorphosed into the central parts of the nervous system."-G. N., April 18, 1853.

† Philosophical Transactions, Part I. 1851, p. 176. 
middle of the dark hemisphere of the yelk, and which, possibly, may be of less specific gravity than the contents of the light-coloured hemisphere.

The facility with which the yelk can thus be made to rotate, and its flattened surface, and the clear space, or chamber above it,-commenced within one hour after the first encounter of spermatozoa with the egg, -can be brought beneath any portion of the vitellary membrane into which spermatozoa have penetrated,-thus enabled me to observe, within a comparatively short period after fecundation, whether any of those bodies are at that time in the act of passing through it. But although no spermatozoa could then be detected within the vitellary cavity, it must be borne in mind that these observations were made after the commencement of the formation of the clear space, or respiratory chamber, the consequence of a shrinking and depression of the surface of the dark hemisphere of the yelk as the result of impregnation, so that these negative observations did not afford any proof that penetration by the spermatozoon bad not previously taken place. Indeed, all circumstances considered, there seems reason to believe that impregnation is effected very quickly after the encounter of the spermatozoon with the egg, as appeared to be shown in my former experiments with solutions of potass*. It is probable that it is commenced, as then suggested, within a few seconds, or at most a very few minutes, after such encounter; as in one instance of artificial impregnation in some observations made subsequently to those above detailed, I detected a spermatozoon in contact with the vitellary membrane, within one minute after the impregnating bodies had been supplied to an egg beneath the microscope. Certainly I believe that it is commenced, and probably completed, within the first half-hour; because, after that lapse of time, I have not yet been able to detect any change of place or position of the spermatozoa which have passed into the envelopes of the egg; whether they may have already arrived at, and become partially imbedded in the vitellary membrane, or whether they are still contained in the clear substance of the outer coverings, their force of penetration being exhausted before arrival at the membrane. After the lapse of half an hour, and frequently of a much shorter time, the caudal portion of the body of a spermatozoon which has penetrated into the envelopes becomes looped on itself, and this is a certain indication of the death of the object.

As no spermatozoa were seen, in these observations $\psi$, within the vitellary cavity at the early period above stated, it was not to be expected that they were likely to be observed at a later ; although the eggs which had been the subject of these investigations, and which had been fecundated naturally, were continued to be watched until segmentation of the yelks commenced. This took place in the two eggs, in which alone, out of the fifteen first examined, spermatozoa were detected,-at the expiration of five hours and twenty minutes. But this was much earlier than in the great mass of eggs, of which these were a part; and was due to their having been exposed to a higher temperature, owing to heat radiated from my own body during their 
constant observation beneath the microscope,-rather than to that to which the undisturbed mass of eggs was exposed. The temperature of the atmosphere of the room at the time the eggs were deposited was $54^{\circ} \mathrm{F}_{A H R}$., but it gradually sunk to $51^{\circ} .5 F_{A H R}$, and the water in which the eggs were contained to $50^{\circ} \mathrm{F}_{A H R}$. at the time when segmentation commenced, at the end of six hours and thirty-five minutes. In the most submerged it did not take place until six hours and forty-five minutes had elapsed.

In nearly the whole of the eggs of this mass which had been fecundated by the natural union of the sexes, I was struck with the fact that the quantity of spermatozoa which had penetrated into every part of their envelopes was very considerable. Very many of these had arrived at, and were sticking by their larger end into the vitellary membrane, from which they projected like spines from the head of a thistle; while there were many others which had not arrived at this part, their power of penetration being exhausted, and their progress inwards being arrested before they had passed more than half-way through the outer gelatinous coverings. Others, again, had penetrated to scarcely more than their own length into them, while a still greater number were simply in contact with, and adhering to the external surface.

When segmentation took place in these fully impregnated eggs, their yelks seemed to contract more powerfully, and the clear space, or respiratory chamber, formed in each becume much larger than in others from the same mass in which but a few spermatozoa were detected; so that the inference deducible from the fact seemed to be, that a plurality of spermatozoa is necessary for the full impregnation of the egg, and the production of the robust and healthy embryo-although simple fecundation may result from the influence of only a very few spermatozoa, especially when such influence is aided by a considerable increase in the temperature of the surrounding medium.

Mode of Penetration by the Spermatozoon.-The preceding observations on naturally fecundated eggs were so decisive of the fact of penetration by the spermatozoa into at least the envelopes of the egg, and of the arrival at, and partial imbedment of these bodies in the vitellary membrane, that it seemed desirable to make further observations, by the artificial method, with a view to ascertain more directly the mode and circumstances of their entry; and these it was hoped might be learned through the facility with which the egg may be impregnated by direct application of spermatozoa to almost any part of its surface. Accordingly, on the following day, I placed an egg in a glass cell, beneath the microscope, and quickly afterwards applied to one side of it, by means of a pin-bead, a quantity of spermatic fluid, obtained from the male only a few minutes before, and immediately filled the cell with water, and commenced the observation. The fluid was applied four times to the same part of the egg, the pin-head being loaded for each application, in order that a full sufficiency of spermatozoa might be furnished, before the water was added. The temperature of the room at the time of the experiment had been intentionally raised 
to $65^{\circ} \mathrm{FAHR}_{\mathrm{AH}}$, to afford a greater chance of success; as all my previous experiments had shown that more eggs became fecundated at a moderately elevated, than, under otherwise similar circumstances, at a low temperature. The instant the object-glass (the half-inch of Ross's microscope) was brought into focus, a vast quantity of spermatozoa were seen adhering to the surface of the egg at the part to which the pin's head had been applied. Many of them, attached laterally to the surface, had already ceased to move; others, only partially attached by their larger end, still vibrated the candal or ciliated extremity rapidly, but did not appear to penetrate; while others, more centripetally attached by their body portion, vibrated the free extremity rapidly, and were seen in the act of gradually penetrating into the substance of the envelopes. I distinctly recognised one of these bodies which had just entered the envelope to a depth equal to about twice its own length, and when first seen had not reached so far as the middle or granulous layer of the envelope. Its motion was then slightly serpentine, and its course from without inwards was in a perfectly centripetal direction, with its thicker or body portion extended forwards, and in a line with the centre of the yelk, its progress inwards, as seen beneath the microscope, being as continued and as direct as that of an arrow. I kept this object in focus for several seconds, and watched it through the granulous layer, but ultimately lost it in the inore dense and, as yet, unexpanded portions of the inner layers of the envelope, after it had been distinctly seen by a friend, who was with me at the time of the observation. A few seconds afterwards, as the envelopes became more expanded, very many of these spermatic bodies were seen to have already arrived at, and be in the act of passing through the inner or laninated portion of the envelopes, - the portion which, when the envelopes have acquired their full distension, by the imbibition of water, is seen to be that which immediately covers the vitellary membrane. A few seconds later a great abundance of them were seen in contact with the vitellary membrane itself; and some were even partially imbedded by their thicker extremity in its substance, and some of these showed an appearance as if they were actually penetrating through it. But in no one instance could $\mathbf{I}$ then satisfy myself that they did really pass through; since by alternately elevating and depressing the lens, and carefully noticing when the margin of the vitellary membrane was most distinctly defined, the appearances of perforation which some of them showed, seemed to be due to the spermatic bodies being imbedded in the membrane at some inclination to the plane of observation and to that of their direction being not quite centripetal. Yet there were other circumstances which seemed to show a likelihood that some spermatozoa do actually pass through the membrane. Thus, within the first few minutes after the impregnating fluid had been supplied to the egg under observation, and at the time when the spermatozoa, which had penetrated its envelopes, were first seen to have arrived at, and begun to enter the laminated portion, or zona pellucida, some of them were noticed to pass gutudually onwards for a time, and then suddenly to disappear in an instant; as if, having passed into this tissue, they had also escaped 
through the vitelline membrane which it covers. This mode of disappearance certainly is that by which the spermatozoa might be supposed to penetrate to the yelk, if in reality they do so*. Thus, presuming the body, or thicker portion of the spermatozoon, to perforate and pass through the vitelline membrane, the more slender or tail portion would follow quickly. But if this occurs with some, then it would be fair to expect that it would happen to the whole which arrive at and become partially imbedded in the membrane; especially to those which have sunk into it to a depth equal to one-half the length of the thicker or body portion; or, further, that the progress of others might be arrested before they had completely passed into the vitelline cavity; and, consequently, that some would occasionally be seen protruding into the interior. But I was not able, in the instance of the observations now detailed, nor in other's afterwards made, to prove either of these suggested conditions.

In. the observation now referred to, as well as in others since made, there were many spermatozoa which remained distinctly visible for several hours, in the same place, and in almost precisely the same position, sticking into the vitelline membrane, and retaining, at the end of a lengthened period, the same appearance as at first, excepting only that they seemed to have become smaller in diameter and to have their caudal portion more looped. In the present instance, at the high temperature of $65^{\circ} \mathrm{F}_{A H R}$. to $66^{\circ} \mathrm{F}_{\mathrm{AHR}}$., not only were they distinctly seen at the commencement of segmentation of the yelk, which happened at the end of three hours and twenty-two minutes, but many of them were present until after the yelk had undergone several of its subsequent divisions. This was the case not only with those which had arrived at the vitelline membrane, but also with others which had never reached it, and had not penetrated further than to about the middle, or granulous portion of the envelopes; as happened with many spermatozoa, both in the eggs which were fecundated naturally, as well as in those which were the subjects of experiment, and were artificially affected. It was those which remained in the substance of the envelopes which usually disappeared earliest, becoming at first gradually fainter, and then more undefined in outline. This change was supposed to be due to a gradual diffluence of the substance of the spermatozoon, through the influence of the water imbibed by the envelopes; but whether this happened as part of the fecundatory process, or whether it was simply the natural process of decay, as other circumstances to be mentioned seemed to intimate, there was no distinct proof. It was remarkable, however, with reference to the act of fecundation, that in almost every instance, even of those spermatozoa which never arrived at the vitelline membrane, the body portion was always directed towards the yelk, usually peripherally, but sometimes inclined at slight angles to one side or the other; thus showing that it is invariably the body portion which penetrates.

* That this is really the fact, and that the actual penetration by the spermatozoon into the yelk chamber was observed on this occasion, is now rendered almost certain by my recent observations stated in the preceding note, p. 271.-G. N., April 18, 1853.

MDCCCLIII. 
It may be matter of surprise, that, considering the immense quantity of spermatozoa which exist even in a microscopic drop of fluid, and considering also the abundance which come in contact with the surface of the egg, even when but a small quantity of fluid is employed, as in artificial impregnation, a much greater number do not penetrate jthan are usually observed to do so. There are conditions and circumstances which affect this result. Thus I have found, in repeated observations, that only those spermatozoa which, at the moment of first contact with the egg-envelopes, are in rapid action, and have their body portion directed, either perfectly centripetally towards the yelk, or at angles but slightly inclined to it, do by any possibility enter; while those which happen to be directed horizontally to the surface of the egg at the instant of contact, always adhere to it laterally, and lose their power of motion, but do not penetrate; and the like also is the case with those which become attached by their caudal end, and even with many which adhere by their thicker end, when they come into contact with the egg at very acute angles. Further, I have noticed, that a relatively nuch greater number of spermatozoa penetrate the envelopes when supplied to the egg immediately after this has been removed from the female into water; - especially when the sperinatic fluid also has been recently passed from the male;--and more decidedly so when passed from a male in full season, at which time the inovements of the spermatozoa are most energetic. Thus the chances of penetration through the envelopes, and consequently of fecundation of the egg by the spermatozoon, are in direct relation to these circumstances; and inversely to those of an opposite character, being less in proportion to the length of time the egg has been removed from the female, or the fluid from the male; the healthfulness of the parent, and consequent power of motion in the spermatozoon; - the temperature of the season, and the quantity supplied to the egg.

These were the conclusions deduced from the previous observations, and they have been fully borne out by subsequent experiments, some of which have been made in the presence of my friends Professors Bell, Bowman, Carpenter, and Mr. Busk, Fellows of the Royal Society, and Professor Elurs, who permit me to mention the circumstance.

Narcotization of the Spermatozoon.-I may now mention some experiments which were inade with the view to test the fecundatory influence of recently obtained spermatozoa when narcotized by chloroform. These experiments were suggested by a communication made to me by Mr. Busk, F.R.S., who, after witnessing my mode of procuring the eggs of the Frog, conceived that a similar result might be attained by narcotizing the gravid animal without killing it, as is necessarily done in my experiment; and on putting this opinion to the test be found that it may be accomplished with ease and success. It then occurred to him to try the effect of exposing the sperinatozoa to the vapour of chloroform, by simply covering the spermatic fluid contained in a watch-glass covered with blotting-paper wetted with the liquid, 
and afterwards to apply the narcotized bodies to some eggs in the way done by myself.

The facility with which the spermatozoa can be narcotized by the inode now mentioned has enabled me to test the relation of their power of motion to that of their fecundatory property, and although my results differ somewhat from those obtained by Mr. Busk, it may be well, perhaps, to relate them.

MM. Prevost and Dumas found, in addiition to their many other excellent results, that spermatozoa are rendered motionless by an electric shock, and that then they do not impregnate the egg. They also found that opium and strychnine have a similar paralysing effect on these bodies. But it has since been suggested that the latter agents act on these bodies only in so far as they affect the cliemical composition of their substance, and that the operation of electricity on them also is similar. But it yet remains to be shown whether any chemical change is produced in the substance of the spermatozoon, when simply narcotized by the vapour of chloroform, and not mixed with it in the fluid state; and when, although the power of motion is arrested, the vitality of the body is not destroyed.

Three eggs were placed in separate cells, and the spermatic fluid, immediately it had been obtained, was applied, once only to each, by means of the pin's head. These trials with the fluid in its natural state, mixed only with a small quantity of water, were made for the purpose of comparing their results, with those of others to be made with portions of the same fluicl after it had been narcotized, and applied to eggs in this state at different periods. One minute after the application of the fluid I found an abundance of spermatozoa on the surface of each egg at the part touched, and some spermatozoa had not only already penetrated into the envelopes, but lad arrived at, and were in contact with the vitelline membrane, or rather the zona pellucida. The respiratory chamber was afterwards formed above the yelk in each of these eggs, and two of these subsequently formed embryos; the third was only partially fecundated.

The spermatic fluid was then exposed to the influence of chloroform, in the way mentioned, about fifteen minutes after it had been obtained; and after seven minutes' exposure to it, and when the majority of the spermatozoa it contained had become narcotized, was employed in experiments. The signs of full narcotization are the entire cessation of all motion in the spermatozoon, which lies with its body extended at length, and not looped on itself. In the latter condition it is usually dead.

Three eggs placed in separate cells were then supplied with the narcotized spermatozoa applied to each egg three times by means of the pin's head. On examining the eggs six minutes afterwards, I was unable to detect even a single spermatozoon within the envelopes of either of them, either in contact with the vitelline inembrane or in any part of the substance of their envelopes; although there was a great abundance of perfectly motionless spermatozoa on the surface. No chamber was formed above the yelk in either of them, nor did either of them produce an embryo. 
Twenty minutes after narcotization, and during which time not a single spermatozoon had been observed in motion, a portion of them were applied in the same way as abore to three other eggs, but not one of these became fecundated, no chamber being formed within them, and no embryo was produced. Many of the spermatozoa at this time were dead, as was shown by the looping of their bodies, but there was still a quantity which had been simply narcotized and lay extended at length.

One hour after narcotization another portion was applied to two eggs, one of which became partially fecundated. The chamber appeared in it above the yelk, the yelk underwent segmentation, and afterwards an embryo was begun to be formed, but its developnient was not completed, and the egg then perished. The second was not. fecundated. The circumstance of this egg having been fertilized at so long a period after the fluid had been nurcotized, leads to the conclusion that impregnation had been effected by revived spermatozoa.

On the following day I repeated these experiments with very mature fluid immediately after it was obtained, and in which the spermatozoa were exceedingly vigorous. One minute and a half after it had been exposed to chloroform, I found that the same effect had been produced on the spermatozoa as that which is produced in them by their admixture with very weak solution of potass; their power of motion was greatly increased, and the whole were in a state of intense action. After a few minutes' longer exposure their motion was perceptibly diminished, and at the end of about ten minutes it had almost entirely ceased, as only $a^{\prime}$ few of them were then observed to move.

Three eggs were supplied, by means of the pin's head, with these narcotized spermatozoa. The respiratory chamber was formed in two of these eggs, and one of them underwent segmentation, and at the end of the fifth day an embryo had begun to be produced, but its development did not proceed, and this egg like the other two perished.

Six eggs were then supplied copiously by means of the loaded pin's head, three times applied to each, nearly the whole of the spermatozoa employed being then motionless, and having already remained so for about ten minutes, only an occasional one being observed in feeble action. Two of these eggs became partially impregnated, the usual chamber being formed in them, but neither of them underwent segmentation, nor was any embryo formed either in these or the others.

Three eggs were then supplied as above after the spermatozoa had been notionless during twenty minutes, not one being observed with the slightest action at the time of the experiment. No chamber was formed in either of these, but the whole remained unimpregnated.

Three eggs were the subject of further trial, when the spermatozoa employed had been motionless during half an hour. At this time one or two spermatozoa were again observed to be in feeble action, but no impregnation was effected.

Thirteen eggs were employed when the spermatozoa had remained motionless 
during one hour, and when there was reason to believe that the majority of them had perished, but when there were still a very few among them in motion, having either revived, or but recently escaped from spermatozoal cells contained in the fluid. No impregnation took place in either of these instances.

Thus the results of these experiments appear to show that the spermatozoon does not impregnate when entirely deprived of its power of motion by narcotization, and disenabled to penetrate into the envelopes of the egg; and, consequently, that its fecundatory power has a close relation with its motion, or force of vitality. In this, then, they coincide with those of the previously detailed experiments, and go with them to show that the act of fecundation of the egg of the Frog, and probably also of all the Vertebrata, is the result of a power in the spermatozoon, which, in its operative condition, is characterized by motion; and that this power is totally independent of everything approaching to volitional influence, in the impregnating body, but seems to be in direct relation to physical causes.

MM. Prevost and Dumas appear to have thought that the spermatozoa which they observed within the cgg-envelopes had entered through means of the infiltration, or imbibition of water by the envelopes; and the gist of their experiments was to show that particles of solid matter do enter during such infiltration, or, as it has since been designated, endosmosis. But some experiments, elsewhere detailed*, have led me to believe, that only such solid particles as are very mucl smaller in diameter than the spernatozoon can so enter with the water by endosmosis; while the circumstances now detailed fully prove that the entrance of the spermatozoon is not the result of simple infiltration, but is that of the operation of direct mechanical or physical power in that body. Thus, if it were mainly dependent on endosmosis, the perfectly motionless spermatozoon would enter the tissues and fecundate the egg equally well with the active, but this, as we have seen, is not the case, and this was shown by the physiologists now referred to. On the other hand, the circumstance that the spermatozoon invariably enters the tissues with its thicker or body portion directed forwards, and sometimes even at an angle slightly inclined to the centre of the yelk, and always impelled by an oscillatory or vibratile motion of its caudal portion, seems to show that its power of penetration is not only a necessary condition of its function, but is inherent as such in its organic composition. It may yet be true, nevertheless, that the passing of the spermatozoon through the substance of the envelopes to the vitellary membrane may be indirectly aided by the endosmic action of the envelopes. But this aid does not consist of any imbibing property in the tissues. It appears to be simply of a negative character, and to be the result of a decrease of density in the tissues, which, through their imbibition of water, and consequent expansion, are caused to offer less and less resistance to the propulsive force of the spermatozoon. 'This I believe is the proper explanation of the fact of penetration by this body.

But although penetration be not caused by the endosmic action of the envelopes,

$$
\text { * Philosophical Transactions, 1851, p. } 224 .
$$


it may yet be thought to be induced by some attractive power in the substance of the yelk itself; and that, therefore, the entrance of the spermatozoon may be as much due to the egg as to any power of motion in the penetrating body. An accident has enabled me to test the validity of this surmise.

I had promised to show the fact of penetration to a friend, but circumstances prevented me from doing so until the season had nearly passed, and the whole of my frogs had spawned. I determined therefore, as a last resource, to endeavour to obtain some fecundatory fluid from a male which had already paired two or three days previously, and to employ it with the only eggs I had then left, which remained in the body of a frog that had been killed twenty-six hours before, and which, as former experiments had shown, it was probable had lost their vitality. The fluid required was obtained with ease, but mixed with a large quantity of spermatozoal cells. This was supplied to some eggs from the dead frog, since, although I did not expect that the eggs would be fecundated, I hoped for an opportunity of again witnessing the penetration by the spermatozoon. The spermatozoa in the fluid obtained were very active, and fully efficient, and were supplied in abundance to several eggs in separate cells under the microscope. The envelopes of the eggs expanded as usual, and endosmosis went on in a perfectly natural way, and an abundance of spermatozoa adhered to their surface. At the expiration of from fourteen to twenty minutes $I$ found that several spermatozoa had penetrated the envelopes and were adhering in the usual way to the vitelline membrane. In one egg there were six, in another five, and in a third four, distinctly visible in the plane of observation that could be brought at once within view with the microscope, besides others recognisable on changing the focus. It was thus evident that spermatozoa, even of the previously paired Frog, still retained their power of penetrating into dead eggs, as these ultimately proved to be, after careful preservation to the sixth day in a favoniable temperature. The spermatozoa were distinctly visible within the envelopes, without change of position, for several hours, but no fecundation was effected by them; no chamber was formed in either of the eggs, no segmentation took place, nor was any embryo produced. These circumstances seem to show that the eggs were already dead, as was supposed, before contact of the spermatozoon; consequently that the entrance of the spermatozoon into the envelope is due to a power inherent in the penetrating body, and not simply to an attraction on the part of the yelk; although from the fact that the spermatozoa usually enter in a centripetal direction, it is probable that some influence may be exerted by the yelk or its vesicle, although penetration is mainly the result of force in the spermatozoon.

The facts now stated of penetration by the spermatozoon seem to lead us better to understand the nature of some experiments with solutions of caustic potass, which are detailed in my former paper. I bave repeated these experiments, during the past season, in the presence of several friends, Professors Sharpey, Ellis, and Bell, and Messrs. Busk, Tomes and Waterhouse, with results precisely similar to those which 
are detailed in that paper; viz. that when diluted spermatic fluid, recently obtained, is applied to a set of eggs, and-as soon afterwards as the experiment can be made, a solution of potass, - of such a strength as is known by previous nicroscopic observation to have the property of instantly decomposing the spermatic body,-the solution being washed away quickly after its application, by repeated quantities of water,to prevent its affecting the egg itself-that then-in some instances-even when the interval of time between the application of the spermatic fluid and the subsequent application of the potass does not exceed a few seconds, -impregnation of the egg is effected; as is proved by the formation of the chamber, the segmentation of the yelk, and perhaps the formation of an embryo. Further, that, all circumstances being similar, excepting only that the interval of time between the application of the spermatic fluid, and, subsequently, that of the solution of potass be prolonged,- the production of an embryo is not only more certain to take place, but the number of embryos produced is increased. The now ascertained fact of almost instantaneons penetration by the spermatozoon, which, as before shown, sometimes arrives at the vitelline inembrane in less than one minute after its application to the egg, confirms the principal conclusion deduced from the potass experiments at the time they were made, viz. that impregnation is commenced at the instant the spermatozoon is in contact with the egg; while it also seems to afford the true explanation of the nature of those experiments, in which it may now be presumed that some spermatozoa had actually penetrated into the substance of the envelopes before the application of the solution of potass, and thus had already passed out of the reach of its destructive influence, the effect of which on the egg itself was obviated by speedy dilution and ablution with water.

The potass experiments may thus be regarded as confirming by anticipation the results now obtained by direct observation with the microscope, with respect to the rapidity of operation by the spermatozoon; and they seem also to support the view of the essentiality of the motor power of this body to its functional action. A similar view may be taken, as indeed was held at the time, of the nature of the Carmine, the Gum, and the Starch experiments, that the operation of these substances in preventing the fecundation of the egg is entirely mechanical, and that they do so simply by offering a mechanical impediment to the spermatozoon, a conclusion which seems to be fully supported in the present inquiry.

\section{NATURE OF THE INFLUENCE OF THE SPERMA'TOZOON.}

Having seen in the preceding experiments and observations that fecundation of the egg is effected by the spernatozoon only while this body retains and continues to give evidence of its vitality in its power of motion, and that its vitality either may be destroyed, or its operation be for a time entirely arrested by electricity and by chloroform, - the question naturally arises-in what way, then, is its fecundatory influence to be explained? Is it simply by diffluence of the substance of the spermatozoon, and the chemical fusion or combination of this with the contents of the egg, after the sper- 
matozoon has penetrated through the envelopes and arrived at the vitelline membrane, or the yelk: Or is it by its expenditure on the yelk, of a force or power of vitality, which is inherent in the body of the spermatozoon? Or is it by the joint cooperation of both these conditions-the expenditure of a force with diffluence of material substance? I have endeavoured to put the first of these questions to the test of experiment;although, it must be remarked, that the experiments made seem to be open to some objections, which at present cannot be fully answered. Yet knowing what we do of the disposition and great readiness of all matter to enter into new combinations, and affect, or entirely change the condition of the whole body operated upon,-as, - not to mention the effect of the poison of serpents, or the introduction of dead inatter into the living, in dissection,- - can be shown in the effect, on the yelk of the Frog's egg, of extremely minute quantities of chemical compounds diffused in water,- - there has seemed fair reason to think that the question thus started may be examined by experiment. The rapid endosmic action of the envelopes of the egg at the instant of their contact with any aqueous fluid, and the rapidity with which the yelk itself then becomes affected, seemed to favour the idea that if the bodies of the newly obtained spermatozoa could be quickly reduced to a state of diffluence simply by mechanical means, without the addition of any menstruum, saving only a very small quantity of water, and be applied in this state of diffluence to the egg at the instant after it has left the body of the female,- - that then an experiment thus made would be a fair test of the question. Some imbibition of the substance of the spermatozoon with the water might thus be expected to take place, and some changes in the egg to follow, if impregnation be the result of simple chemical combination of the substance of the male with that of the female. The presence in the experiment of a portion of water holding the diffluent spermatic substance in suspension, appeared at first sight to be an objection, but this seemed to be met by the fact that water must always be present to ensure the natural fecundation of the Frog's egg ; and that it not only permeates the envelopes, and is the means of facilitating the entrance of the spermatozoon, but that it passes even to the substance of the yelk itself, as shown in the experiments with large quantities of potass before alluded to, and also in others made by immersion of eggs in water with given proportions of potass in solution. As the details of these latter experiments are contained in a paper which is now in the Archives of the Royal Society*, I need give but little more than the results of these experiments, in the present communication, before proceeding to relate those now referred to with the diffluent spermatozoa.

Immersion of Ova in Solutions of Potass and Soda.-These experiments were commenced in April 1850, before the publication of some which were made with solutions of caustic potass, by M. Quatrefages, on the spermatozoa of one of the marine worms, Hermella, and read to the Institute on the 24th of June $1850 \uparrow$.

* MS., No. 762, p. 13 to 26 ; also Proceedings, vol. vi. p. 83.

† Comptes Rendus, June 24, 1850, and Annales des Sciences Naturelles, $3^{\text {me }}$ série, tom. xiii. in Nos. marked "February" and "Marck. 1850." 
The object which I had in view was to endeavour to learn what proportion of the carbonates of potass and soda may be present in a given quantity of water without destroying the fertility of the egg. The first trials with potass were made with eggs which had already been fecundated, and were undergoing segmentation. It was then found that when fecundated eggs, alrived at the second stage of segmentation of the yelk, were immersed in a solution, composed of twenty grains of the fused carbonate of potass to one ounce of water, the yelks became shrivelled, and decomposition was commenced within three minutes after immersion; thus proving that even when the envelopes of the egg are almost fully expanded, and, consequently, when their endosmic action may be expected to have become greatly diminished, that endosmosis may still be going on with much energy. It is right to mention, however, that in this and the following experiments, the endosmic action may have been, and probably was, increased by the removal of the eggs $\rightarrow$ which already retained water in their tissues-to the more dense fluid solution; but as the experiments are comparative, the circumstance is not of much importance.

On the contrary, when some eggs were immersed in a solution of one-fourth of a grain of the salt to one ounce of water, and the potass in admixture with the water was thus reduced to $\frac{1}{1920}$ th part of the whole, development went on more quickly than in other eggs of the same brood, impregnated at the same time, but which were placed in pure water apparently through the potass occasioning a slight increase of temperature.

These results appear to be explicable only on the assumption that the weak potass solution acts as a chemical stimulus, - perhaps both to the egg and to the spermatozoon, - at the time of fecundation, a view which derives some support, in so far as refers to the spermatozoon, from direct observation with the microscope. Thus, when a drop of the two-grain solution of potass is applied to spermatozoa on a plate of glass, covered with talc, beneath the microscope, the movements of these bodies are not instantly arrested, as by the stronger solutions, but gradually become slower and slower, until they entirely cease, apparently, in proportion as their substance becomes affected by the potass. 'The one-grain solution very much accelerates the movements of these bodies during the first few seconds; but in a few seconds longer these also become diminished like the preceding. But the effect of the half-grain solution, although exciting the spermatic bodies to activity as soon as it comes into contact with them, continues its effect for a much longer time withont acting injuriously upon their substance; and it is not until after the lapse of many minutes that the intensity of the motion excited by it is observed to be diminished, and the movement to slacken and afterwards gradually cease.

With regard to the carbonates of soda, I may state that the general effect of these on the impregnated and on the unimpregnated egg are very similar to those of potass, but are far less prejudicial, or marked, so that it is unnecessary to detail the experiments. 
The general conclusions deducible from these observations, with reference to the nature of the influence of the spermatozoon in impregnation, seemed to be, that as water which holds in suspension or solution any chemical substance, conveys some portion of that substance at all times, with great rapidity, to the immediate vicinity of the yelk itself, which becomes affected by it, and especially so at the time of its first coming into contact with the envelopes of the newly deposited egg, - the substance of the spermatozoon also, if diffused in water, might be so conveyed, in the experiments proposed. In addition to this conclusion, there are others, which, although less directly connected with the object in view, are not less inportant. Thus it appears that an alkaline fluid, in large quantity, is as injurious to the vitality and fecundatory influence of the spermatozoon as to the fertility of the egg.

Trituration Experiments.-The endeavoul in these experiments was to put to the test the question proposed in the preceding observations, - whether, if the spermatozoon be reduced to a state of diffluence in water quickly after it has left the body of the Frog, and before it can reasonably be supposed that any change in the chemical constituents of its body has taken place, the egg can be fecundated through simple imbibition of the substance of the spermatozoon, conveyed to the vicinity of the yelk with the water during endosmosis, at the time when endosmosis of the envelopes of the egg is most energetic?

Although it had been constantly found, both by the authorities before cited, and since by myself, that when the spermatozoon has ceased to move, and is believed to be dead, no impregnation results from the contact of its motionless body with the egg; yet there still appeared to remain some doubt as to what this want of operation is then due; whether it is to be attributed to the organic death and incipient decomposition of the body, or whether to the loss or suspension of some power which is characterized by motion, and through which its function is exercised ?

The following experiments, with reference to this question, were commenced before I was aware of the fact that the spermatozoon penetrates into the envelopes of the egg; a fact which, when known, seemed further to necessitate the inquiry, as probably tending to show whether impregnation is merely the result of a union of the substance of the spermatozoon with that of the yelk or its vesicle; or whether it be not primarily due to the transmission of some dynamic influence, force, or peculiar vitalizing power from the spermatozoon to the egg at the time of, or previous to any fusion with it of its material substance.

The first experiments were made by breaking down the bodies of the spermatozoa mixed with water, and, after filtration, applying the filtered liquid directly to the egg; the following being the method pursued:-

The bottom and sides of a very small glass mortar, and the glass pestle employed with it were ground together with fine sand and water, for the purpose of slightly roughening their surfaces, and of ensuring their contact at every part, and thus to render the crushing of the spermatozoa more certain. 
The spermatic fluid first employed was procured from a Frog early in the season, and consequently contained a large quantity of spermatozoal cells from which the spermatic bodies had not been liberated. A difficulty immediately occurred which had not been anticipated. The fluid was divided into two parts, one of which was triturated gently with the pestle and mortar for two minutes, and was then examined with the microscope. It still contained an abundance of active spermatozoa, and many cells. The trituration was continued for three or four minutes longer, without any marked result, as active spermatozoa were still abundant in the specimens of fluid examined. It was then repeated for several minutes with increased rapidity and force, when the fluid suddenly became partially coagulated, and separated into opake white flocculi, composed almost entirely of cells and granules, and a transparent fluid in which there were searcely any granules. It was then found that nearly the whole of the spermatozoa had been destroyed, as I was not able to detect even one in motion. The thinner portion only of this fluid, when placed on the filter, passed through, and it did so with great slowness and difficulty.

These circumstances are stated to show the mode of proceeding, and the accidents to be guarded against. The conclusions deduced from these trials were, that the spermatic fluid was not fully matured, and probably contained albumen, which, it is stated*, does not exist in mature spermatozoa; also that the substance of the spermatozoa had undergone some chemical decomposition, perhaps from excess of heat evolved in the act of trituration, through too much force being employed; so that the results of these experiments could not be depended on. A further trial was therefore made a few days afterwards. The fluid obtained from a mature Frog was divided into two'parts, one of which was reserved for simple artificial impregnation; while the other was triturated slowly and carefully in the mortar with but little more exertion than was necessary to keep the pestle in constant motion for about fifteen minutes; no water being added to the fluid. When placed on the filter it became necessary to add to it about an equal quantity of water to facilitate its filtration. Portions of the fluid which then passed through, holding the substance of the brokendowu spermatozoa in solution, were caught in separate glass cells.

Ten eggs were passed into a cell about half filled with the filtered fluid, and the cell was afterwards filled up with water. No other change than a slight enlargement, after the lapse of some hour's, occurred in these eggs; no chamber was formed, nor did any segmentation take place in either of them, consequently no embryos were produced.

Fifteen eggs were placed in a cell which contained about half the quantity of filtered fluid employed in the preceding; but no fecundation took place in either of these eggs.

Eleven eggs in a third cell with filtered fluid were equally unfruitful.

Ten eggs in a fourth cell gave similar results.

* Article "Semen," Cyclop. Anatomy and Physiology, vol, iv. p. 506. 
One hundred and forty-seven eggs were then placed on the topmost of the filter papers, which bad been employed in separating the fluid used in the preceding trials, and on which were the remains of the broken-down spermatozoa, with, probably, some which had not been injured. This was about four hours and a half after the spermatic fluid had been obtained, so that on this ground but little success could be expected. Not a single embryo was produced.

The portion of reserved fluid which had not been triturated was then applied to four eggs in separate cells, by means of the pin's head, when each of these eggs became fecundated, and not only underwent seginentation, but each afterwards produced an embryo. As this experiment was made for the purpose of comparison with the preceding, it is clear that the failure in the case of the mass of eggs on the filter paper was not due to the length of time the fluid had been obtained, but to the effect of trituration; and it seems equally clear that the substance of the broken-down spermatozoa dissolved in water and passed through the filter is as inefficient as the liquor seminis has heretofore been proved to be*.

These experiments were afterwards repeated, in the presence of Professors Sharpey and EuLis, with similar results. Usually there are still some spermatozoa which escape being crushed during trituration, and, being uninjured, remain on the filter paper capable of effecting impregnation when eggs are passed upon it in water, as was the case on the following occasion.

Seventy eggs were first added to some filtered fluid, which resulted from the trituration of spermatic fluid, and had passed through four filter papers, but not one egg became affected, not one embryo was afterwards produced from them; while of sixty-two eggs placed on the topmost filter paper in water, amidst the remains of broken-down spermatozoa, with many which were still active and uninjured, more than one-third of the eggs became fertilized, and twenty-three afterwards produced embryos.

It was thus evident that no impregnation results from an immersion of the egg in fluid which is derived from the broken-down body of the spermatozoon, mixed with water, and separated from the more solid parts by filtration. But as some objections may fairly be offered as to the validity of this experiment, it seemed desirable that trial should be made without having recourse to filtration, and without removing any portion of the destroyed spermatozoon; but, on the contrary, by applying the whole of the triturated fluid immediately to the egg before it is immersed in water; and at the same time to compare the result obtained with that of an experiment by simple artificial impregnation, with a sample of the same spermatic fluid which had not been triturated; the experiments in both cases being made at the same time, and with eggs from the same female, and placed under precisely similar conditions in regard to light, heat, \&c. A comparison of the relative number of embryos which might result from these experiments, it was thought, would show, not merely whether

* Philosophical Transactions, 1851. 
impregnation can or cannot be effected by the direct application of the diffluent substance of the spermatozoon to the egg, but also whether the influence of the spermatic body is essentially dynamic in its character.

The quantity of spermatic fluid obtained for these experiments, mixed with a sinall proportion of water, measured about fifteen minims; and to this a further quantity of water was added, making the whole thirty minims. This was divided into three equal portions. The first portion (a) was triturated slowly and contincously for fifteen minutes, after which it was slightly turbid, and on examination with the microscope was found to contain a large quantity of granules, each of which did not exceed in size one half of the diameter of a spermatozoon. It also still contained a good abundance of active spermatozoa, although the quantity of these was greatly reduced, and the movements of those which remained were impeded by the quantity of granules. The second portion of fluid $(b)$ was triturated with the addition to it of about one grain weight of well-washed sand, and after three or four minutes presented a turbid appearance. At the end of seven minutes, when examined by the microscope, it was found to contain a great abundance of organic granules, intermixed with the sand, and the number of sperinatozoa had been greatly reduced; and three or four minutes later nearly the whole of the spermatozoa were destroyed. The following experiments were then made with eggs obtained from the female with which the male that supplied the fluid had been paired. The temperature of the atmosphere at the commencement of the experiments was $57^{\circ} \mathbf{F}_{A H R}$, and that of the water employed $55^{\circ} \mathrm{F}_{\mathrm{AHR}}$. At the end of the experiment, the commencement of

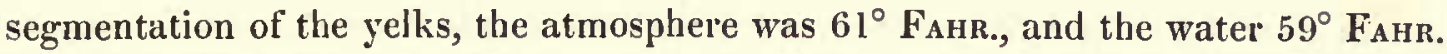

One hundred and seventy-nine eggs were passed into a glass dish, and the triturated fluid $(a)$ was immediately poured over them, and the dish quickly filled with water. The yelks of many of the eggs soon became irregular and contracted, and at the end of four hours and thirty-one minutes seginentation had commenced in some of them, and ultimately, sixty-seven embryos were produced; so that one hundred and twelve eggs were not fecundated.

One hundred and sixty-seven eggs were passed into a second dish, and the fluid (b) which had been triturated with sand was immediately added to them, and afterwards the dish filled with water as in the preceding. But not a single egg becaine fecundated, nor was a single embryo produced. It must be stated, however, that much of this result was afterwards found to have been due to the admixture of sand with the fluid acting mechanically, as I shall presently show.

Two hundred and thirty-nine eggs were also passed into a dish of the same dimensions as the preceding, and the third portion of fluid $(c)$ reserved for simple artificial impregnation, and which bad not been triturated, was supplied to them at, as nearly as possible, the same time as the triturated fluid to the preceding. 'This was at thirtyfive ininutes after it was obtained. Segmentation commenced in nearly the whole of these eggs in four hours and fourteen minutes, and at the end of the fifth day two 


\section{MR. NEWPORT ON THE IMPREGNATION OF THE OVUA IN THE AMPHIBIA}

hundred and six embryos were produced, so that only thirty-three eggs failed; thus leading to the inference that the failure in the experiments $(a)$ and $(b)$ was owing to the spermatozoa being destroyed; and, consequently, that the application of the substance of the body of the spermatozoon to the egg is not alone sufficient to effect fecundation; so that fecundation cannot be regarded as the result of simple chemical combination of the substance of the spermatozoon with that of the egg, but, essentially, may be due to some dynamical influence in that body.

At the time of making these experiments I made also two others with a view to this hypothesis; and for the sake of correct comparison employed eggs from the same female, and placed them in a precisely similar condition with regard to light, heat, and the quantity of water employed. The fecundatory fluid, however, was not from a male in full season, as above, but was what may properly be regarded as senile, it being purposely obtained from some frogs which had been kept separate from the females, having already paired and spawned from five to ten days previous. It was slightly translucent, and contained, relatively, but few living spermatozoa, the majority of which were languid in their movements; but there were many which appeared perfectly dead and motionless, and there was a good proportion of spermatozoal cells. In the first experiment one hundred and sixty-seven eggs were supplied with a portion of this fluid, and segmentation commenced in some of them in four hours and forty-two minutes, or not so soon as in the experiment $(c)$ by twenty-eight minutes, and afterwards only forty-three embryos were produced. In the second trial, made at the same time with one hundred and seventy-three eggs, segmentation took place in four hours and forty-one minutes, and one hundred and twenty-six embryos were produced, forty-seven eggs being unimpregnated. If the difference in the length of time which elapsed between the encounter of the spermatozoon with the egg and the commencement of segmentation in these two experiments, as compared with the preceding one, be not fairly referable to a less degree of vitalizing power in the spermatozoon in the latter, it seems difficult to understand to what other cause it can be assigned; seeing that the eggs employed were from the same female in each experiment, and that all the conditions were similar. It seems, as it were, inversely, to show, that the most important condition of the impregnating agent is its possession of some dynamical quality, the degree or intensity of which is expressed in that of its power of motion, and which, possibly, it may transmit from itself to the egg, during the act of fecundation.

These results sufficiently mark the injurious effect produced on the fecundatory fluid by trituration, whether with or without admixture of foreign substances; and while these seem to prove that attrition of the spermatic bodies with particles of solid matter, by lacerating and mechanically destroying them, is fatal to their function, other experiments showed that even their simple admixture with any finely comminuted solid materials greatly interferes with their operation, by the mechanical impediment which such materials oppose to their free motion, and to their penetra- 
tion into the envelopes of the eggs, whether such admixture be made with the bodies themselves, or with the water in which the eggs are immersed before they are supplied to it.

The question proposed in these experiments by trituration we may now look upon as to some extent, if not entirely, answered; as it seems that although the spermatozoon be broken down mechanically before any chemical change can be supposed to have taken place in it,-indeed, at the very time it is giving evidence of its vitality, - and its organic substance so broken down be quickly afterwards brought into contact with the egg in water, at the moment when the egg is most susceptible of its influence, yet that no fecundation is then effected by it. It may be urged, it is true, that there was no direct proof that the spermatic substance was actually conveyed to the yelk by, or with, the water in these trials; but there was one circumstance which gave fair reason to believe that it really was so conveyed. The yelks of some of the eggs became much contracted, and, as it were, shrivelled, as when affected by potass solution; of the penetration of which to the yelk there is absolute proof in the decomposition of the egg which quickly succeeds to its introduction. It has also been shown in a preceding experiment (p. 24l) that the yelk becomes similarly affected when decomposing spermatic fluid is applied to it.

The conclusion then which seems to me to be deducible from these investigations is, that fecundation is not simply the result of a mere fusion or chemical admixture of the substance of the spermatozoon with that of the egg; although such fusion, probably, is necessary to the production of the organized body of the embryo, in determining its structural and psychical peculiarities, and its definite species; and more or less of which may, possibly, belp to determine the sex, and the extent to which the structural and psychical peculiarities of the male parent are transmitted to the offspring. That this fusion of some portion of the spermatic substance with the egg does actually take place, either when the spermatozoon has arrived at, and become imbedded in the vitelline membrane, as in the Frog; or, as stated by a recent observer*, to occur in the Ascaris Mystax, when it is in immediate contact with the yelk itself, is probable, from the considerations now adduced. These views are countenanced by the now established fict that the spermatozoon of the Frog, and probably also of other Vertebrata, does not fertilize the egg either when it is perfectly motionless, - whether from actual death, or from suspension of vitality by narcotization; nor even, as we now find, though living, while simply in contact with the surface; nor until after it has actually passed into the envelopes, and arrived at the immediate vicinity of the yelk,-facts which seem, I think, inferentially, to show a probability that, whatever conjugation of materials may be effected, some vitalizing dynamic influence is also expended by the spermatozoon on the contents of the yelk in the production of its changes, - phenomena which have not been found to take place

* Dr. Nelson, "On the Reproduction of the Ascaris Mystax," Proceedings of the Royal Society, vol. vi. p. 86. Philosophical Transactions, 1852. 
on the simple application to the egg of the diffluent spermatic snbstance. In the absence, then, of all proof that simple fusion only of the substance of the spermatozoon with the contents of the egg is the chief condition of fecundation, we have, in the facts now referred to, much reason to regard fecundation as primarily dependent on the existence of a force or power in the spermatozoon, by which this body is enabled to arrive at the object to be fertilized, and which, visibly expressed in that of its power of motion, is lost quickly after it has penetrated into the yelk-membrane or yelk :-this, probably, is the instant of fecundation. May not the spermatozoon,. then, be viewed as the organ of a special form of force in the male body for the production of these results, in the same way as the nervous structure is regarded as that of the nervous, and the muscular as that of muscular power? We have already seen that its function is exercised more or less readily and perfectly in relation to two conditions : first, that of its full maturity, in which its power of motion is most intense; and next, in relation to the influence of external physical agencies, which cause this power to be evolved through its organic composition, in a greater or less degree, whether the external influence be that of heat; or the operation of a chemical power, as in the instance of potass in the preceding experiments. 




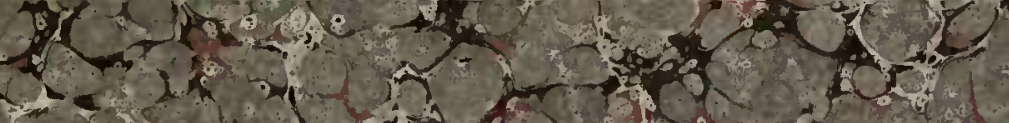

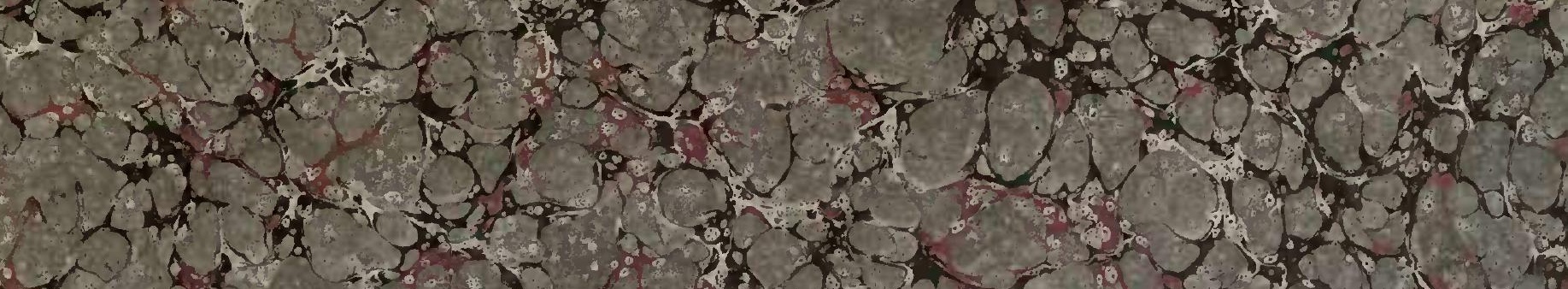
(1)

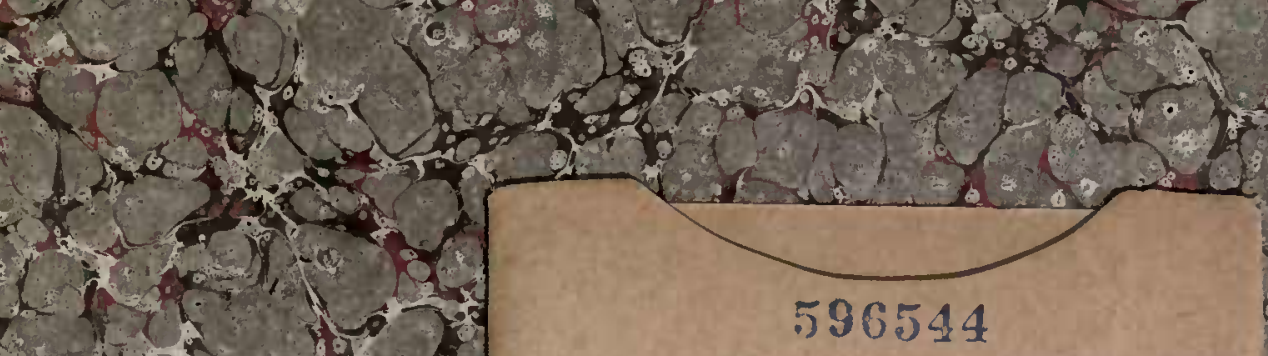

$x+2 x^{2}+2 x$

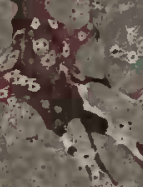

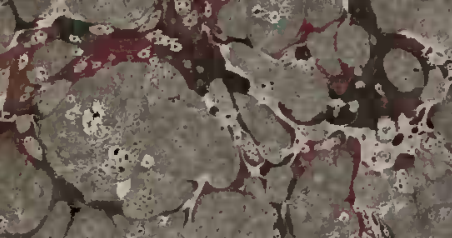

UNIVERSITY OF CALIFORNIA LIBRARY

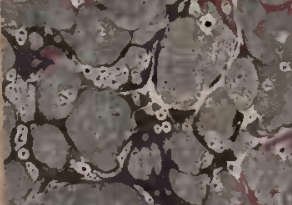

ati

$x$

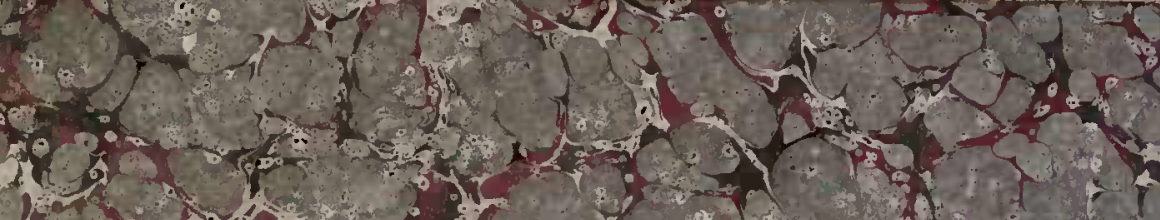

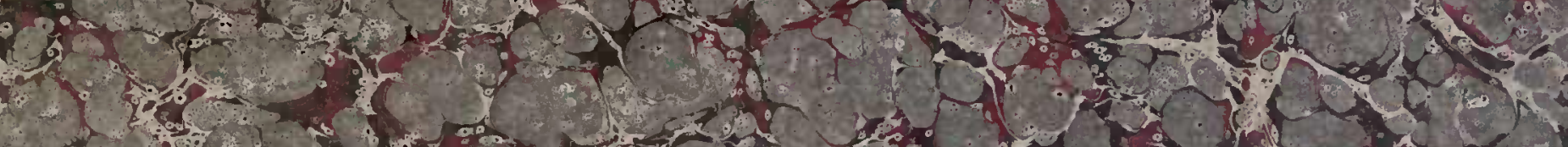

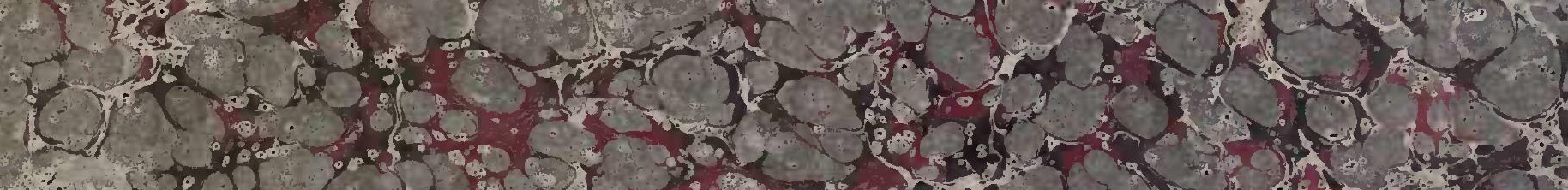

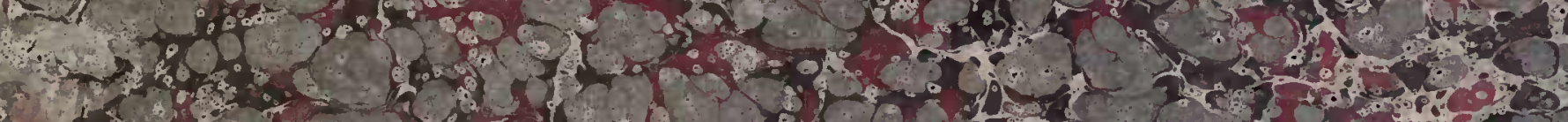

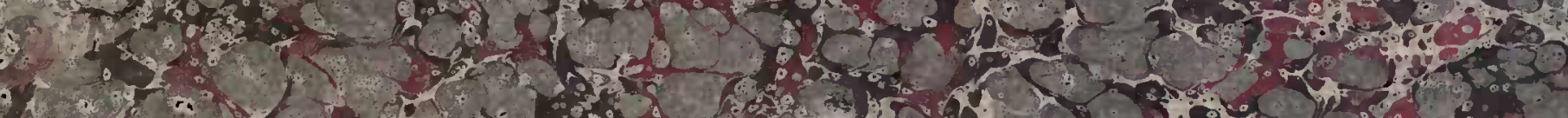

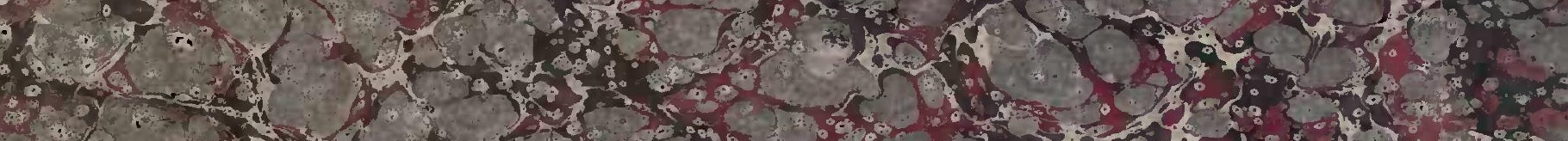

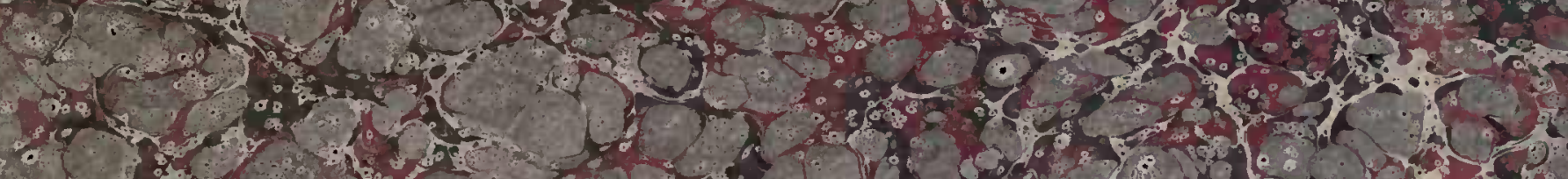

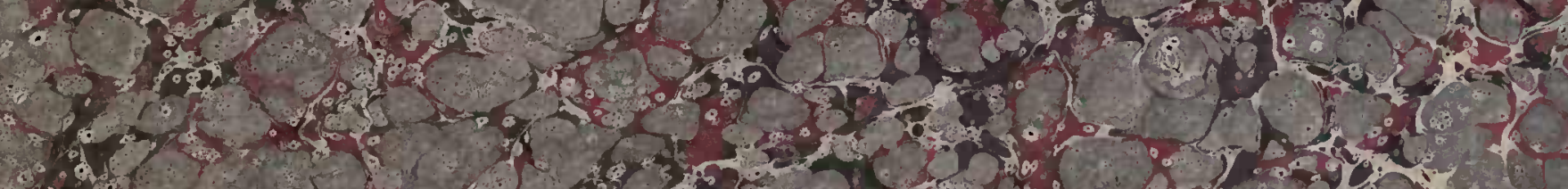

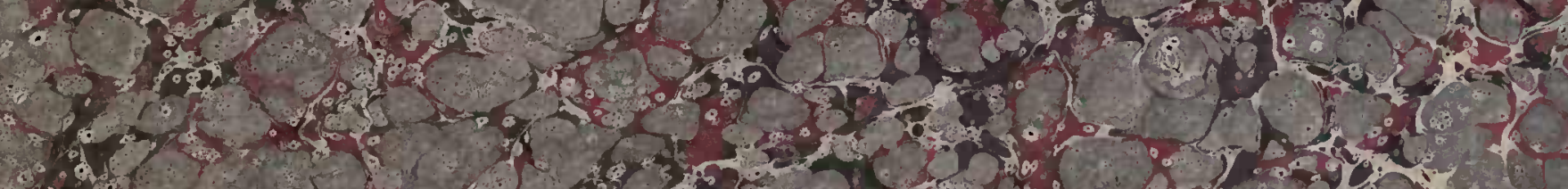

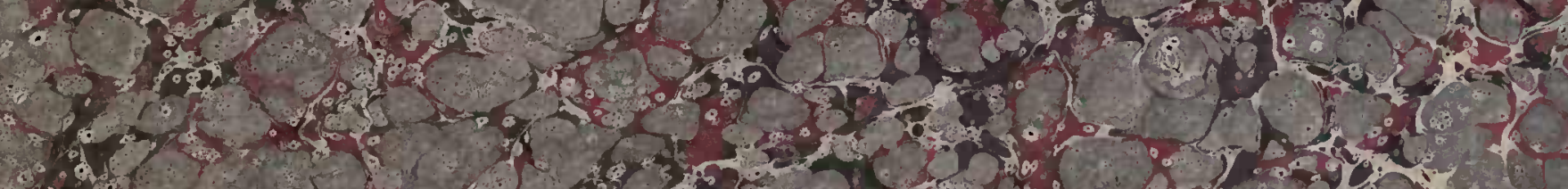

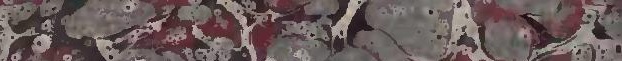

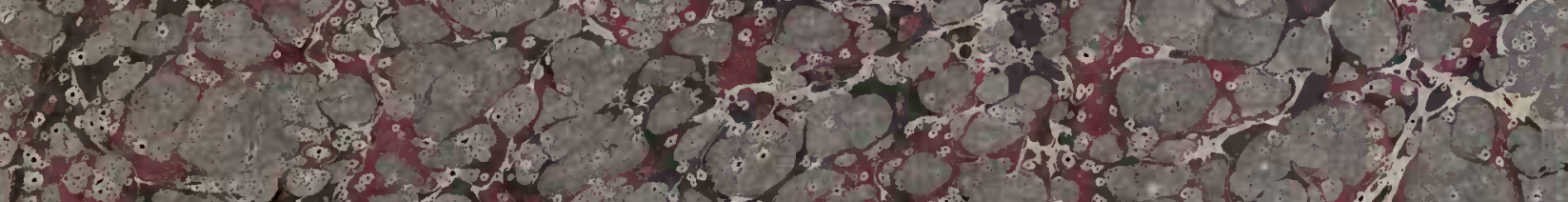

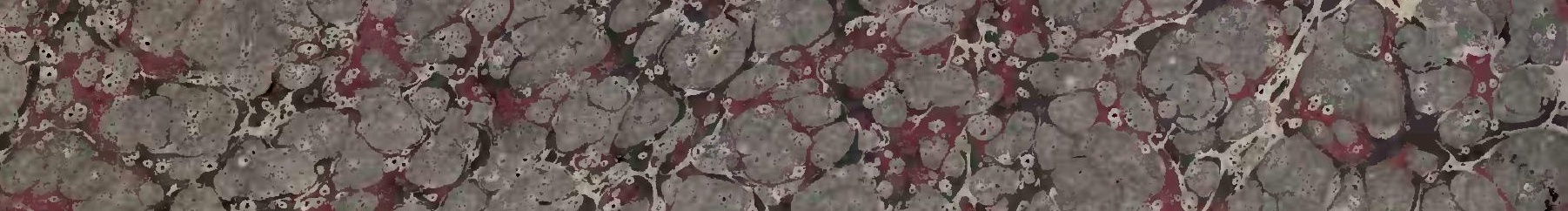

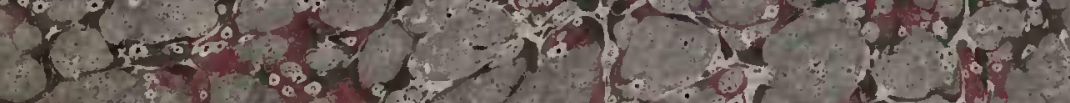
T. 


\section{ty}



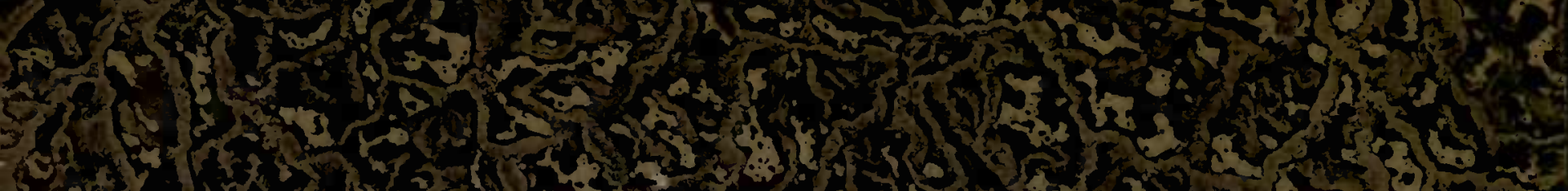

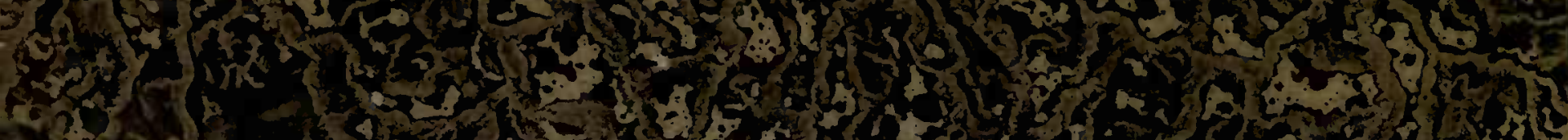

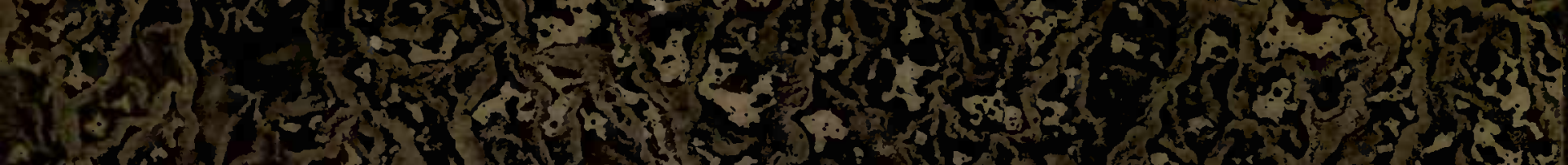

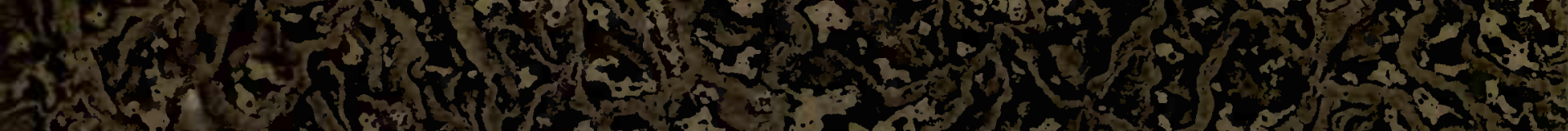

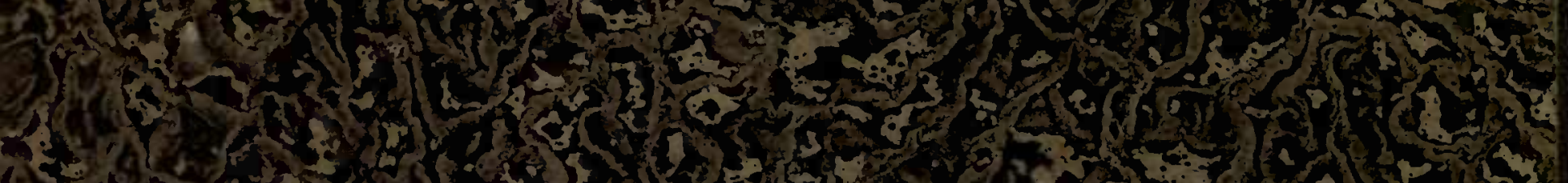
3 3 ,

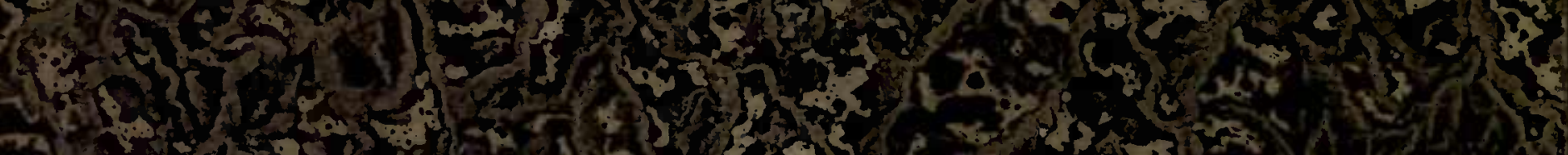

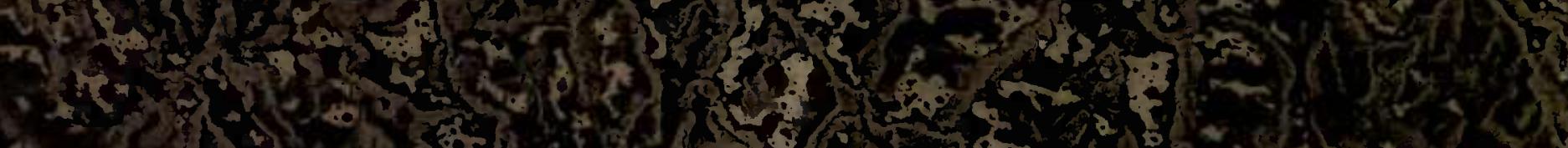

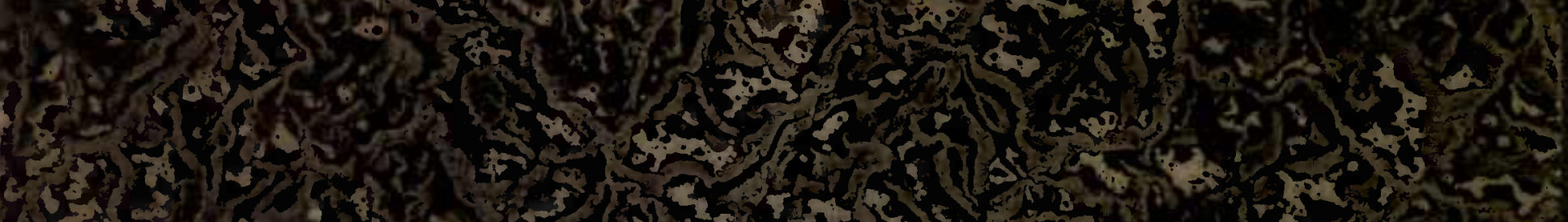

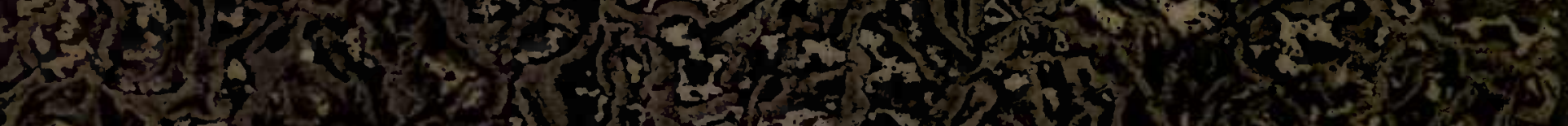
Mnc

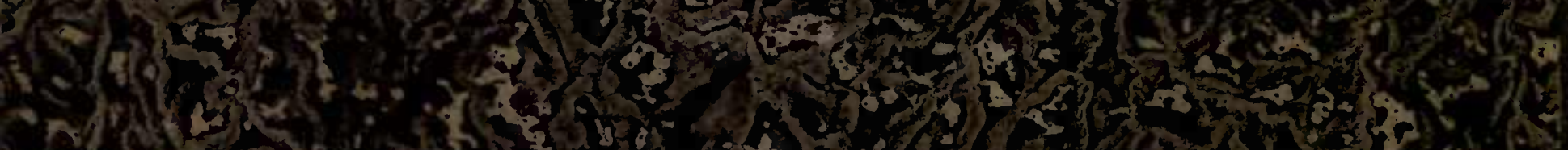

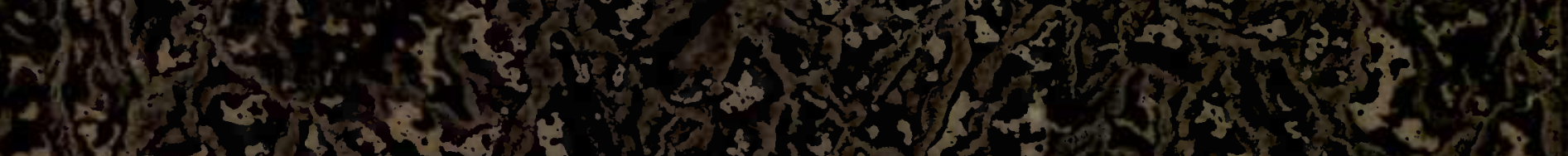

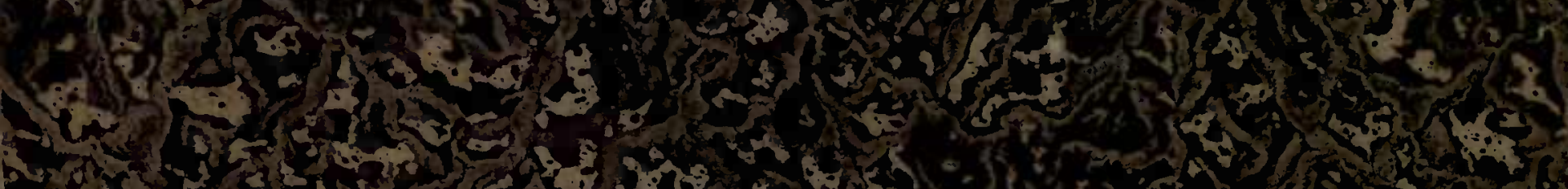

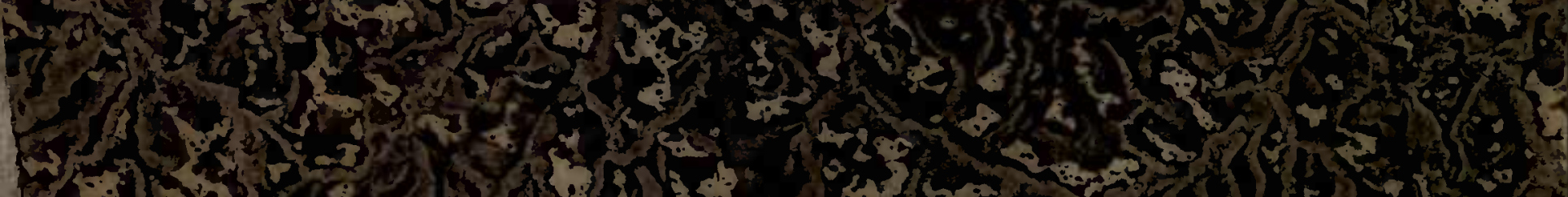



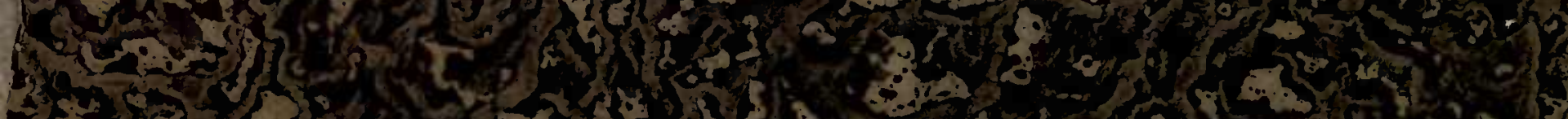

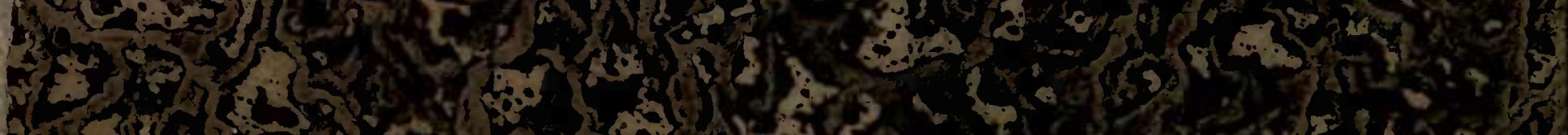

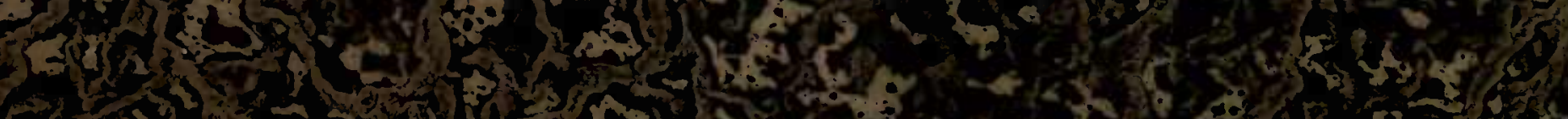

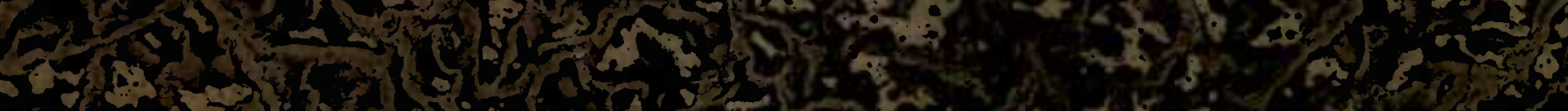

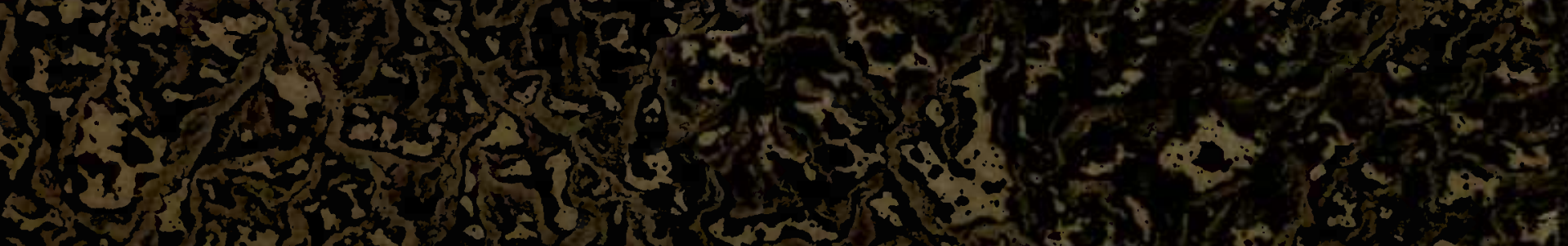

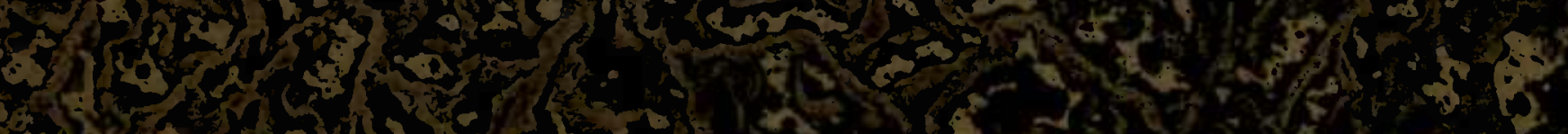

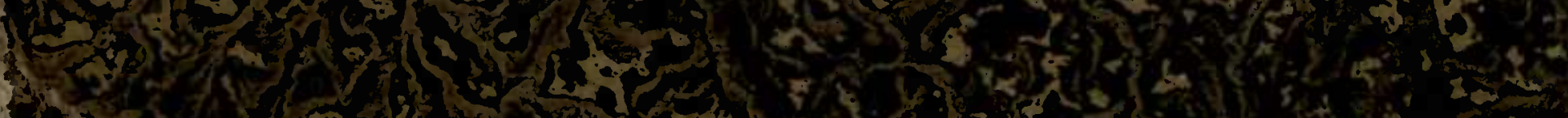

